\title{
ESSAYS ON LABOR MARKET POLICIES IN KOREA
}

\author{
A Dissertation \\ presented to \\ the Faculty of the Graduate School \\ at the University of Missouri-Columbia \\ In Partial Fulfillment \\ of the Requirements for the Degree \\ Doctor of Philosophy

By
TAI LEE
Prof. Peter Mueser, Dissertation Supervisor \\ May 2019
}


(C) Copyright by Tai Lee 2019

All Rights Reserved 
The undersigned, appointed by the Associate Vice Chancellor of the Office of Research and Graduate Studies, have examined the dissertation entitled

\section{ESSAYS ON LABOR MARKET POLICIES IN KOREA}

presented by Tai Lee,

a candidate for the degree of doctor of philosophy,

and hereby certify that, in their opinion, it is worthy of acceptance.

Professor Peter Mueser

Professor Cory Koedel

Professor David Kaplan

Professor Brian Kisida 


\section{ACKNOWLEDGEMENT}

My deep gratitude goes first to my advisor, Professor Peter Mueser, who have been continuously supportive of my dissertation research and who actively motivated me to explore the Korean labor market. Under his supervision, I learned how to interpret the empirical findings and write cohesively a research paper in Economics. I could not have imagined having a better advisor and mentor for my Ph.D. study. My appreciation for comments and suggestions on this dissertation is also extended to Dr. Cory Koedel, Dr. David Kaplan, and Dr. Brian Kisida who were committee members for my dissertation.

I am indebted to all professors in the Department of Economics who taught me about Economics. Their dedicated teaching underlies the foundation of my dissertation and intuition on Economics. In addition, I will not forget Dr. X.H. Wang, Lynne, and Linda for their helps from the beginning of my study in the U.S.

Last but not the least, I especially would like to thank my wife, Sunyoung Lim, for

unlimited support and patience and my lovely daughter, Claire Hyun Lee for filling my life with happiness and pleasure. 


\section{TABLE OF CONTENTS}

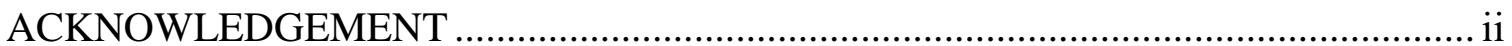

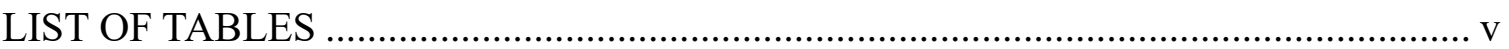

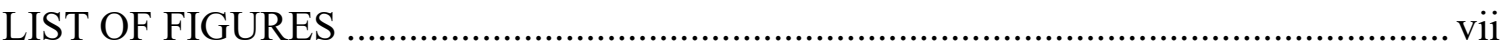

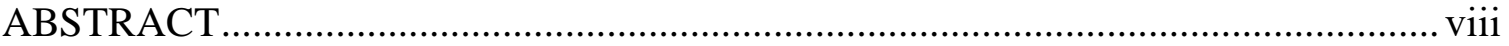

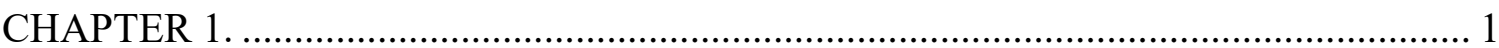

The Impact of Employment Protection on the Quality of Job Match:

Evidence from Job Duration Data in South Korea

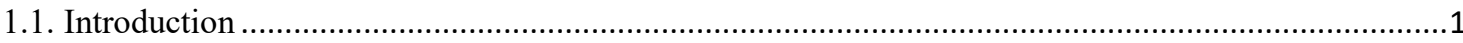

1.2. 2007 labor market reform in Korea and its possible effects on job separation .....................................

1.2.1. Institutional background of 2007 reform in Korea ....................................................................

1.2.2. The possible effects of the 2007 reform on the termination of employment ................................

1.3. Analysis I: Firm's behavioral change after the reform ………....................................................11

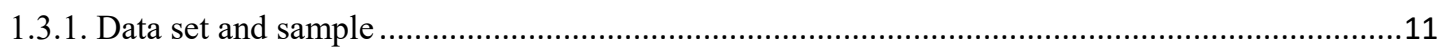

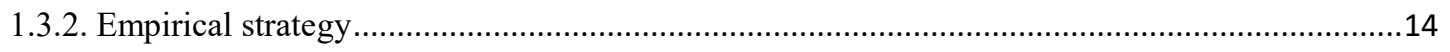

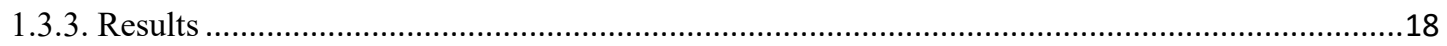

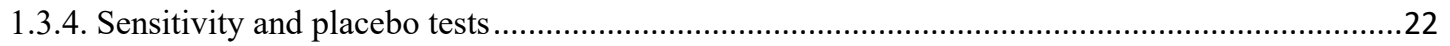

1.4. Analysis II: Workers' behavioral change after the reform ...........................................................23

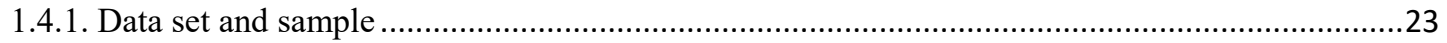

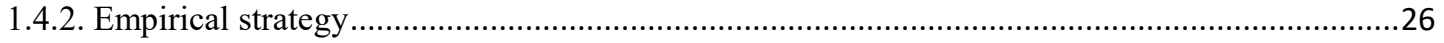

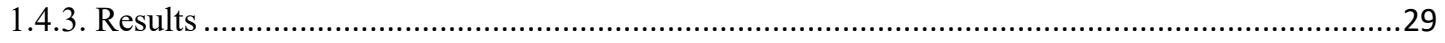

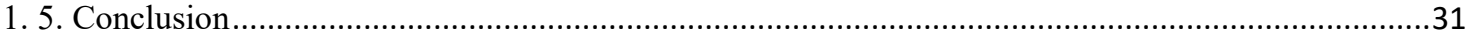

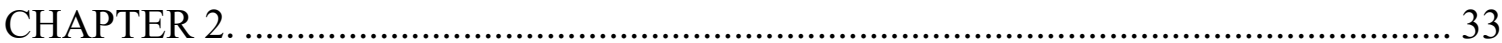

How firms evade stronger protection for fixed-term employees:

Evidence from alternative employment arrangements in South Korea

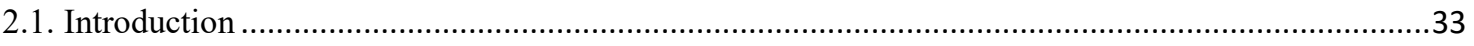

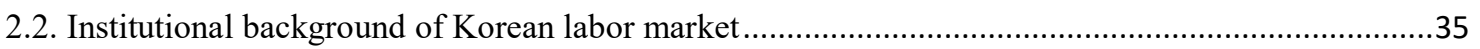

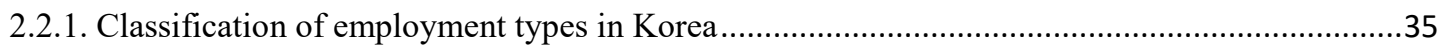

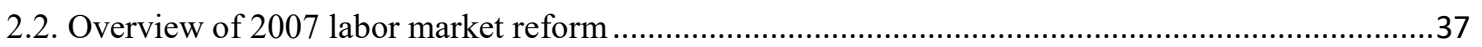

2.3. Previous studies on the effect of 2007 labor market reform ...........................................................38 
2.4. The effect of the reform on changes in employment types .............................................................41

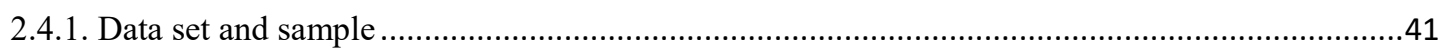

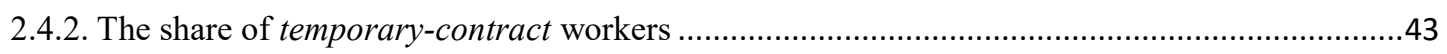

2.4.3. Employment termination and change in employment type ……............................................45

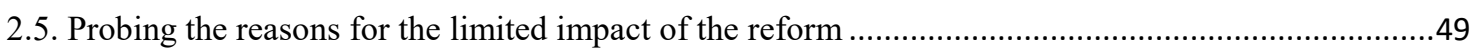

2.5.1. Employer's incentives to evade the new regulation ............................................................

2.5.2. Survey questions in KLIPS to classify employment arrangements ...........................................50

2.5.3. An upsurge of an alternative employment arrangement to evade the regulation ...........................54

2.5.4 The Impact of the Reform on the Probability of having Alternative Jobs ....................................59

2.5.5. Movements between conditional employment and the other alternative employment arrangements . .63

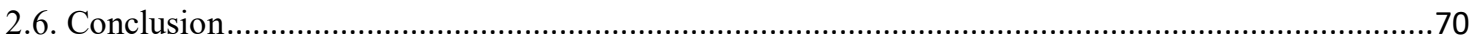

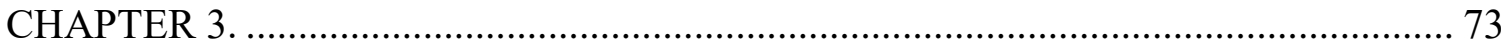

\section{Comparison of two popular labor surveys in Korea from the perspective of reported} employment arrangements: EAPS and KLIPS

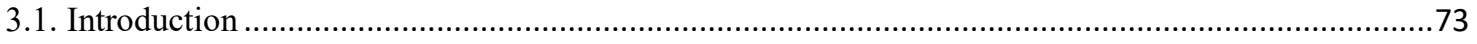

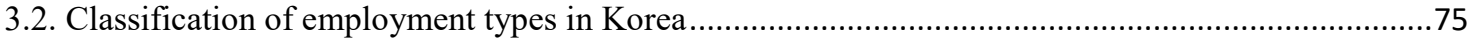

3.3. Measurement of the number of temporary workers in the EAPS and KLIPS ..................................76

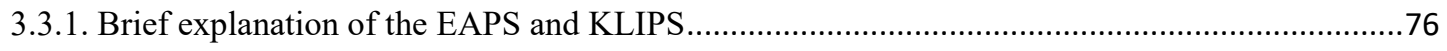

3.3.2. Survey questions in the EAPS and KLIPS to classify the temporary workers .............................78

3.3.3. Changes in alternative employment arrangements in the EAPS and KLIPS ..............................82

3.4. Comparison of the EAPS and KLIPS in demographic characteristics ............................................86

3.4.1. Employment rates and the proportion of wage and salary workers in the total population ..........86

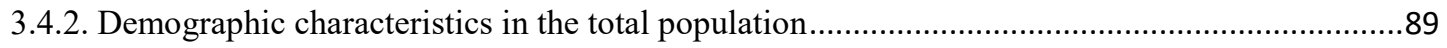

3.4.3. Demographic characteristics in wage and salary workers ........................................................92

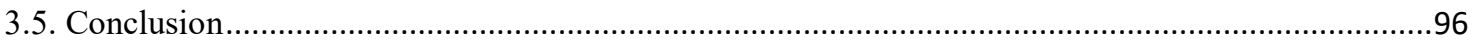

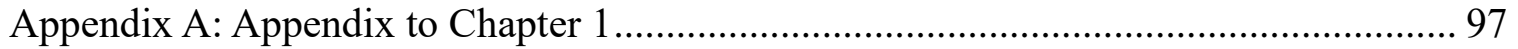

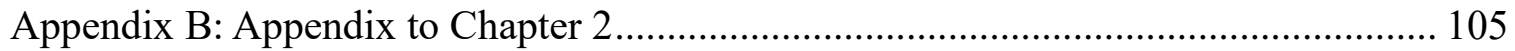

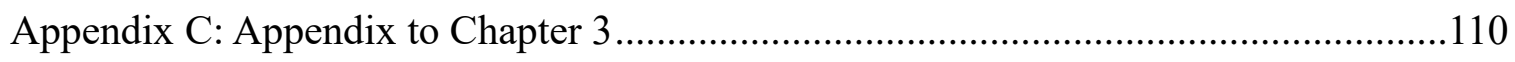

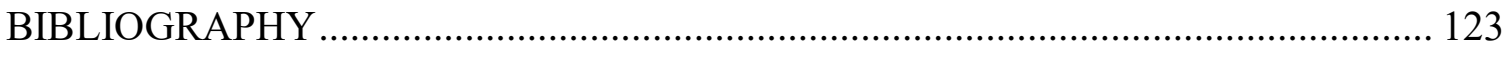

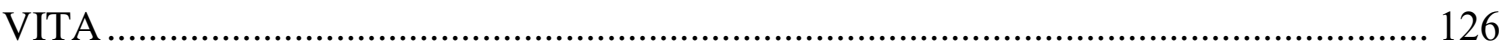




\section{LIST OF TABLES}

Table 1.1. Basic statistics for the control and treatment group ...............................................................14

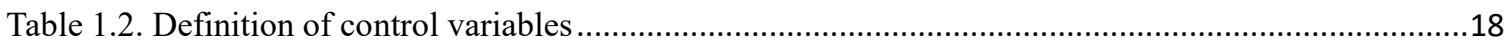

Table 1.3. Probit analysis for workers on temporary-contracts ................................................................19

Table 1.4. The comparison of hazard estimates and marginal effects at the sample mean ............................21

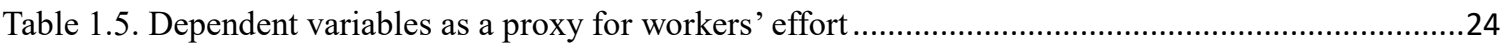

Table 1.6. The proportion of workers providing overtime hours (\%) ........................................................25

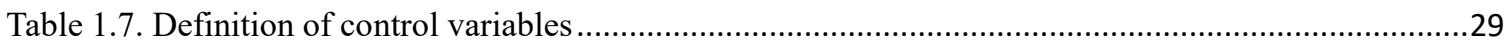

Table 1.8. The effect of the reform on workers' overtime work ….................................................................

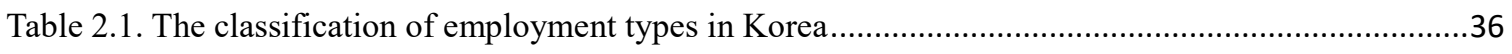

Table 2.2. The classification of wage and salary workers in KLIPS ......................................................42

Table 2.3. The proportion of temporary contract workers by employment duration and job-start year ........44

Table 2.4. Termination and change in employment type for temporary-contract jobs...................................48

Table 2.5. The structure of questions on employment contracts and workers' perceived job security ...........53

Table 2.6. The number of workers who chose each answer to the four questions ..........................................56

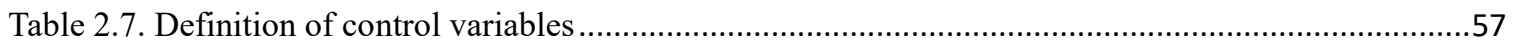

Table 2.8. Average marginal effect of each year and proportion of insecure job in total workers .................58

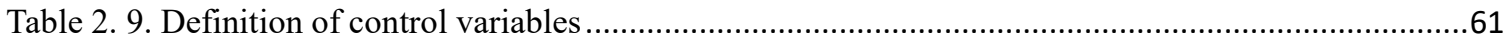

Table 2.10. The effect of the reform on the probability of having insecure jobs for involuntary reason.......62

Table 2.11. Movements from conditional employment to the other group between 2002 and $2016 \ldots \ldots \ldots \ldots . . .64$

Table 2.12. Changes in movements between worker groups: Employment arrangement ${ }_{t+1} / C_{\boldsymbol{t}}(\%) \ldots . . . . . .66$

Table 2.13. Movements from the other groups to conditional employment (C) between 2002 and $2016 \ldots . .67$

Table 2.14. Changes in movements between worker groups: Employment arrangement $t_{t} / C_{t+1}(\%) \ldots . . . . .68$

Table 2.15. Changes in movements between worker groups: $C_{t+1} /$ Employment arrangement $t(\%)$..........69

Table 3.1. The classification of employment types in Korea .....................................................................

Table 3.2. The structure of questions on employment contracts and workers' perceived job security ...........81

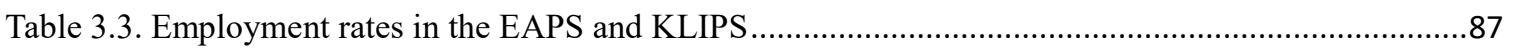

Table 3.4. The proportion of workers in wage and salary employment.......................................................8

Table 3.5. Differences in the share of age category between the EAPS and KLIPS ...................................90

Table 3.6. Differences in the share of women between EAPS and KLIPS..................................................91 
Table 3.7. Differences in the share by educational attainment category between the EAPS and KLIPS ......92

Table 3.8. Differences in the share of age category between the EAPS and KLIPS ....................................93

Table 3.9. Differences in the share of women between EAPS and KLIPS...................................................94

Table 3.10. Differences in the share by educational attainment category between the EAPS and KLIPS ............95

Table A.1. Kaplan-Meier nonparametric estimates for the hazard function $h(r)$.......................................97

Table A.2. The effect of the reform on the hazards of job separation: Probit analysis ..................................98

Table A.3. Sensitivity test: Probit analysis with various sample periods...................................................100

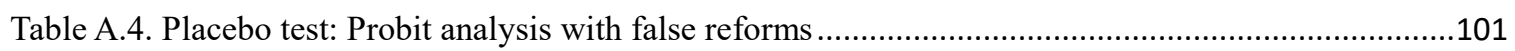

Table A.5. The descriptive statistics for the workers providing overtime hours..........................................102

Table A.6. The descriptive statistics for the workers providing unpaid overtime hours ..............................102

Table A.7. The effect of the reform on workers' overtime ….................................................................103

Table B.1. Survey questions on employment arrangement and perceived job security in KLIPS...............105

Table B.2. The time (year) fixed effect on the probability of having insecure jobs: Logit analysis ............106

Table B.3. The effect of the reform on the probability of having insecure jobs: Logit analysis ..................108

Table C.1. Survey questions on employment arrangement and perceived job security ..............................110

Table C.2. EAPS - Unweighted: The number of workers who chose each answer to the four questions ....111

Table C.3. EAPS - Weighted: The number of workers who chose each answer to the four questions .........112

Table C 4. KLIPS - Unweighted: The number of workers who chose each answer to the four questions ..113

Table C.5. KLIPS - Weighted: The number of workers who chose each answer to the four questions .......114

Table C.6. EAPS: The share of age category in the total population aged 15 and over .............................115

Table C.7. KLIPS: The share of age category in the total population aged 15 and over ...........................116

Table C.8. EAPS: The share of women in the total population aged 15 and over .....................................117

Table C.9. KLIPS: The share of women in the total population aged 15 and over ...................................117

Table C.10. EAPS: The share of education level in the total population aged 15 and over .......................118

Table C.11. KLIPS: The share of education level in the total population aged 15 and over .....................118

Table C.12. EAPS: The share of age category in the total wage and salary workers ...............................119

Table C.13. KLIPS: The share of age category in the total wage and salary workers ................................120

Table C.14. EAPS: The share of women in the total wage and salary workers ........................................121

Table C.15. KLIPS: The share of women in the total wage and salary workers .......................................121

Table C.16. EAPS: The share of education level in the total wage and salary workers ............................122

Table C.17. KLIPS: The share of education level in the total wage and salary workers ............................122 


\section{LIST OF FIGURES}

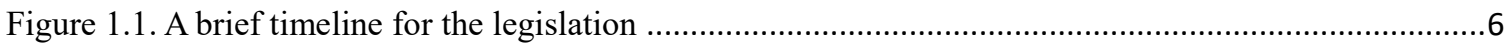

Figure 1.2. An example of fixed-term contracts after the reform ...........................................................

Figure 1.3. A change in firms' options after the reform and its possible effect ............................................9

Figure 1.4. An example of jobs in control and treatment groups............................................................13

Figure 1.5. Kaplan-Meier hazard estimates for the workers on temporary-contracts...................................15

Figure 1.6. The difference in hazard estimates between the periods of before and after the reform .............16

Figure 1.7. The comparison of average marginal effects (AMEs)..........................................................21

Figure 1.8. The proportion of workers providing overtime hours ..........................................................25

Figure 1.9. Three groups of sample observation and two types of treatment effects....................................27

Figure 2.1. Change in employment type in a job: transition from temporary to regular employment ..........46

Figure 2.2. The proportions of worker groups in total wage and salary workers .......................................55

Figure 2.3. Average Marginal Effect and Proportion of Insecure Job in total wage and salary workers .......58

Figure 2.4. Three groups of sample observation according to job-start and interview dates.........................60

Figure 2.5. Transition patterns in a job: Employment arrangement ${ }_{t+1} / C_{t}(\%)$........................................66

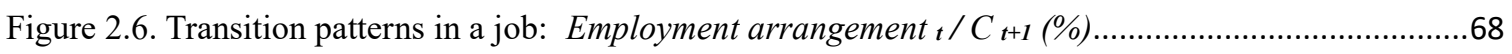

Figure 2.7. Transition patterns in a job: $C_{t+1} /$ Employment arrangement $t(\%)$.........................................69

Figure 3.1. The proportions of worker groups in the total wage and salary workers .................................83

Figure 3.2. The proportions of temporary worker groups in the total wage and salary workers ...................85 


\begin{abstract}
This dissertation examines the impact of employment protection regulations using job duration data in Korea. In 2007, the Korean government introduced a labor market reform that required employers to convert a worker's contract from a temporary to permanent one in order to continue to employ a worker for more than two years. I analyzes the effects of the reform from the perspectives of employers and employees.
\end{abstract}

The first chapter approaches the consequence of employment protection from the point of view of job separations. I analyze how firms and workers respond to regulations limiting the use of temporary employment. From the perspective of employers, the new regulation can be thought of as a potential increase in firing costs for temporary workers after two years. Thus, employers have an incentive to improve the screening process to establish better matches and weed out bad matches prior to the increase in firing costs. My result shows economically and statistically significant decreases in the probability of job separation in the first five months of tenure after the policy change, which implies that firms respond to the increased protection for temporary workers by improving their recruitment practices. From the perspective of workers, temporary workers have an incentive to provide greater effort after the policy change because the reform offers a potential path to permanent employment. However, based on observed overtime, I find no evidence supporting the view that temporary employees provide greater effort after the reform.

In the second chapter, I examine the extent to which Korean firms have evaded a new regulation by hiring workers in employment arrangements not subject to the 
regulation. First, this study determines whether the reform influenced the likelihood of a transition of temporary into permanent employment. However, I do not find any evidence that the reform increased the probability of such a transition. On the contrary, fewer conversions to permanent employment occurred after the reform, while more people were hired on temporary contracts. Second, this study tries to answer why there was no significant change in the transition from temporary to permanent employment after the reform. My results suggest that firms changed human resource management practice in response to the new regulation, taking advantage of certain types of employment that are less likely to be subject to the new regulation. Such employment includes temporary workers whose employment contracts are open-ended and whose level of job security is low. In addition, the increase in the proportion is barely explained by either worker or employer characteristics. Rather, the reform has a statistically significant and positive effect on the probability of having the temporary jobs even after controlling for other covariates as well as the time effect.

In the third chapter, I verify if the upsurge of alternative employment arrangements is found after the 2007 Korean labor market reform in the Economically Active Population Survey (EAPS) as well as Korean Labor \& Income Panel Study (KLIPS). For this, I compare the two labor market surveys, the EAPS and KLIPS, from the perspective of reported employment arrangements using the same survey questions on the employment types of wage and salary workers. However, we are confronted with a puzzle because the results using the two data sets show different patterns for the shares of temporary worker groups. The continued growth in the proportion of alternative employment arrangements after 2007 was not found in the results using EAPS data. To answer as to what factors cause 
the different results in the two data sets, I investigate if there are differences in demographic characteristics between the EAPS and KLIPS data sets. However, I cannot find any significant difference that is large enough to explain the different pattern of the share of alternative employment arrangements between the EAPS and KLIPS. Therefore, we conclude the difference in demographic characteristics is not a main factor causing different results in the EAPS and KLIPS. 


\section{CHAPTER 1.}

\section{The Impact of Employment Protection on the Quality of Job Match: Evidence from Job Duration Data in South Korea}

\subsection{Introduction}

An extensive literature has studied the effect of employment protection legislation ${ }^{1}$ (EPL) on the labor market. Prior studies focused on whether strict protection for workers had an impact on the level of unemployment and employment in European countries in 1970s-90s, but their findings were inconclusive.

In the 1980s, several European countries introduced labor market reforms that allowed new forms of employment such as temporary contracts, fixed-term contracts or hiring through temporary help agencies, which relaxed existing labor market protection for specified classes of employment. Through the introduction of such alternative employment structure, policymakers hoped to make the labor markets more flexible and to lower unemployment. These reforms are usually called "two-tier" labor market policies or "partial" reforms because they tried to improve the flexibility "at the margin" of labor markets by easing restrictions on the use of temporary or fixed-term contracts while keeping strong protection for permanent workers (Bentolila and Dolado, 1994; Blanchard and Landier, 2002). Although such policies may have reduced rigidity in labor markets, they also encouraged firms to substitute temporary jobs for permanent ones. In fact, these reforms were associated with a surge of temporary jobs. ${ }^{2}$ Two-tier labor market policies can also be evaluated in terms of human capital accumulation. On one hand, strong protection and job security may help both employers and permanent workers to invest on firm-specific human capital by reducing concerns about

\footnotetext{
${ }^{1}$ Employment protection legislation (EPL) includes labor market policies and institutions that regulate or constrain a firm's hiring and firing behaviors. Barone (2001) refers to EPL as the multidimensional regulations that influence a firm's behavior in terms of human resource management. EPL may not be in the form of law, but could result from court rulings or collective bargaining between management and worker groups.

${ }^{2}$ As pointed out in Lee's (1996) study, the surge in temporary employment could be attributed to not only changes in labor market policy that protect permanent workers from the market adjustment but also changes in economic environment (e.g., technological progress and the rapid integration of trade markets).
} 
job termination (Kahn, 2012). On the other hand, the extensive protections for permanent workers may induce employers to fill existing permanent jobs with temporary workers, impeding the accumulation of specific human capital (Kahn, 2007).

The extensive use of temporary jobs provoked a debate on whether they are stepping stones to better jobs, which ensure job security and higher wages, or just dead-ends. In countries with fewer employment protection regulations such as the United States and the United Kingdom, temporary jobs seem to play a role as stepping stones to permanent jobs (Booth et al., 2002). In contrast, temporary jobs are less likely to function as stepping stones in the countries such as Spain where segmented labor markets result from rules providing strict protection for permanent jobs but few restrictions on temporary employment. The segmented labor market consists of core and peripheral sectors: the core sector is filled with permanent jobs that provide high job security and good compensation while jobs in a peripheral sector are characterized by bad working conditions, low job security, and low wages. Amuedo-Dorantes (2000) suggested that temporary work in Spain is more likely to be a dead-end rather than a stepping stone to a permanent job, and argued that Spain's experience could be generalized to other segmented labor markets.

Employment protection regulation in South Korea (below denoted simply as Korea) seems to follow the model of Spain and several other European countries. Since the Asian financial crisis in the late 1990s, the Korean government has tried to increase flexibility in the labor market by allowing the extensive use of temporary jobs while keeping strict protection for permanent workers. As a result, the dual labor market structure solidified in the early 2000 s, and the share of temporary employment in wage and salary workers almost doubled from $16.6 \%$ in 2001 to $29.4 \%$ in 2005 (Grubb et al., 2007). In addition, similar to Spain's case, temporary employment in Korea seems not to function as a stepping stone since the transition rate from temporary to permanent employment over a one-year period was only $11.1 \%$ in Korea, while the transition in most European countries was above 50\% (OECD, 2013).

The drastic increase in temporary jobs has been pointed out as a main source of social inequality in Korea. Temporary jobs are usually characterized as inferior, as most temporary workers are paid less, are offered less training, and are less satisfied with their jobs (Booth et al., 2002). Thus, a steady increase in the proportion of temporary jobs could lower the welfare for workers and be a source of wage inequality. From 
workers' perspectives, temporary workers hope to advance to permanent employment through temporary jobs, but they must endure poor labor conditions in the temporary jobs in terms of wage, working time and job security (D'Addio and Rosholm, 2005).

Accordingly, the Korean government proposed a labor market reform in 2007 to lower the incidence of temporary jobs and to encourage employers to convert temporary contracts into permanent ones. The main policy change was to restrict the maximum duration of employment to two years in a job with a fixed-term contract. After the reform, an employer who employed a worker in a fixed-term contract for two years would need to convert the worker's contract from a temporary to permanent one. According to Yoo and Kang (2012) who examined the impact of 2007 Korean reform on the incidence of employment and temporary jobs, the intensity of the reform was weak, and the effect fades away by two years after the reform. While their analysis focused on the process of job creation - the changes in the probability of being employed and having a temporary job after the reform - I investigate employment dynamics after the policy change. This study relates the change in protection for temporary employment to job sorting mechanisms, and hence it is in line with the research by Boockmann and Hegen (2008) and Marinescu (2009) who focused on a firm's screening process using duration analysis.

In this study, I describe in detail the policy change in the Korean labor market in 2007 first and then consider how firms and workers are expected to react to the policy change. The policy change is expected to induce behavioral changes of both firms and workers on fixed-term contracts. From the perspective of employers, the reform can be thought of as a potential increase in firing costs. Thus, the employers may try to improve the screening process to establish better matches and weed out bad matches prior to the increase in firing costs, which results in better job match quality. From the perspective of workers, workers on fixedterm contracts have an incentive to provide greater effort after the reform because the reform offers a potential path to permanent employment that ensures higher job security and compensation.

According to the results of this study, the probability of job separation decreased in the first five months of tenure after the introduction of the new regulation, which suggests that firms reacted to the policy change by improving their recruitment process, Firms' better recruitment practice can result in well-matched jobs, which can lower the separation probability. However, I cannot find any evidence supporting the view that 
temporary workers provide greater effort in their jobs after the reform.

This study contributes to the understanding of the consequence of employment protection regulations in several ways. First, it provides evidence on a developing country in Asia that is characterized by a segmented labor market like that in Spain. Thus, we can verify whether Spain's experience can be generalized to another country that has a similar labor market structure. Second, the Korean 2007 reform offers an unusual policy change that increases protection for temporary workers, while previous empirical studies have focused on policy changes for permanent employment or the policies that made it easier for firms to create temporary jobs. Thus, the Korean case can give policymakers insight into the consequences of alternative policy options. Lastly, this study approaches the consequence of employment protection from the perspective of job separations, while previous studies analyze the effect of employment protection on the net job creation.

\subsection{7 labor market reform in Korea and its possible effects on job separation}

\subsubsection{Institutional background of 2007 reform in Korea}

Between 1960 and the mid-1990s, Korea experienced rapid economic growth, and benefits from it seemed to be shared with workers through high job security and increased compensation (Sakong, 1993). According to Kang and Yun (2008), the Korean economy experienced not only one of the highest growth rates in the world but also persistent declines in wage inequality between 1980s and the mid-1990s. In addition, most Korean firms adopted seniority-based pay systems at that time, which ensured steady increases in wages given the high job security.

However, as Korea's economic growth slowed following the Asian financial crisis in the late 1990s, the high employment and income security for the workers was pointed out as a source of inefficiency, and firms demanded a more flexible labor market environment. The Korean government responded to the demand by instituting a "two-tier policy" that introduced new forms of employment ${ }^{3}$, while keeping strong employment

\footnotetext{
${ }^{3}$ The new forms of employment include workers on fixed-term contract, temporary agency workers, dispatched workers, and atypical workers who are classified as self-employment by labor law but still have many characteristics of employees. The workers in these types of employment are called "non-regular" or "non-standard" employees in Korea.
} 
protection for permanent workers. Since then, workers on fixed-term contract - a type of employment contract that terminates at a future date when a specific term expires or when a particular task is completed - has accounted for a majority of the new forms of employment. However, the government did not place any restrictions on the use of fixed-term contracts as there was no restriction on either the duration of contracts or on repeated renewal of fixed-term contracts.

As Lazear (1990) pointed out, employers have an incentive to evade the strict employment protection laws by hiring uncovered (temporary) workers. In most cases, Korean firms set the period of fixed-term contract to less than one year to avoid offering severance pay, which is required by Korean labor law to be given to a worker who has been employed for one year or more. ${ }^{4}$ Moreover, firms could renew the fixed-term contract many times with agreement of the worker, which allows them to not only continue employing the worker for several years but also terminate the employment effectively without severance pay. Accordingly, many permanent jobs had been replaced with temporary ones in an attempt to reduce labor costs and increase employment flexibility: a Korean government survey showed $32.1 \%$ of firms cited reducing labor costs and $30.3 \%$ cited increasing employment flexibility as the most important reason for hiring temporary (or nonregular) workers (Jones and Urasawa, 2012).

As a result, the share of temporary employment in wage and salary workers almost doubled from $16.6 \%$ in 2001 to $29.4 \%$ in 2005 (Grubb et al., 2007), which solidified the dual labor market structure in Korea. ${ }^{5}$ Recently, the high level of labor market dualism has been pointed out as one of the major factors responsible for rising income inequality because temporary workers are paid about $60 \%$ as much as permanent workers (Jones and Urasawa, 2012, 2014). Furthermore, wage of temporary workers are reduced because of their relatively short tenure under the prevalent seniority-based systems in Korea (OECD, 2016).

After five years of discussion with social partners, legislators proposed bills on temporary employment in

\footnotetext{
${ }^{4}$ In Korea, severance pay is based on years of service with a company on a specific contract, and at least one month's wages are provided to the worker for each full year of employment. Firms must offer the severance pay to any salary and wage workers who has worked for one year or more under a specific employment contract.

${ }^{5}$ The proportion of temporary jobs increased substantially in Korea after the financial crisis in 1997 since not only did the government allow firms to use more flexible employment contracts but also people became desperate for jobs during the severe recession. Holmlund and Storrie (2002) show the incidence of temporary jobs is greatly influenced by macroeconomic conditions and, more importantly, severe recession can cause a surge of temporary jobs by both making not only firms more liable to offer temporary contract but workers more willing to accept them.
} 
November 2004 with the goal of lowering the incidence of temporary jobs and preventing firms from using fixed-term contracts as a long-term substitute for permanent workers. Legislation was passed two years later and implemented in 2007. A brief timeline for the legislation and application of the reform is provided in

Figure 1.1.

Figure 1.1. A brief timeline for the legislation

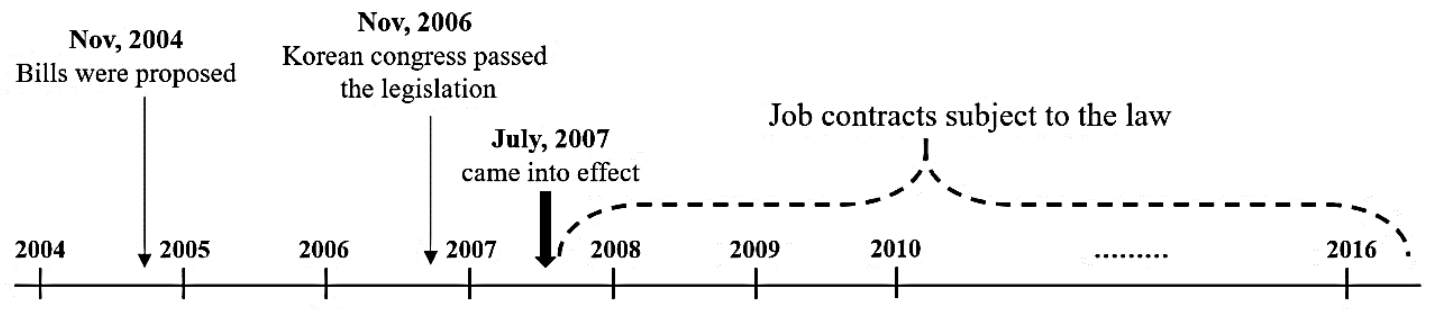

Although the legislation enacted several changes to labor market regulations, the primary one is to restrict the length of fixed-term employment with one employer - even employment on successive fixed term contracts - to a maximum of two years. ${ }^{6}$ More specifically, after the reform, if an employer chose to continue to employ a worker for more than two years, then the employer had to convert the worker's contract from a fixed-term to permanent one. ${ }^{7}$ Of course, employers still had the option to dismiss a worker employed for less than two years on a fixed-term contract with no costs by not renewing the contract. However, if the worker was still on the job at the end of the two-year period, the fixed-term contract would be regarded as a permanent contract. Figure 1.2 shows an example of a fixed-term contract after the reform. The reform took effect in July 2007, and hence any fixed-term contracts signed from July 2007 onward are subject to the new

\footnotetext{
${ }^{6}$ Another regulation in the bills was to prohibit discrimination against temporary workers who perform tasks similar to permanent workers in the same firm. According to the new regulation, temporary workers - workers on fixed-term contracts, part-time workers, and temporary agency workers - can submit complaints of discriminatory treatment relating to wages and working conditions to the Korean Labor Relations Commission (Grubb et al., 2007). However, only 2,443 cases affecting 5,262 workers were filed between July 2007 and February 2012 (Jones and Urasawa, 2013), and hence the number of correction orders by the Korean Labor Relations Commission had to be small. Thus, the regulation is considered to have little effect on the labor market.

${ }^{7}$ There are some exceptions in the new regulation, and the following cases are excluded from the application of two-year maximum duration of fixed-term employment: (i) firms in the private sector with fewer than five employees (ii) workers aged 55 or older at the time of signing a fixed-term contract, (iii) Workers who work less than 15 hours per week regularly (iv) workers holding doctoral degrees or other highly technical and professional qualifications, (v) part-time instructors in tertiary education institutions, (vi) workers subject to other contract duration specified by other laws (Yoo and Kang, 2012).
} 
regulation.

Figure 1.2. An example of fixed-term contracts after the reform

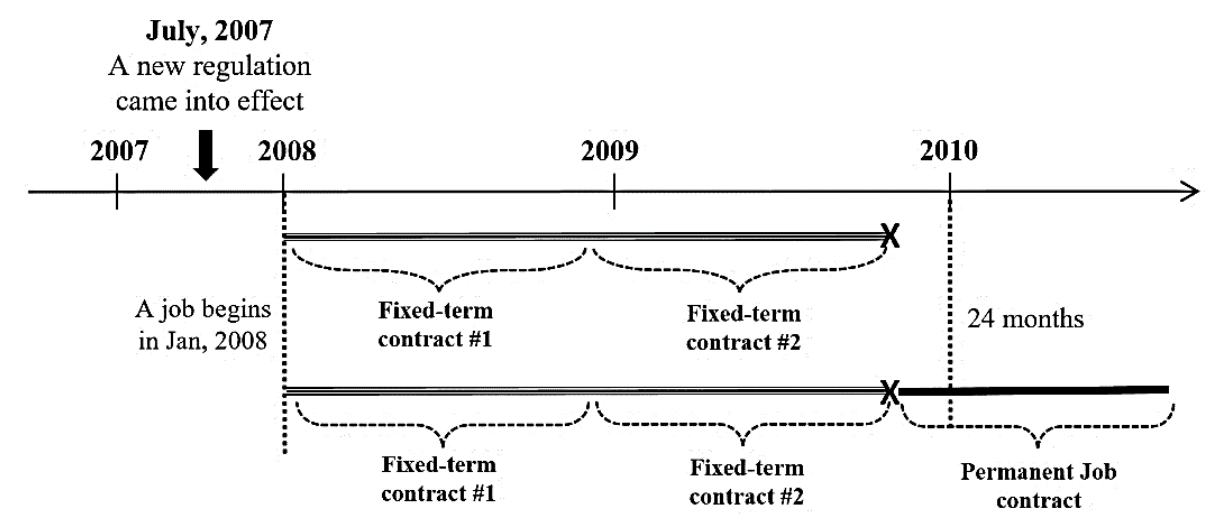

Note) $\boldsymbol{X}$ denotes a separation from a job.

\subsubsection{The possible effects of the 2007 reform on the termination of employment}

\section{(1) Firms' behavioral change}

Before the policy change, firms that hired workers on fixed-term contracts had three choices twenty-four months after first hiring a worker on a fixed-term contract: (i) Continue to employ the worker by converting the contract from fixed-term to permanent, (ii) Continue to employ the worker by offering another fixed-term contract, (iii) Dismiss the worker and possibly replace him or her with a new employee. However, since the firms' second option - continue to employ the worker under a fixed-term contract - is no longer available after the reform, the firms must consider alternatives among the other options - (i) and (iii) - depending on the type of the job that has been filled by the fixed-term employment (Figure 1.3 summarizes the change in a firm's choice before and after the reform). Here, jobs can be classified according to whether they involve accumulation of firm-specific human capital.

If firm-specific human capital can be accumulated through working on a job, and the employer values it (Job type I), then the firm that would have chosen option (ii) may choose the option (i) after the reform. In 
this case, firms valuing the accumulation of specific human capital face a discontinuous increase in firing costs after 24 months of employment. Thus, they have an incentive to improve their screening process to establish better job matches and weed out bad matches. For this, firms can change their human resource management practice in two ways. ${ }^{8}$ First, at the various stages of the recruitment process, firms can exert greater effort to establish better job matches. For example, they may require strict qualification for a job, review job applications more thoroughly, or filter candidates through in-depth interviews and so improve the quality of job matches. Even though the quality of job matches is difficult to quantify, the result of the change in the quality can be captured by the change in the probability of job separation. Thus, better recruitment practices and higher match quality could cause a decrease in the probability of employment termination $-a$ recruitment channel (H1). The decrease in the probability is expected to be more prominent at very low tenures because most separations from jobs happen in the early stages of working (Marinescu, 2009). Second, firms can exert greater effort in their monitoring and evaluation process to weed out bad matches before the increase in firing costs. Through higher monitoring effort and rigorous evaluation, the match quality of the remaining jobs may be improved. The result, however, can be represented statistically as an increase in the probability of job separation before 24 months of tenure. Furthermore, since it is better, in the view of the human capital accumulation, to identify bad matches as early as possible and replace unproductive workers with new ones, the increase in the probability is more likely to be observed in the early stages of employment - a monitoring channel (H2).

On the other hand, if a job is simple, and working on it accumulates little specific human capital (Job type II), then firms that have filled the simple job with a temporary worker can replace the worker with another temporary one easily. Then, the firm's best choice after the reform is to initially hire a worker on a fixedterm contract for a period of less than a year, renew that contract, and then dismiss the workers right before his/her tenure reaches 24 months, after which firing costs increase discontinuously. In this case, even though firms may not experience the new employment regulation as an increase in firing costs, their reaction to the regulation could change the probability of job separation. More specifically, job separation hazards may

\footnotetext{
${ }^{8}$ Marinescu (2009) found that increased job security for workers with 1-2 years of tenure can lower the firing hazards for workers with $0-1$ year of tenure, which is prior to the period of the increased security. She explained this finding as due to firms' behavioral changes in recruitment and monitoring practices. The reasoning of this study about firms' reaction to the reform is in line with her arguments.
} 
increase right before 24 months of workers' tenure after the reform - a replacement channel (H3).

Figure 1.3. A change in firms' options after the reform and its possible effect

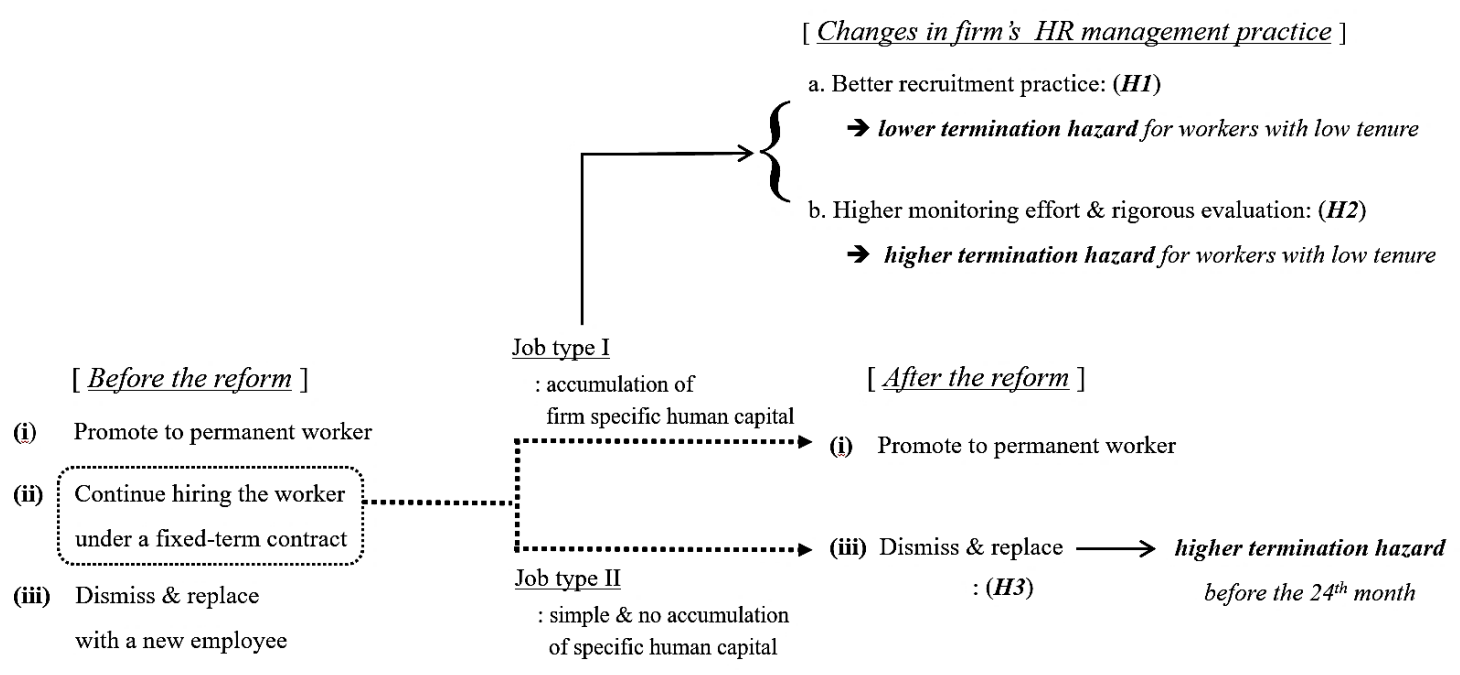

Based on the reasoning so far, I suggest three hypotheses on how the reform influences firm behavior and what changes in the hazards of employment termination are expected after the reform. A summary of the possible effects of the reform is suggested in Figure 1.3. In the first part of the empirical analysis, this study investigates evidence that supports each hypothesis and tests the hypotheses using statistical models. In the recruitment (H1) and monitoring (H2) channels, the direction of reform changes in termination hazards is opposite. Thus, if we can observe either an increase or a decrease in the termination hazards at low tenures, we can tell which hypothesis dominates the other. In addition, the replacement effect $(H 3)$ can be easily verified by looking at the change in the hazards around 24 months. 


\section{(2) Workers' behavioral change}

Workers' effort in their jobs could be considered an important factor when their employers decide which worker should be kept or weeded out (Booth et al., 2002). Because the new regulation requires employers to convert a fixed-term contract to a permanent one when tenure with the employer exceeds two years, workers on fixed-term employment have an incentive to exert greater effort in their job to achieve an advancement to permanent employment, which usually offers high job security and compensation. Putting greater effort into

a job may include enduring harsh working conditions, complying with excessive requests from their employer or boss without reasonable compensation, or working overtime voluntarily. If many workers on fixed-term contracts prefer permanent employment and expect the chance of getting converted to permanent employment to be relatively high after the reform, then their higher effort in their jobs could be expressed statistically as a decrease in the termination hazards throughout the duration of a fixed-term employment $-a$ worker's effort channel (H4). Thus, when we investigate the consequence of a new employment regulation, the response of employers as well as employees should be considered. Accordingly, the last hypothesis $(\mathrm{H} 4)$ is added to the possible effects of the reform from the perspective of workers.

In the second part of the analysis, this study seeks to find empirical evidence that supports the view that workers on fixed-term contracts exert greater effort after the reform. Although it is difficult to measure workers' effort, changes in the level of their efforts could be investigated by using a proxy variable. To date, few studies on workers' effort have been conducted in economics, but two studies used similar variables to proxy the level of workers' effort. First, Booth et al. (2002) used the number of weekly unpaid overtime hours to proxy the effort and showed high effort increases the probability of exiting from temporary employment only for women. Second, Engellandt and Riphahn (2005) used a binary variable - whether a worker provides unpaid overtime hours or not - as a proxy for workers' effort levels and confirmed workers on temporary contracts exert significantly greater effort than permanent workers in Switzerland. Following these studies, I use the information on worker's overtime work to proxy the level of effort. 


\subsection{Analysis I: Firm's behavioral change after the reform}

In the first empirical analysis, this study investigates the effect of the 2007 Korean reform on the probability (or hazard) of employment termination. Through the analysis, I seek to examine how firms' reactions to the reform are reflected in the changes in employment termination hazards.

This study uses the duration $(r)$ in months reaching to the termination of employment as a dependent variable and examines various factors that influence on the duration. The termination of employment includes both voluntary and involuntary separations from jobs. There are some reasons why both kinds of separations are included in the sample. First, all separations may result from the interaction between employers and employees, which is the main concern of this study. Second, an interviewee may choose "voluntary separation" as a reason for his/her job termination, even though he or she was dismissed. Third, although the questionnaire on which our data based has a question asking about a specific reason for job separation, the question response rate is only $56.8 \%$.

\subsubsection{Data set and sample}

To investigate the impact of the 2007 Korean reform on the labor market, this study uses the Korean Labor \& Income Panel Study (KLIPS). ${ }^{9}$ The KLIPS consists of three data sets, for households, individuals, and job histories. The job history data are composed of observations of jobs (rather than individuals) and contain information on the jobs held by individuals who were surveyed between Jan, 1998 and Aug, 2016. The data offer information on the jobs such as the date at which a job began or terminated (if the job ends before an interview), interview date, type of employment (regular, temporary-contract or casual), and other job characteristics (occupation, industry, firm size, sector, average hours of regular or overtime work, wage, etc.). Although KLIPS is a yearly survey and began in 1998, it also asks every interviewee about his/her job history since entering the labor market. Thus, it contains the full records of job history for all respondents.

\footnotetext{
${ }^{9}$ KLIPS is a longitudinal survey of the labor market/income activities of households and individuals residing in urban areas. Being the first domestic panel survey on labor-related issues, it has served as a valuable data source for microeconomic analysis concerning labor market activities and transitions.

This data set is publicly available on the Korea Labor Institute's website (https://www.kli.re.kr/klips_eng/index.do).
} 
Furthermore, an in-depth analysis is possible when the job history data are combined with the data set of KLIPS for individuals that contains workers' characteristics such as gender, age, education level, marital status, and the area of residence.

Fixed-term employees regulated by the 2007 Korean reform are defined as the workers whose contracts end on a specified date or when a specific task is completed; temporary-contract employees according to the classification of KLIPS ${ }^{10}$ cover workers whose employment contracts are at least one month and less than one year. Thus, temporary-contract employees are a subset of fixed-term employees. In the Korean labor market, however, most fixed-term employees are on temporary-contracts because firms set the period of the fixed-term contract to less than one year to avoid offering severance pay, which is required by Korean labor law for contracts of one year or more. Thus, only observations classified as jobs that began with temporarycontracts in KLIPS data are selected for the sample to analyze the effect of the reform; other types of employment status - regular workers, casual workers (or day laborers) - are excluded.

The dependent variable $(r)$, which is the tenure of a job in months, ${ }^{11}$ is measured by the duration in months from job start date to job end date if a job terminated before the interview. Where a job is still in progress at the last interview date, the dependent variable is measured by the time from job start date to the last interview date and the case is coded as right-censored.

The sample includes only jobs that began from January 2001 and onward. Since the Korean economy had experienced the Asian financial crisis in 1998, the effect of which persisted for several years, the early years of the survey were still affected by the crisis. To prevent the experience of the crisis from influencing the results of this study, the jobs that began before January 2001 are excluded from the analysis. Thus, the final sample includes only the jobs beginning under temporary-contracts that span the period between January 2001 and August 2016.

\footnotetext{
${ }^{10}$ KLIPS classifies salary and wage workers into three groups: 1) Regular worker: workers whose employment contract period is at least one year, or workers who can be kept employed as long as he/she wants if their employment contracts are not pre-specified. 2) Temporary-contract worker: workers whose employment contracts are at least one month and less than one year, or the workers who expect their job to be terminated within a year if the period of their contracts is not specified in advance. 3) Casual worker (or day laborer): workers whose contract period is less than one month, or the workers who are hired and paid on a daily basis.

${ }^{11}$ The survey asks the exact year, month, and day for the date of job start, job end, and interview. However, about $40 \%$ of the respondents didn't answer the exact day of the date. For the purpose of using as many observations as possible, the tenure of a job is measured in months.
} 
Lastly, the sample is divided into two parts, a control group - jobs that began before the reform - and a treatment group - jobs that began after the reform. In addition, jobs in the control group that continue beyond the effective date of the regulation (July, 2007) are treated as being censored at the reform's effective date in order to exclude the possibility that the jobs in the control group could also be affected by the introduction of the new regulation and to estimate precisely the change in the termination hazard caused by the reform. Thus, the analysis examines whether the termination hazards of temporary-contract employment differ significantly for the control and treatment group. Figure 1.4 shows an example of jobs in the control and treatment groups.

Figure 1.4. An example of jobs in control and treatment groups

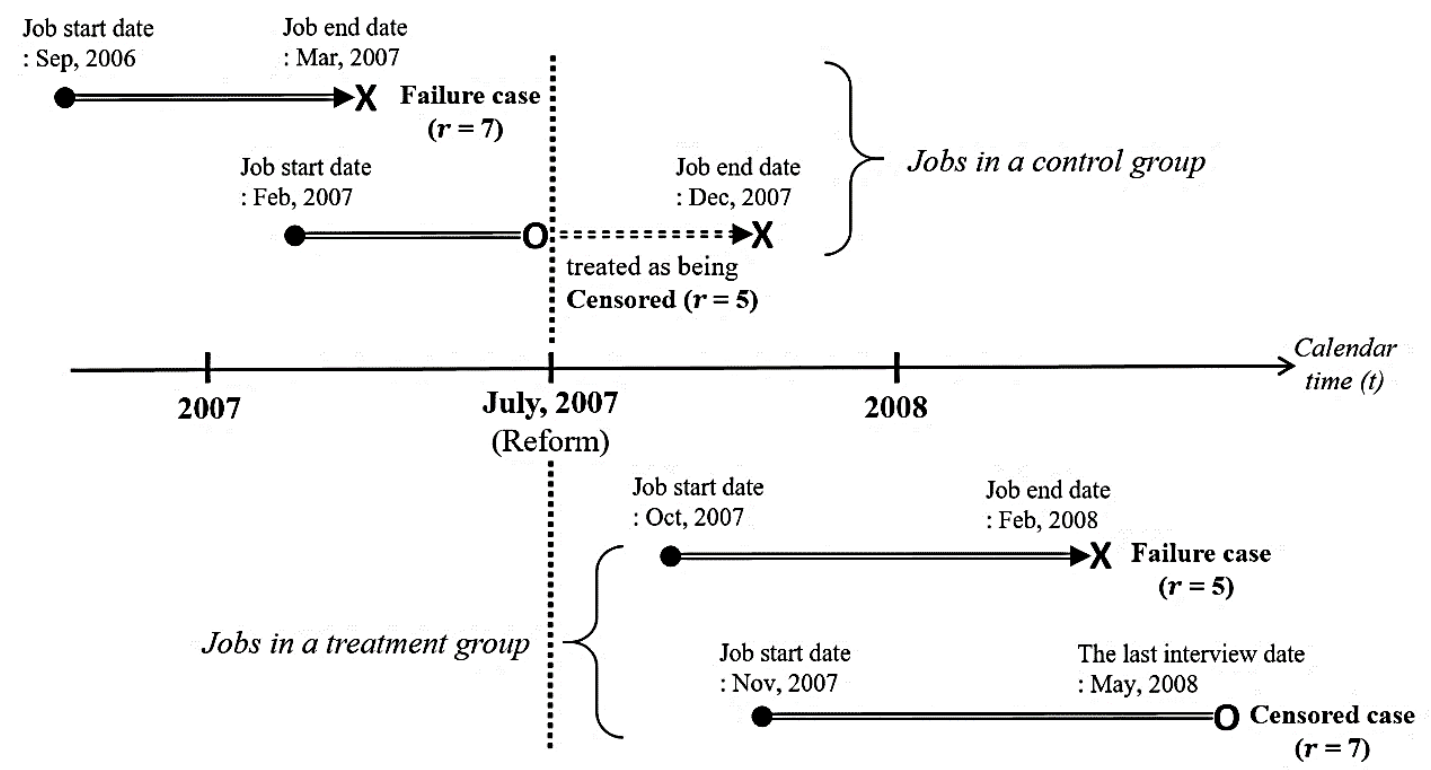

Note) 1. $\boldsymbol{X}$ denotes a separation from a job; $O$ means that the observation is right-censored.

2. $\boldsymbol{r}$ stands for the duration of a job in months. 


\subsubsection{Empirical strategy}

As a first step, I estimate the hazard function $h(r)$ for the control and treatment groups using the nonparametric method suggested by Kaplan and Meier. The hazard function for a job is the limiting probability that employment termination occurs right after the tenure of $r$ conditional on the job having lasted

until $r$ :

$$
h(r)=\lim _{\Delta r \rightarrow 0} \frac{\operatorname{Pr}(r<R<r+\Delta r \mid R>r)}{\Delta r}
$$

The Kaplan-Meier estimate of the hazard function can be represented by (Eq. 1.2) where $n r$ is the number of jobs at risk at $r$, and $f_{r}$ is the number of jobs terminating at $r{ }^{12}$

$$
\hat{h}(r)=\frac{f_{r}}{n_{r}}
$$

First, jobs under temporary-contracts are divided into the control and treatment groups, and the basic statistics for each group are presented in Table 1.1.

Table 1.1. Basic statistics for the control and treatment group

\begin{tabular}{|c|c|c|c|c|c|}
\hline Jobs under & The number of & & \multicolumn{2}{|c|}{ Median value of job tenure } \\
\cline { 4 - 6 } jemporary-contracts & jobs & $\begin{array}{c}\text { Sumber of } \\
\text { failures }\end{array}$ & $\begin{array}{c}\text { The number of } \\
\text { censored cases }\end{array}$ & Full sample & $\begin{array}{c}\text { Subluding only } \\
\text { uncensored } \\
\text { cases }\end{array}$ \\
\hline $\begin{array}{c}\text { Control group } \\
(2001.01 \sim 2007.06)\end{array}$ & 2,236 & $\begin{array}{c}1,596 \\
(71.4 \%)\end{array}$ & $\begin{array}{c}640 \\
(28.6 \%)\end{array}$ & 9 months & 9 months \\
\hline $\begin{array}{c}\text { Treatment group } \\
(2007.07 \sim 2016.08)\end{array}$ & 3,454 & $\begin{array}{c}2,282 \\
(66.1 \%)\end{array}$ & $\begin{array}{c}1,172 \\
(33.9 \%)\end{array}$ & 13 months & 12 months \\
\hline Total & 5,690 & $\begin{array}{c}3,878 \\
(68.2 \%)\end{array}$ & $\begin{array}{c}1,812 \\
(31.8 \%)\end{array}$ & 11 months & 10 months \\
\hline
\end{tabular}

Note) Full sample consists of the total 5,690 jobs; sub-sample contains only failure cases $(3,878)$ in which specific date of job separation is known.

Although jobs in the control group began earlier than those in the treatment group, the median value of job tenure is lower for the jobs in the control group since the jobs are treated as being censored at July, 2007. In

${ }^{12}$ Another way of describing the changes in analysis time $r$ is a survivor function, which is the probability that there is no termination of employment prior to the analysis time $r$. The survivor function is simply the reverse cumulative distribution function: $S(r)=1-F(r)$ $=\operatorname{Prob}(R>r)$. The survivor function can be estimated nonparametrically using Kaplan-Meier's nonparametric version of the survivor function $S(t): \hat{S}(r)=\prod_{j \mid r_{j} \leq r}\left(\frac{n_{j}-f_{j}}{n_{j}}\right)=\prod_{j \mid r_{j} \leq r}\left(1-\hat{h}\left(r_{j}\right)\right)$ where $n_{r}$ is the number of jobs at risk at $r$, and $f_{r}$ is the number of jobs terminated at $\mathrm{r}$. 
addition, the treatment group has more jobs since the post-reform period is longer than pre-reform period. However, the proportion of failure and censored cases are almost the same in the control and treatment groups.

Second, the hazard functions for each group are nonparametrically estimated using (Eq. 1.2). The detailed hazard table is provided in the Appendix (Table A1). Figure 1.5 shows the nonparametrically estimated hazard functions for the control and treatment groups visually using the estimates $(h(r))$ in the Table A1. For jobs that started before the reform (the control group), the hazards of employment termination increase drastically at first having a peak at three months and then declines overall, ${ }^{13}$ although it shows some fluctuations across tenure, and it has another peak around twenty-five months. However, the shape of the hazard function for the treatment group is different from that for the control group. The termination hazard for the treatment group increases at first, peaks at thirteen months, and declines gradually with some fluctuation.

Figure 1.5. Kaplan-Meier hazard estimates for the workers on temporary-contracts

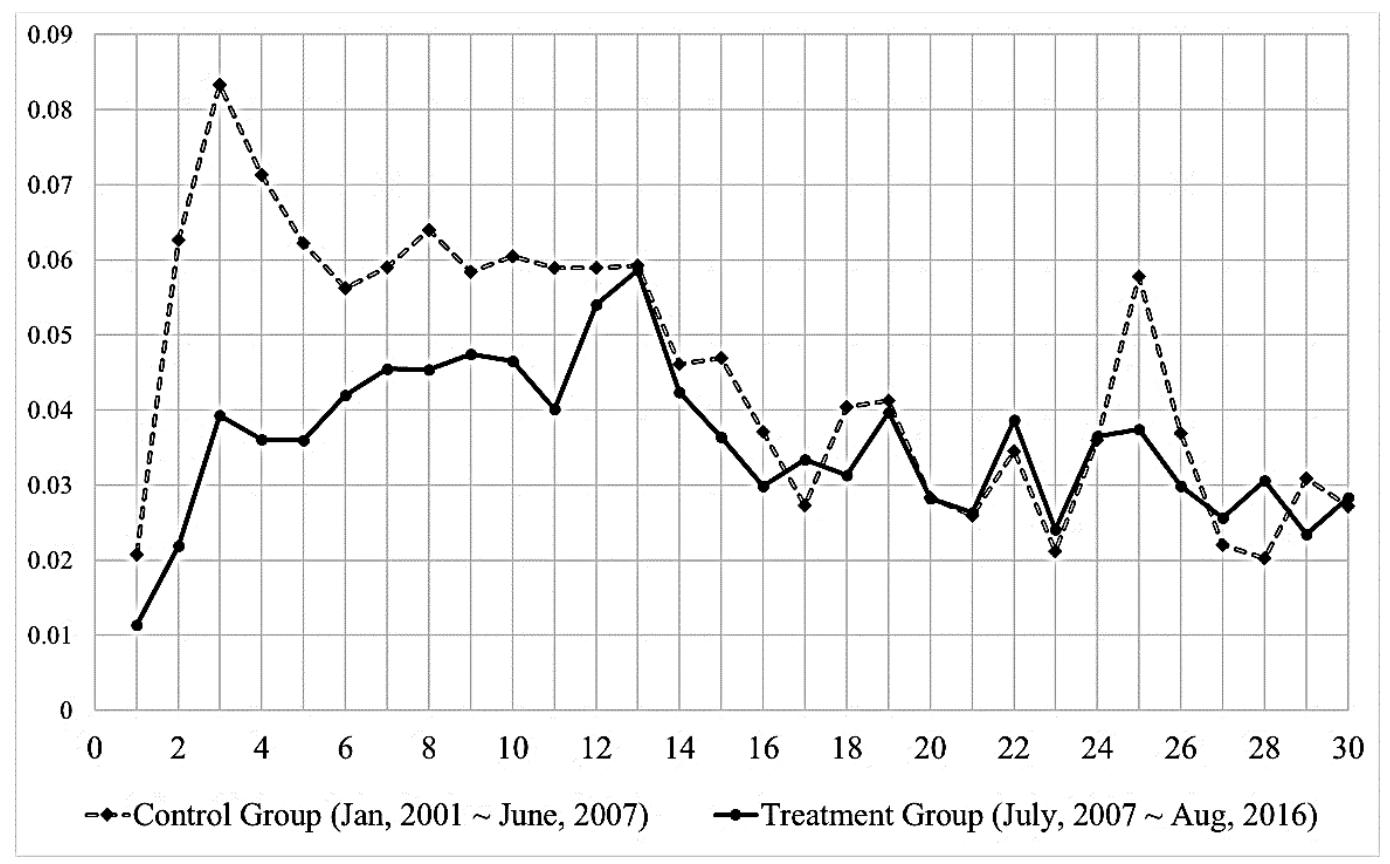

\footnotetext{
${ }^{13}$ The overall shape of the hazard functions for both the control and treatment groups is consistent with the prediction of Jovanovic's (1979a) model. He regards the quality of a job match as an "experience good", which is revealed as firms and workers experience it. The hazard of employment termination is low at the very early stage and then increases as quality is revealed and bad matches are weeded out. However, the hazard declines afterward, since the remaining matches are progressively better. This main prediction from the theoretical model was also confirmed empirically by Faber (1994). Using monthly data, he showed the hazard of a job ending increases to a maximum at 3 months and declines thereafter.
} 
The main difference in the hazard functions can be found in the first eleven months of tenure. The hazard function of the treatment group is much lower than that of the control group in the early portion of the job spells implying that the probability of employment termination decreases substantially for that period.

Figure 1.6. The difference in hazard estimates between the periods of before and after the reform

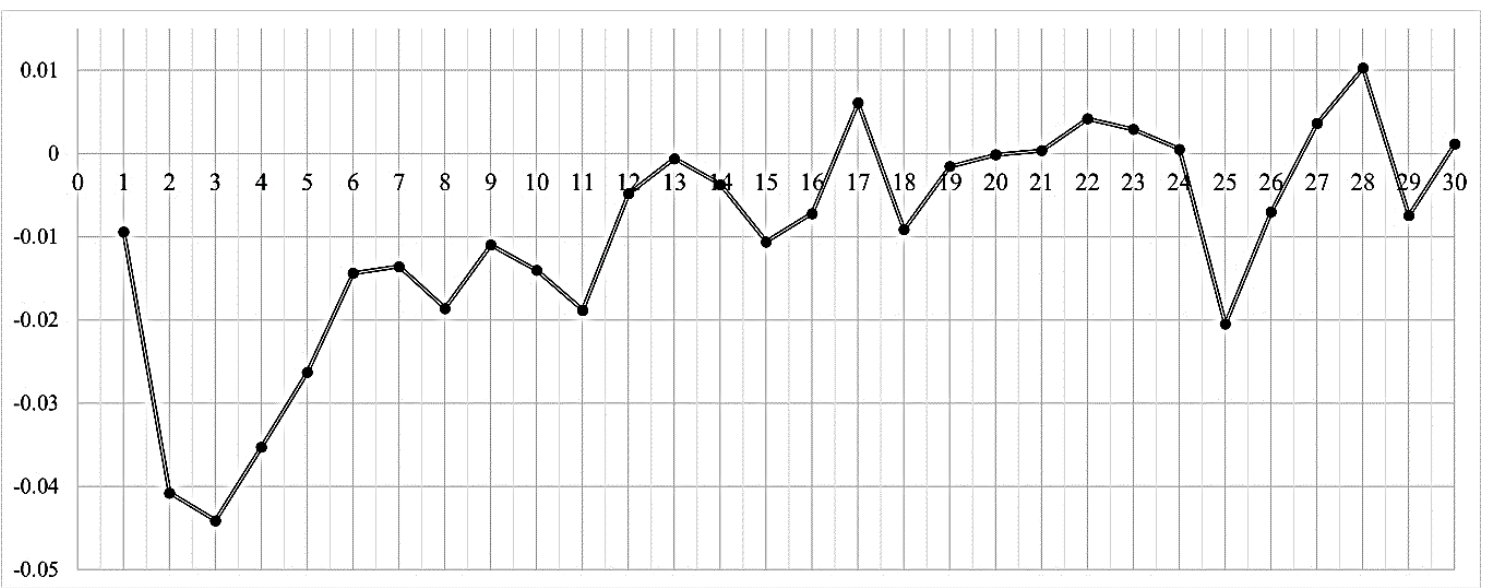

Figure 1.6 provides the difference of the hazard rates between the control and treatment group at each month of tenure. It shows large decreases in the hazards in the first eleven months and at twenty-five months after the reform; decreases are relatively large between two to five months. However, the difference is about as likely to be positive as negative after thirteen months. Thus, the main concern of this study is whether the difference in the two hazard functions remains significantly different even after controlling for other variables relevant to the employment. To verify this, I estimate the following Probit model:

\section{- $\quad \underline{\text { Probit Model }}$}

Posit an unobserved latent variable, $Y_{i t}^{*}$, for individual $i$ in a job lasting at least $t$, as

$$
Y_{i t}^{*}=X_{i t} \Pi+\sum_{r=2}^{30} \beta_{r} D_{\text {rit }}+\sum_{r=1}^{30} \delta_{r}\left(D_{\text {rit }} \cdot \text { Post-job }_{i}\right)+\varepsilon_{i t}
$$

The observed variable, $Y_{i t}=1\left\{Y_{i t}^{*} \geq 0\right\}$ 
Here, $Y_{i t}$ is a dummy variable indicating whether a job $i$ terminated at $t$. Post-job $b_{i}$ represents a treatment effect that has a value of one when a job began after the reform (July 2007), and $D_{\text {rit }}$ is a dummy identifying month of tenure $(r)$ for a job. The coefficient, $\delta_{r}$, of the interaction term captures the effect of the reform on hazards of employment termination at each month of tenure $(r)$. In the model, the error term, $\varepsilon_{i t}$, is assumed to follow a normal distribution.

The variable $X_{i t}$ is a set of controls including worker characteristics (gender, marital status, education level, and age), job characteristics (firm size, occupation, industry, and union membership), and a constant. In addition, the number of previous jobs for a worker is also included in the model to control for worker heterogeneity. In the presence of worker's unobservable heterogeneity, the duration dependence in the probability of job separation cannot be estimated consistently without controlling for the heterogeneity. Farber (1994) proposed to use the information on worker's previous jobs as one way of controlling worker heterogeneity. He showed the frequency of job change prior to the start of the current job has a positive impact on the hazards of job separation. I found a similar result that the hazard is positively related to the number of previous jobs since a worker entered the labor market. The detailed results can be found in the Appendix (Table A2).

In order to control for the macroeconomic conditions upon job separation, I tested various unemployment rates of the previous months, and the average unemployment rate over the last three months gives the most statistically significant result. Moreover, all the coefficients of the previous unemployment rates that I tested show negative signs, and this can be interpreted in terms of workers' incentives. Higher unemployment rates imply that temporary workers have fewer outside opportunities to find better jobs and, accordingly, so higher unemployment increases their interest in remaining in their jobs (Güell and Petrongolo, 2007).

The control variables used in the model are briefly summarized in Table 1.2, and a detailed explanation can be found in the Appendix (Table A2). 
Table 1.2. Definition of control variables

\begin{tabular}{|c|c|}
\hline Variables & Description of variables \\
\hline - Female $_{i}$ & Female indicator \\
\hline - Married $_{i}$ & Marital status at the beginning of a job \\
\hline - $\quad$ Edu level $j_{i}$ & Indicators for education level $j$ where $j=1, \ldots, 7$ \\
\hline Age $k_{i}$ & Indicators for an age category $k$ at the beginning of a job where $k=1, \ldots, 11$ \\
\hline - $\quad$ Previous job $_{i}$ & The number of previous jobs since a worker entered the labor market \\
\hline - $\quad$ Unemp_rate $_{i t}$ & The average unemployment rate over the last three months \\
\hline . $\quad$ Firm size $l_{i}$ & Indicators for a firm size $l$ where $l=1, \ldots, 7$ \\
\hline - $\quad$ Occupation $m_{i}$ & Indicators for an occupation $m$ where $m=1, \ldots, 10$ \\
\hline - $\quad$ Industry $n_{i}$ & Indicators for an industry $n$ where $n=1, \ldots, 17$ \\
\hline Union $_{i}$ & Indicator for the existence of a labor union in the workplace \\
\hline - $\quad$ In_union $_{i}$ & Indicator for labor union membership \\
\hline
\end{tabular}

\subsubsection{Results}

In the analysis, the duration of a job $(r)$ is restricted to thirty months because there are just a few observations after thirty months of tenure. The full results from the Probit analysis are provided in the Appendix (Table A2), and Table 1.3 collects only the estimates for the coefficient, $\delta_{r}$, of the interaction term, which captures the effect of the reform on the hazard of employment termination at each month of tenure $(r)$.

The first section (No Control) of Table 1.3 provides the result from Probit analysis without controlling for the covariates except for $D_{\text {rit }}$, Post-job, and the interaction terms. The result is similar to the difference in the hazard functions suggested in Figure 1.6. After the reform, the hazards decrease significantly in the first five months, and at eight months. After eleven months, the coefficient has either negative or positive sign, but it is not statistically significant except at twenty-eight months of tenure. The result from the analysis controlling for the covariates is suggested in the second section (Control). 
Table 1.3. Probit analysis for workers on temporary-contracts

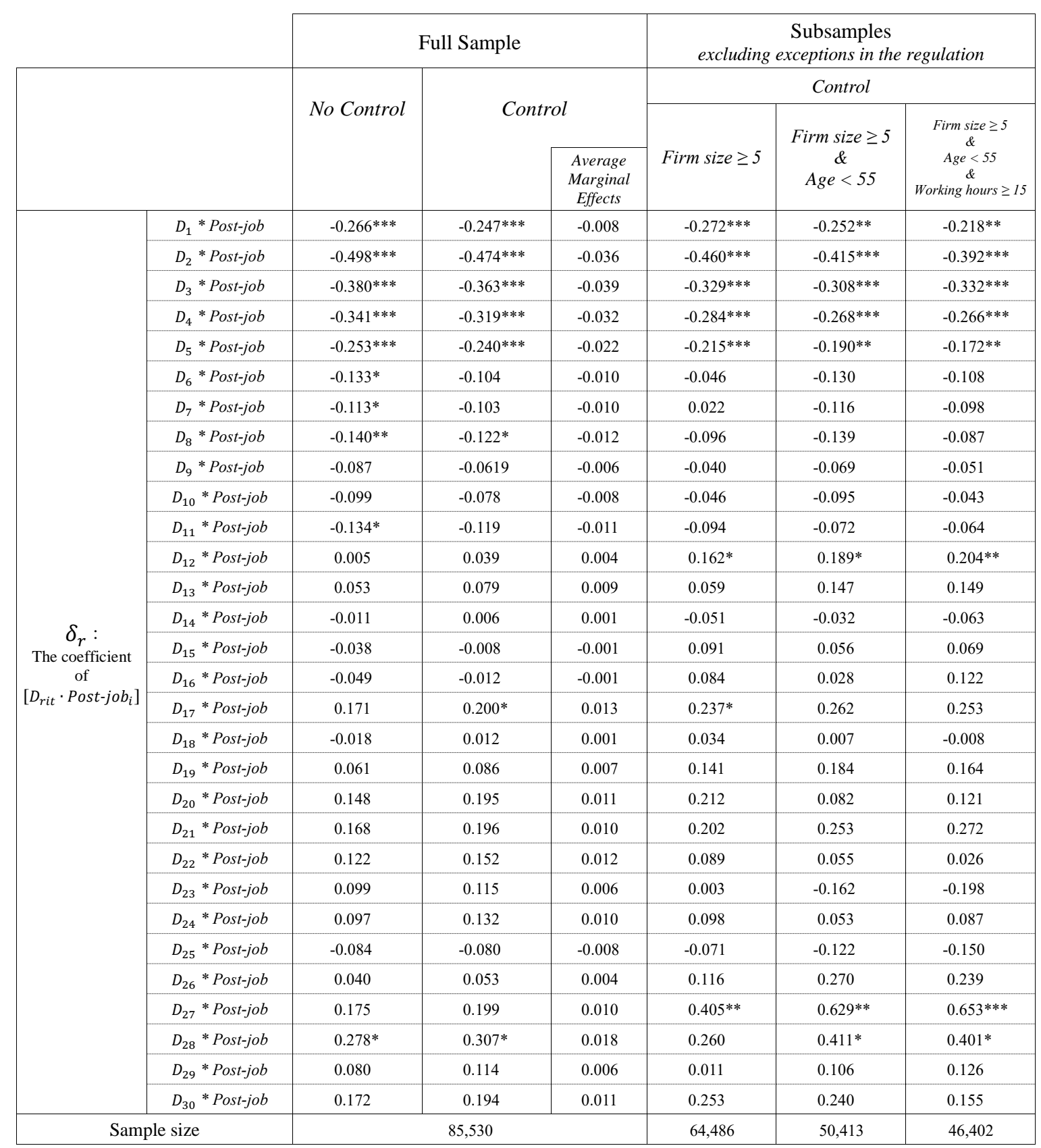

Note) $1 .{ }^{* * *} \mathrm{p}<0.01,{ }^{* *} \mathrm{p}<0.05,{ }^{*} \mathrm{p}<0.1$

2. The results without controlling for the covariate are presented under No Control, and the results controlling for the covariate are under Control.

3. The average marginal effect (AME) is the average of conditional marginal effects computed at all sample values. The AME of Post-job at $r$ is computed as follows: $A M E\left(\right.$ Post-job $\left.\mid D_{r}=1\right)=\frac{1}{n} \sum_{i=1}^{n} M E_{i}\left(\right.$ Post-job $\left.\mid D_{r}=1\right)$ where $M E_{i}(\cdot)=\hat{P}\left(y_{i}=1 \mid\right.$ Post-job $=$ $\left.1, D_{r}=1, D_{s}=0, \boldsymbol{X}_{i} ; \widehat{\boldsymbol{\Pi}}, \widehat{\beta_{r}}, \widehat{\delta_{r}}\right)-\hat{P}\left(y_{i}=1 \mid\right.$ Post-job $\left.=0, D_{r}=1, D_{s}=0, \boldsymbol{X}_{i} ; \widehat{\boldsymbol{\Pi}}, \widehat{\beta_{r}}, \widehat{\delta_{r}}\right)$ for $s \neq r$.

4. The exceptions of the regulation that can be identifiable in the data set are as follows: (i) Firms in the private sector with fewer than five employees, (ii) Workers aged 55 or older at the time of signing an employment contract, (iii) Workers who work less than 15 hours per week regularly. 
The three right columns contain the results estimated by using subsamples, considering the exceptions of the regulation. The legislation allows exceptions in the application of two-year maximum duration of fixedterm employment, and the three subsamples in Table 1.3 exclude exceptional cases that can be identifiable in the data set: (i) firms in the private sector with fewer than five employees, (ii) workers aged 55 or older at the beginning of a job, (iii) workers who work less than 15 hours per week regularly. ${ }^{14}$ Although the sample size decreases by $45 \%$ after taking the exceptions (i)-(iii) into account, the results do not change much except that statistical significance of coefficients increase at twelve and twenty-seven months of tenure.

The results can be interpreted as follows: First, even after controlling for covariates, the effect of the reform is still statistically significant in the first five months of tenure. The decrease in the hazards at tenure of less than six months could be evidence supporting the first hypothesis, (H1) recruitment channel, or could be interpreted as the recruitment effect of (H1) dominates the monitoring effect of $(H 2)$. Second, the estimates of the coefficients have positive signs after seventeen months of tenure except at twenty-five months, but they are not statistically significant at the 5\% significance level. Thus, the third hypothesis, (H3) replacement effect, cannot be accepted, and the reform seems not to influence the termination hazards through replacement channel- the replacement of a worker on fixed-term contract with another one. In conclusion, the results support the effect of the reform on the hazards of job termination only through (H1) Recruitment channel.

Table 1.4 provides the average marginal effects (AMEs) for the first twelve months of tenure to compare those with the results from Kaplan-Meier nonparametric estimation. In addition, Figure 1.7 shows visually the AMEs for the interaction term $\left(D_{\text {rit }} \cdot\right.$ Post-job $\left.b_{i}\right)$ across tenure. Through the comparison of the estimates, it can be confirmed that the AME from the Probit analysis without controlling for the covariates (No Control) is similar to the difference in Kaplan-Meier hazard estimates in Figure 1.6 in terms of the shape of the hazard function. Moreover, although the effect of the reform becomes slightly smaller after controlling for the covariates, it is still statistically significant in the first five months of tenure.

\footnotetext{
${ }^{14}$ Since job characteristics such as firm size and hours of working could change over time in a job spell, it is not obvious in some jobs whether a worker is excluded from the regulation throughout a job spell. To identify the exceptional cases in terms of firm size and working week, I used information on jobs (firm size and hours of working) at the date of the last interview. As for the age of a worker, a worker who was aged 55 or older at the beginning of a job is considered the exceptional case.
} 
Table 1.4. The comparison of hazard estimates and marginal effects at the sample mean

\begin{tabular}{|c|c|c|c|c|c|c|c|c|c|c|c|c|c|}
\hline & & \multicolumn{12}{|c|}{ Duration in month } \\
\hline & & 1 & 2 & 3 & 4 & 5 & 6 & 7 & 8 & 9 & 10 & 11 & 12 \\
\hline \multicolumn{2}{|c|}{$\begin{array}{c}\text { Difference in K-M } \\
\text { hazard estimates }\end{array}$} & -0.009 & -0.041 & -0.044 & -0.035 & -0.026 & -0.014 & -0.014 & -0.019 & -0.011 & -0.014 & -0.019 & -0.005 \\
\hline \multirow{5}{*}{$\begin{array}{l}\text { Average } \\
\text { Marginal } \\
\text { Effects } \\
\text { (AMEs) }\end{array}$} & No Control & $\begin{array}{l}-0.010 \\
(0.004)\end{array}$ & $\begin{array}{l}-0.042 \\
(0.007)\end{array}$ & $\begin{array}{l}-0.044 \\
(0.008)\end{array}$ & $\begin{array}{l}-0.036 \\
(0.007)\end{array}$ & $\begin{array}{l}-0.025 \\
(0.007)\end{array}$ & $\begin{array}{l}-0.013 \\
(0.008)\end{array}$ & $\begin{array}{l}-0.012 \\
(0.008)\end{array}$ & $\begin{array}{l}-0.015 \\
(0.008)\end{array}$ & $\begin{array}{l}-0.009 \\
(0.008)\end{array}$ & $\begin{array}{l}-0.010 \\
(0.009)\end{array}$ & $\begin{array}{l}-0.013 \\
(0.008)\end{array}$ & $\begin{array}{l}0.001 \\
(0.009)\end{array}$ \\
\hline & Control & $\begin{array}{l}-0.008 \\
(0.003)\end{array}$ & $\begin{array}{l}-0.036 \\
(0.005)\end{array}$ & $\begin{array}{l}-0.039 \\
(0.007)\end{array}$ & $\begin{array}{l}-0.032 \\
(0.007)\end{array}$ & $\begin{array}{l}-0.022 \\
(0.006)\end{array}$ & $\begin{array}{l}-0.010 \\
(0.007)\end{array}$ & $\begin{array}{l}-0.010 \\
(0.007)\end{array}$ & $\begin{array}{l}-0.012 \\
(0.007)\end{array}$ & $\begin{array}{l}-0.006 \\
(0.007)\end{array}$ & $\begin{array}{l}-0.008 \\
(0.008)\end{array}$ & $\begin{array}{l}-0.011 \\
(0.008)\end{array}$ & $\begin{array}{l}0.004 \\
(0.009)\end{array}$ \\
\hline & Firm size $\geq 5$ & $\begin{array}{l}-0.009 \\
(0.004)\end{array}$ & $\begin{array}{l}-0.035 \\
(0.006)\end{array}$ & $\begin{array}{l}-0.035 \\
(0.008)\end{array}$ & $\begin{array}{l}-0.027 \\
(0.007)\end{array}$ & $\begin{array}{l}-0.019 \\
(0.007)\end{array}$ & $\begin{array}{l}-0.004 \\
(0.008)\end{array}$ & $\begin{array}{l}0.002 \\
(0.008)\end{array}$ & $\begin{array}{l}-0.010 \\
(0.008)\end{array}$ & $\begin{array}{l}-0.004 \\
(0.008)\end{array}$ & $\begin{array}{l}-0.005 \\
(0.009)\end{array}$ & $\begin{array}{l}-0.009 \\
(0.009)\end{array}$ & $\begin{array}{l}0.017 \\
(0.01)\end{array}$ \\
\hline & $\begin{array}{c}\text { Firm size } \geq 5 \\
\text { Age }<55\end{array}$ & $\begin{array}{l}-0.009 \\
(0.004)\end{array}$ & $\begin{array}{l}-0.034 \\
(0.007)\end{array}$ & $\begin{array}{l}-0.034 \\
(0.009)\end{array}$ & $\begin{array}{l}-0.027 \\
(0.008)\end{array}$ & $\begin{array}{l}-0.018 \\
(0.008)\end{array}$ & $\begin{array}{l}-0.012 \\
(0.008)\end{array}$ & $\begin{array}{l}-0.011 \\
(0.009)\end{array}$ & $\begin{array}{l}-0.014 \\
(0.009)\end{array}$ & $\begin{array}{l}-0.006 \\
(0.009)\end{array}$ & $\begin{array}{l}-0.010 \\
(0.011)\end{array}$ & $\begin{array}{l}-0.007 \\
(0.01)\end{array}$ & $\begin{array}{l}0.022 \\
(0.011)\end{array}$ \\
\hline & $\begin{array}{c}\text { Firm size } \geq 5 \\
\text { Age }<55 \\
\text { Working } \\
\text { hr } \geq 15\end{array}$ & $\begin{array}{l}-0.008 \\
(0.004)\end{array}$ & $\begin{array}{l}-0.033 \\
(0.008)\end{array}$ & $\begin{array}{l}-0.037 \\
(0.009)\end{array}$ & $\begin{array}{l}-0.026 \\
(0.008)\end{array}$ & $\begin{array}{l}-0.017 \\
(0.009)\end{array}$ & $\begin{array}{l}-0.010 \\
(0.009)\end{array}$ & $\begin{array}{l}-0.009 \\
(0.009)\end{array}$ & $\begin{array}{l}-0.009 \\
(0.01)\end{array}$ & $\begin{array}{l}-0.005 \\
(0.009)\end{array}$ & $\begin{array}{l}-0.005 \\
(0.011)\end{array}$ & $\begin{array}{l}-0.007 \\
(0.011)\end{array}$ & 0.024 \\
\hline
\end{tabular}

Note) 1. Robust standard errors are in parenthesis, which are clustered at the worker level and calculated by using the delta-method.

2. The average marginal effect (AME) is the average of conditional marginal effects computed at all sample values.

Figure 1.7. The comparison of average marginal effects (AMEs)

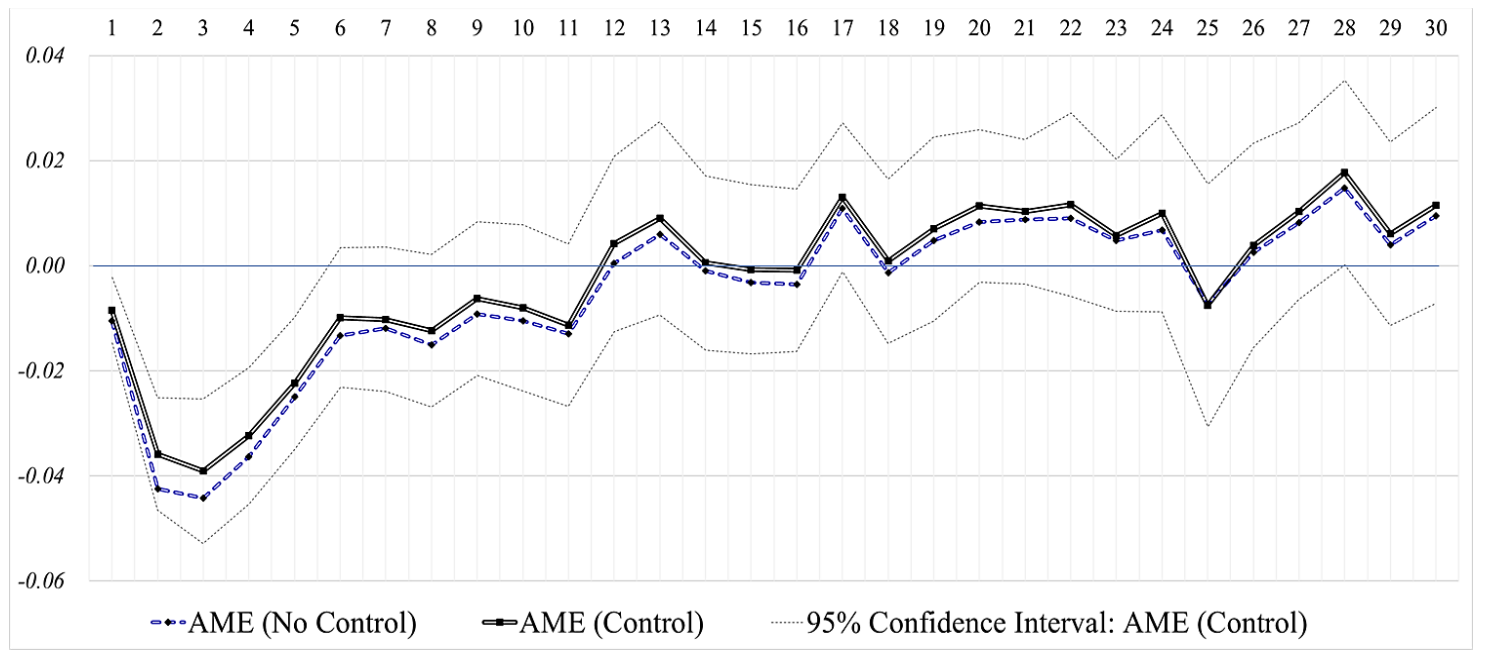

In summary, the probability of job separation decreases in the first five months of tenure after the reform, which suggests that firms react to the policy change by improving their recruitment process. Firms' better recruitment practice can result in well-matched jobs, which can lower the separation probability in several 
ways: workers with well-matched jobs have less incentive to search for alternative jobs, and they are also less likely to accept outside job offers (Jovanovic, 1979b); we also expect that better matched workers are less likely to be terminated.

The results can also be interpreted in terms of the firms' purpose of hiring fixed-term employees. AlbaRamirez (1998) suggested the reasons why firms use temporary employment contracts: first, they use temporary workers to perform temporary work or to avoid the employment rigidity of a permanent contract; second, a temporary contract can also be used as a screening device. In the Korean labor market, temporary jobs have been used mainly as a long-term substitute for permanent ones to reduce labor costs and increase employment flexibility. However, they seem to function as a screening tool as well after the reform improving job matches.

\subsubsection{Sensitivity and placebo tests}

I perform a sensitivity test to examine how estimates of the effect change if a shorter sample period is used for the same Probit model. I use shorter periods, 2001-2013 and 2004-2010, instead of full sample period, 2001-2016, and the results are provided in the Appendix (Table A3). When the shorter sample periods are used, the effect of the reform is still statistically significant in the first five months of tenure, although a point estimate for month seventeen is statistically significant, and estimates for seven later months are significant for the shortest period.

In addition, placebo tests are performed to see how the results look with false reforms, and the results are provided in the Appendix (Table A4). In the first placebo test, I code the data as if the reform occurred in Jan. 2004 or Jan. 2013 (instead of the actual reform in Jul. 2007) and estimate the effects of the two false reforms with the same Probit model. The results show no statistically significant effect of the false reforms in the first five months of tenure, except for a point estimate at five months of tenure when the false reform is set in Jan. 2013.

In the second placebo test, I code the data as if there was a reform effecting permanent workers instead of temporary workers and estimate the effect of the false reform with the same Probit model. To identify 
permanent workers in the data set, I select regular workers who were provided with social insurance by their employers, since they can be thought of as the most protected workers in the Korean labor market. Social insurance in Korea include unemployment insurance, national pension coverage, national health insurance, and industrial accident compensation insurance. The results show no statistically significant effect of the false reform on permanent workers in the first five months of tenure, although positive effects of the false reform are found in month twenty and five later months of tenure.

As neither placebo test finds effect of the false reforms in the first five months of tenure, these results support the view that the actual reform in July 2007 has a casual effect on termination hazards in the early stages of temporary employment.

\subsection{Analysis II: Workers' behavioral change after the reform}

The goal of the second analysis is to test the last hypothesis, (H4). The analysis seeks to find empirical evidence which supports the view that workers on temporary-contracts provide greater effort after the reform to obtain advancement to permanent employment. If evidence supports this view, it can be argued that the reform also influences the hazards of employment termination through the channel of workers' effort, which results in decreases in the exit hazard. However, it is difficult to measure the level of workers' effort quantitively. Thus, this study follows previous studies, Booth et al. (2002) and Engellandt and Riphahn (2005), which use information on workers' overtime as a proxy for workers' effort.

\subsubsection{Data set and sample}

As above, we use the KLIPS data for individuals to investigate the impact of the 2007 Korean reform on workers' effort. The data set consists of nineteen annual waves, but, as in the previous analyses, the first three waves (1998-2000) of the survey are excluded from the analysis to prevent the experience of the 1998 Asian financial crisis from influencing the results of this study. Thus, the final sample that has a panel structure consists of sixteen waves of the data surveyed between 2001 and 2016. In addition, we exclude casual 
workers (day laborers), so the sample includes only regular workers and temporary-contract workers.

This study compares the effort levels of temporary-contract workers - those subject to the regulation and permanent workers - those not subject to the regulation. To identify permanent workers among regular workers, we use a criterion whether a worker is provided with social insurance programs from his/her employer in a job since workers covered by the insurance programs can be thought of as the most protected workers in the Korean labor market. Social insurance programs in Korea include unemployment insurance, national pension, national health insurance, and industrial accident compensation insurance. Thus, the final sample consists of selected regular workers and temporary-contract workers.

The survey offers various information on working hours of wage and salary workers - for example, regular working hours per week, whether a worker provides overtime hours, the average of weekly (or monthly) overtime hours, and whether the overtime hours is paid or unpaid. Using this information, four dependent variables - two binary variables and two continuous variables - are derived to proxy workers' effort (see Table 1.5). The binary variables - OTit and UOTit - indicate whether a worker provides overtime hours or not (OTit includes both paid and unpaid overtime; UOTit denotes unpaid overtime). Second two continuous variables - HRit and UHRit - stand for how many hours of overtime a worker provides on average per week (HRit includes both paid and unpaid overtime hours; UHRit denotes the hours of unpaid overtime). The continuous variables - HRit and UHRit - are censored at zero because they have positive values only when workers provide overtime hours and have the value of zero for workers who didn't provide overtime hours.

Table 1.5. Dependent variables as a proxy for workers' effort

\begin{tabular}{|c|c|c|}
\hline \multirow{2}{*}{ Binary variables } & (1) & OT $i$ t $=1$, if a worker provides overtime hours (including both paid and unpaid OT) \\
\cline { 2 - 4 } & (2) & UOT $i$ t $=1$, if a worker provides unpaid overtime hours \\
\hline \multirow{2}{*}{$\begin{array}{c}\text { Continuous variables } \\
\text { (censored at zero) }\end{array}$} & (3) & HRit $=$ Average weekly overtime hours (including both paid and unpaid $O T$ ) \\
\cline { 2 - 4 } & (4) & UHRit = Average weekly unpaid overtime hours \\
\hline
\end{tabular}

Descriptive statistics for each dependent variable are provided in the Appendix (Table A5 and A6) in detail.

Table 1.6 provides the proportion of the regular or temporary-contract workers who provide overtime hours. 
To see the changes in the proportions visually across the survey years, Figure 1.8 plots the proportions at each year.

Table 1.6. The proportion of workers providing overtime hours (\%)

\begin{tabular}{|c|c|c|c|c|c|c|c|c|c|c|c|c|c|c|c|c|c|}
\hline & & \multirow[b]{2}{*}{2001} & \multirow[b]{2}{*}{2002} & \multirow[b]{2}{*}{2003} & \multirow[b]{2}{*}{2004} & \multirow[b]{2}{*}{2005} & \multirow[b]{2}{*}{2006} & \multirow[b]{2}{*}{2007} & \multirow[b]{2}{*}{2008} & \multirow[b]{2}{*}{2009} & \multirow[b]{2}{*}{2010} & \multirow[b]{2}{*}{2011} & & & & & \\
\hline & & & & & & & & & & & & & 2012 & 2013 & 2014 & 2015 & 2016 \\
\hline \multirow{3}{*}{$\begin{array}{c}O T_{i t}=1, \\
\text { if } \\
\text { providing } \\
\text { overtime } \\
\text { hours }\end{array}$} & Regular & 46.2 & 46.2 & 35.3 & 37.0 & 36.9 & 37.3 & 36.2 & 39.7 & 37.4 & 37.7 & 38.5 & 36.9 & 37.8 & 40.1 & 37.6 & 36.1 \\
\hline & Temporary & 14.4 & 14.4 & 7.2 & 6.9 & 9.2 & 12.2 & 12.0 & 10.8 & 9.4 & 9.2 & 9.6 & 8.6 & 7.2 & 8.0 & 5.4 & 7.9 \\
\hline & $\begin{array}{c}\text { Difference } \\
\left(\Delta O T_{t}\right)\end{array}$ & 31.8 & 31.8 & 28.1 & 30.1 & 27.8 & 25.0 & 24.3 & 28.9 & 28.0 & 28.5 & 28.9 & 28.3 & 30.6 & 32.1 & 32.2 & 28.1 \\
\hline \multirow{3}{*}{$\begin{array}{c}U^{U O T_{i t}}=1 \text {, } \\
\text { if } \\
\text { providing } \\
\text { unpaid } \\
\text { overtime } \\
\text { hours }\end{array}$} & Regular & 17.8 & 16.9 & 15.0 & 16.1 & 15.9 & 15.6 & 14.6 & 17.5 & 17.3 & 16.4 & 16.9 & 16.0 & 17.4 & 18.5 & 18.7 & 17.5 \\
\hline & Temporary & 8.9 & 7.0 & 3.0 & 5.4 & 1.8 & 4.6 & 3.8 & 3.1 & 5.0 & 4.7 & 4.8 & 4.3 & 2.9 & 3.7 & 2.5 & 2.6 \\
\hline & $\begin{array}{c}\text { Difference } \\
\left(\Delta U O T_{t}\right)\end{array}$ & 8.9 & 9.9 & 12.0 & 10.7 & 14.1 & 11.0 & 10.9 & 14.4 & 12.3 & 11.7 & 12.0 & 11.7 & 14.5 & 14.8 & 16.2 & 14.9 \\
\hline
\end{tabular}

Figure 1.8. The proportion of workers providing overtime hours

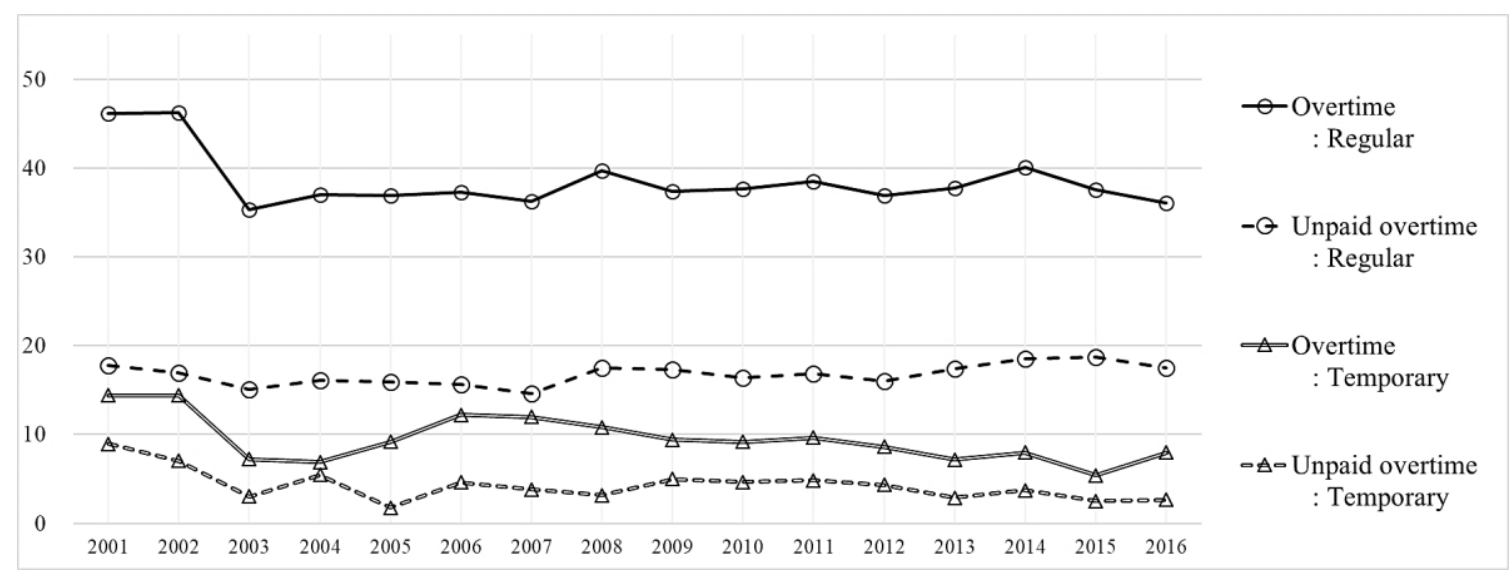

First, the proportion of regular workers who work overtime $\left(O T_{i t}=1\right)$ is much higher than that of temporary-contract workers. The proportion for regular workers fluctuated around $38 \%$, but that for temporary-contract workers seemed to decrease over time. In addition, the difference in the proportions $\left(\Delta O T_{t}\right)$ decreased slightly until 2007 , but it showed small increases thereafter. 
Second, similar patterns are found in the proportion of employees who work unpaid overtime $\left(U O T_{i t}=1\right)$. The proportion of workers who work overtime without financial compensation was nearly three times higher for regular workers in the early survey years. However, the differences in the proportions $\left(\Delta U O T_{t}\right)$ became larger in later years due to the decrease in unpaid overtime for temporary-contract employees.

Third, the two differences - for both overtime $\left(\Delta O T_{i t}\right)$ and unpaid overtime $\left(\Delta U O T_{i t}\right)$ - in the proportions between regular and temporary-contract workers fluctuated relatively less during the pre-reform period (2001 2006), and the gaps seemed to become larger after the reform. This suggests that the proportions for the temporary-contract workers evolved in a similar way as the proportions for the regular workers during the pre-reform period. Based on the finding, this study applies a difference-in-differences approach ${ }^{15}$ to the analysis for workers' effort. In the setting, the control and treatment groups are composed of regular workers and temporary-contract workers respectively because only the temporary-contracts - which are signed from July 2007 and onward - are subject to the new regulation, and there was no significant change in regulations on permanent contracts during the analysis period that would directly influence working hours.

\subsubsection{Empirical strategy}

In order to examine whether workers on temporary-contracts $\left(\right.$ Temp $\left._{i t}=1\right)$ show greater effort after the reform, observations in the sample are divided into three groups. Group 1 includes workers who were surveyed before the reform $\left(\right.$ After $\left.t_{t}=0\right)$; hence, their jobs had to begin before the reform $\left(\right.$ Post-job $\left._{i t}=0\right)$. Group 2 consists of workers who started their jobs before the reform $\left(P o s t-j o b_{i t}=0\right)$ but were surveyed after the reform $\left(\right.$ After $\left._{t}=1\right)$. Group 3 has workers whose jobs began after the reform $\left(\right.$ Post-job $\left._{i t}=1\right)$; hence, they had to be surveyed after the reform $\left(\right.$ After $\left._{t}=1\right)$. Figure 1.9 describes the three groups visually.

Although only temporary-contract workers in Group 3 are subject to the new regulation initially, we test whether the reform influences the effort levels of temporary-contract workers in Group 2 as well as Group 3. For this, two econometric models - (Eq.4) and (Eq.5) - are employed based on a difference-in-differences

\footnotetext{
${ }^{15}$ Blundell and Costas Dias (2000) suggest the common trends condition that is crucial for difference-in-differences estimator to be consistent, which means that treatment and control groups respond to macroeconomic shocks in the similar way.
} 
approach.

Figure 1.9. Three groups of sample observation and two types of treatment effects

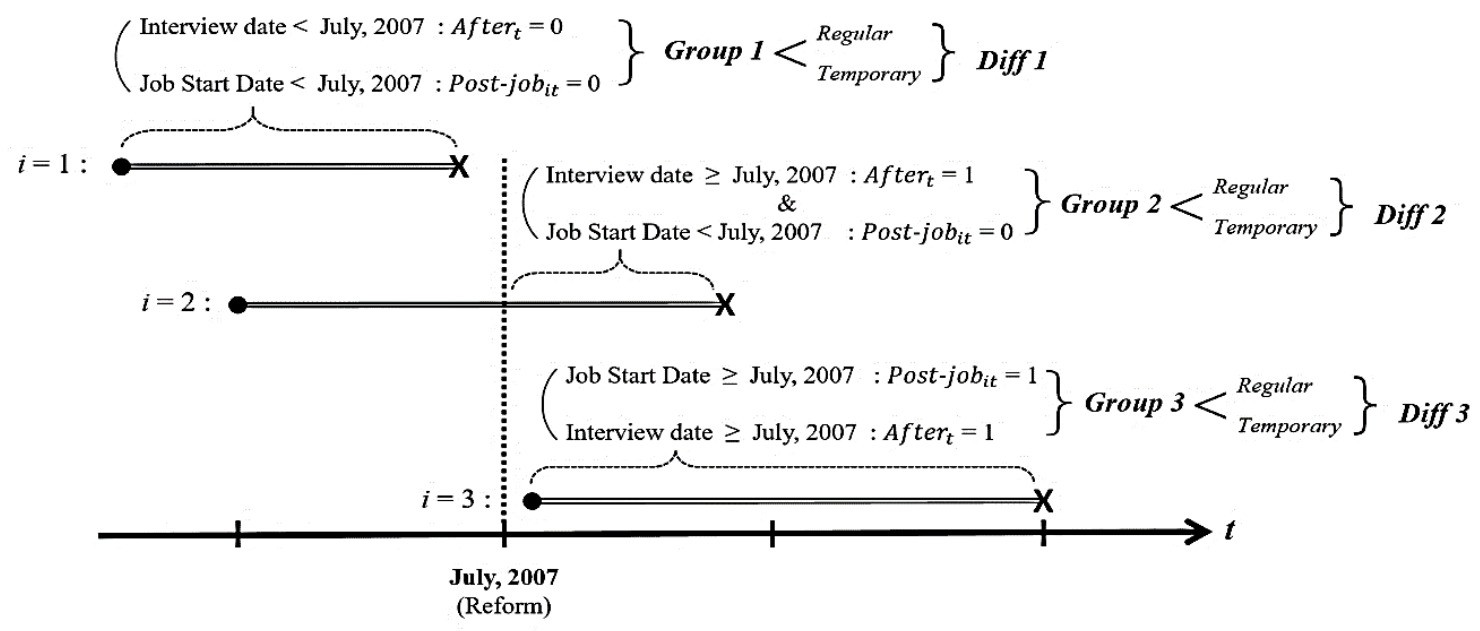

- $\underline{\text { Probit Model }}$

An unobserved latent variable, $Y_{i t}^{*}$, is assumed to be predicted as follows:

$$
\begin{aligned}
& Y_{i t}^{*}=X_{i t} \Pi+\beta_{1} \text { Temp }_{i t}+\beta_{2} \text { After }_{t}+\beta_{3} \text { Post-job }_{i t}
\end{aligned}
$$

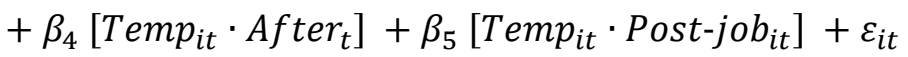

$$
\begin{aligned}
& \text { where } Y_{i t}^{*}=O T_{i t}^{*} \text { or } U O T_{i t}^{*} \quad \text { (Eq. 1.4) }
\end{aligned}
$$

The observed variable, $Y_{i t}=1\left\{Y_{i t}^{*} \geq 0\right\}$, where $Y_{i t}=O T_{i t}$ or $U O T_{i t}$

In the specification of the models, two interaction terms - ' Temp $_{i t} \cdot$ After $_{t}$ ' and 'Temp $p_{i t} \cdot$ Post-job $_{i t}$ ' - are included to examine the two types of treatment effects. The coefficient, $\beta_{4}$, of the first interaction term captures the first treatment effect - whether the temporary-contract employees in the Group 2 provide greater effort after the reform relative to the regular workers $\left(\beta_{4}=\right.$ Diff $f_{2}-$ Diff $\left.f_{1}\right)$. The coefficient, $\beta_{5}$, of the second interaction term compares the effort levels of the temporary-contract workers in Groups 2 and 3. Thus, $\beta_{5}$ captures the additional treatment effect for the observations that were surveyed after the reform, where a job 
contract was also made after the reform $\left(\beta_{5}=\operatorname{Diff}_{3}-\operatorname{Diff}_{2}\right)$.

This model implies a Probit model for the binary dependent variables (OTit and UOTit); for the continuous dependent variables (HRit and UHRit), a Tobit model is used to deal with the censoring issue. In both models, the error term, $\varepsilon_{i t}$, is assumed to follow a normal distribution.

- $\quad$ Tobit Model

An unobserved latent variable, $Y_{i t}^{*}$ :

$$
\begin{aligned}
& Y_{i t}^{*}=X_{i t} \Pi+ \beta_{1} \text { Temp }_{i t}+\beta_{2} \text { After }_{t}+\beta_{3} \text { Post-job }_{i t} \\
&+\beta_{4}\left[\text { Temp }_{i t} \cdot \text { After }_{t}\right]+\beta_{5}\left[\text { Temp }_{i t} \cdot \text { Post-job }_{i t}\right]+\varepsilon_{i t} \\
& \text { where } Y_{i t}^{*}=H R_{i t}^{*} \text { or } U H R_{i t}^{*}
\end{aligned}
$$

The observed variable, $Y_{i t}=\max \left\{0, Y_{i t}^{*}\right\}$, where $Y_{i t}=H R_{i t}$ or $U H R_{i t}$

In the models, the variable $X_{i t}$ is a set of controls including worker characteristics (gender, marital status, education level, age, and tenure) and job characteristics (sector, union membership, firm size, occupation, and industry). Moreover, in order to capture the time effect and the macro economic conditions in the survey year, a linear time trend and its square term, employment rates, and unemployment rates are controlled. The control variables used in the model are briefly summarized in Table 1.7, and a detailed explanation can be found in the Appendix (Table A7). 
Table 1.7. Definition of control variables

\begin{tabular}{|c|c|c|}
\hline - & Female $_{i}$ & Female indicator \\
\hline . & Married $_{i t}$ & Marital status \\
\hline . & Female $_{i} \times$ Married $_{i t}$ & An interaction term of Female and Married dummies \\
\hline . & Edu level $j_{i t}$ & Indicators for education level $j$ where $j=1, \ldots, 7$ \\
\hline . & Age $k_{i t}$ & Indicators for an age category $k$ where $k=1, \ldots, 11$ \\
\hline . & Tenure $l_{i t}$ & Indicators for an tenure category $l$ where $l=1, \ldots, 8$ \\
\hline$\cdot$ & Private sector $_{i t}$ & Indicator for a private sector \\
\hline . & Union $_{\text {it }}$ & Indicator for the existence of a labor union in the workplace \\
\hline . & In_union $_{i t}$ & Indicator for labor union membership \\
\hline$\cdot$ & Firm size $m_{i t}$ & Indicators for a firm size $m$ where $m=1, \ldots, 8$ \\
\hline . & Occupation $n_{i t}$ & Indicators for an occupation $n$ where $n=1, \ldots, 11$ \\
\hline - & Industry $s_{i t}$ & Indicators for an industry $s$ where $s=1, \ldots, 18$ \\
\hline . & Year $_{t}$ & Calendar time effect with a linear trend and its square term \\
\hline . & Emp_rate $_{t}$ & The employment rate in each year \\
\hline . & Unemp_rate $_{t}$ & The unemployment rate for the people of age 15 to 64 in each year \\
\hline
\end{tabular}

\subsubsection{Results}

Full results estimated by the Probit and Tobit models are provided in the Appendix (Table A7). Table 1.8 contains only the four coefficients of interest and the conditional average marginal effects. The two sections, (1) and (2), show the results for the binary dependent variables, $O T_{i t}$ and $U O T_{i t}$. First, temporary-contract workers (Temp) are less likely to work overtime and unpaid overtime compared to regular workers. ${ }^{16}$ The estimated average marginal effect implies a 11 percentage point difference in overtime work and 3.9 percentage point difference in unpaid overtime work. ${ }^{17}$ Second, the likelihood that regular workers work overtime increased by 3.3 percentage points in the period of post-reform (After), but there is no statistically

\footnotetext{
${ }^{16}$ This result is contrary to the main finding of Engellandt and Riphahn (2005). They showed empirically the likelihood of working unpaid overtime is much higher for temporary workers than permanent ones in Switzerland. They argued that temporary workers have more incentive to exert greater effort because temporary contracts function as a screening tool and provide stepping stones into permanent employment in Switzerland. On the other hand, Landers et al. (1996) and Booth et al. (2003) suggested permanent workers have incentives to prove they are hardworking. In Korea, it seems that both higher promotion incentives for permanent workers and limited advancement from temporary to permanent employment result in longer (unpaid) overtime hours and higher chance of working (unpaid) overtime for permanent workers.

${ }^{17}$ The conditional average marginal effect (AME) is computed by averaging conditional marginal effect (ME) for each observation $i$ over all sample values. For example, the conditional AME of temporary-contract (Temp) is computed as follows: AME $($ Temp $\mid$ After $=0$, Post -job $=0)=\frac{1}{n} \sum_{i=1}^{n} M E_{i}($ Temp $\mid$ After $=0$, Post -job $=0) \quad$ where $\quad M E_{i}(\cdot)=\hat{P}\left(y_{i}=1 \mid\right.$ Temp $=1$, After $=0$, Post-job $\left.=0, \boldsymbol{X}_{i} ; \widehat{\boldsymbol{\beta}}, \widehat{\boldsymbol{\pi}}\right)-\hat{P}\left(y_{i}=1 \mid\right.$ Temp $=0$, After $=0$, Post-job $\left.=0, \boldsymbol{X}_{i} ; \widehat{\boldsymbol{\beta}}, \widehat{\boldsymbol{\pi}}\right)$. Similarly, the conditional AME of After and Post-job stand for $A M E(A f t e r \mid T e m p=0$, Post $-\mathrm{job}=0)=\frac{1}{n} \sum_{i=1}^{n} M E_{i}(A f t e r \mid T e m p=0$, Post -job $=0)$ and AME $($ Post -job $\mid$ Temp $=0$, After $=1)=$ $\frac{1}{n} \sum_{i=1}^{n} M E_{i}($ Post-job $\mid \mathrm{Temp}=0$, After $=1)$ respectively.
} 
significant increase in the likelihood of unpaid overtime. Third, whether a job contract was made before or after the reform (Post-job) has a statistically significant impact on neither overtime or unpaid overtime work for regular workers. Fourth, temporary-contract workers in Group 2 seem not to work more overtime or unpaid overtime after the reform (Temp-After) compared to regular workers. Fifth, there is also no statistically significant diffrence in the likelihood of providing overtime or unpaid overtime work between the temporary-contract workers in Groups 2 and 3 (Temp · Post-job). In sum, I cannot find any evidence that temporary-contract workers are more likely to work overtime or unpaid overtime after the reform compared to regular workers.

Table 1.8. The effect of the reform on workers' overtime work

\begin{tabular}{|c|c|c|c|c|c|c|}
\hline & \multicolumn{6}{|c|}{ Dependent variables } \\
\hline & \multicolumn{2}{|c|}{$\begin{array}{c}(1) \\
\text { OTi }=1, \\
\text { if providing } \\
\text { overtime work } \\
\text { (paid \& unpaid) }\end{array}$} & \multicolumn{2}{|c|}{$\begin{array}{c}\text { (2) } \\
\text { UOTi }=1, \\
\text { if providing } \\
\text { unpaid } \\
\text { overtime work }\end{array}$} & \multirow{2}{*}{$\begin{array}{c}\text { (3) } \\
\begin{array}{c}H R i=\text { average } \\
\text { weekly } \\
\text { overtime hours } \\
\text { (paid \& unpaid) }\end{array} \\
\text { Tobit }\end{array}$} & \multirow{2}{*}{$\begin{array}{c}\text { (4) } \\
\begin{array}{c}\text { UHRi = average } \\
\text { weekly } \\
\text { hours of unpaic } \\
\text { overtime }\end{array} \\
\text { Tobit }\end{array}$} \\
\hline Variables & Probit & $\begin{array}{l}\text { Average } \\
\text { Marginal } \\
\text { Effect }\end{array}$ & Probit & $\begin{array}{l}\text { Average } \\
\text { Marginal } \\
\text { Effect }\end{array}$ & & \\
\hline $\begin{array}{c}\text { Temp : } \boldsymbol{\beta}_{\mathbf{1}} \\
\text { (Temporary-contract) }\end{array}$ & $\begin{array}{c}-0.396^{* * * *} \\
(0.053)\end{array}$ & -0.110 & $\begin{array}{l}-0.215^{* * * *} \\
(0.065)\end{array}$ & -0.039 & $\begin{array}{c}-4.768 * * * \\
(0.620)\end{array}$ & $\begin{array}{c}-3.152 * * * \\
(0.934)\end{array}$ \\
\hline $\begin{array}{c}\text { After : } \boldsymbol{\beta}_{\mathbf{2}} \\
\text { (After }=1, \text { if surveyed } \\
\text { after July, 2007) }\end{array}$ & $\begin{array}{l}0.106 * * * \\
(0.036)\end{array}$ & 0.033 & $\begin{array}{l}0.044 \\
(0.044)\end{array}$ & 0.009 & $\begin{array}{l}1.484 * * * \\
(0.389)\end{array}$ & $\begin{array}{l}0.755 \\
(0.596)\end{array}$ \\
\hline $\begin{array}{c}\text { Post-job : } \boldsymbol{\beta}_{\mathbf{3}} \\
\text { (Post-job }=1 \text {, if a job } \\
\text { began after July, 2007) }\end{array}$ & $\begin{array}{l}0.058 \\
(0.037)\end{array}$ & 0.018 & $\begin{array}{l}0.031 \\
(0.041)\end{array}$ & 0.006 & $\begin{array}{l}0.451 \\
(0.403)\end{array}$ & $\begin{array}{l}0.544 \\
(0.573)\end{array}$ \\
\hline $\begin{array}{c}\text { Temp x After } \\
: \boldsymbol{\beta}_{4}\end{array}$ & $\begin{array}{l}0.031 \\
(0.093)\end{array}$ & 0.002 & $\begin{array}{r}-0.017 \\
(0.111)\end{array}$ & -0.005 & $\begin{array}{l}0.201 \\
(1.107)\end{array}$ & $\begin{array}{l}-0.186 \\
(1.602)\end{array}$ \\
\hline $\begin{array}{c}\text { Temp x Post-job } \\
: \beta_{5}\end{array}$ & $\begin{array}{r}-0.128 \\
(0.094)\end{array}$ & -0.037 & $\begin{array}{r}-0.142 \\
(0.109)\end{array}$ & -0.024 & $\begin{array}{r}-1.097 \\
(1.105)\end{array}$ & $\begin{array}{r}-1.570 \\
(1.553)\end{array}$ \\
\hline $\begin{array}{l}\text { The Number of } \\
\text { Observations }\end{array}$ & & & & 37,835 & & \\
\hline
\end{tabular}

Note) 1. Robust standard errors are in parenthesis, which are clustered at the individual level (the number of individuals: 8,497 ).

2. The average marginal effect is the average of conditional marginal effects computed at all sample values.

3. ${ }^{* * *} \mathrm{p}<0.01,{ }^{* *} \mathrm{p}<0.05,{ }^{*} \mathrm{p}<0.1$ 
The last two sections, (3) and (4), provide the results for workers' average weekly overtime and unpaid overtime hours, $H R_{i t}$ and $U H R_{i t}$, which were estimated with a Tobit model. The results are similar to those in the first two columns. First, temporary-contract workers are likely to provide fewer overtime and unpaid overtime hours than regular workers: temporary-contract employees work about 4.7 fewer hours overtime and about 3.1 fewer unpaid hours overtime in a week than regular workers. Second, regular workers work overtime about 1.4 hours more in a week after the reform, but there is not statistically significant increase in the hours of unpaid overtime. Third, for regular workers, the average weekly hours of overtime and unpaid overtime seem not to depend on whether a job contract was entered into before or after the introduction of the new regulation. Fourth, for the temporary-contract workers in Group 2 and Group 3, the reform has no significant impact on the average weekly hours of overtime and unpaid overtime.

In summary, the results do not support the view that temporary-contract workers work overtime more after the reform relative to permanent workers (or selected regular workers). If workers' effort levels in their jobs are captured by overtime work (or the hours of overtime work), then the results do not suggest any evidence that supports the last hypothesis $(\mathrm{H} 4)$ - workers on temporary-contract provide greater effort after the reform. Hence, there is no evidence that greater worker effort produces the decrease in the hazards of employment termination that we observe in the first five months on the job. Thus, the hypothesis $(\mathrm{H} 4)$ is not supported, and I conclude that there is no change in the hazards of employment termination through the channel of workers' effort.

\section{5. Conclusion}

This study analyzes how firms and workers respond to increased protection for temporary employment. In 2007 , the Korean government introduced a new regulation that restricts the length of fixed-term employment with an employer to a maximum of two years. After the policy change, an employer who employed a worker

in a fixed-term contract for two years would need to convert the worker's contract from a fixed-term to a permanent one.

First, from the perspective of employers, the new regulation can be thought of as a potential increase in 
firing costs for temporary workers. Thus, the employers may try to improve the screening process to establish better matches and weed out bad matches prior to the increase in firing costs, which results in better job match quality. In order to test hypotheses on firms' and workers' behavioral change, this study employs survival analysis that investigates the change in the probability of employment termination after the reform. The results show statistically significant decreases in the probability of job separation in the first five months of tenure after the policy change, which implies that firms respond to the strict protection for temporary workers by improving their recruitment practices.

Second, temporary workers have an incentive to provide greater effort after the policy change because the reform offers a potential path to permanent employment that ensures higher job security and compensation. Moreover, the greater effort in their jobs can result in a decrease in the probability of employment termination. This study uses information on workers' overtime as a proxy for worker's effort since it is difficult to measure the level of workers' effort. However, the results provide no evidence supporting the view that temporary employees are more likely to work overtime after the policy change. Thus, if workers' effort levels in their jobs are captured by overtime work, our results do not confirm the hypothesis that strict protection for temporary workers can decrease the probability of employment termination through the increase in the level of workers' effort.

In conclusion, the increased protection for temporary workers through the reform induces employers to improve recruitment process, which results in better-matched jobs. Temporary jobs in the Korean labor market have been used mainly as a long-term substitute for permanent ones to reduce labor costs and increase employment flexibility. However, they seem to function as a screening tool as well after the reform, improving job matches. 


\section{CHAPTER 2.}

\section{How firms evade stronger protection for fixed-term employees: Evidence from alternative employment arrangements in South Korea}

\subsection{Introduction}

In the 1980s, several European countries adopted policies that allowed new forms of employment that relaxed worker protections and therefore provided greater employer discretion. Through such alternatives, which included temporary contracts, fixed-term contracts or hiring through temporary help agencies, policymakers hoped to make the labor markets more flexible and to lower unemployment (Bentolila and Dolado, 1994; Blanchard and Landier, 2002). Although such policies may have reduced rigidity in labor markets, they also encouraged firms to substitute temporary jobs for permanent ones. In fact, these policies were associated with a surge of temporary jobs. The drastic increase in temporary jobs has been pointed out as a source of social inequality because temporary jobs are usually characterized as inferior, as most temporary workers are paid less, are offered less training, and are less satisfied with their jobs (Booth et al., 2002).

The Korean labor market was no exception to the increasing trend toward temporary jobs. The Korean government allowed an extensive use of temporary jobs to increase flexibility in the labor market in the late 1990s. As a result, the share of temporary employment in wage and salary workers almost doubled from $16.6 \%$ in 2001 to $29.4 \%$ in 2005 (Grubb et al., 2007). Accordingly, the Korean government proposed a labor market reform in 2007 to lower the incidence of temporary jobs and to protect temporary workers. The main policy change was to restrict the maximum duration of employment to two years in a job with a fixed-term contract. After the reform, an employer who employed a worker in a fixed-term contract for two years would need to convert the worker's contract from a temporary to permanent one.

However, as Lazear (1990) pointed out, employers have an incentive to evade employment protection 
regulations by hiring workers in employment arrangements not subject to the regulations. Previous studies on the Korean labor market reform suggested that the reform induced firms to use alternative employment arrangements instead of fixed-term employment. Lee (2009) found there were increases in the number of indirectly employed workers such as temporary agency workers and workers provided by subcontract firms. Thus, firms may have learned how to evade the new regulation by taking advantage of outsourcing and subcontracts instead of hiring workers directly on fixed-term contracts (Yoo and Kang, 2012).

While the previous studies focused on the increases in the use of indirectly employed workers instead of hiring workers directly on fixed-term contracts, this study investigates if firms have found a way to evade the regulation but still hire workers directly. This study examines if the number of workers in alternative employment arrangements has changed significantly after the introduction of the regulation restricting the maximum length of fixed-term employment.

According to the results of this study, it appears that firms changed human resource management practice in response to the new regulation, taking advantage of certain types of employment that are less likely to be subject to the new regulation. Such employment includes temporary workers whose employment contracts are open-ended and whose level of job security is low. The proportion of this type of temporary workers increased from 2007 prior to the reform, accounting for more than half of total temporary workers after the reform. In addition, the increase in the proportion over time is barely explained by either worker or employer chracteristics. Rather, the reform has a statistically significant and positive effect on the probability of having the temporary jobs even after controlling for other covariates as well as the time effect.

More importantly, the increase in these employment types has been mainly driven by the increase in the proportion of conditional employment - in which a worker was hired on the condition that the worker quit his/her job at the employer's request. The increase in the share of conditional employment is dramatic: the share was less than $1 \%$ of total salary and wage workers before the reform, but it increased sharply after the reform, reaching about $10 \%$ of all workers in 2012 and remaining at that level in our most recent data, in 2016. Conditional employment is not to be subject to the new regulation because the period of employment contract is not fixed when the worker is hired. In addition, employment termination is totally up to an employer. Thus, the employer can arrange for separation of a worker on conditional employment without 
worrying about an unjust dismissal complaint. For this reason, conditional employment seems to be used as a way by which employers have evaded the regulation, substituting for fixed-term contract employment.

This study consists of the following sections. First, I explain classification of employment types in Korea. Second, I describe in detail the policy change in the Korean labor market in 2007 and review previous studies on the effects of the policy change. Third, I examine whether the reform increased the transition of temporary into permanent employment. In fact, after the reform, fewer transitions to permanent employment occurred, while more people were hired on temporary contracts. Finally, we try to answer why there was no significant change in the transition from temporary to permanent employment after the reform. For this, we investigate changes in human resource management practices that occurred in response to the new regulation. We will show that these practices resulted in a reduction in the reform's effect on the labor market.

\subsection{Institutional background of Korean labor market}

\subsubsection{Classification of employment types in Korea}

The classification of employment types in Korea is based on a 2002 agreement on the range of nonstandard workers in the Korean Tripartite Commission (KTC). Established by the Korean government to facilitate social dialogue, the KTC consisted of representatives from trade unions, business organizations, and national government. In July 2002, the three parties agreed on the definition of non-standard workers and the use of statistics for calculating the size of Korea's non-standard employment. After this, the Korean ministry of labor has announced the sizes of standard and non-standard employment based on the definition. In addition, many Korean researchers use the definition to analyze the Korean labor market. Thus, in this section, the employment types in Korea according to the 2002 agreement are explained briefly in order to help understand various forms of temporary work in the Korean labor market.

Employment types in Korea are classified into standard and non-standard employment (see Table 2.1.).

Standard employment is considered as having the following characteristics: (i) the period of employment contract is not fixed (or is permanent), (ii) the employee works full-time, (iii) the employer and the labor user 
are not different, (iv) the employee works on a physical workplace that is provided by the employer.

Forms of employment that do not satisfy all these standards can be thought of as non-standard employment, which can be divided into three subcategories: (i) Temporary workers (or limited-period workers), (ii) Parttime workers, (iii) Atypical workers (or alternative employment arrangement).

First, the category of temporary workers emphasizes the limited duration of work regardless of whether the period of employment contracts is pre-specified. One group of workers in this category consists of fixedterm employees whose contract period is specified in advance. The other group consists of workers with open-ended contracts but who expect limited duration of their work for involuntary reasons. The reason for such a definition based on the expected duration is that there is no universal practice of signing a written employment contract in Korea (Grubb et al., 2007).

Second, part-time workers are workers whose working week is shorter than that of full-time workers (usually 40-hour working week) with the same job in the same workplace.

Third, the category of atypical workers includes alternative employment arrangement such as temporary agency workers (or dispatched workers), workers provided by subcontract firms, independent contractors (or individual contract workers), at-home workers (or domestic worker/helper), and on-call workers.

Table 2.1. The classification of employment types in Korea

\begin{tabular}{|c|c|c|}
\hline $\begin{array}{l}\text { I. } \\
\text { Standard } \\
\text { Employment }\end{array}$ & \multicolumn{2}{|c|}{$\begin{array}{l}\text { The period of employment contract is not fixed. } \\
\circ \text { The employee works full-time. } \\
\circ \text { The employer and the labor user are not different. } \\
\circ \text { The employee works on a physical workplace provided by the employer. }\end{array}$} \\
\hline \multirow{8}{*}{$\begin{array}{l}\text { II. } \\
\text { Non-standard } \\
\text { Employment }\end{array}$} & \multirow{2}{*}{$\begin{array}{l}\text { 1. Temporary workers } \\
\text { (Limited-period workers) }\end{array}$} & (1) Workers with fixed-term contracts \\
\hline & & $\begin{array}{l}\text { (2) Workers with open-ended contracts but who expect limited } \\
\text { duration of their work for involuntary reasons }\end{array}$ \\
\hline & 2. Part-time workers & $\begin{array}{l}\text { Workers whose working week is shorter than that of } \\
\text { workers considered full-time worker with the same job in } \\
\text { the same workplace }\end{array}$ \\
\hline & \multirow{5}{*}{ 3. Atypical workers } & (1) Temporary agency workers (dispatched workers) \\
\hline & & (2) Workers provided by subcontract firms \\
\hline & & (3) Independent contractors (individual contract workers) \\
\hline & & (4) At-home workers (domestic worker/helper) \\
\hline & & (5) On-call workers \\
\hline
\end{tabular}




\subsection{Overview of $\mathbf{2 0 0 7}$ labor market reform}

After five years of discussion with social partners, legislators proposed bills on temporary employment in November 2004 with the goal of lowering the incidence of temporary jobs and preventing firms from using fixed-term contracts as a long-term substitute for permanent workers. The legislation - The Act on the Protection of Fixed-term and Part-time Employees - was passed two years later and implemented in July 2007.

The primary regulation in the legislation restricts the length of fixed-term employment with one employer - even employment on successive fixed term contracts - to a maximum of two years. More specifically, after the reform, if an employer chose to continue to employ a worker for more than two years, then the employer had to convert the worker's contract from a fixed-term to permanent one. Of course, employers still had the option of dismissing a worker employed for less than two years on a fixed-term contract with no costs by not renewing the contract. However, if the worker was still on the job at the end of the two-year period, the fixedterm contract would be regarded as a permanent contract. Hence, if an employer dismisses a worker who has been on a fixed-term contract for more than two years for reason of other than cause or financial exigency, then the worker can submit an unjust dismissal complaint to the Korean Labor Relations Commission, at which point the employer is responsible for proving that the dismissal is not unfair.

However, there are some exceptions in the new regulation, and the following cases are excluded from the application of the two-year maximum duration of fixed-term employment: (i) firms in the private sector with fewer than five employees (ii) workers aged 55 or older at the time of signing a fixed-term contract, (iii) workers who work less than 15 hours per week regularly (iv) workers holding doctoral degrees or other highly technical or professional qualifications, (v) part-time instructors in tertiary education institutions, (vi) workers subject to contract duration specified by other laws (Yoo and Kang, 2012). The reform on the length of fixed-term contracts took effect in July 2007, and hence any fixed-term contracts signed from July 2007 onward are subject to the new regulation.

Another regulation in the legislation prohibits discrimination against temporary workers who perform tasks similar to permanent workers in the same workplace. Provisions on discrimination were introduced gradually by firm size from 2007 to 2009: firms with at least 300 workers were subject to the regulation beginning in 
July 2007; firms with at least 100 and less than 300 workers in July 2008; firms with at least 5 and less than 100 workers in July 2009.

According to the anti-discrimination law, temporary workers - workers on fixed-term contracts and parttime workers - can submit complaints of discriminatory treatment relating to wages and working conditions to the Korean Labor Relations Commission (Grubb et al., 2007). In practice, however, workers seem reluctant to file complaints because not only is it difficult to prove the existence of discrimination, but workers fear a negative reaction from company management. Consequently, only 2,433 cases were filed between July 2007 and December 2011, and the number of correction orders by the Korean Labor Relations Commission was 961 (39.6\%) (Jones and Urasawa, 2013; KLI, 2012). Since the regulation had been considered to have little effect on the labor market, it was revised in 2012 to require labor inspectors to encourage firms to correct any discrimination even in the absence of complaints from their workers. In 2014, 343 firms were inspected and 48 were found to have discriminatory practices (OECD, 2016).

This study focuses on the first regulation, which restricts the maximum length of fixed-term employment with one employer, because the second regulation is considered to have little effect on the labor market. Most previous studies also have focused on the effect of first regulation on Korean labor market, and they are summarized in the next section.

\subsection{Previous studies on the effect of 2007 labor market reform}

A year after the regulation was introduced, there was a change in the composition of wage and salary workers. In August 2008, the number of fixed-term workers declined, while there was an increase in the number of temporary workers who not only were less likely to be subject to the regulation but also were working for low wages and in low job security. Accordingly, previous studies in the early years after the reform focused on whether the new regulations had influenced total employment or the composition of employment. However, they offered conflicting results: some of them suggested negative impacts of the reform on employment level and argued that the maximum period of a fixed-term contract should be extended 
to four years (from two year); others found no significant negative effects and insisted that a decrease in the level of employment in 2008 was mainly due to the global financial crisis.

All previous Korean studies introduced in this section used a data set drawn from the Economically Active Population Survey (EAPS). EAPS is the official monthly labor force survey of Korea and collects information on an individual's employment status in the previous week and other demographic characteristics for about 70,000 individuals in Korea (Yoo and Kang, 2012).

Lee (2009) analyzed the impact of the legislation a year after the introduction of the regulations. First, there had been a change in the composition of employment. After the reform, employment using fixed-term contracts decreased. Instead, there were increases in the number of permanent workers and indirectly employed workers - temporary agency workers and workers provided by subcontract firms. Second, he tried to examine whether the reform influenced job retention rates of fixed-term contract workers. He showed that after the reform job retention rates fell from $74.5 \%$ to $68.6 \%$ for fixed-term contract workers with tenure of at least a year. However, according to his further analysis based on a difference-in-differences approach, the decrease in job retention rates was not statistically significant, and he concluded that the decrease was not purely due to the new regulation on the length of fixed-term employment. This study also presented analyses suggesting that firms preferred using indirectly employed workers over hiring workers on fixed-term contracts after the reform. However, one might question his results since they are based on the assumption that the reform has an impact on only the fixed-term workers with tenure of at least a year and no impact on the workers with tenure of less than a year. Lee used the group of fixed-term workers with tenure of at least a year as a treatment group, which was subject to the reform; the group of fixed-term workers with tenure of less than a year were used as a comparison group, which was assumed not to be influenced by the reform.

Lee (2011) expanded his previous study with the same survey data but longer sample periods. First, according to a difference-in-differences analysis, he confirmed that the regulation had negative effects on the job retention rates of fixed-term contract workers, but it was not statistically significant. Second, the transition probability of a fixed-term employee into indirect employment increased after the reform. He pointed out this result implied employers' evasion of the regulation.

Nam and Park (2010) investigated the effects of the reform on employment level. Taking into account that 
workers over 55 years of age are not subject to the regulation on the length of fixed-term employment, they used this group as a control and performed the regression analysis combining a difference-in-differences (DID) with a regression discontinuity design (RDD). They found that the regulation negatively affected workers' employment. Their results implied the reform had decreased not only the employment of fixed-term workers - who were directly subject to it - but also that of permanent workers - who were not regulated by the reform.

Yoo and Kang (2012) examined the impact of the 2007 Korean reform on the incidence of employment and temporary jobs. Combining the regression discontinuity designs with difference-in-differences methods, they estimated the changes in the probability of being employed and having a temporary job after the reform. The results showed that the reform reduced the size of total and temporary employment in the post-reform period. However, the intensity of the reform was weak, and the effect faded away by two years after the reform. Based on the results, they argued that an increase in the protection level for workers is likely to come at a cost of a reduction of employment at least in the short run. In addition, they offered an evasion hypothesis to explain the fading effects of the reform: Employers were likely to gradually learn how to evade the new regulation by taking advantage of outsourcing and subcontracts. In other words, for the early years after the reform, firms seemed reluctant to hire workers on fixed-term contracts, which resulted in a decrease in employment. However, as time passed, the use of indirectly employed workers was likely to increase replacing workers hired directly on fixed-term contracts, returning employment to its prior level.

When we review the results from the previous studies, it should be kept in mind that the effect of the reform in a RDD is estimated only for individuals close to age 55. The analyses combining RDD and DID methods rely on the 55 years of age cutoff at which the application of the regulation changes discontinuously. Thus, the results from the studies of Nam and Park (2012) and Yoo and Kang (2012) should be interpreted considering local validity.

In summary, the previous studies of the reform have focused mainly on whether the reform influenced total employment or the composition of employment. Although fixed-term and total employment declined a year after the regulation was introduced, the negative effects were not statistically significant after controlling for macroeconomic conditions. Even in analyses using the sample of individuals aged close to 55, the decrease 
in total and fixed-term employment was only statistically significant in the short run, and the effect faded away by two years after the reform. Thus, based on the results in the previous studies, we can find little longterm effect of the regulation that restricts the maximum length of fixed-term employment with one employer.

Another important insight from the previous studies is that the reform might cause changes in the composition of employment type for wage and salary workers. Firms may have learned how to evade the new regulation by taking advantage of outsourcing and subcontracts instead of hiring workers directly on fixed-term contracts.

In contrast to most of the previous studies that focused on the effect of the reform on employment level, this study determines whether the reform influences the transition of temporary employment into permanent, which can be thought of as one of the main goals of the reform. In the next section, we examine the transition of temporary workers by comparing the number of workers whose employment type had changed in the same job before and after the reform. In addition, duration to employment type change is also considered to see the effect of the reform.

\subsection{The effect of the reform on changes in employment types}

\subsubsection{Data set and sample}

To investigate the impact of the 2007 Korean reform on the transition from temporary into permanent employment, this study uses the Korean Labor \& Income Panel Study (KLIPS). KLIPS is a longitudinal survey of the labor market activities of households and individuals residing in urban areas. Being the first domestic panel survey of labor-related issues in Korea, it has served as a valuable data source for microeconomic analysis concerning labor market transitions. ${ }^{18}$

\footnotetext{
${ }^{18}$ In designing and managing KLIPS, the Korean Labor Institute used as models a set of successful longitudinal surveys conducted in industrialized countries, such as NLS(1968-), NLSy(1979-), PSID(1968-) in the USA, SLID(1993-) in Canada, BHPS(1991-) in the UK, and GSOEP(1984-) in Germany, among others. The survey is conducted annually on a sample of 5,000 urban households and members of the households (all members aged 15 or older in the households). This data set is publicly available on the Korea Labor Institute's website (https://www.kli.re.kr/klips_eng).
} 
The KLIPS consists of three data sets, for households, individuals, and job histories. The job history data are composed of observations of jobs (rather than individuals) and contain information on the jobs held by individuals who were surveyed between 1998 and 2016. The data offer information on the jobs such as the date at which a job began or terminated (if the job ends before an interview), interview date, type of employment (regular, temporary-contract or casual), and other job characteristics (occupation, industry, firm size, sector, wage, etc.). Although KLIPS is a yearly survey and began in 1998, it also asks every interviewee about his/her job history since entering the labor market. Thus, it contains full records of job histories for all respondents. For an in-depth analysis, this study combined the job history data with the individual data, which contain not only workers' characteristics such as gender, age, education level, and marital status but also information on employment contracts such as the length of a contract and perceived job security.

The KLIPS classifies salary and wage workers into three groups based on the length of employment contracts (classification criteria are summarized in Table 2.2.): 1) Regular worker: workers whose employment contract period is at least one year, or workers who can be kept employed as long as he/she wants if their employment contracts are not pre-specified. 2) Temporary contract worker: workers whose employment contracts are at least one month and less than one year, or workers who expect their job to be terminated within a year if the period of their contracts is not specified in advance. 3) Casual worker (or day laborer): workers whose contract period is less than one month, or workers who are hired and paid on a daily basis.

Table 2.2. The classification of wage and salary workers in KLIPS

\begin{tabular}{|c|c|c|}
\hline & \multicolumn{2}{|r|}{ Employment Contract Period } \\
\hline & A. Pre-specified & B. Not specified in advance (open-ended contract) \\
\hline [1] Regular worker & - Contract period $\geq 12$ months & - Workers who can be kept employed as long as he/she wants \\
\hline $\begin{array}{l}\text { [2] Temporary-contract } \\
\text { worker }\end{array}$ & - $1 \mathrm{~m} \leq$ Contract period $<12 \mathrm{~m}$ & - Workers who expect their job to be terminated within a year \\
\hline $\begin{array}{l}\text { [3] Casual worker } \\
\text { (day laborer) }\end{array}$ & - Contract period $<1$ month & - Workers who are hired and paid on a daily basis \\
\hline
\end{tabular}

On the other hand, fixed-term employees regulated by the 2007 Korean reform are defined as the workers whose contracts end on a specified date or when a specific task is completed. Thus, temporary-contract 
employees in the classification of KLIPS are a subset of fixed-term employees since there could be fixedterm workers whose employment contracts are longer than a year (e.g., two years) - who would be classified as regular workers in the KLIPS. In the Korean labor market, however, most fixed-term employees are on temporary-contracts because firms set the period of the fixed-term contract to less than one year to avoid offering severance pay, which is required by Korean labor law for employment contracts of one year or more. ${ }^{19}$ Thus, only observations classified as jobs that began with temporary-contracts in KLIPS data are selected for the sample when we analyze the effect of the reform that restricts the maximum length of fixedterm employment with one employer.

\subsubsection{The share of temporary-contract workers}

Table 2.3. shows the share of each employment type (regular, temporary-contract, and casual) according to the classification of KLIPS by job-start year and the duration of employment. Wage and salary workers are divided according to the period in which they started their jobs. Then, in each job-start period, the share of each employment type was calculated according to employment duration measured in months. For example, between 2001 and 2002, 3,332 new jobs were created, and 1,096 jobs among them terminated within twelve months: $54 \%$ and $32 \%$ of the terminated jobs were regular and temporary-contract jobs, respectively. In addition, since the sample period covers up to 2016, many jobs that were created in the last job-start period (2012-2013) were still in progress at the end of the sample period compared to other job-start periods. Thus, jobs of which employment duration is $37 \sim 48$ months possibly continue to the next duration category (over 48 months) if they are observed beyond 2016. Due to this censoring issue, the last two employment duration categories in 2012-2013 job-start period are combined. Based on the results in Table 2.3., we can verify the share of temporary-contract workers increased after the reform.

First, the share of temporary-contract workers in total wage and salary workers has increased in the sample period: While temporary-contract workers took up 20 24\% of total employment before the reform, the share

\footnotetext{
${ }^{19}$ In Korea, severance pay is based on years of service with a company on a specific contract, and at least one month's wages are provided to the worker for each full year of employment. Firms must offer the severance pay to any salary and wage workers who has worked for one year or more under a specific employment contract.
} 
increased significantly right after the reform, accounting for $30 \%$ of jobs that were created after 2007 . This suggests that temporary-contract jobs grew particularly fast even after the new regulation.

Table 2.3. The proportion of temporary contract workers by employment duration and job-start year

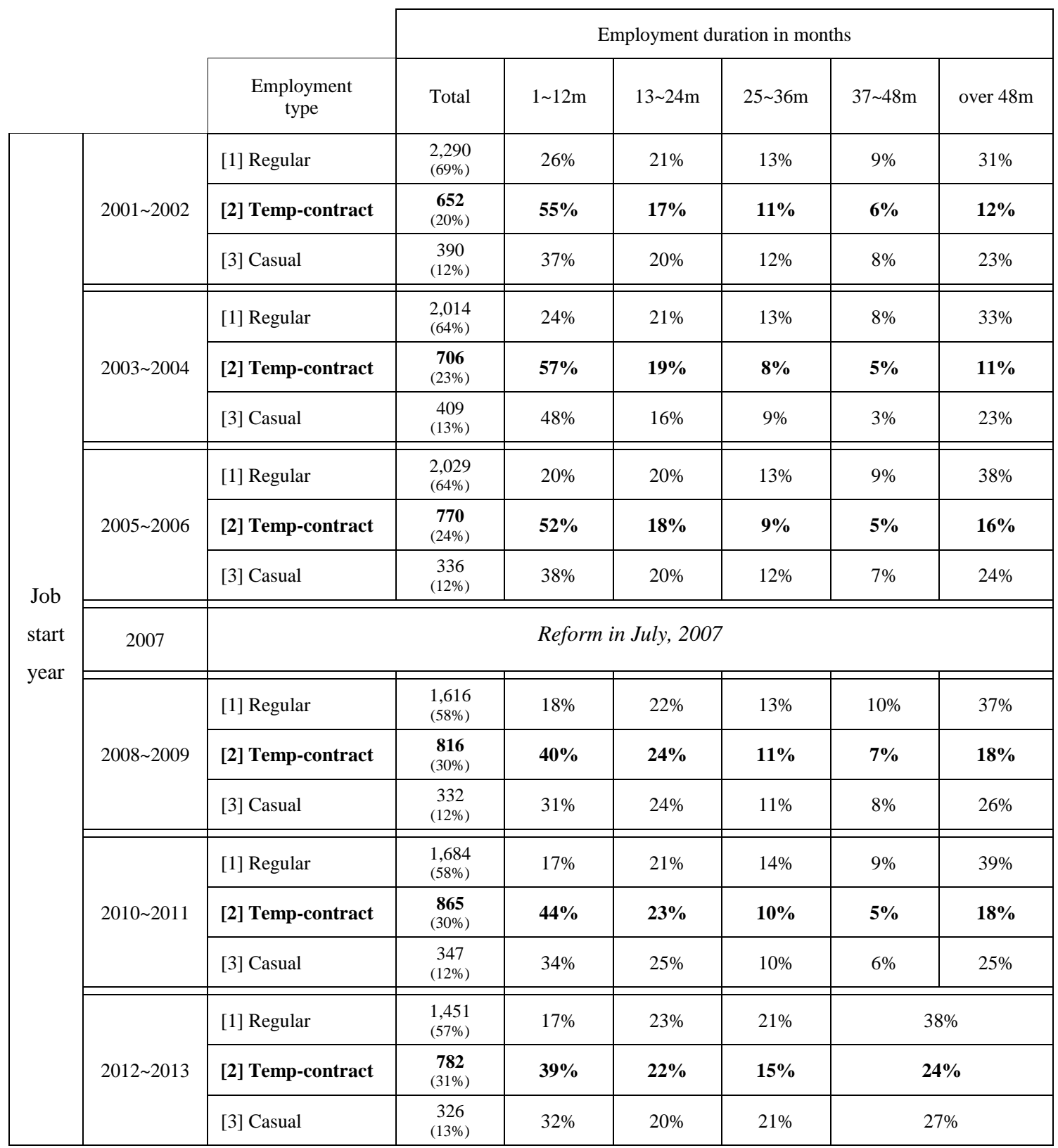

Note) 1. Employment duration stands for the length of employment with the same employer, which is measured in months.

2. Total means the number of wage and salary workers who fall into each employment type; The percentages in the parentheses stand for the share of each employment type in total employment.

3. Due to censoring issue, the last two employment duration categories in 2012-2013 job-start period are combined. 
Second, when we compare the share of temporary-contract workers across employment duration, we can see the share has increased in all duration categories as time passed except for the duration of $1 \sim 12 \mathrm{~m}$. In other words, the share of temporary-contract employment increased not only for the duration greater than 12 months and shorter than 24 months - employment not regulated by the reform - but also the duration longer than 24 months - employment subject to the reform. If the new regulation worked well, we expect temporarycontract employment - more precisely, fixed-term employment - will not be continued beyond 24 months in most jobs, and hence the share of temporary-contract workers should decrease for employment durations exceeding 24 months. However, the results contradict this expectation suggesting something has undercut the impact of the reform.

In the next section, the effect of the reform is evaluated in terms of the transition from temporary-contract to regular employment and the timing within the span of a job. We examine whether the reform shortened the time for a worker's employment type to be changed from temporary-contract to regular employment under the same employer.

\subsubsection{Employment termination and change in employment type}

The survey of the KLIPS asks interviewees whether their employment types changed since the last interview and, if so, when it happened and what their employment type is after the change. Thus, the information on employment type - job-start date, previous employment type, the date of employment type change, and current employment type (after the change) - can be used for a deeper analysis.

In this section, we consider employment termination and change in employment classification (transitions) for jobs that began with temporary-contracts. In addition, we examine whether the reform increased the chance that a worker's employment type would be changed from temporary-contract to regular employment throughout a job spell with the same employer. For this, we measure the time to an employment type change, which is defined as a period from job-start date to employment classification change date. Figure 2.1. shows an example of a job in which employment type changed: the job had started in Jan. 2008 on a temporarycontract, but its employment type changed to regular in Jan. 2009. In this case, the time to employment type 
change is thirteen months.

Figure 2.1. Change in employment type in a job: transition from temporary to regular employment

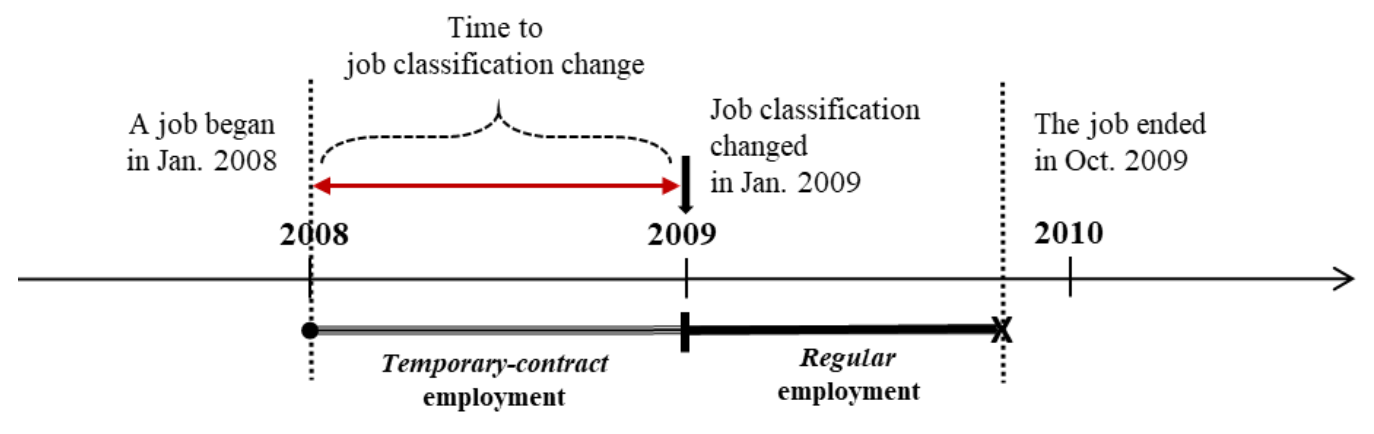

One thing to be kept in mind here is that we focus on the transition from temporary-contract to regular employment - based on the classification of KLIPS - and this does not correspond exactly to transition from fixed-term to permanent employment, which is one of the main goals of the reform. Since the employment classification in KLIPS is based on the length of the employment contract period, if a person's employment contract was renewed with an extension of the contract period, then this may be counted as an employment type change. For example, if a worker on a six-month employment contract renewed his/her contract for another twelve-months, then this change is regarded as a transition from temporary-contract to regular employment because the renewed contract is classified as regular employment according to the KLIPS classification. Thus, the number of transitions from temporary-contract to regular employment may be greater than the number of actual transitions from fixed-term to permanent employment. However, as we will see later, the number of the transitions from temporary-contract to regular employment is much smaller than what we expect, and we do not find any significant change in the number of transition at the time of the reform.

Table 2.4. shows how many temporary-contract jobs began, terminated, and were converted to regular employment by tenure in a job. All jobs that were created between Jan. 2001 and Dec. 2015 in the sample were divided into two groups according to whether the employment started before or after the reform; then, the number of temporary-contract jobs, employment terminations, and transitions from temporary-contract to regular employment were tabulated. The jobs that were created in the pre-reform period are observed for 
nine to fifteen years (2001-2016), whereas jobs created after the reform are observed for less than nine years (2007-2016), being censored at the end of 2016. To take into account this censoring issue, the number of censored cases is also provided in Table 2.4., which presents temporary-contract employment that is still in progress at the last interview date.

For example, in the pre-reform period, there were 2,444 temporary-contract jobs, of which 1,177 jobs (48.2\%) terminated and 73 jobs $(3.0 \%)$ were censored in the first twelve months of tenure. In addition, 34 transitions from temporary-contract to regular employment were observed, which consists of just $1.4 \%$ of the existing temporary-contract jobs. Accordingly, the remaining 1,160 temporary-contract jobs continued to the second year of tenure.

The results in Table 2.4. can be summarized as follows:

First, when we compare the number of jobs that began with temporary-contracts, more temporary-contract jobs were created in the post-reform period: 2,444 and 3,433 jobs began with temporary-contracts before and after the reform, respectively. This is because the post-reform period covers a longer survey period than the pre-reform period.

Second, a higher rate of employment terminations was observed for the temporary-contract jobs that were created in the pre-reform period than in the post-reform period with each tenure range. This can be confirmed comparing censored cases in each period. More temporary-contract jobs were censored in the post-reform period: $31.7 \%$ of total temporary-contract jobs were censored in the post-reform period compared to $11.6 \%$ in the pre-reform period.

Third, it was extremely rare for temporary-contract employment to be converted to regular one. Only 83 cases (3.4\%) out of 2,444 temporary-contract jobs were converted to regular jobs in the pre-reform period and 69 cases $(2.0 \%)$ out of 3,433 temporary-contract jobs in the post-reform period. Moreover, transition from temporary-contract to regular employment occurred more often in the pre-reform period, even though fewer temporary-contract jobs were created in that period. 
Table 2.4. Termination and change in employment type for temporary-contract jobs

\begin{tabular}{|c|c|c|c|c|c|c|}
\hline & & \multicolumn{4}{|c|}{ Tenure in months } & \multirow[b]{2}{*}{ Total } \\
\hline & & $1 \sim 12 \mathrm{~m}$ & $13 \sim 24 m$ & $25 \sim 36 m$ & over $36 m$ & \\
\hline \multirow{7}{*}{$\begin{array}{l}\text { Contracts beginning } \\
\text { before the reform: } \\
\text { Jan. } 2001 \sim \text { Jun. } 2007\end{array}$} & The number of Contracts at risk & 2,444 & 1,160 & 699 & 458 & 2,444 \\
\hline & $\begin{array}{l}\text { The number of } \\
\text { Employment Terminations }\end{array}$ & 1,177 & 411 & 212 & 361 & 2,161 \\
\hline & {$[\%]$} & {$[48.2 \%]$} & {$[35.4 \%]$} & {$[30.3 \%]$} & [78.8\%] & [88.4\%] \\
\hline & The number of Censored Cases & 73 & 26 & 21 & 163 & 283 \\
\hline & {$[\%]$} & {$[3.0 \%]$} & {$[2.2 \%]$} & {$[3.0 \%]$} & {$[35.6 \%]$} & [11.6\%] \\
\hline & $\begin{array}{l}\text { The number of Transitions: } \\
\text { Temporary } \Rightarrow \text { Regular }\end{array}$ & 34 & 24 & 8 & 17 & 83 \\
\hline & [\%] & {$[1.4 \%]$} & {$[2.1 \%]$} & {$[1.1 \%]$} & {$[3.7 \%]$} & {$[3.4 \%]$} \\
\hline
\end{tabular}

\begin{tabular}{|c|c|c|c|c|c|c|}
\hline & & \multicolumn{4}{|c|}{ Tenure in months } & \multirow[b]{2}{*}{ Total } \\
\hline & & $1 \sim 12 \mathrm{~m}$ & $13 \sim 24 m$ & $25 \sim 36 m$ & over $36 m$ & \\
\hline \multirow{7}{*}{$\begin{array}{l}\text { Contracts beginning } \\
\text { after the reform: } \\
\text { Jul. } 2007 \sim \text { Dec. } 2015\end{array}$} & The number of Contracts at risk & 3,433 & 2,000 & 1,114 & 642 & 3,433 \\
\hline & $\begin{array}{l}\text { The number of } \\
\text { Employment Terminations }\end{array}$ & 1,194 & 606 & 287 & 258 & 2,345 \\
\hline & {$[\%]$} & [34.8\%] & [30.3\%] & {$[25.8 \%]$} & [40.2\%] & [68.3\%] \\
\hline & The number of Censored cases & 224 & 256 & 167 & 441 & 1,088 \\
\hline & {$[\%]$} & {$[6.5 \%]$} & {$[12.8 \%]$} & {$[15.0 \%]$} & {$[68.7 \%]$} & [31.7\%] \\
\hline & $\begin{array}{l}\text { The number of Transitions: } \\
\text { Temporary } \Rightarrow \text { Regular }\end{array}$ & 15 & 24 & 18 & 12 & 69 \\
\hline & {$[\%]$} & {$[0.4 \%]$} & {$[1.2 \%]$} & {$[1.6 \%]$} & {$[1.9 \%]$} & {$[2.0 \%]$} \\
\hline
\end{tabular}

Note) 1. The number of contracts at risk is the total number of existing temporary-contracts that continued to each tenure range.

2. The number of employment terminations is the number of temporary-contracts that terminated within each tenure range.

3. The number of censored cases is the number of temporary-contracts that were still in progress at the date of the last interview.

4. The number of transitions is the number of temporary-contracts that were converted to regular in each tenure range. 
Fourth, most transitions happened within twenty-four months of tenure: 58 out of 83 transitions $(69.9 \%)$ occurred in twenty-four or fewer months of tenure in the pre-reform period; 39 out of 69 transitions (56.5\%) in the post-reform period. On the other hand, transitions took place relatively more often after the reform in the later months of job tenure: 25 out of 83 transitions (30.1\%) occurred after twenty-four months of job tenure in the pre-reform period; 30 out of 69 transitions (43.5\%) occurred in the post-reform period. This reflects the fact that the duration of such jobs is longer, as the risk of such a conversion is not greater.

Based on these results, we do not find any evidence that the reform increased the probability of a change from temporary-contract to regular employment. On the contrary, fewer transitions to regular employment occurred after the reform, while more people were hired on temporary-contracts in the same period.

The next question is why there was no significant change in the transition from temporary-contract to regular employment after the reform. To answer this question, we investigate in the next section changes in human resource management practices that occurred in response to the new regulation. We will show that these practices resulted in reduction in the reform policy's effect on the labor market.

\subsection{Probing the reasons for the limited impact of the reform}

\subsubsection{Employer's incentives to evade the new regulation}

Lazear (1990) pointed out that employers have an incentive to evade employment protection laws by hiring workers in employment arrangements not subject to the regulations. As the previous Korean studies suggested, the reform seemed to induce firms to use alternative employment arrangements instead of fixedterm contracts. According to Lee $(2009,2011)$, employment using fixed-term contracts decreased after the introduction of the new regulation restricting the maximum length of fixed-term employment with one employer. There were increases in the number of indirectly employed workers - temporary agency workers and workers provided by subcontract firms. Similarly, Yoo and Kang (2012) suggested an evasion hypothesis that firms have learned how to evade the new regulation by taking advantage of outsourcing and subcontracts.

While the previous studies pointed out that the reform may cause increases in the use of indirectly 
employed workers instead of hiring workers directly on fixed-term contracts, this study investigates if firms have found a way to evade the regulation but still hire workers directly. In this section, we focus on whether there was an increase in alternative employment arrangements that were less likely to be subject to the regulation. For this, we use survey questions in the KLIPS about employment contracts and workers' perceived job security.

\subsubsection{Survey questions in KLIPS to classify employment arrangements}

The extent of non-standard employment in Korea has been measured based on a supplemental survey of the Economically Active Population Survey (EAPS), which consists of various questions about types of employment. The supplemental survey of the EAPS has been carried out once a year by Statistics Korea (Korea's statistical agency) since it was established in 2001. In 2002, the Korean Tripartite Commission (KTC) agreed on the definition of non-standard workers in Korea and suggested improvements in the EAPS in order to measure the size of non-standard employment accurately. In compliance with the KTC's recommendation, some questions in the supplemental survey of the EAPS were modified for 2002 and later years.

In 2002, the Korean Labor \& Income Panel Study (KLIPS) also added questions on the classification of employment arrangements to its fifth wave questionnaires. These questions are similar to the questions in the EAPS supplemental survey. Since then, the KLIPS has provided information on alternative employment arrangements. Table 2.5. shows the structure of KLIPS questions on employment contracts and workers' perceived job security.

Using the four questions $Q 1-Q 4$ in Table 2.5., we can identify the number of temporary workers (or limited-period workers) in the Korean labor market, one of the subcategories of non-standard employment ${ }^{20}$. To distinguish worker groups easily according to workers' answers to the four questions, I have assigned

\footnotetext{
${ }^{20}$ For the size of the other two subcategories of non-standard employment - part-time workers and atypical workers, additional questions can be used, which ask whether the working week is shorter than that of a full-time worker with the same job in the same workplace or whether a worker's employment type falls into any subcategory of alternative employment arrangements.
} 
alphabetic codes to each answer to the four questions.

According to the official classification of employment types suggested in the previous section (refer to Table 2.1.), temporary workers (or limited-period workers) are categorized into two groups: workers with fixed-term contracts and workers with open-ended contracts but who expect limited duration of their work for involuntary reasons. The first group of temporary workers - fixed-term contract workers (A) in Table 2.5. - accounts for more than half of all temporary workers (A, B2, C, D1-D5). Fixed-term contract workers (A) are explicitly subject to the new regulation that restricts the maximum length of fixed-term employment with one employer.

The other group of temporary workers consists of workers with open-ended contracts but who expect limited duration of work for involuntary reasons (B2, C, D1-D5). We consider this second group of temporary workers too because it is often unclear how to distinguish these workers from fixed-term contract workers empirically. In the sample, we observe many workers whose reported employment type changed back and forth between the first and second groups of temporary workers throughout a job spell with the same employer. In addition, workers who fall into the second group of temporary workers (B2, C, D1-D5) could be subject to the new regulation, even if their contract periods were not determined when they signed contracts. For example, if a worker's employment continues over two years through repeated renewal of his/her contract without specifying a contract period, then an employer of the worker can be deemed to violate the regulation according to a decision of the Korean Labor Relation Commission. In practice, however, workers seem reluctant to submit complaints to the commission since workers fear a negative reaction from their employers.

It is necessary to understand the structure of the survey questions through which the number of temporary workers is measured because some temporary workers may be subject to the new regulation, whereas others may not be.

First, as presented in Table 2.5., all the wage and salary workers are asked whether their employment contract period is fixed in advance: [Q1] Was the period of an employment contract determined when you (a worker) were hired on the job $?^{21}$ If a worker answers 'Yes' to the first question, then the worker is classified

\footnotetext{
${ }^{21}$ The survey questions are originally written in Korean and translated by the author. Full sentences of the questions are provided in the Appendix (Table A1).
} 
as a fixed-term employee (A), who falls under the first group of temporary workers (Temp (1)).

Second, if a worker says ' $N o$ ' to the first question, then the second question on job security follows: [Q2] Unless the firm discontinues its business or lay off workers due to financial exigency, or you do something wrong, can you continue your current job in the firm as long as you want? One thing to be kept in mind here is that the job security surveyed in the second question is the worker's subjective perception of job security in the current employment.

Third, the reason that the job is secure is asked if a worker answered 'Yes' to the second question: [Q3] What is the reason for answering 'Yes' to the second question? There are three options (see Table 2.5.). If a worker chooses '(2) Employment continues with repeated renewal of a contract', then the worker falls under the second group of temporary workers - those hired on an open-ended contract but with expected limited duration (Temp (2) - B2, C, D1-D5).

Fourth, the reason for an insecure job is asked if a worker answered ' $N o$ ' to the second question: [Q4] What is the reason for answering 'No' to the second question? There are eleven options, of which the first six options (1) - (6) are involuntary reasons for expected termination of current employment (see Table 2.5. for details). Workers - who chose options (1) through (6) - fall into the second group of temporary workers (Temp (2) - B2, C, D1-D5) as well.

In the next section, we examine if the number of workers in each employment type has changed significantly after the introduction of the regulation restricting the maximum length of fixed-term employment with one employer. We focus on changes in temporary workers (or limited-period workers) because they are likely to be subject to the new regulation. 
Table 2.5. The structure of questions on employment contracts and workers' perceived job security

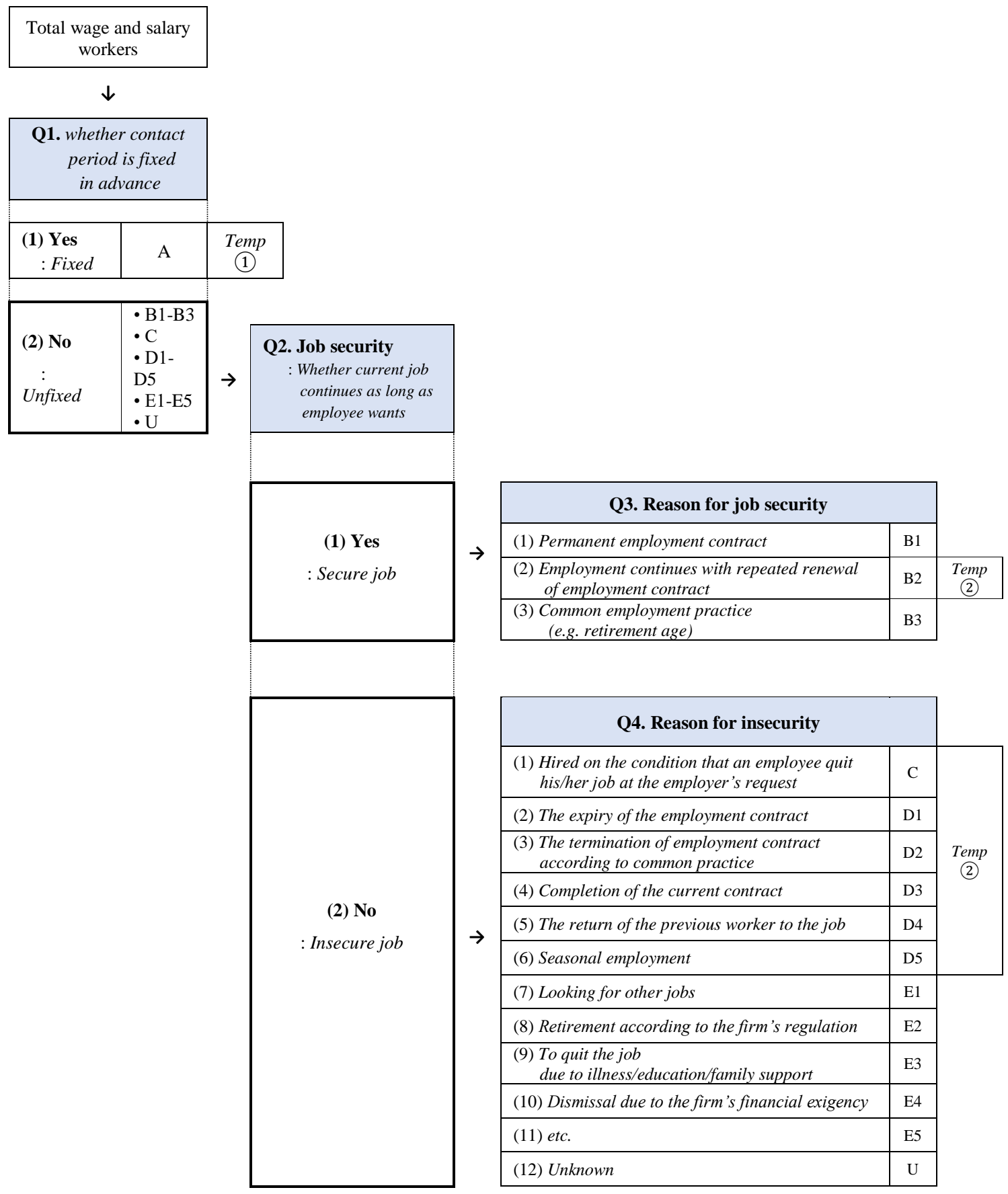

Note) 1. Temp (1) stands for the first group of temporary workers (or limited-period workers) that includes workers with fixed-term contracts. Temp (2) stands for the second group of temporary workers, which consists of workers with open-ended contracts but who expect limited duration of their work for involuntary reasons.

2. The survey questions are originally written in Korea and translated by the author. Full sentences of the questions can be found in the Appendix (Table B1). 


\subsubsection{An upsurge of an alternative employment arrangement to evade the regulation}

Table 2.6. shows the total number of wage and salary workers and the number of workers who chose each answer to the four questions in each survey year. For example, 4,346 workers were surveyed in 2007, of which 398 workers (9.2\%) were hired on fixed-term contracts (A). 3,948 workers (90.8\%) answered that their employment contract period was not fixed in advance, and 3,760 of them thought of their jobs as being secured. On the other hand, only 188 out of 3,948 workers thought their employment could terminate in the future for involuntary or voluntary reasons.

Figure 2.2. shows changes in the share of temporary worker groups in total wage and salary workers over time. One thing to be kept in mind here is that the proportion of total temporary workers in Figure 2.2. was calculated excluding one group (B2) of temporary workers - those whose employment continues with repeated renewal of employment contract. The question $Q 3$ on a specific reason for job security added to KLIPS in 2007 and has been surveyed since then. Thus, KLIPS offers no information on the group (B2) of temporary workers for the pre-reform period. However, the number of workers who fall under the group (B2) is not large enough to dominate the total number of temporary workers. In addition, employment contracts of workers in the group (B2) were often deemed permanent according to recent precedents by the Korean court, even though workers in the group (B2) were hired formally on temporary contracts. According to court rulings in Korea, if a worker expect a renewal of his/her current employment contract based on the fact that his/her employment has been prolonged by repeated renewal of temporary contract over a long period of time, then rejection of contract renewal by his/her employer without reasonable causes can be considered invalid just as an unjust dismissal (Jang, 2012).

Some important facts can be found in Table 2.6. and Figure 2.2. implying changes in firms' human resource management practices that occurred in response to the new regulation.

First, the share of fixed-term contract workers (A) - the first group of temporary workers (Temp (1)) increased overall during the sample period. The share was about 5-6\% in the early survey years; it increased gradually to $11-12 \%$ in the later years. Despite the general increase, the share decreased in 2008 , right after the introduction of the new regulation. Although the share increased again in 2009, it didn't change much after that until 2011. This result is in accord with Lee's $(2009,2011)$ finding that employment using fixed- 
term contracts decreased after the reform.

Second, the proportion of the second group of temporary workers (Temp (2) - C, D1-D5) - not only those whose employment contract is open-ended but also whose perceived level of job security is low - increased over time. In other words, more people expected that their employment would terminate in the future.

Third, the increase in the proportion of the workers (C, D1-D5) - who chose the involuntary reasons $((1)$ $\sim(6))$ for their insecure jobs - is mainly due to an increase in the number of workers (C) who chose the first reason - '(1) Hired on the condition that employee quit his/her job at the employer's request'. The increase in the share of the worker who chose this first reason - conditional employment $(\mathrm{C})$ - is prominent: less than $1 \%$ of total salary and wage workers chose this answer for the reason of limited duration of their employment before the reform, but the share of the workers choosing this reason started to increase in 2007. Furthermore, increases were dramatic after the reform, reaching about $10 \%$ of all workers in 2012 , and remaining at that level to the end of our survey window in 2016. In addition, other kinds of insecure temporary jobs (D1-D5) also increase three to four times over time. Although not as significant as the increase of conditional employment (C), it still contributes substantially to the observed increase in temporary workers.

Figure 2.2. The proportions of worker groups in total wage and salary workers

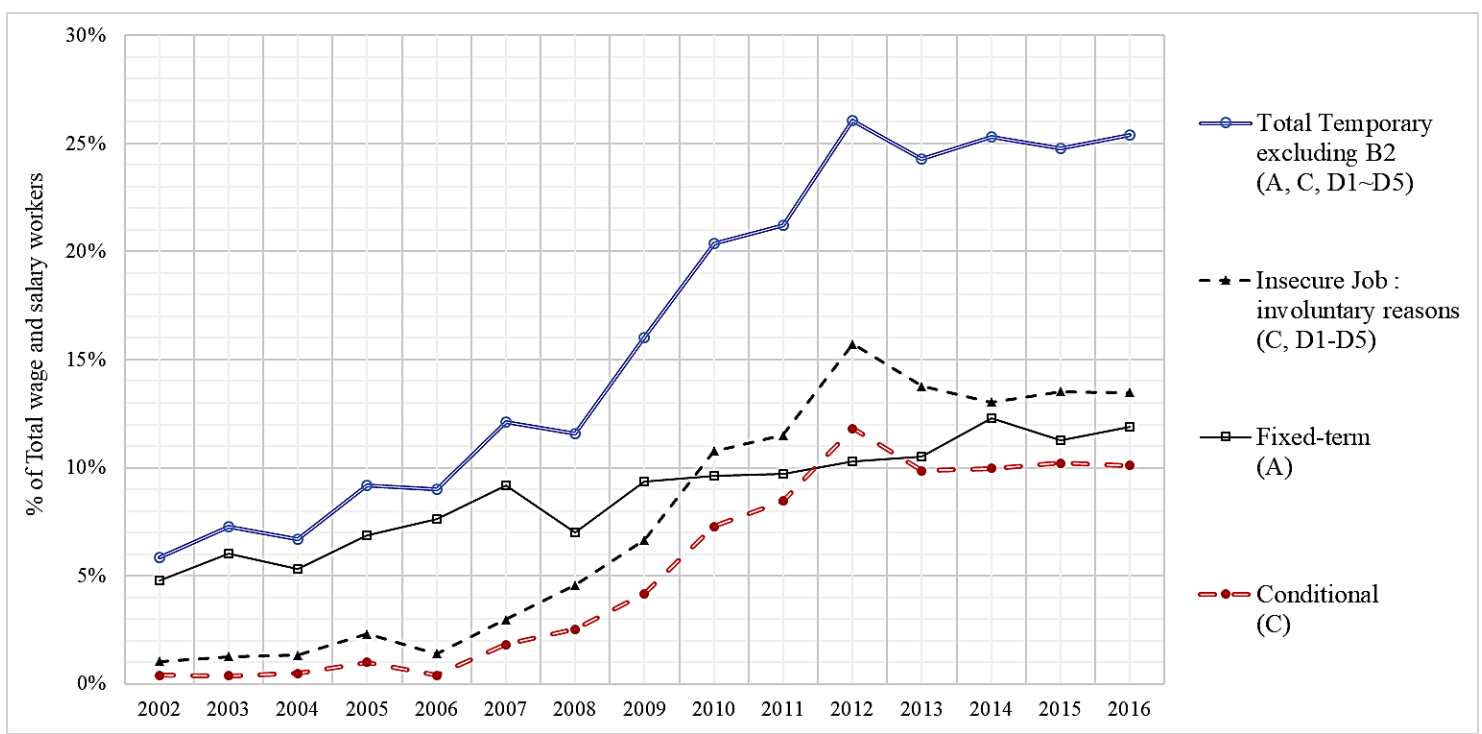


Table 2.6. The number of total workers and the number of workers who chose each answer to the four questions

\begin{tabular}{|c|c|c|c|c|c|c|c|c|c|c|c|c|c|c|c|}
\hline & \multicolumn{15}{|c|}{ Interview Year (the number of workers surveyed in each year) } \\
\hline & 2002 & 2003 & 2004 & 2005 & 2006 & 2007 & 2008 & 2009 & 2010 & 2011 & 2012 & 2013 & 2014 & 2015 & 2016 \\
\hline Total wage and salary workers & 3,975 & 4,211 & 4,257 & 4,085 & 4,300 & 4,346 & 4,340 & 5,189 & 5,289 & 5,361 & 5,450 & 5,462 & 5,327 & 5,611 & 5,784 \\
\hline
\end{tabular}

\begin{tabular}{|c|c|r|r|r|r|r|r|r|r|r|r|r|r|r|r|r|r|r|r|r|r|}
\hline $\begin{array}{c}\text { Q1. } \\
\begin{array}{c}\text { Fixed- } \\
\text { term } \\
\text { contract? }\end{array}\end{array}$ & $\begin{array}{c}\text { 1. YES : Fixed-term employment } \\
\text { (Employment contract period is fixed in advance) }\end{array}$ & $\begin{array}{c}\text { 2. NO : Unfixed } \\
\text { (Employment contract period is not fixed in advance) }\end{array}$ & $3.8 \%$ & 6.709 & 3,913 & 4,000 & 3,755 & 3,949 & 3,948 & 4,033 & 4,703 & 4,781 & 4,840 & 4,887 & 4,886 & 4,671 & 4,976 & 5,096 \\
\hline
\end{tabular}

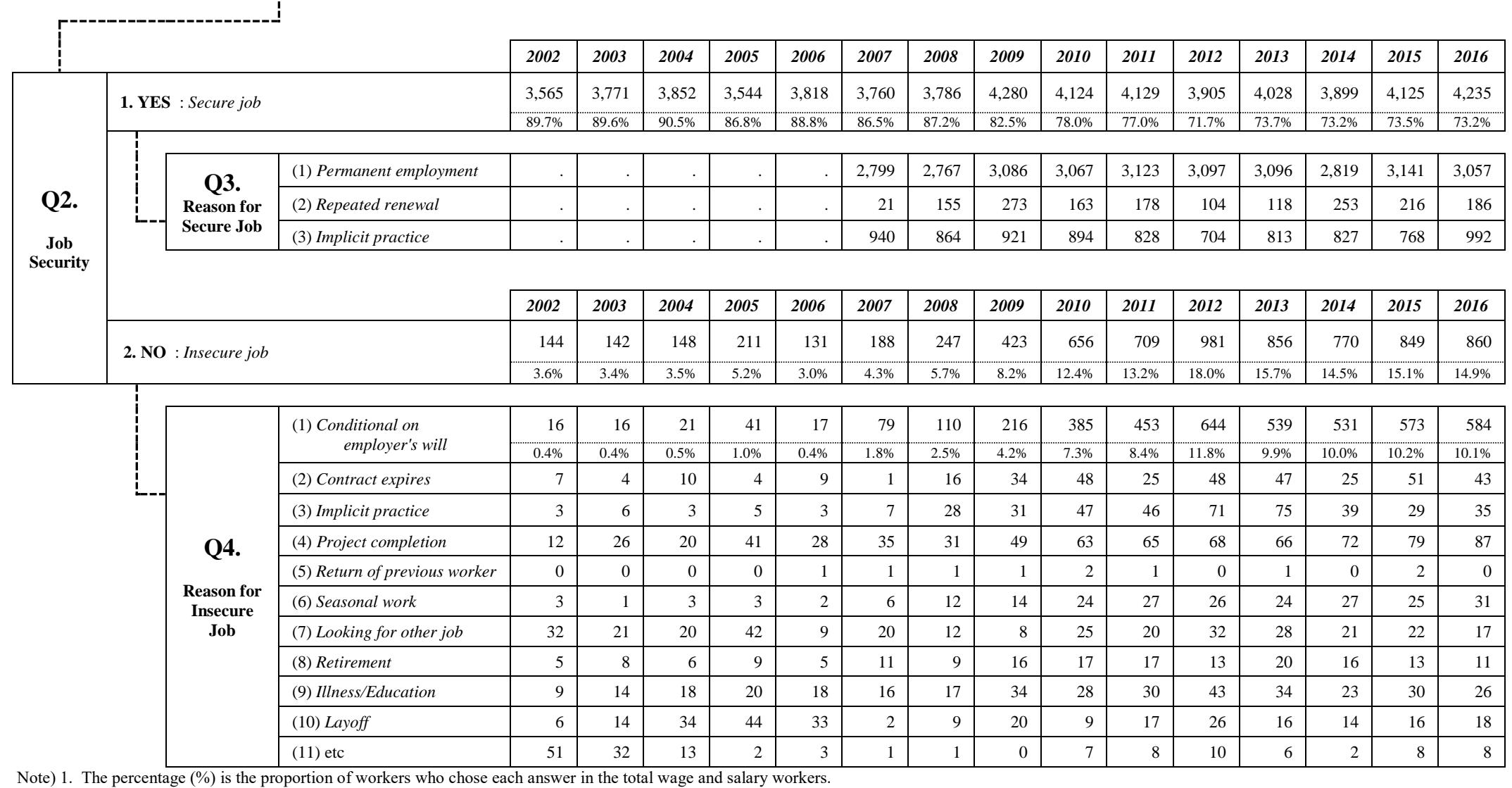

Note) 1 . The percentage (\%) is the proportion of workers who chose each answer in the total wage and salary workers.

2. $T(1)$ means that the group falls into the first category of temporary workers; $T(2)$ indicates the second group of temporary workers - those hired on an open-ended contract but with expected limited duration 
The main concern of this study is whether the increase of the alternative employment arrangement - the second type of temporary employment (Temp (2) - C, D1-D5) - is still statistically significant even after controlling for other variables relevant to the employment. To verify this, I estimate the following logit model with time (year) fixed effects:

\section{- Logit Model}

Posit an unobserved latent variable, $Y_{i t}^{*}$, for a worker $i$ on employment at $t$, as

$$
Y_{i t}^{*}=X_{i t} \Pi+\theta_{t}+\varepsilon_{i t}
$$

The observed variable, $Y_{i t}=1\left\{Y_{i t}^{*} \geq 0\right\}$.

Here, $Y_{i t}$ is a dummy variable indicating whether a worker $i$ is on insecure employment for involuntary reasons (C, D1-D5) at $t$; it has a value of zero when a worker $i$ is holding other types of jobs. $\theta_{t}$ represents time fixed effects that capture the effect of each year $(t)$ on the probability of having insecure jobs for involuntary reasons (C, D1-D5). In the model, the error term, $\varepsilon_{i t}$, is assumed to follow a logistic distribution. The variable $X_{i t}$ is a set of controls including worker characteristics (gender, marital status, education level, and age), employer characteristics (firm size, industry, and region), tenure, occupation, and a constant. The control variables used in the model are briefly summarized in Table 2.7., and a detailed explanation can be found in the Appendix (Table A2).

Table 2.7. Definition of control variables

\begin{tabular}{|c|l|l|}
\hline$\cdot$ & Female $_{i}$ & Female indicator \\
\hline$\cdot$ & Married $_{i t}$ & Marital status \\
\hline$\cdot$ & Female $_{i} \times$ Married $_{i t}$ & An interaction term of female and married dummies \\
\hline$\cdot$ & Edu level $_{i t}$ & Indicators for education level $j$ where $j=1, \ldots, 7$ \\
\hline$\cdot$ & Age $_{i t}$ & Indicators for an age category $k$ where $k=1, \ldots, 11$ \\
\hline$\cdot$ & Tenure $_{i t}$ & Indicators for an tenure category $l$ where $l=1, \ldots, 8$ \\
\hline$\cdot$ & ${\text { Firm size } m_{i t}}$ & Indicators for a firm size $m$ where $m=1, \ldots, 11$ \\
\hline$\cdot$ & Occupation $_{i t}$ & Indicators for an occupation $n$ where $n=1, \ldots, 11$ \\
\hline$\cdot$ & Industry $s_{i t}$ & Indicators for an industry $s$ where $s=1, \ldots, 17$ \\
\hline$\cdot$ & ${\text { Region } w_{i t}}$ & Indicators for a region $w$ where $w=1, \ldots, 17$ \\
\hline
\end{tabular}

Full results estimated by the logit model are provided in the Appendix (Table A2). Table 2.8. contains only the average marginal effects (AME) of the time fixed effects $\left(\theta_{t}\right)$. To compare the probability of having 
insecure job over time before and after controlling for other variables, adjusted proportion $\left(\mathrm{P}_{t}-\mathrm{P}_{2002}\right)$ of insecure job is provided in Table 2.8. along with $\operatorname{AME}\left(\theta_{t}\right)$, which is the difference in the proportions between year $t$ and a base year (2002). Figure 2.3. shows the results in Table 2.8. in a graph.

Table 2.8. Average marginal effect of each year and proportion of insecure job in total workers

\begin{tabular}{|c|c|c|c|c|c|c|c|c|c|c|c|c|c|c|c|}
\cline { 2 - 15 } & \multicolumn{10}{c|}{} & \multicolumn{10}{c|}{$\begin{array}{c}2002 \\
(I)\end{array}$} & $\begin{array}{c}2003 \\
(2)\end{array}$ & $\begin{array}{c}2004 \\
(3)\end{array}$ & $\begin{array}{c}2005 \\
(4)\end{array}$ & $\begin{array}{c}2006 \\
(5)\end{array}$ & $\begin{array}{c}2007 \\
(6)\end{array}$ & $\begin{array}{c}2008 \\
(7)\end{array}$ & $\begin{array}{c}2009 \\
(8)\end{array}$ & $\begin{array}{c}2010 \\
(9)\end{array}$ & $\begin{array}{c}2011 \\
(10)\end{array}$ & $\begin{array}{c}2012 \\
(11)\end{array}$ & $\begin{array}{c}2013 \\
(12)\end{array}$ & $\begin{array}{c}2014 \\
(13)\end{array}$ & $\begin{array}{c}2015 \\
(14)\end{array}$ & $\begin{array}{c}2016 \\
(15)\end{array}$ \\
\hline $\begin{array}{c}\text { Average Marginal } \\
\text { Effect: AME }\left(\theta_{t}\right)\end{array}$ & - & 0.2 & 0.3 & 1.1 & 0.6 & 2.0 & 3.7 & 5.8 & 10.1 & 10.5 & 15.0 & 13.1 & 12.5 & 13.1 & 13.4 \\
\hline $\begin{array}{c}\text { Adjusted } \\
\text { Proportion: } \\
\mathbf{P}_{t}-\mathbf{P}_{2002}\end{array}$ & - & 0.2 & 0.3 & 1.3 & 0.4 & 1.9 & 3.5 & 5.6 & 9.7 & 10.5 & 14.7 & 12.7 & 12.0 & 12.5 & 12.5 \\
\hline $\begin{array}{c}\text { Observed } \\
\text { Proportion: } \\
\mathbf{P}_{t}(\%)\end{array}$ & 1.0 & 1.3 & 1.3 & 2.3 & 1.4 & 3.0 & 4.6 & 6.6 & 10.8 & 11.5 & 15.7 & 13.8 & 13.0 & 13.5 & 13.5 \\
\hline
\end{tabular}

Figure 2.3. Average Marginal Effect and Proportion of Insecure Job in total wage and salary workers

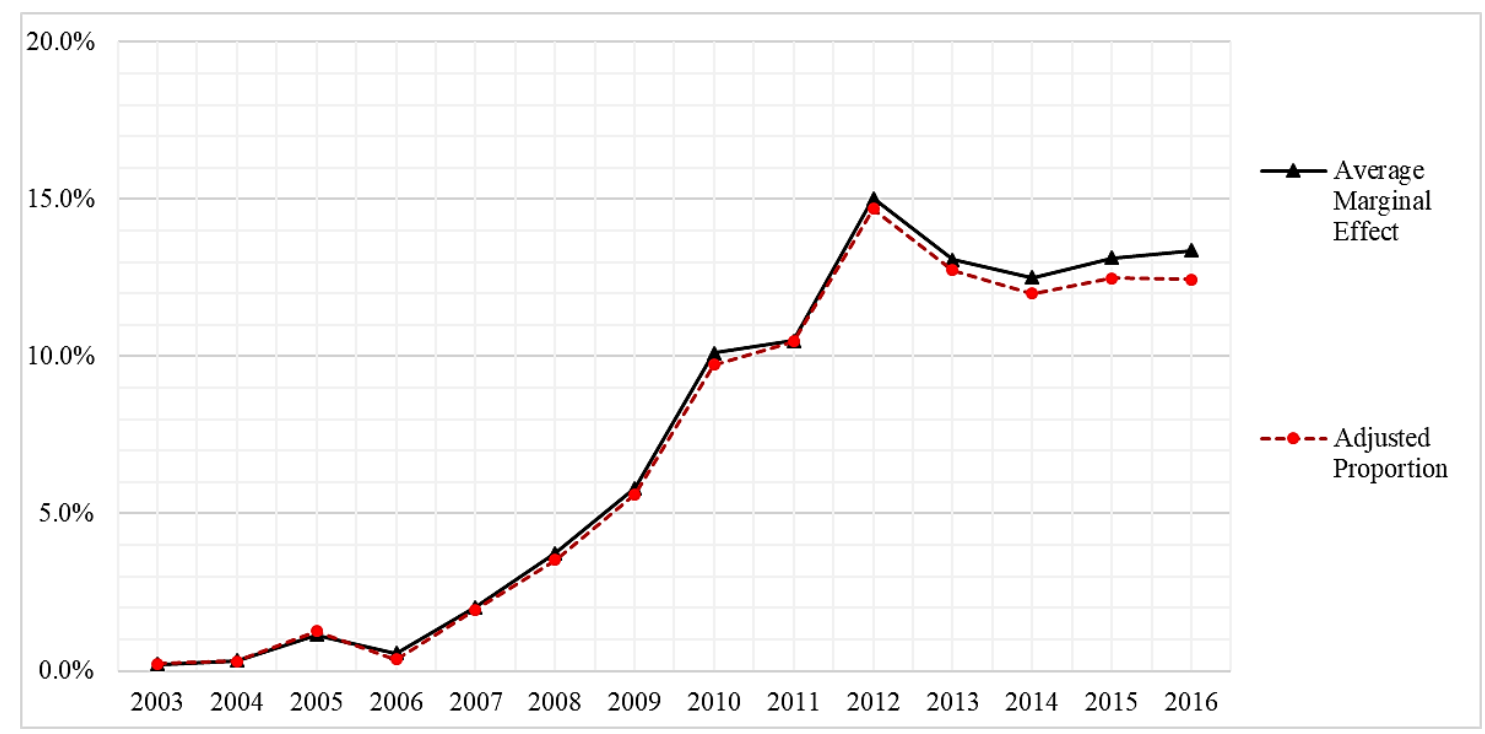

The average marginal effect of the time effects, $\operatorname{AME}\left(\theta_{t}\right)$, is almost the same as the adjusted proportion $\left(\mathrm{P}_{t}-\mathrm{P}_{2002}\right)$ until 2012. Although the gap started to increase after 2012, it was still very small (less than 1.0 percentage point). Thus, the change in the proportion of insecure job over time is barely explained by either worker or employer chracteristics. Rather, based on the fact that the probality of having an insecure job for involuntary reasons started to increase from 2007, the change in the proportion of insecure jobs could be 
mainly attributed to the introduction of the new regulation in 2007.

In summary, fixed-term workers (A) accounted for more than $80 \%$ of total temporary workers before the reform. However, the portion of fixed-term workers in temporary employment has decreased since 2007. The second type of temporary employment (C, D1-D5) now accounts for a much larger portion of temporary workers, making up more than half of temporary workers after 2010. More importantly, the increase in the second type of temporary employment (C, D1-D5) - not only those whose employment contract is openended but also whose perceived level of job security is low - has been mainly driven by the increase in the proportion of conditional employment (C). Therefore, it appears that firms changed human resource management practice in response to the new regulation, taking advantage of alternative employment arrangements.

We can think of reasons why conditional employment (C) has been used as a way by which employers have evaded the regulation. First, Conditional employment (C) - in which a worker was hired on the condition that the worker quit his/her job at the employer's request - is less likely to be subject to the regulation because the period of employment contract is not fixed when the worker was hired. Second, assuming the employee abides by the agreement, employment termination is up to an employer, so the employer can arrange for separation of a worker on conditional employment (C) without worrying about an unjust dismissal complaint. Third, even when an employment termination is very likely to be deemed an unjust dismissal, the worker may agree to the employer's request for job termination rather than submitting a complaint. This is because the employment relation between employers and employees in Korea has been based on the hierarchical nature of Asian culture, and hence employees are subordinate to employers especially in a peripheral sector of the Korean labor market. For this reason, conditional employment (C) seems to be used as a way by which employers have evaded the regulation, substituting for fixed-term contract employment.

\subsubsection{The Impact of the Reform on the Probability of having Alternative Jobs}

In this section, based on the fact that the alternative employment arrangement - the second type of temporary employment (Temp (2) - C, D1-D5) - increased dramatically in the post-reform period, we examine the effect of the reform on the probability of having an alternative job for particular time periods. 
We decompose the total effect of the reform into two parts. The first one is the effect of a post-reform period $\left(A f t e r_{t}\right)$, which has the value of one for the sample period after the reform $\left(A f t e r_{t}=1\right)$. The second one is the effect of post-job (Post-job $i t$ ), which has the value of one for the observations that started their jobs after the reform $\left(\right.$ Post-job $\left._{i t}=1\right)$. Through this decomposition, we try to distinguish the casual effect of the reform from the time effect because only jobs that started after the reform (July 2007) are subject to the new regulation initially.

For this, observations in the sample are divided into three groups. Group 1 includes workers who were surveyed before the reform $\left(\right.$ After $\left.t_{t}=0\right)$; hence, their jobs had to begin before the reform $\left(\right.$ Post-job $\left._{i t}=0\right)$. Group 2 consists of workers who started their jobs before the reform $\left(P o s t-j o b_{i t}=0\right)$ but were surveyed after the reform $\left(\right.$ After $\left._{t}=1\right)$. Group 3 has workers whose jobs began after the reform $($ Post-job $i t=1)$; hence, they had to be surveyed after the reform $\left(\right.$ After $\left._{t}=1\right)$. Figure 2.4. describes the three groups visually.

Figure 2.4. Three groups of sample observation according to job-start and interview dates

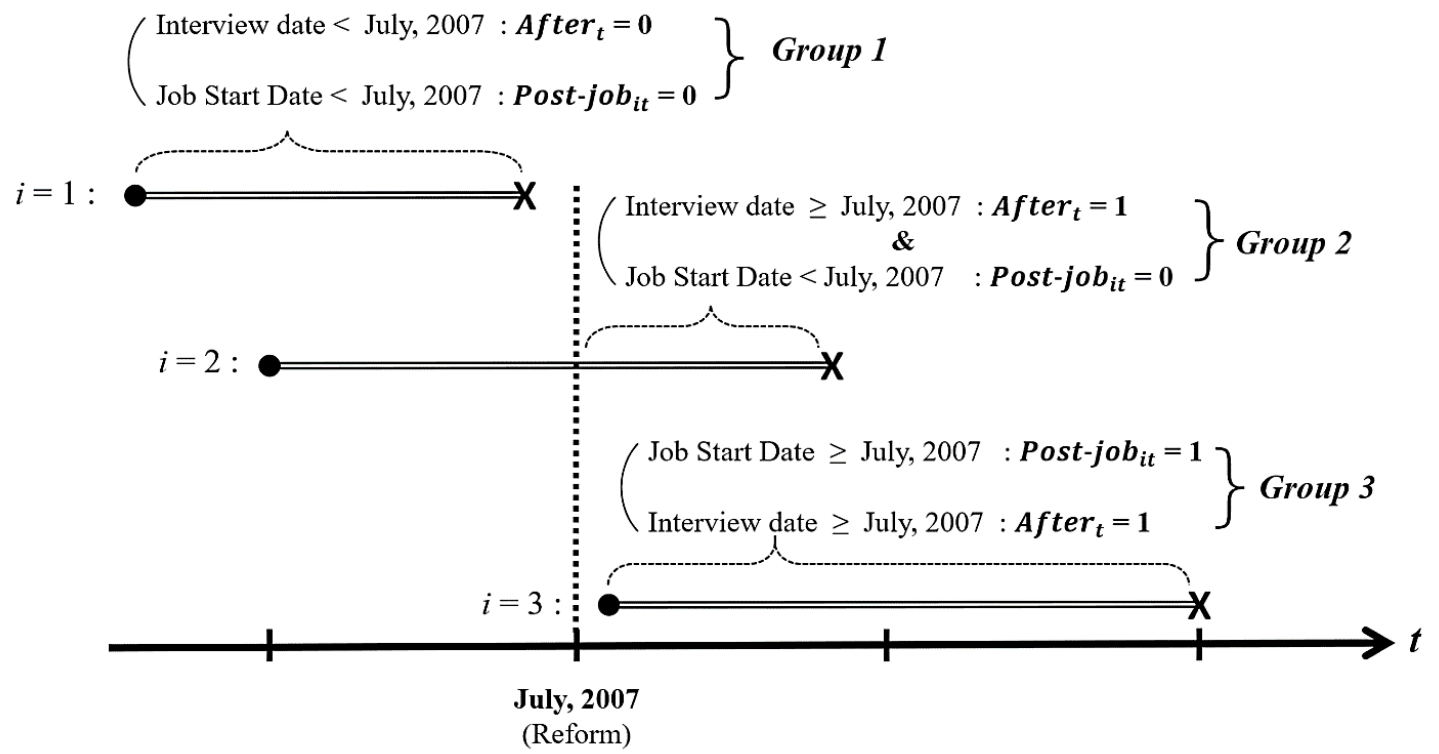

To distinguish the casual effect of the reform from the time effects, an econometric model in (Eq. 2.2) is employed. Here, $Y_{i t}$ is a dummy variable indicating whether a worker $i$ is on insecure employment for involuntary reasons (C, D1-D5) at $t$; it has a value of zero when a worker $i$ is holding other types of jobs. 


\section{- $\underline{\text { Logit Model }}$}

Posit an unobserved latent variable, $Y_{i t}^{*}$, for a worker $i$ on employment at $t$, as

$$
Y_{i t}^{*}=X_{i t} \Pi+\beta_{1} \text { After }_{t}+\beta_{2}{\text { Post }-j o b_{i t}}+\varepsilon_{i t}
$$

The observed variable, $Y_{i t}=1\left\{Y_{i t}^{*} \geq 0\right\}$

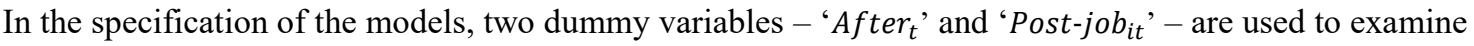
the two types of effects. The coefficient $\beta_{1}$ of 'After ${ }_{t}$ ' variable captures the time effect - whether the probability of having an alternative job is higher for the observations surveyed after the reform. The coefficient $\beta_{2}$ of 'Post-jobit' variable compares the probability for a worker having an alternative job in Groups 3 versus 2. Thus, $\beta_{2}$ captures the treatment effect of having a job contract initiated after the reform.

In the model, the error term $\varepsilon_{i t}$ is assumed to follow a logistic distribution. The control variables $X_{i t}$ is a set of controls including worker characteristics (gender, marital status, education level, and age), employer characteristics (firm size, industry, and region), tenure, occupation, and a constant. Moreover, in order to control for the reginal economic conditions in the survey year, regional employment rates and regional unemployment rates are controlled. The control variables used in the model are briefly summarized in Table 2.9., and a detailed explanation can be found in the Appendix (Table A3).

Table 2. 9. Definition of control variables

\begin{tabular}{|c|c|c|}
\hline - & Female $_{i}$ & Female indicator \\
\hline - & Married $_{i t}$ & Marital status \\
\hline - & Female $_{i} \times$ Married $_{i t}$ & An interaction term of female and married dummies \\
\hline - & Edu level $j_{i t}$ & Indicators for education level $j$ where $j=1, \ldots, 7$ \\
\hline - & Age $k_{i t}$ & Indicators for an age category $k$ where $k=1, \ldots, 11$ \\
\hline - & Tenure $l_{i t}$ & Indicators for an tenure category $l$ where $l=1, \ldots, 8$ \\
\hline · & Firm size $m_{i t}$ & Indicators for a firm size $m$ where $m=1, \ldots, 11$ \\
\hline - & Occupation $n_{i t}$ & Indicators for an occupation $n$ where $n=1, \ldots, 11$ \\
\hline - & Industry $s_{i t}$ & Indicators for an industry $s$ where $s=1, \ldots, 17$ \\
\hline - & Region $w_{i t}$ & Indicators for a region $w$ where $w=1, \ldots, 17$ \\
\hline - & Emp_rate $_{t}$ & Regional employment rate in each year \\
\hline - & Unemp_rate $_{t}$ & Regional unemployment rate in each year \\
\hline
\end{tabular}


Table 2.10. The effect of the reform on the probability of having insecure jobs for involuntary reason

\begin{tabular}{|c|c|c|c|c|}
\hline & & \multicolumn{3}{|c|}{ Logit Model } \\
\hline & VARIABLES & \multicolumn{3}{|c|}{$\begin{array}{l}\mathbf{1}=\text { Insecure Job }(\mathbf{C} \& \mathbf{D}) \\
0=\text { Other Jobs }\end{array}$} \\
\hline \multirow{2}{*}{\multicolumn{2}{|c|}{ Controlling for other variables }} & \multirow{3}{*}{$\begin{array}{c}\text { (1) No Control } \\
1.645^{* * *}\end{array}$} & \multicolumn{2}{|c|}{ (2) Control } \\
\hline & & & & \multirow{2}{*}{$\frac{A M E}{0.067}$} \\
\hline After & Post-reform period ( $1=$ after July, 2007) & & $1.880^{* * * *}$ & \\
\hline Post-job & Post-job $=1$, if a job began after the reform & $0.747 * * *$ & $0.674 * * *$ & 0.053 \\
\hline \multirow{10}{*}{$\begin{array}{c}\text { Control } \\
\text { variables }\end{array}$} & Female and Marriage status & No & \multicolumn{2}{|c|}{ Yes } \\
\hline & Education Level (base: High school) & No & \multicolumn{2}{|c|}{ Yes } \\
\hline & Age Cohort (base: age 35-39) & No & \multicolumn{2}{|c|}{ Yes } \\
\hline & Tenure in month (base: 13-24 months) & No & \multicolumn{2}{|c|}{ Yes } \\
\hline & Firm size (base: 1-4 people) & No & \multicolumn{2}{|c|}{ Yes } \\
\hline & Occupation (base: Office clerk) & No & \multicolumn{2}{|c|}{ Yes } \\
\hline & Industry (base: Manufacturing) & No & \multicolumn{2}{|c|}{ Yes } \\
\hline & Region (base: Seoul) & No & \multicolumn{2}{|c|}{ Yes } \\
\hline & Regional employment rate in each year & No & \multicolumn{2}{|c|}{ Yes } \\
\hline & Reginal unemployment rate in each year & No & \multicolumn{2}{|c|}{ Yes } \\
\hline & Observations & 72,986 & \multicolumn{2}{|c|}{70,200} \\
\hline & The number of workers & 12,043 & \multicolumn{2}{|c|}{11,744} \\
\hline
\end{tabular}

Note) 1. Robust standard errors are in parenthesis, which are clustered at the individual level.

2. The average marginal effect is the average of conditional marginal effects computed at all sample values.

3. $* * * \mathrm{p}<0.01, * * \mathrm{p}<0.05, * \mathrm{p}<0.1$

4. The conditional average marginal effect $(A M E)$ is computed by averaging conditional marginal effect $(M E)$ for each observation $i$ over all sample values.

- AME (After $\mid$ Post -job $=0)=\frac{1}{n} \sum_{i=1}^{n} M E_{i}($ After $\mid$ Post -job $=0)$

where $M E_{i}(\cdot)=\hat{P}\left(y_{i}=1 \mid\right.$ After $=1$, Post-job $\left.=0, \boldsymbol{X}_{i} ; \widehat{\boldsymbol{\beta}}, \widehat{\boldsymbol{\pi}}\right)-\hat{P}\left(y_{i}=1 \mid\right.$ After $=0$, Post-job $\left.=0, \boldsymbol{X}_{i} ; \widehat{\boldsymbol{\beta}}, \widehat{\boldsymbol{\pi}}\right)$.

- $A M E($ Post -job $\mid$ After $=1)=\frac{1}{n} \sum_{i=1}^{n} M E_{i}($ Post -job $\mid$ After $=1)$

where $M E_{i}(\cdot)=\hat{P}\left(y_{i}=1 \mid\right.$ Post-job $=1$, After $\left.=1, \boldsymbol{X}_{i} ; \widehat{\boldsymbol{\beta}}, \widehat{\boldsymbol{\pi}}\right)-\hat{P}\left(y_{i}=1 \mid\right.$ Post-job $=0$, After $\left.=1 \boldsymbol{X}_{\boldsymbol{i}} ; \widehat{\boldsymbol{\beta}}, \widehat{\boldsymbol{\pi}}\right)$.

Full results estimated by the Logit model are provided in the Appendix (Table A3). Table 2.9. contains only the two coefficient of interest and the conditional average marginal effects. The first section (No Control) provides the result from Logit analysis without controlling for the covariates except for the two dummy variables - 'After ${ }_{t}$ ' and 'Post-job ${ }_{i t}$ '. The results from the analysis controlling for the covariates are provided in the second section (Control). Even after controlling for other variables, both the time effect and the treatment effect of the reform are still statistically significant, although the treatment effect decreased slightly. 
According to the results of conditional average marginal effects $(A M E)$, the probability of having the alternative jobs (C, D1-D5) increases by 6.7 percentage points in the post-reform period for the workers who started their jobs before reform. In addition, if we focus on the workers who surveyed in the post-reform period, the reform increases the probability of having the alternative jobs by 5.3 percentage points. Thus, even after controlling for other covariates as well as the time effect, the reform has a statistically significant and positive effect on the probability of having the insecure jobs for involuntary reason. In conclusion, the results support the view that firms changed human resource management practice in response to the new regulation, taking advantage of alternative employment arrangements that are less likely to be subject to the new regulation. These types of employment include temporary workers (limited-period workers) whose employment contract is open-ended but also whose perceived level of job security is very low because they have to leave their jobs for involuntary reasons.

\subsubsection{Movements between conditional employment and the other alternative employment arrangements}

As presented in the previous section, alphabetic codes (A, B1-B3, C, D1-D5, E1-E5, and U) were assigned to each category of employment based on answers to the four questions that are used to classify temporary employment arrangements. Using these codes, we examine movements between groups since this could be the key to understanding why there is little impact of the reform. We focus largely on movements from/into conditional employment $(\mathrm{C})$ in the face of the dramatic increases in its share of total wage and salary workers

after the reform. Through analyses of movements from/into conditional employment (C), we answer important questions: (i) How many workers have remained in conditional employment over time? (ii) Where are those entering conditional employment coming from? (iii) What is the chance for other statuses of moving to conditional employment?

To answer the first question - (i) How many workers have remained in conditional employment over time, we need to classify possible movement from conditional employment $\left(\mathrm{C}_{\mathrm{t}}\right)$ at a certain survey year $t$ to the other group at the next survey year $t+1$. We focus on movements for workers who remain with the same employer, and Table 2.10. summarizes possible movements from conditional employment. A worker in the 
group of conditional employment $\left(\mathrm{C}_{t}\right)$ can stay in the same group $\left(\mathrm{C}_{t+1}\right)$, leave one's job $\left(\mathrm{T}_{\mathrm{t}+1}\right)$, or move to the other groups $\left(A_{t+1}, B_{t+1}, D_{t+1}, E_{t+1}\right)$. Also, there are censored cases, where a worker was not observed in the next survey year $\left(\mathrm{U}_{\mathrm{t}+1}\right)$.

Table 2.11. Movements from conditional employment (C) to the other group between 2002 and 2016

$$
: \mathrm{C}_{\mathbf{t}}(\text { conditional employment }) \rightarrow \text { Employment arrangement } \mathbf{t + 1}
$$

\begin{tabular}{|c|c|c|c|c|c|}
\hline$[t]$ & & \multicolumn{2}{|r|}{$[t+1]$} & \multicolumn{2}{|c|}{$2002 \sim 2016(t \rightarrow t+1)$} \\
\hline \multirow{7}{*}{$\begin{array}{c}\mathbf{C}_{\mathbf{t}} \\
\text { (Conditional } \\
\text { employment) }\end{array}$} & \multirow{7}{*}{$\rightarrow$} & $\circ \mathbf{C}_{\mathbf{t}+\mathbf{1}}$ & Conditional employment & 1,383 & $39.3 \%$ \\
\hline & & $\circ \mathbf{T}_{\mathbf{t + 1}}$ & Employment termination & 1,069 & $30.4 \%$ \\
\hline & & $\circ \mathbf{B}_{t+1}(\mathrm{~B} 1-\mathrm{B} 3)$ & Secure job & 584 & $16.6 \%$ \\
\hline & & $\circ \mathbf{A}_{t+1}$ & Fixed-term contract & 142 & $4.0 \%$ \\
\hline & & $\circ \mathbf{D}_{\mathbf{t + 1}}(\mathrm{D} 1-\mathrm{D} 5)$ & $\begin{array}{l}\text { Insecure job-involuntary } \\
\text { reason }\end{array}$ & 180 & $5.1 \%$ \\
\hline & & $\circ \mathbf{E}_{\mathbf{t}+\mathbf{1}}(\mathrm{E} 1-\mathrm{E} 5)$ & Insecure job - voluntary reason & 96 & $2.7 \%$ \\
\hline & & $\circ \mathbf{U}_{\mathbf{t + 1}}$ & Unknown (censored) & 63 & $1.8 \%$ \\
\hline & & Total & & 3,517 & $100 \%$ \\
\hline
\end{tabular}

The last two columns in Table 2.10. show the total number of moves between the groups in consecutive years throughout the sample period (2002-2016). 39.3\% of workers who were in the group of conditional employment $\left(\mathrm{C}_{\mathrm{t}}\right)$ at $t$ stayed the same group at $t+1 ; 30.4 \%$ of the workers left their jobs $\left(\mathrm{T}_{\mathrm{t}+1}\right) ; 16.6 \%$ of the workers moved to the group $\left(\mathrm{B}_{\mathrm{t}+1}\right)$ - secure job. However, movements to the other groups $-\mathrm{A}, \mathrm{D}, \mathrm{E}, \mathrm{U}-\mathrm{are}$ relatively limited.

According to the results in Table 2.10., it seems that most workers stay in the same group (C) or leave their job over the sample period. However, we found dramatic changes in certain movements when we compare the pattern of movement over time. Table 2.11. and Figure 2.5. shows how the movements between the groups changed over time, and the results can be summarized as follows.

First, as we confirmed in the previous section, the total number of workers in conditional employment $\left(\mathrm{C}_{\mathrm{t}}\right)$ was small in the early survey years, but it increased significantly after the new regulation was introduced in 2007. 
Second, before the reform, about $40 \%$ of the workers in the group $\left(C_{t}\right)$ left their jobs $\left(T_{t+1}\right)$ and another $40 \%$ of the workers moved to the group of secure job $\left(\mathrm{B}_{t+1}\right)$ in the next year, although the total number of workers in the group $\left(\mathrm{C}_{t}\right)$ was small. After the reform, the share of workers who moved to secure job $\left(B_{t+1}\right)$ shrunk substantially, while the share of workers terminating their employment $\left(T_{t+1}\right)$ decreased gradually. Thus, workers in conditional employment $\left(\mathrm{C}_{\mathrm{t}}\right)$ seemed to have had a greater chance of moving to secure jobs before the reform.

Third, it was not common to remain in conditional employment (C) in two consecutive years before the reform, but the share of the workers who stayed in this group (C) increased dramatically right after the new regulation was introduced. Therefore, we may guess conditional employment (C) has been used as a way keeping workers in temporary employment after the reform.

In sum, workers in conditional employment (C) have a greater chance to move to secure jobs before the reform, although the total number of workers in the group (C) was small. Conditional employment (C) started to be used widely after the new regulation was introduced. In addition, a significant share of workers in the group $(\mathrm{C})$ remained in the same group, and a smaller share moved to a secure job (B) after the new regulation was introduced. 
Table 2.12. Changes in movements between worker groups: Employment arrangement ${ }_{t+1} / C_{\boldsymbol{t}}(\%)$

\begin{tabular}{|c|c|c|c|c|c|c|c|c|c|c|c|c|c|c|}
\hline & \multicolumn{14}{|c|}{$\frac{\text { Employment arrangement }_{\boldsymbol{t}+\mathbf{1}}}{C_{t}} \times 100$} \\
\hline & $\begin{array}{l}02^{\prime} \rightarrow \\
03^{\prime}\end{array}$ & $\begin{array}{l}03^{\prime} \rightarrow \\
04^{\prime}\end{array}$ & $\begin{array}{c}04^{\prime} \rightarrow \\
05^{\prime}\end{array}$ & $\begin{array}{l}05^{\prime} \rightarrow \\
06^{\prime}\end{array}$ & $\begin{array}{l}06^{\prime} \rightarrow \\
07^{\prime}\end{array}$ & $\begin{array}{l}07^{\prime} \rightarrow \\
08^{\prime}\end{array}$ & $\begin{array}{l}08^{\prime} \rightarrow \\
09^{\prime}\end{array}$ & $\begin{array}{l}09^{\prime} \rightarrow \\
10^{\prime}\end{array}$ & $\begin{array}{l}10^{\prime} \rightarrow \\
11^{\prime}\end{array}$ & $\begin{array}{l}11^{\prime} \rightarrow \\
12^{\prime}\end{array}$ & $\begin{array}{l}12^{\prime} \rightarrow \\
13^{\prime}\end{array}$ & $\begin{array}{c}13^{\prime} \rightarrow \\
14^{\prime}\end{array}$ & $\begin{array}{c}14^{\prime} \rightarrow \\
15^{\prime}\end{array}$ & $\begin{array}{r}15^{\prime} \rightarrow \\
16^{\prime}\end{array}$ \\
\hline $\begin{array}{l}\mathbf{C}_{\mathbf{t}} \rightarrow \mathbf{C}_{\mathrm{t}+1} \\
\text { (Conditional) }\end{array}$ & $0.0 \%$ & $0.0 \%$ & $10.5 \%$ & $0.0 \%$ & $0.0 \%$ & $26.3 \%$ & $22.9 \%$ & $20.7 \%$ & $29.9 \%$ & $39.8 \%$ & $32.9 \%$ & $37.2 \%$ & $55.7 \%$ & $57.7 \%$ \\
\hline $\begin{array}{l}\mathbf{C}_{\mathbf{t}} \rightarrow \mathbf{T}_{\mathbf{t + 1}} \\
\text { Termination) }\end{array}$ & $40.0 \%$ & $43.8 \%$ & $26.3 \%$ & $51.5 \%$ & $35.3 \%$ & $34.2 \%$ & $31.4 \%$ & $37.0 \%$ & $33.3 \%$ & $29.5 \%$ & $29.2 \%$ & $25.0 \%$ & $30.9 \%$ & $29.8 \%$ \\
\hline $\begin{array}{l}\mathbf{C}_{\mathbf{t}} \rightarrow \mathbf{B}_{\mathrm{t}+1} \\
(\text { Secure Job) }\end{array}$ & $46.7 \%$ & $50.0 \%$ & $47.4 \%$ & $27.3 \%$ & $52.9 \%$ & $31.6 \%$ & $32.4 \%$ & $26.9 \%$ & $23.5 \%$ & $15.7 \%$ & $21.2 \%$ & $23.0 \%$ & $1.7 \%$ & $2.1 \%$ \\
\hline $\begin{array}{c}\mathbf{C}_{\mathbf{t}} \rightarrow \mathbf{A}_{\mathrm{t}+1} \\
\text { (Fixed-term) }\end{array}$ & $6.7 \%$ & $6.3 \%$ & $0.0 \%$ & $6.1 \%$ & $5.9 \%$ & $0.0 \%$ & $4.8 \%$ & $5.3 \%$ & $3.7 \%$ & $4.5 \%$ & $4.8 \%$ & $5.3 \%$ & $2.7 \%$ & $2.9 \%$ \\
\hline $\mid \begin{array}{c}\mathbf{C}_{\mathbf{t}} \rightarrow \mathbf{D}_{\mathbf{t + 1}} \\
\text { (Involuntary) }\end{array}$ & $0.0 \%$ & $0.0 \%$ & $5.3 \%$ & $3.0 \%$ & $5.9 \%$ & $5.3 \%$ & $1.9 \%$ & $6.3 \%$ & $4.8 \%$ & $4.3 \%$ & $6.4 \%$ & $5.8 \%$ & $4.4 \%$ & $5.0 \%$ \\
\hline $\begin{array}{l}\mathbf{C}_{\mathbf{t}} \rightarrow \mathbf{E}_{\mathbf{t}+1} \\
\text { (Voluntary) }\end{array}$ & $0.0 \%$ & $0.0 \%$ & $10.5 \%$ & $9.1 \%$ & $0.0 \%$ & $2.6 \%$ & $4.8 \%$ & $2.9 \%$ & $1.9 \%$ & $3.2 \%$ & $2.7 \%$ & $1.9 \%$ & $3.1 \%$ & $2.5 \%$ \\
\hline $\begin{array}{l}\mathbf{C}_{t \rightarrow U_{t+1}} \\
(\text { Unknown) }\end{array}$ & $6.7 \%$ & $0.0 \%$ & $0.0 \%$ & $3.0 \%$ & $0.0 \%$ & $0.0 \%$ & $1.9 \%$ & $1.0 \%$ & $2.9 \%$ & $3.0 \%$ & $2.7 \%$ & $1.8 \%$ & $1.4 \%$ & $0.0 \%$ \\
\hline $\begin{array}{l}\text { (Total } \\
\text { number } \\
\text { of } \mathrm{C}_{1} \text { ) }\end{array}$ & $\begin{array}{l}100 \% \\
(15)\end{array}$ & $\begin{array}{c}100 \% \\
(16)\end{array}$ & $\begin{array}{c}100 \% \\
(19)\end{array}$ & $\begin{array}{c}100 \% \\
(33)\end{array}$ & $\begin{array}{c}100 \% \\
(17)\end{array}$ & $\begin{array}{c}100 \% \\
(76)\end{array}$ & $\begin{array}{l}100 \% \\
(105)\end{array}$ & $\begin{array}{l}100 \% \\
(208)\end{array}$ & $\begin{array}{l}100 \% \\
(375)\end{array}$ & $\begin{array}{l}100 \% \\
(440)\end{array}$ & $\begin{array}{l}100 \% \\
(623)\end{array}$ & $\begin{array}{l}100 \% \\
(513)\end{array}$ & $\begin{array}{l}100 \% \\
(517)\end{array}$ & $\begin{array}{l}100 \% \\
(560)\end{array}$ \\
\hline
\end{tabular}

Figure 2.5. Transition patterns in a job: Employment arrangement ${ }_{t+1} / C_{t}(\%)$

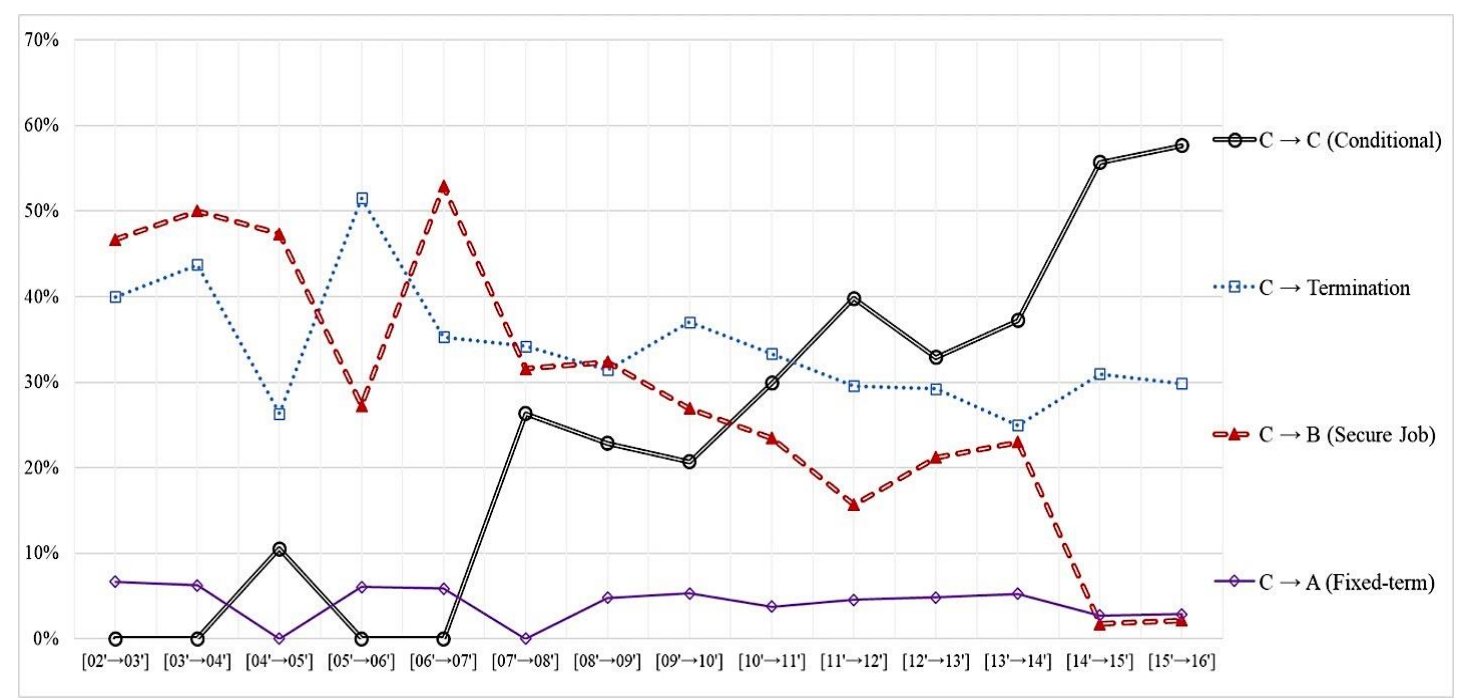

To answer the second question - (ii) Where are those entering conditional employment coming from?, we focus on movement from an employment arrangement at $t$ to conditional employment at $t+1$. Table 2.12 . shows possible movement into conditional employment. A worker in the group of conditional employment 
$\left(C_{t+1}\right)$ can be from the same group $\left(C_{t}\right)$ or the other groups $\left(A_{t}, B_{t}, D_{t}, E_{t}\right)$. Moreover, a worker might be hired on a different job $\left(\mathrm{DJ}_{\mathrm{t}}\right)$ or be in non-employment status $\left(\mathrm{NE}_{\mathrm{t}}\right)$ at $t$ so that the worker is to start a new job on conditional employment $\left(\mathrm{C}_{\mathrm{t}+1}\right)$ at $t+1$. Also, there are censored cases, where a worker was not observed at $t$ $\left(\mathrm{U}_{\mathrm{t}}\right)$. The last two columns in Table 2.9. show the total number of moves between the groups in consecutive years throughout the sample period (2002-2016). 33.9\% of workers who are in the group of conditional employment $\left(\mathrm{C}_{\mathrm{t}+1}\right)$ at $t+1$ came from the same group $\left(\mathrm{C}_{\mathrm{t}}\right)$ at $t ; 33.2 \%$ of the workers started new jobs on conditional employment $\left(\mathrm{DJ} / \mathrm{NE}_{\mathrm{t}}\right) ; 18.6 \%$ of the workers moved from the group $\left(\mathrm{B}_{\mathrm{t}}\right)-$ secure job. However, movements from the other groups - A, D, E, U - are relatively small.

Table 2.13. Movements from the other groups to conditional employment (C) between 2002 and 2016 $:$ Employment arrangement $\mathbf{t} \rightarrow \mathrm{C}_{\mathbf{t}+\mathbf{1}}$ (conditional employment)

\begin{tabular}{|c|c|c|c|c|c|}
\hline \multicolumn{2}{|r|}{$[t]$} & & {$[t+1]$} & \multicolumn{2}{|c|}{$2002 \sim 2016(t \rightarrow t+1)$} \\
\hline$\circ \mathbf{C}_{\mathbf{t}}$ & Conditional employment & \multirow{7}{*}{$\rightarrow$} & \multirow{7}{*}{$\begin{array}{c}\mathbf{C}_{\mathbf{t}+\mathbf{1}} \\
\text { (Conditional } \\
\text { employment) }\end{array}$} & 1,383 & $33.9 \%$ \\
\hline $\mathrm{DJ} / \mathbf{N E}_{\mathrm{t}}$ & Different job or Non-employment & & & 1,311 & $33.2 \%$ \\
\hline ○ $\quad \mathbf{B}_{\mathbf{t}}(\mathrm{B} 1-\mathrm{B} 3)$ & Secure job & & & 758 & $18.6 \%$ \\
\hline$\circ \mathbf{A}_{\mathbf{t}}$ & Fixed-term contract & & & 142 & $3.5 \%$ \\
\hline ○ $\quad \mathbf{D}_{\mathbf{t}}(\mathrm{D} 1-\mathrm{D} 5)$ & Insecure job-involuntary reason & & & 191 & $4.7 \%$ \\
\hline$\circ \quad \mathbf{E}_{\mathbf{t}}(\mathrm{E} 1-\mathrm{E} 5)$ & Insecure job-voluntary reason & & & 94 & $2.3 \%$ \\
\hline$\circ \mathbf{U}_{\mathbf{t}}$ & Unknown (censored) & & & 196 & $4.8 \%$ \\
\hline & & & Total & 4,075 & $100 \%$ \\
\hline
\end{tabular}

Table 2.13. and Figure 2.6. show how the movements between the groups changed over time, and the results are very similar to those in the previous analysis. It was not common to remain in conditional employment (C) in two consecutive years before the reform, but the share of the workers who stayed in this group (C) increased dramatically after the reform. Moreover, the share of workers who moved from other groups $\left(\mathrm{DJ} / \mathrm{NE}_{\mathrm{t}}, \mathrm{B}_{\mathrm{t}}\right)$ shrunk substantially. Thus, we may guess conditional employment $(\mathrm{C})$ has been used as a way keeping workers in temporary employment after the reform. 
Table 2.14. Changes in movements between worker groups: Employment arrangement ${ }_{t} / C_{t+1}(\%)$

\begin{tabular}{|c|c|c|c|c|c|c|c|c|c|c|c|c|c|c|}
\hline & \multicolumn{14}{|c|}{$\frac{\text { Employment arrangement }_{\boldsymbol{t}}}{C_{\boldsymbol{t}+\mathbf{1}}} \times 100$} \\
\hline & $\begin{array}{l}02^{\prime} \rightarrow \\
03^{\prime}\end{array}$ & $\begin{array}{l}03^{\prime} \rightarrow \\
04^{\prime}\end{array}$ & $\begin{array}{l}04^{\prime} \rightarrow \\
05^{\prime}\end{array}$ & $\begin{array}{c}05^{\prime} \rightarrow \\
06^{\prime}\end{array}$ & $\begin{array}{c}06^{\prime} \rightarrow \\
07^{\prime}\end{array}$ & $\begin{array}{l}07^{\prime} \rightarrow \\
08^{\prime}\end{array}$ & $\begin{array}{l}08^{\prime} \rightarrow \\
09^{\prime}\end{array}$ & $\begin{array}{l}09^{\prime} \rightarrow \\
10^{\prime}\end{array}$ & $\begin{array}{l}10^{\prime} \rightarrow \\
11^{\prime}\end{array}$ & $\begin{array}{l}11^{\prime} \rightarrow \\
12^{\prime}\end{array}$ & $\begin{array}{l}12^{\prime} \rightarrow \\
13^{\prime}\end{array}$ & $\begin{array}{l}13^{\prime} \rightarrow \\
14^{\prime}\end{array}$ & $\begin{array}{l}14^{\prime} \rightarrow \\
15^{\prime}\end{array}$ & $\begin{array}{c}15^{\prime} \rightarrow \\
16^{\prime}\end{array}$ \\
\hline $\begin{array}{l}\mathbf{C}_{\mathbf{t}} \rightarrow \mathbf{C}_{\mathrm{t}+1} \\
\text { (Conditional) }\end{array}$ & $0.0 \%$ & $0.0 \%$ & $6.1 \%$ & $0.0 \%$ & $0.0 \%$ & $19.0 \%$ & $11.5 \%$ & $11.5 \%$ & $25.5 \%$ & $28.1 \%$ & $40.0 \%$ & $36.9 \%$ & $51.4 \%$ & $56.4 \%$ \\
\hline $\begin{array}{c}\mathbf{D J} / \mathbf{N E}_{\mathbf{t}} \\
\rightarrow \mathbf{C}_{\mathrm{t}+1} \\
(\mathrm{Other} \\
\mathrm{job} / \mathrm{NE})\end{array}$ & $56.3 \%$ & $63.2 \%$ & $39.4 \%$ & $52.9 \%$ & $40.8 \%$ & $41.0 \%$ & $33.7 \%$ & $40.5 \%$ & $34.8 \%$ & $31.9 \%$ & $30.8 \%$ & $27.5 \%$ & $31.3 \%$ & $25.3 \%$ \\
\hline $\begin{array}{l}\mathbf{B}_{\mathrm{t}} \rightarrow \mathbf{C}_{\mathrm{t}+1} \\
(\text { Secure Job) }\end{array}$ & $25.0 \%$ & $26.3 \%$ & $42.4 \%$ & $29.4 \%$ & $48.7 \%$ & $28.6 \%$ & $31.7 \%$ & $33.1 \%$ & $25.2 \%$ & $26.0 \%$ & $13.1 \%$ & $20.5 \%$ & $2.7 \%$ & $2.1 \%$ \\
\hline $\mid \begin{array}{l}\mathbf{A}_{\mathbf{t}} \rightarrow \mathbf{C}_{\mathbf{t + 1}} \\
(\text { Fixed-term) }\end{array}$ & $6.3 \%$ & $5.3 \%$ & $3.0 \%$ & $5.9 \%$ & $2.6 \%$ & $1.9 \%$ & $2.4 \%$ & $2.7 \%$ & $3.2 \%$ & $3.7 \%$ & $3.7 \%$ & $3.3 \%$ & $4.3 \%$ & $3.8 \%$ \\
\hline $\begin{array}{l}\mathbf{D}_{\mathbf{t}} \rightarrow \mathbf{C}_{\mathbf{t + 1}} \\
\text { (Involuntary) }\end{array}$ & $0.0 \%$ & $5.3 \%$ & $0.0 \%$ & $5.9 \%$ & $1.3 \%$ & $1.9 \%$ & $1.4 \%$ & $4.3 \%$ & $5.5 \%$ & $4.2 \%$ & $5.5 \%$ & $6.2 \%$ & $4.5 \%$ & $5.6 \%$ \\
\hline $\begin{array}{l}\mathbf{E}_{\mathbf{t}} \rightarrow \mathbf{C}_{\mathbf{t}+1} \\
\text { (Voluntary) }\end{array}$ & $0.0 \%$ & $0.0 \%$ & $3.0 \%$ & $5.9 \%$ & $1.3 \%$ & $1.0 \%$ & $1.4 \%$ & $3.5 \%$ & $1.6 \%$ & $2.4 \%$ & $2.9 \%$ & $2.7 \%$ & $2.0 \%$ & $2.1 \%$ \\
\hline $\begin{array}{l}\mathbf{U}_{\mathbf{t}} \rightarrow \mathbf{C}_{\mathrm{t}+1} \\
(\text { Unknown) }\end{array}$ & $0.0 \%$ & $0.0 \%$ & $6.1 \%$ & $0.0 \%$ & $0.0 \%$ & $19.0 \%$ & $11.5 \%$ & $11.5 \%$ & $25.5 \%$ & $28.1 \%$ & $40.0 \%$ & $36.9 \%$ & $51.4 \%$ & $56.4 \%$ \\
\hline $\begin{array}{l}\text { (Total } \\
\text { number } \\
\left.\text { of } C_{t+1}\right)\end{array}$ & $\begin{array}{l}100 \% \\
(16)\end{array}$ & $\begin{array}{l}100 \% \\
(19)\end{array}$ & $\begin{array}{l}100 \% \\
(33)\end{array}$ & $\begin{array}{l}100 \% \\
(17)\end{array}$ & $\begin{array}{l}100 \% \\
(76)\end{array}$ & $\begin{array}{l}100 \% \\
(105)\end{array}$ & $\begin{array}{l}100 \% \\
(208)\end{array}$ & $\begin{array}{l}100 \% \\
(375)\end{array}$ & $\begin{array}{l}100 \% \\
(440)\end{array}$ & $\begin{array}{l}100 \% \\
(623)\end{array}$ & $\begin{array}{l}100 \% \\
(513)\end{array}$ & $\begin{array}{l}100 \% \\
(517)\end{array}$ & $\begin{array}{l}100 \% \\
(560)\end{array}$ & $\begin{array}{l}100 \% \\
(573)\end{array}$ \\
\hline
\end{tabular}

Figure 2.6. Transition patterns in a job: Employment arrangement $t_{t} / C_{t+1}(\%)$

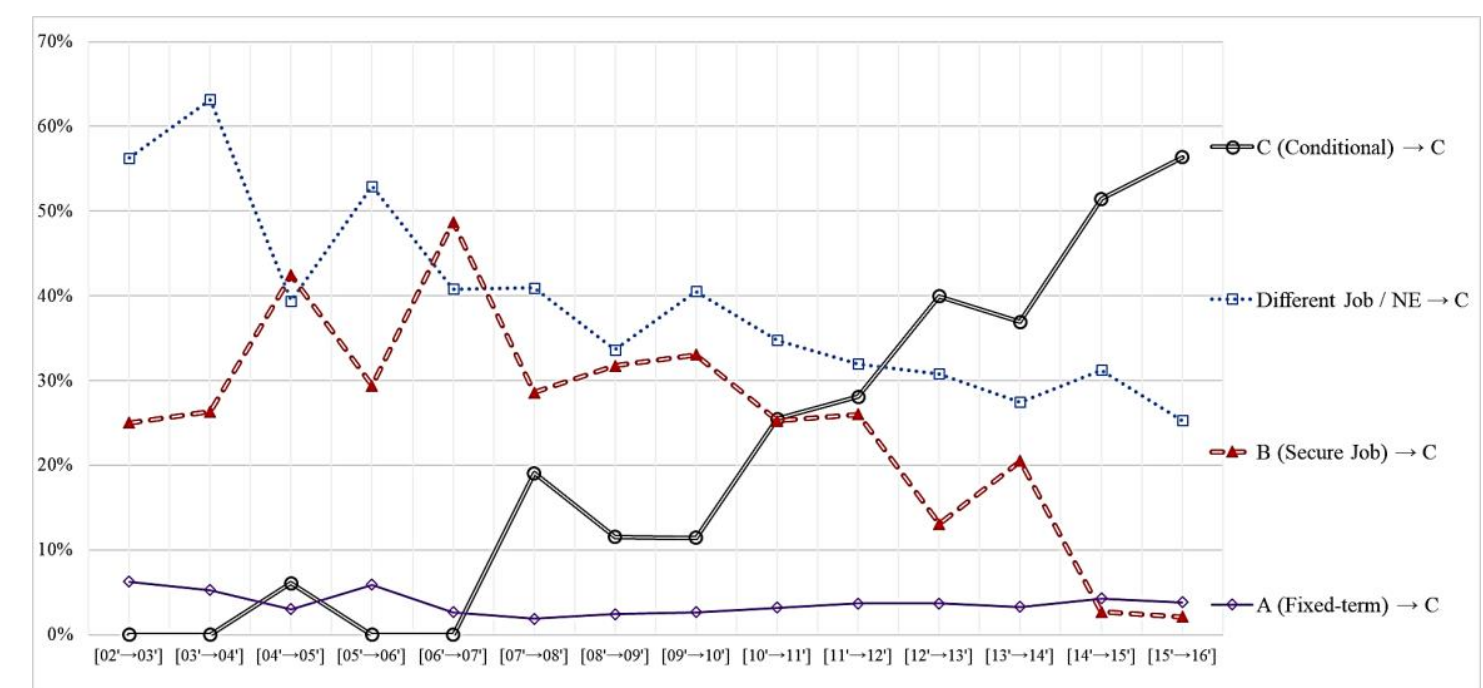

Lastly, to answer the third question - (iii) What is the chance for other statuses of moving to conditional employment?, the same kinds of movements $\left(\mathrm{C}_{\mathrm{t}} \rightarrow \mathrm{C}_{\mathrm{t}+1}, \mathrm{~B}_{\mathrm{t}} \rightarrow \mathrm{C}_{\mathrm{t}+1}, \mathrm{~A}_{\mathrm{t}} \rightarrow \mathrm{C}_{\mathrm{t}+1}\right.$, etc. $)$ as in Table 2.10. are considered, but the source job is used as the denominator. 
Table 2.15. Changes in movements between worker groups: $C_{\boldsymbol{t}+1} /$ Employment arrangement $\boldsymbol{t}(\%)$

\begin{tabular}{|c|c|c|c|c|c|c|c|c|c|c|c|c|c|c|}
\hline & \multicolumn{14}{|c|}{$\frac{C_{\boldsymbol{t}+\mathbf{1}}}{\text { Employment arrangement }_{\boldsymbol{t}}} \times 100$} \\
\hline & $\begin{array}{l}02^{\prime} \rightarrow \\
03^{\prime}\end{array}$ & $\begin{array}{r}03^{\prime} \rightarrow \\
04^{\prime}\end{array}$ & $\begin{array}{l}04^{\prime} \rightarrow \\
05^{\prime}\end{array}$ & $\begin{array}{l}05^{\prime} \rightarrow \\
06^{\prime}\end{array}$ & $\begin{array}{l}06^{\prime} \rightarrow \\
07^{\prime}\end{array}$ & $\begin{array}{l}07^{\prime} \rightarrow \\
08^{\prime}\end{array}$ & $\begin{array}{l}08^{\prime} \rightarrow \\
09^{\prime}\end{array}$ & $\begin{array}{l}09^{\prime} \rightarrow \\
10^{\prime}\end{array}$ & $\begin{array}{l}10^{\prime} \rightarrow \\
11^{\prime}\end{array}$ & $\begin{array}{l}11^{\prime} \rightarrow \\
12^{\prime}\end{array}$ & $\begin{array}{l}12^{\prime} \rightarrow \\
13^{\prime}\end{array}$ & $\begin{array}{l}13^{\prime} \rightarrow \\
14^{\prime}\end{array}$ & $\begin{array}{l}14^{\prime} \rightarrow \\
15^{\prime}\end{array}$ & $\begin{array}{l}15^{\prime} \rightarrow \\
16^{\prime}\end{array}$ \\
\hline $\begin{array}{l}\mathbf{C}_{\mathbf{t}} \rightarrow \mathbf{C}_{\mathrm{t}+1} \\
\text { (Conditional) }\end{array}$ & $0.0 \%$ & $0.0 \%$ & $10.5 \%$ & $0.0 \%$ & $0.0 \%$ & $26.3 \%$ & $22.9 \%$ & $20.7 \%$ & $29.9 \%$ & $39.8 \%$ & $32.9 \%$ & $37.2 \%$ & $55.7 \%$ & $57.7 \%$ \\
\hline $\begin{array}{l}\mathbf{B}_{\mathrm{t}} \rightarrow \mathbf{C}_{\mathrm{t}+1} \\
(\text { Secure Job) }\end{array}$ & $0.1 \%$ & $0.1 \%$ & $0.4 \%$ & $0.2 \%$ & $1.0 \%$ & $0.8 \%$ & $1.8 \%$ & $3.0 \%$ & $2.8 \%$ & $4.0 \%$ & $1.8 \%$ & $2.7 \%$ & $0.4 \%$ & $0.3 \%$ \\
\hline $\begin{array}{l}\mathbf{A}_{\mathbf{t}} \rightarrow \mathbf{C}_{\mathbf{t}+1} \\
\text { (Fixed-term) }\end{array}$ & $0.6 \%$ & $0.4 \%$ & $0.5 \%$ & $0.4 \%$ & $0.6 \%$ & $0.5 \%$ & $1.7 \%$ & $2.1 \%$ & $2.8 \%$ & $4.5 \%$ & $3.4 \%$ & $3.0 \%$ & $3.7 \%$ & $3.5 \%$ \\
\hline 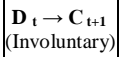 & $0.0 \%$ & $3.2 \%$ & $0.0 \%$ & $2.2 \%$ & $2.5 \%$ & $5.0 \%$ & $3.8 \%$ & $12.9 \%$ & $13.5 \%$ & $16.7 \%$ & $13.7 \%$ & $15.8 \%$ & $16.1 \%$ & $17.8 \%$ \\
\hline $\begin{array}{l}\mathbf{E}_{\mathbf{t}} \rightarrow \mathbf{C}_{\mathbf{t}+1} \\
\text { (Voluntary) }\end{array}$ & $0.0 \%$ & $0.0 \%$ & $1.2 \%$ & $0.9 \%$ & $1.6 \%$ & $2.0 \%$ & $6.8 \%$ & $16.9 \%$ & $8.8 \%$ & $17.0 \%$ & $12.4 \%$ & $14.0 \%$ & $14.7 \%$ & $13.5 \%$ \\
\hline
\end{tabular}

Figure 2.7. Transition patterns in a job: $C_{t+1} /$ Employment arrangement $\boldsymbol{t}(\%)$

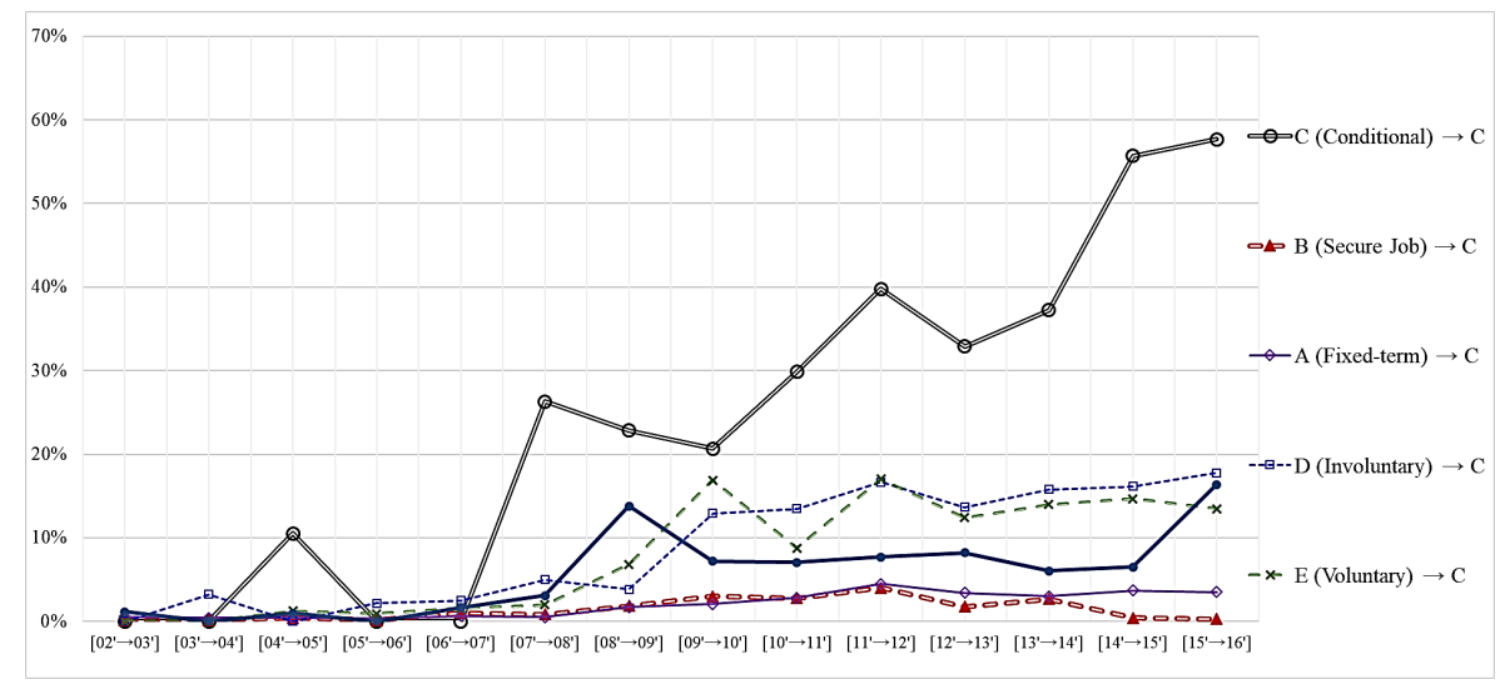

Table 2.14. and Figure 2.7. show how many workers in each employment arrangement at $t$ moved to conditional employment in the next year, $t+1$. According to the results, the share of the workers who moved into conditional employment at $t+1$ increased after the reform in all types of employment arrangements at $t$. Thus, the chance of moving to conditional employment increased for all types of employment arrangements. 
In addition, the increase in the share of the workers who remained in conditional employment is extraordinary: the share was less than $1 \%$ of the workers in conditional employment $\left(\mathrm{C}_{\mathrm{t}+1}\right)$ before the reform, but it started to increase dramatically after the reform, reaching about $55 \%$ of the workers in conditional employment $\left(\mathrm{C}_{\mathrm{t}+1}\right)$ at the end of our survey window.

In conclusion, it was not common to remain in conditional employment $(\mathrm{C})$ in two consecutive years before the reform, but the share of the workers who stayed in this group (C) increased dramatically right after the new regulation was introduced. Moreover, the chance of moving to conditional employment increased for all types of employment arrangements after the reform. Based on the results, we may guess conditional employment $(\mathrm{C})$ has been used as a way by which employers evade the regulation, substituting for fixed-term contract employment.

\subsection{Conclusion}

Employers always have an incentive to evade employment protection regulations by hiring workers in employment arrangements not subject to the regulations. This study examines if the Korean firms have evaded a new regulation by hiring uncovered workers. The Korean government proposed a labor market reform in 2007 to lower the incidence of temporary jobs and to protect temporary workers. The main policy change is to restrict the maximum duration of employment to two years in a job with a fixed-term contract.

First, this study examines whether the reform influences the transition of temporary into permanent employment, which can be thought of as one of the main goals of the reform. In fact, we do not find any evidence that the reform increased the probability of a change from temporary to permanent employment. On the contrary, fewer transitions to permanent employment occurred after the reform, while more people were hired on temporary contracts in the same period.

Second, this study tries to answer why there was no significant change in the transition from temporary to permanent employment after the reform. Previous studies on the Korean labor market reform suggested that 
the reform induced firms to use uncovered workers - those who were indirectly employed, such as temporary agency workers and workers provided by subcontract firms - undercutting the impact of the reform. In contrast, this study investigates if firms have found a way to evade the regulation but still hire workers directly. For this, we examine if the number of workers in alternative employment arrangements has changed significantly after the introduction of the regulation.

Our results suggest that firms changed human resource management practice in response to the new regulation, taking advantage of certain types of employment that are less likely to be subject to the new regulation. These types of employment include temporary workers (limited-period workers) whose employment contract is open-ended but also whose perceived level of job security is low. The proportion of this type of temporary workers increased from 2007 prior to the reform, accounting for more than half of total temporary workers after the reform. In addition, the increase in the proportion is barely explained by either worker or employer chracteristics. Rather, the reform has a statistically significant and positive effect on the probability of having the temporary jobs even after controlling for other covariates as well as the time effect.

More importantly, the increase in these employment types has been mainly driven by the increase in conditional employment - in which a worker was hired on the condition that the worker quit his/her job at the employer's request. The increase in the share of conditional employment is extraordinary: the share was less than $1 \%$ of total salary and wage workers before the reform, but it started to increase dramatically after the reform, reaching about 10\% of all workers in 2012 and remaining at that level until 2016.

We can think of reasons why conditional employment has been used as a way by which employers have evaded the regulation. First, Conditional employment is less likely to be subject to the regulation because the period of employment contract is not fixed when the worker was hired. Second, assuming the employee abides by the agreement, employment termination is up to an employer, so the employer can arrange for separation of a worker on conditional employment without worrying about an unjust dismissal complaint. Third, even when an employment termination is very likely to be deemed an unjust dismissal, the worker may agree to the employer's request for job termination rather than submitting a complaint. This is because the employment relation between employers and employees in Korea has been based on the hierarchical 
nature of Asian culture, and hence employees are subordinate to employers especially in a peripheral sector of the Korean labor market. For this reason, conditional employment may have been used as a way by which employers have evaded the regulation, resulting in a reduction in the reform policy's effect on the labor market. 


\title{
CHAPTER 3.
}

\section{Comparison of two popular labor surveys in Korea from the perspective of reported employment arrangements:}

\author{
Economically Active Population Survey and Korean Labor \& Income Panel Study
}

\subsection{Introduction}

In the previous study on the effect of 2007 Korean labor market reform, we found a sudden increase in alternative employment arrangements right after the introduction of the new regulation restricting the maximum length of fixed-term employment. The study interprets the results in terms of firms' incentives to evade the regulation. We suggest that firms changed human resource management practice in response to the new regulation, taking advantage of the alternative employment arrangements that are less likely to be subject to the new regulation. Such employment includes temporary workers whose employment contracts are openended and whose level of job security is low.

The results of the study were derived using the Korean Labor \& Income Panel Study (KLIPS) data that is one of the most popular labor market surveys in Korea. The KLIPS has an advantage in its panel structure and wide-ranging survey questions on economic activities and labor market mobility, and hence it has been used in many studies on the Korean labor market. The other most popular labor market survey in Korea is the Economically Active Population Survey (EAPS), which is cross sectional survey. Since the EAPS surveys more households and individuals than the KLIPS, it can be thought of as representing the Korean labor market better. Thus, the Korean ministry of labor has used the EAPS data to derive official labor market statistics such as the employment and unemployment rates. In addition, the survey questions to classify the employment types in Korea were first introduced to the EAPS in a supplemental survey in 2001. The KLIPS employed the same survey questions on the employment types in the next year, 2002.

The main purpose of the current is that verify if the upsurge of the alternative employment arrangements 
after the reform is found in the EAPS as well as in the KLIPS. For this, we compare the two labor market surveys, the EAPS and KLIPS, from the perspective of reported employment arrangements. The same survey questions in both the EAPS and KLIPS were used to classify the employment types of wage and salary workers. However, we are confronted with a puzzle because the results using the two data sets show different patterns of the shares of temporary worker groups over time. In the EAPS, the proportion of the total temporary workers and the proportion of fixed-term contract workers moved together, decreasing over time, which is contrary to the results using KLIPS data, in which the proportion of the total temporary workers and the proportion of fixed-term workers increased during the sample period. More importantly, we cannot find the same continued growth in the proportion of alternative employment arrangements after 2007 in the EAPS data, although we do observe a sudden increase of these employment arrangement once in 2009. Thus, the next question is why the two data sets give us totally different results in the proportion of worker groups, especially for temporary workers.

To answer as to what factor causes the different results in the two data sets, we investigate if there is any difference in demographic characteristics between the EAPS and KLIPS data due to changes in demographic characteristics, which may be associated with differences in the composition of wage and salary workers. First, we compare the employment rates and the proportions of wage and salary workers in the EAPS and KLIPS. Second, we investigate if there is any difference in demographic characteristics of the two data sets, considering age, gender, and educational attainment. Third, we compare the EAPS and KLIPS again but focusing on wage and salary workers. However, based on all these analyses, we cannot find any factor that explains the different pattern of the share of alternative employment arrangements in the EAPS and KLIPS. We find small difference in the share of women among wage and salary workers between the EAPS and KLIPS, but it is not large enough to explain the different pattern in the EAPS and KLIPS. Therefore, we conclude the differences in demographic characteristics between the EAPS and KLIPS are not a main factor in causing different results in the two data sets.

This study consists of the following sections. First, I explain classification of employment types in Korea to help the reader to understand the institutional background of the Korean labor market. Second, I explain briefly the most popular labor market surveys in Korean, the EAPS and KLIPS, and then introduce survey 
questions in both the EAPS and KLIPS to classify employment types. Third, I verify if the upsurge of the alternative employment arrangements after the reform is found in the EAPS as well as KLIPS using the survey questions on employment types. However, we are confronted with a puzzle because the results using the two data sets show different patterns of the shares of temporary worker groups over time. Finally, I investigate if there is any difference in demographic characteristics between the EAPS and KLIPS data sets to answer as to what factor may cause the discrepant results in the two data sets.

\subsection{Classification of employment types in Korea}

Employment types in Korea are classified into standard and non-standard employment (see Table 3.1.). Standard employment is considered as having the following characteristics: (i) the period of employment contract is not fixed (or is permanent), (ii) the employee works full-time, (iii) the employer and the labor user are not different, (iv) the employee works on a physical workplace that is provided by the employer. Forms of employment that do not satisfy all these standards can be thought of as non-standard employment, which can be divided into three subcategories: (i) Temporary workers (or limited-period workers), (ii) Part-time workers, (iii) Atypical workers.

First, the category of temporary workers emphasizes the limited duration of work regardless of whether the period of employment contracts is pre-specified. One group of workers in this category consists of fixedterm employees whose contract period is specified in advance. The other group consists of workers with open-ended contracts but who expect limited duration of their work for involuntary reasons. The reason for such a definition based on the expected duration is that there is no universal practice of signing a written employment contract in Korea (Grubb et al., 2007).

Second, part-time workers are workers whose working week is shorter than that of full-time workers (usually 40-hour working week) with the same job in the same workplace.

Third, the category of atypical workers includes unconventional employment arrangement such as temporary agency workers (or dispatched workers), workers provided by subcontract firms, independent 
contractors (or individual contract workers), at-home workers (or domestic worker/helper), and on-call workers.

Table 3.1. The classification of employment types in Korea

\begin{tabular}{|c|c|c|}
\hline $\begin{array}{c}\text { I. } \\
\text { Standard } \\
\text { Employment }\end{array}$ & \multicolumn{2}{|c|}{$\begin{array}{l}\text { The period of employment contract is not fixed. } \\
\text { The employee works full-time. } \\
\text { The employer and the labor user are not different. } \\
\text { ○ The employee works on a physical workplace provided by the employer. }\end{array}$} \\
\hline \multirow{8}{*}{$\begin{array}{l}\text { II. } \\
\text { Non-standard } \\
\text { Employment }\end{array}$} & \multirow{2}{*}{$\begin{array}{l}\text { 1. Temporary workers } \\
\text { (Limited-period workers) }\end{array}$} & (1) Workers with fixed-term contracts \\
\hline & & $\begin{array}{l}\text { (2) Workers with open-ended contracts but who expect } \\
\text { limited duration of their work for involuntary reasons }\end{array}$ \\
\hline & 2. Part-time workers & $\begin{array}{l}\text { Workers whose working week is shorter than that of } \\
\text { workers considered full-time with the same job in the } \\
\text { same workplace }\end{array}$ \\
\hline & \multirow{5}{*}{ 3. Atypical workers } & (1) Temporary agency workers (dispatched workers) \\
\hline & & (2) Workers provided by subcontract firms \\
\hline & & (3) Independent contractors (individual contract workers) \\
\hline & & (4) At-home workers (domestic worker/helper) \\
\hline & & (5) On-call workers \\
\hline
\end{tabular}

\subsection{Measurement of the number of temporary workers in the EAPS and KLIPS}

\subsubsection{Brief explanation of the EAPS and KLIPS}

\section{(1) The Economically Active Population Survey (EAPS)}

The Economically Active Population Survey (EAPS) is the official monthly labor force survey of Korea. It collects information on an individual's employment status in the previous week and other demographic characteristics for about 35,000 households and 70,000 individuals in Korea. It surveys members of selected sample households who live in the households and are fifteen years old older. In 2005, EAPS adopted a rotation sampling system in which a selected sample household remains in the sample for thirty-six months and after that the household is removed from the sample: about 970 households $-1 / 36$ of the total sample (35,000 households) - are replaced every month. Accordingly, the ratio of overlapping sample is $35 / 36$ 
compared to the previous month and 24/36 compared to the same month in the previous year.

EAPS has been carried out since 1963 and its main objective is to collect data on the labor force and its various categories (employed, unemployed) as well as on the population outside the labor market (inactive). It was a quarterly survey at first, but it became monthly in 1982. Since then, the Korean ministry of labor has announced basic statistics for national economic activities such as the employment and unemployment rate every month based on the survey. In addition, the EAPS data set has been submitted to international organizations such as the Organization for Economic Cooperation and Development (OECD) and the International Labour Organization (ILO).

A supplemental survey was added to EAPS in 2001 to investigate various employment types in the Korea labor market. The supplemental survey of EAPS has been carried out once a year (every August) since 2001.

\section{(2) The Korean Labor \& Income Panel Study (KLIPS)}

The Korean Labor \& Income Panel Study (KLIPS) is a longitudinal study of a representative sample of Korean households and individuals living in urban areas. Starting from 1998, the panel survey has been conducted annually on a sample of about 5,000 households and members of the households (all members aged fifteen or older). It collects information on households' demographics as well as economic activities, labor market mobility, income and consumption, education, and vocational training. The original sample consisted of about 5,000 households; 13,321 individuals in the households responded in 1998.

KLIPS is a household panel, and hence it surveys not only original households but also branched households - households that were generated from the original households in the event that some members of the original households move out and form new families. On the other hand, the size of the original sample diminished over time as some households left the original sample. To address problems of representability caused by sample attrition, 1,415 households were added to the original sample in 2009 . Thus, the number of the consolidated sample households in 2009 is 6,721 , which consists original sample households $(3,657)$, branched households $(1,649)$, and newly added households $(1,415)$. 


\subsubsection{Survey questions in the EAPS and KLIPS to classify the temporary (limited-period) workers}

The extent of temporary (limited-period) employment in Korea has been measured based on a supplemental survey of the Economically Active Population Survey (EAPS), which consists of various questions about types of employment. The supplemental survey of EAPS has been carried out once a year by Statistics Korea (Korea's statistical agency) since the EAPS was established in 2001.

In 2002, the Korean Labor \& Income Panel Study (KLIPS) also added questions on the classification of employment arrangements to its fifth wave questionnaires. These questions are almost the same as the questions in the EAPS supplemental survey. Since then, the KLIPS has provided information on alternative employment arrangements.

Table 3.2. shows the structure of survey questions on employment contracts and workers' perceived job security. Using the four questions $Q 1-Q 4$ in Table 3.2., we can identify the number of temporary workers (or limited-period workers) in the Korean labor market. To distinguish worker groups easily according to workers' answers to the four questions, I have assigned alphabetic codes to each answer to the four questions.

According to the official classification of employment types suggested in the previous section (refer to Table 3.1.), temporary workers (or limited-period workers) are categorized into two groups: workers with fixed-term contracts and workers with open-ended contracts but who expect limited duration of their work for involuntary reasons. The first group of temporary workers - fixed-term contract workers (A) in Table 3.2. - accounts for more than half of all temporary workers (A, B2, C, D1-D5). Fixed-term contract workers (A) are explicitly subject to the new regulation that restricts the maximum length of fixed-term employment with one employer.

The other group of temporary workers consists of workers with open-ended contracts but who expect limited duration of work for involuntary reasons (B2, C, D1-D5). We consider this second group of temporary workers too because it is often unclear how to distinguish these workers from fixed-term contract workers empirically. In the sample of the KLIPS data set, we observe many workers whose reported employment type changed back and forth between the first and second groups of temporary workers throughout a job spell with the same employer. In addition, workers who fall into the second group of temporary workers (B2, C, 
D1-D5) could be subject to the new regulation, even if their contract periods were not determined when they signed contracts. For example, if a worker's employment continues over two years through repeated renewal of his/her contract without specifying a contract period, then an employer of the worker can be deemed to violate the regulation according to a decision of the Korean Labor Relation Commission. In practice, however, workers seem reluctant to submit complaints to the commission since workers fear a negative reaction from their employers.

It is necessary to understand the structure of the survey questions through which the number of temporary workers is measured because some temporary workers may be subject to the new regulation, whereas others may not be.

First, as presented in Table 3.2., all the wage and salary workers are asked whether their employment contract period is fixed in advance: [Q1] Was the period of an employment contract determined when you (a worker) were hired on the job $?^{22}$ If a worker answers 'Yes' to the first question, then the worker is classified as a fixed-term employee (A), who falls under the first group of temporary workers (Temp (1)).

Second, if a worker says ' $N o$ ' to the first question, then the second question on job security follows: [Q2] Unless the firm discontinues its business or lay off workers due to financial exigency, or you do something wrong, can you continue your current job in the firm as long as you want? One thing to be kept in mind here is that the job security surveyed in the second question is the worker's subjective perception of job security in the current employment.

Third, the reason that the job is secure is asked if a worker answered 'Yes' to the second question: [Q3] What is the reason for answering 'Yes' to the second question? There are three options (see Table 3.2.). If a worker chooses '(2) Employment continues with repeated renewal of a contract', then the worker falls under the second group of temporary workers - those hired on an open-ended contract but with expected limited duration (Temp (2) - B2, C, D1-D5).

Fourth, the reason for an insecure job is asked if a worker answered ' $N o$ ' to the second question: [Q4]

\footnotetext{
${ }^{22}$ The survey questions are originally written in Korean and translated by the author. Full sentences of the questions are provided in the Appendix (Table B1).
} 
What is the reason for answering 'No' to the second question? There are eleven options, of which the first six options (1) - (6) are involuntary reasons for expected termination of current employment (see Table 3.2. for details). Workers - who chose options (1) through (6) - fall into the second group of temporary workers (Temp (2) - B2, C, D1-D5) as well.

Both the EAPS and KLIPS employ the same questions $(Q 1-Q 4)$ to classify the types of temporary workers. Thus, we can compare the number of temporary workers in the EAPS and KLIPS using the four survey questions. In the next section, we examine if the two major labor market surveys in Korea, the EAPS and KLIPS, show similar pattern of the number of each employment types and the number of subgroups of temporary workers. Furthermore, we examine whether the second type of temporary employment (C, D1D5) increased after the introduction of 2007 labor market reform based on the supplemental survey of EAPS. 
Table 3.2. The structure of questions on employment contracts and workers' perceived job security

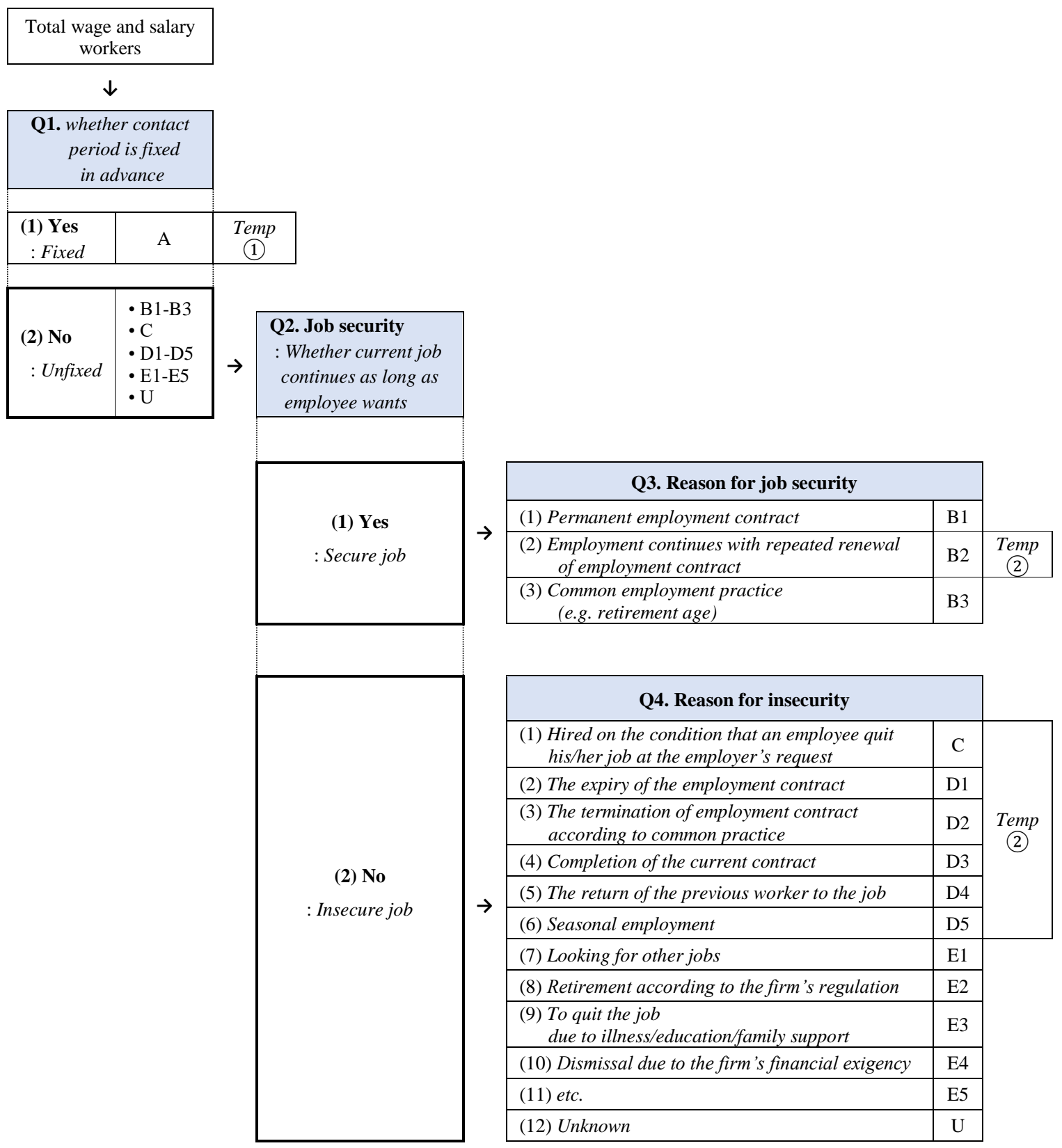

Note) 1. Temp (1) stands for the first group of temporary workers (or limited-period workers) that includes workers with fixed-term contracts. Тemp (2) stands for the second group of temporary workers, which consists of workers with open-ended contracts but who expect limited duration of their work for involuntary reasons.

2. The survey questions are originally written in Korea and translated by the author. Full sentences of the questions can be found in the Appendix (Table C1). 


\subsubsection{Changes in alternative employment arrangements in the EAPS and KLIPS}

The total number of wage and salary workers and the number of workers who chose each answer to the four questions (Q1-Q4) are provided in the Appendix (Tables A2-A5). Figure 3.1. shows changes in the share of various worker groups in the total wage and salary workers over time. One thing to be kept in mind here is that the proportion of worker groups in this section is derived using sample weights of the EAPS and KLIPS data. Although only the results with the use of sample weights are provided in this paper, the author examined the results with no use of sample weights as well and confirmed the proportions of various worker groups are almost the same whether the sample weights are used or not. Tables A2-A5 in the Appendix provide the results with and without using sample weights. The proportion of temporary worker groups differs by not more than 1.0 percentage point in each data set according to whether the sample weights are used or not.

In Figure 3.1., the first panel shows the proportion of worker groups in the total wage and salary workers derived from the supplemental survey of the EAPS, and the second panel provides the proportion from the KLIPS. The share of secure jobs (B1-B3) increased slightly over time in the EAPS (72\% in 2004 to $77 \%$ in 2014) even though the share decreased significantly in the KLIPS ( $85 \%$ in 2004 to $72 \%$ in 2014). As opposed to the share of secured jobs, the proportion of the total temporary workers (A, C, D1-D5) decreased slightly during the sample period in the EAPS ( $20 \%$ in 2004 to $17 \%$ in 2014), while the proportion of the same worker group increased significantly over time in the KLIPS (7\% in 2004 to $20 \%$ in 2014). 
Figure 3.1. The proportions of worker groups in the total wage and salary workers

\section{(1) EAPS}

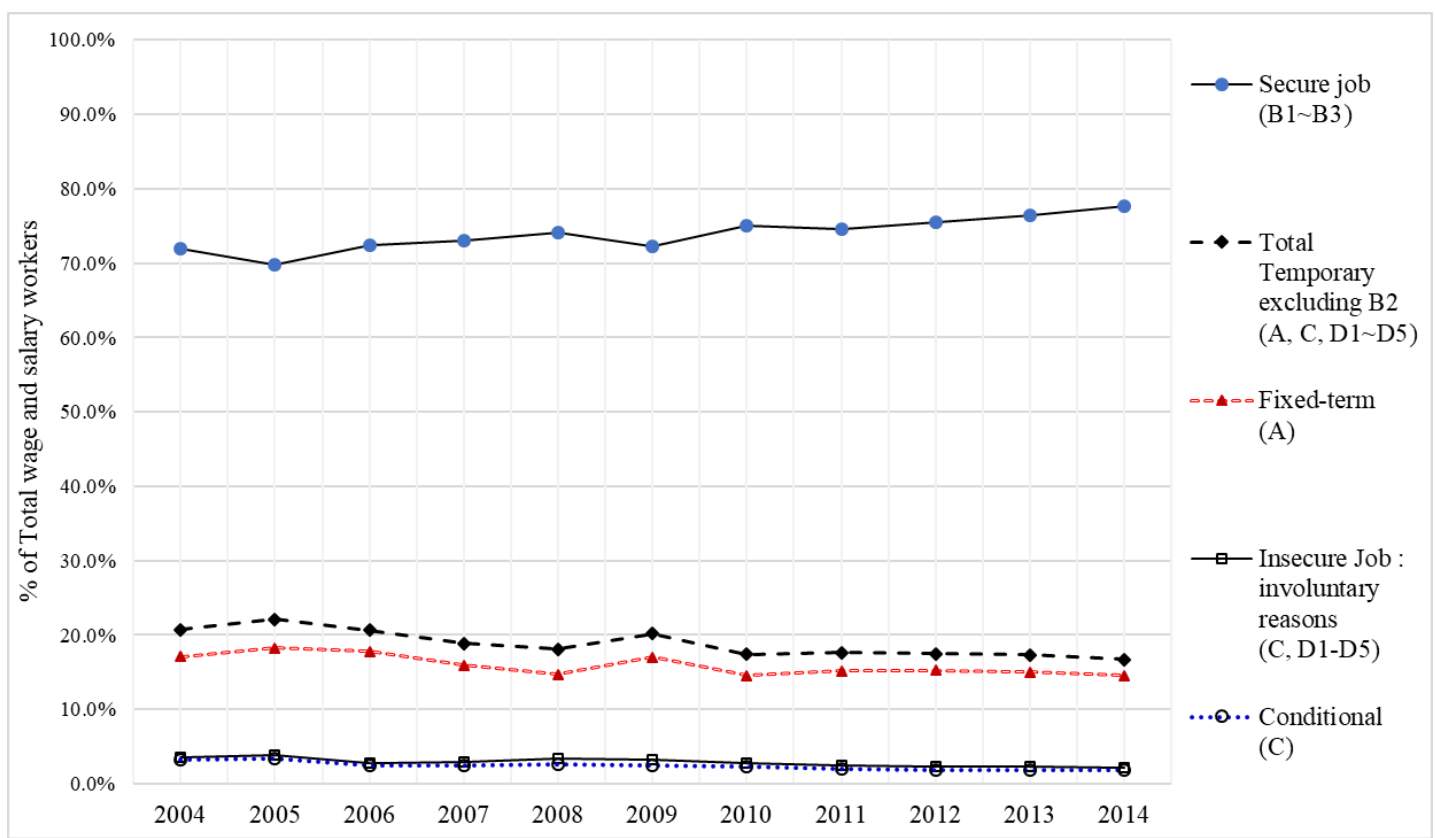

\section{(2) KLIPS}

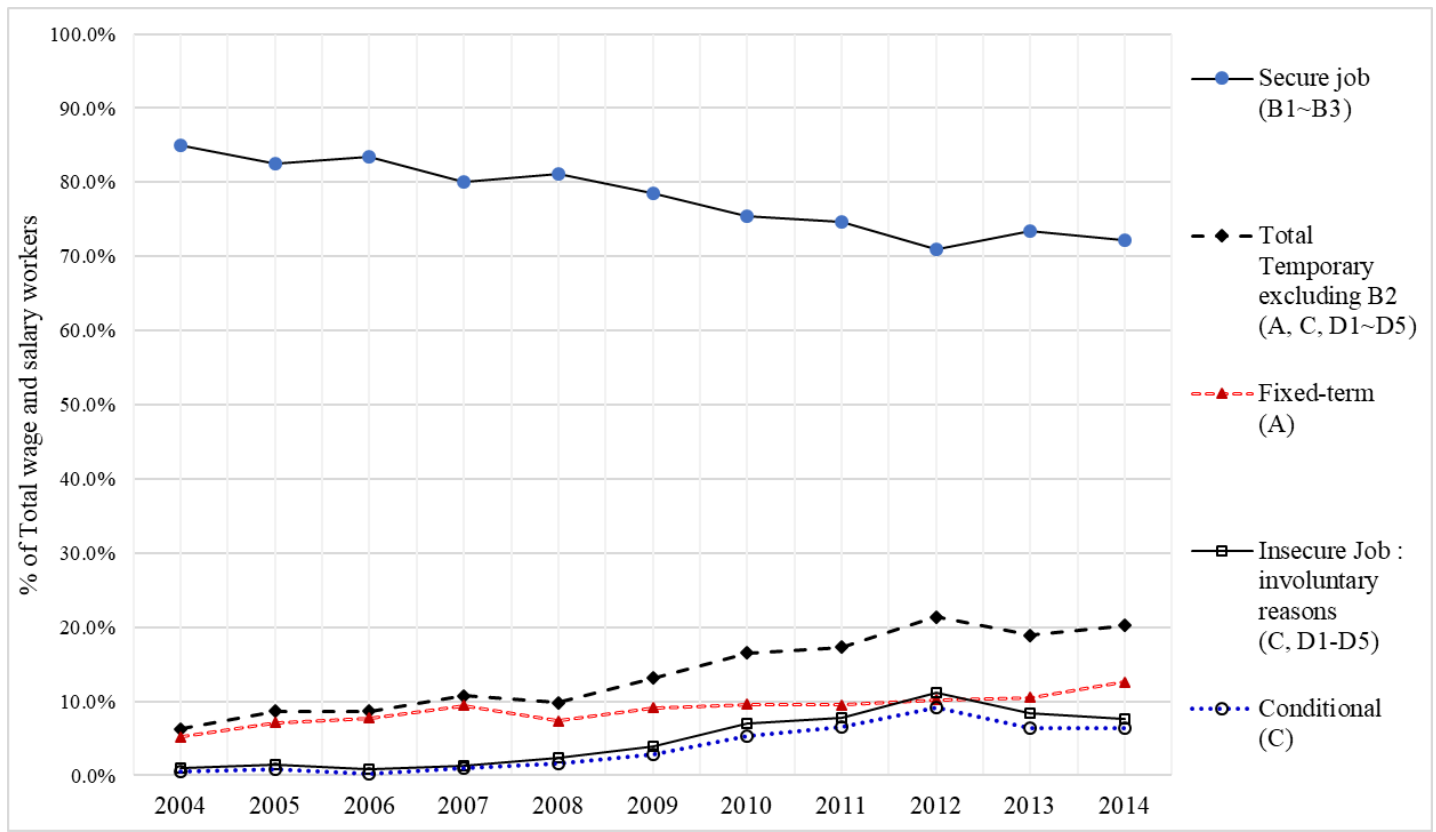


Figure 3.2. shows the proportion of subgroups of temporary workers in detail, comparing the results from the EAPS and KLIPS. First, according to the result from the EAPS, the proportion of the total temporary workers and the proportion of fixed-term contract workers show very similar pattern, and fixed-term contract workers consistently accounted for about $80-85 \%$ of the total temporary worker in the sample period. According to the result from the KLIPS, the proportion of the total temporary workers and that of fixed-term workers move together until 2007, but the gap between the two proportions started to widen after 2007. The fixed-term workers accounted for $83 \%$ initially but had declined to $55-60 \%$ of the total temporary workers at the end of the sample period. Second, the proportion of insecure jobs with involuntary reasons (C, D1-D5) stayed the same or decreased slightly over time in the EAPS (at $3.6 \%$ to $2.2 \%$ ), while the proportion of the insecure jobs (C, D1-D5) increased after 2007 in the KLIPS (from 1.3\% to 8\%). The latter increase is mainly due to an increase in the number of conditional employment $(\mathrm{C})$.

Surprisingly, the two popular data sets on Korean labor market - the EAPS and KLIPS - show totally different patterns in terms of the proportion of worker groups. More importantly, we cannot find the continued growth in the proportion of the total temporary employment after 2007 from the results using the EAPS data although there was a sudden increase of the total temporary employment once in 2009 (from $18.1 \%$ in 2008 to $20.2 \%$ in 2009 ). The next question is why the two data sets give us totally different results in the proportion of worker groups, especially for temporary workers. To answer this question, we investigate in the next section if there are differences in demographic characteristics between the EAPS and KLIPS data sets that could explain these differences. 
Figure 3.2. The proportions of temporary worker groups in the total wage and salary workers

\section{(1) EAPS}

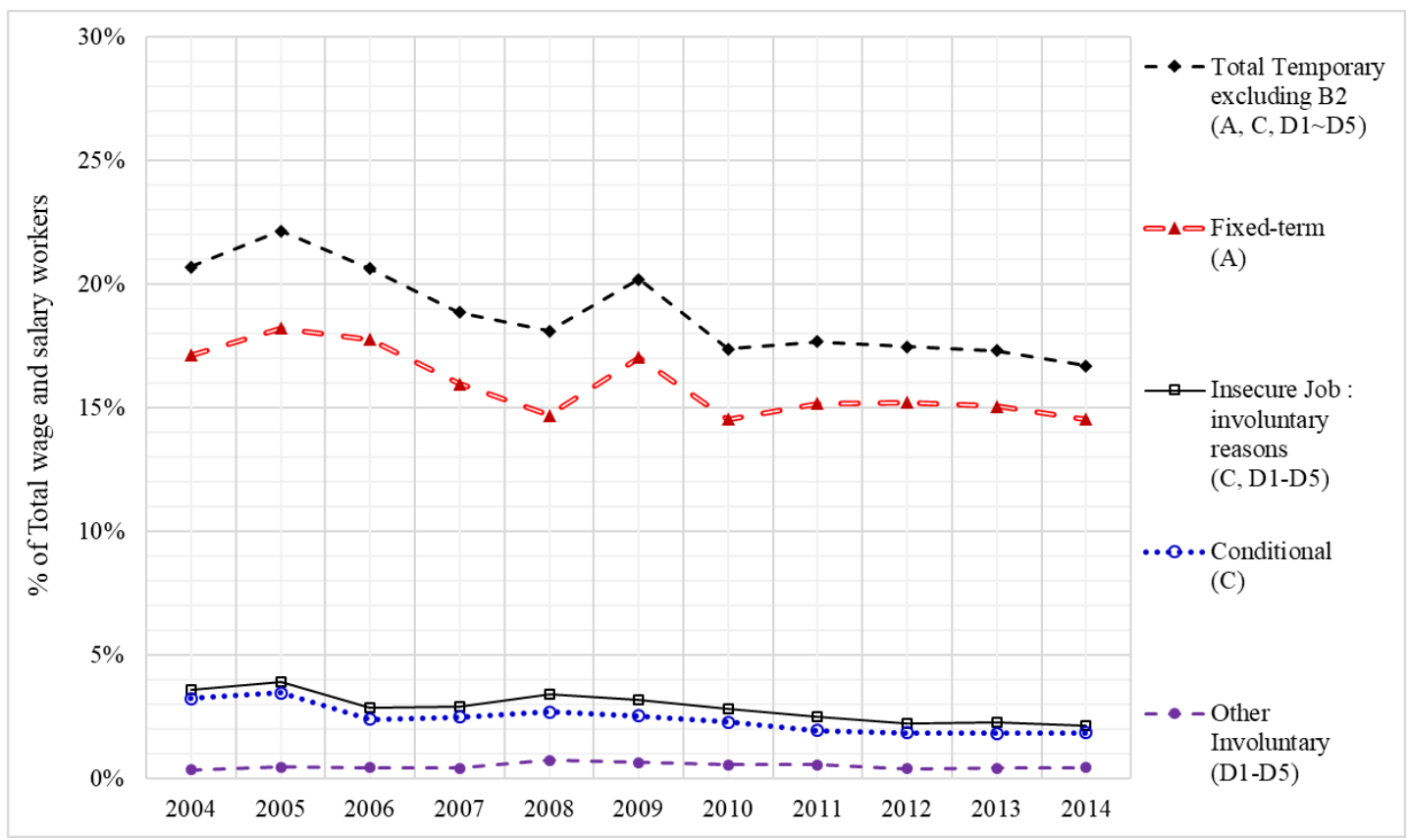

(2) KLIPS

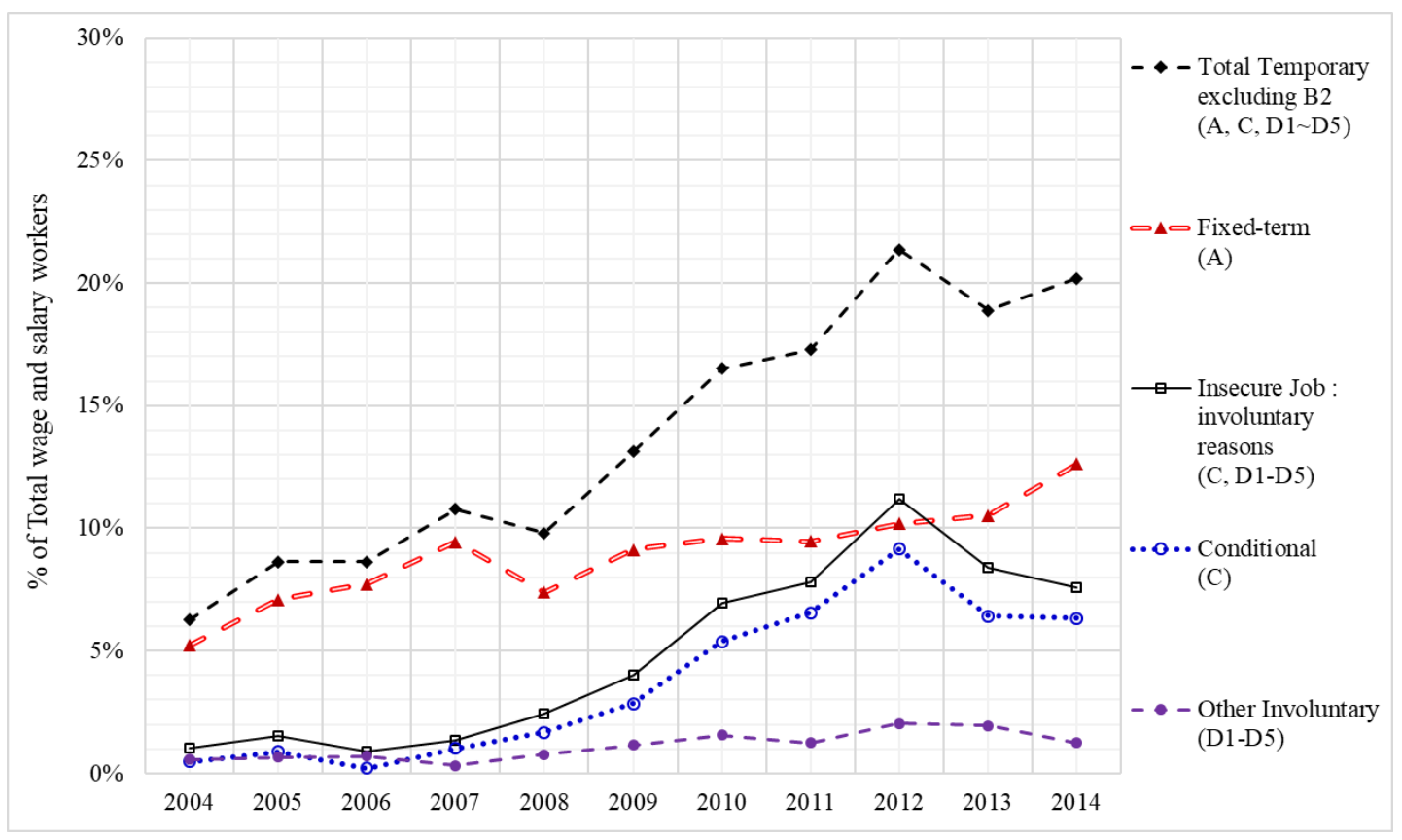




\subsection{Comparison of the EAPS and KLIPS in demographic characteristics}

In the previous section, we were confronted with a puzzle that the two data sets, the EAPS and KLIPS, show different patterns of the share of temporary workers over time. In the EAPS, the proportion of the total temporary workers and the proportion of fixed-term contract workers moved together, decreasing over time except for a sudden temporary increase in 2009. In contrast, in the KLIPS the proportion of the total temporary workers and that of fixed-term workers increased overall in the sample period. In addition, the gap between the proportion of the total temporary workers and the proportion of fixed-term workers in KLIPS started to widen after 2007, which means the upsurge of temporary workers after 2007 is mainly due to the increase of employment identified as insecure jobs for involuntary reasons (C, D1-D5).

In this section, we try to answer as to what factors cause the opposite outcome in the two data sets. For this, we examine if there is any difference in the composition of the total population. (Here, the total population stands for the people aged 15 and over since both the EAPS and KLIPS survey only the people who are eligible for economic activities - the people aged 15 and over.) First, we compare the employment rates and the proportions of wage and salary workers in the two data sets. Second, we investigate if there are differences in the demographic characteristics of the population in the two data sets, focusing on age, gender, and educational attainment. Third, we compare the demographic characteristics of the EAPS and KLIPS populations again focusing on wage and salary workers.

\subsubsection{Employment rates and the proportion of wage and salary workers in the total population}

Table 3.3. shows the share of the employed in the total population in the sample period. The results in the panels (1) and (2) were derived using the EAPS and KLIPS data, respectively: the number of the employed is provided in the first row; the number of the total population aged 15 and over is in the last row; the employment rate $\left(E m p_{t}^{E A P S}\right.$ or $\left.E m p_{t}^{K L I P S}\right)$ in each year $(t)$ - the proportions employed in the total population - is provided in the second row. In the panel (3), the difference in the two employment rates $\left(E m p_{t}^{E A P S}-\right.$ $E m p_{t}^{K L I P S}$ ) in each year is provided, and the difference seems to decrease over time. The last two columns in the panel (3) show the average of the differences and correlation between the two series of employment rates 
$\left(E m p_{t}^{E A P S}\right.$ and $\left.E m p_{t}^{K L I P S}\right)$. Overall, the employment rate of the EAPS is about 3-6 percentage points higher than the employment rate of the KLIPS, but they tend to move together since the correlation between $E m p_{t}^{E A P S}$ and $E m p_{t}^{K L I P S}$ is 0.55 . Thus, the difference in two employment rates is not enough to explain the different patterns of the shares of temporary worker groups. Next, we examine the share of wage and salary workers among employed workers since temporary workers are a subset of wage and salary workers.

Table 3.3. Employment rates in the EAPS and KLIPS

(1) Employment rate in the EAPS: $E m p_{t}^{E A P S}$

\begin{tabular}{|c|c|c|c|c|c|c|c|c|c|c|c|c|}
\cline { 2 - 12 } \multicolumn{1}{c|}{} & \multicolumn{70}{c|}{ Year $(t)$} & 2003 & 2004 & 2005 & 2006 & 2007 & 2008 & 2009 & 2010 & 2011 & 2012 & 2013 & 2014 \\
\cline { 2 - 12 } \multicolumn{1}{c|}{} & 2003 & \\
\hline $\begin{array}{c}\text { The number } \\
\text { of the } \\
\text { employed }\end{array}$ & $22,210,465$ & $22,522,872$ & $22,778,455$ & $23,211,144$ & $23,582,137$ & $23,824,449$ & $23,797,109$ & $24,214,456$ & $24,783,379$ & $25,120,357$ & $25,513,378$ & $26,182,889$ \\
\hline $\begin{array}{c}\text { Emp } \\
t\end{array}$ & $59.3 \%$ & $59.6 \%$ & $59.7 \%$ & $60.0 \%$ & $60.1 \%$ & $59.8 \%$ & $59.0 \%$ & $59.2 \%$ & $59.8 \%$ & $59.9 \%$ & $60.2 \%$ & $61.1 \%$ \\
\hline $\begin{array}{c}\text { Total } \\
\text { population } \\
\text { aged 15 \& } \\
\text { over) }\end{array}$ & $37,461,236$ & $37,818,006$ & $38,158,056$ & $38,708,506$ & $39,250,697$ & $39,851,379$ & $40,366,649$ & $40,889,736$ & $41,458,758$ & $41,909,756$ & $42,359,276$ & $42,860,496$ \\
\hline
\end{tabular}

(2) Employment rate in the KLIPS: $E m p_{t}^{K L I P S}$

\begin{tabular}{|c|c|c|c|c|c|c|c|c|c|c|c|c|}
\hline & \multicolumn{12}{|c|}{ Year $(t)$} \\
\hline & 2003 & 2004 & 2005 & 2006 & 2007 & 2008 & 2009 & 2010 & 2011 & 2012 & 2013 & 2014 \\
\hline $\begin{array}{l}\text { The number } \\
\text { of the } \\
\text { employed }\end{array}$ & $16,586,568$ & $16,628,888$ & $16,460,282$ & $16,417,498$ & $16,483,200$ & $16,710,402$ & $22,162,253$ & $22,428,819$ & 23,891,539 & $24,170,996$ & $24,483,610$ & $24,954,694$ \\
\hline$E m p_{t}^{K L I P S}$ & $53.4 \%$ & $53.4 \%$ & $52.7 \%$ & $53.8 \%$ & $53.8 \%$ & $54.3 \%$ & $54.1 \%$ & $55.8 \%$ & $56.9 \%$ & $56.9 \%$ & $57.1 \%$ & $57.7 \%$ \\
\hline $\begin{array}{c}\text { Total } \\
\text { population } \\
\text { (aged 15 \& over) }\end{array}$ & $31,047,370$ & $31,161,805$ & $31,241,497$ & $30,516,858$ & $30,622,957$ & $30,793,105$ & 40,949,981 & $40,199,553$ & $42,008,503$ & $42,444,804$ & $42,844,461$ & $43,224,979$ \\
\hline
\end{tabular}

(3) Difference in employment rates between the EAPS and KLIPS: $E m p_{t}^{E A P S}-E m p_{t}^{K L I P S}$

\begin{tabular}{|c|c|c|c|c|c|c|c|c|c|c|c|c|c|c|}
\hline & \multicolumn{12}{|c|}{ Year $(t)$} & \multirow[b]{2}{*}{ Mean } & \multirow[b]{2}{*}{ Corr. } \\
\hline & 2003 & 2004 & 2005 & 2006 & 2007 & 2008 & 2009 & 2010 & 2011 & 2012 & 2013 & 2014 & & \\
\hline $\begin{array}{l}E m p_{t}^{E A P S} \\
-E m p_{t}^{K L I P S}\end{array}$ & $5.9 \%$ & $6.2 \%$ & $7.0 \%$ & $6.2 \%$ & $6.3 \%$ & $5.5 \%$ & $4.8 \%$ & $3.4 \%$ & $2.9 \%$ & $3.0 \%$ & $3.1 \%$ & $3.4 \%$ & $4.8 \%$ & 0.55 \\
\hline
\end{tabular}

Note) 1. All values are derived using sample weights.

2. $E m p_{t}$ stands for employment rate: Employment rate=(The number of the employed / The number of the total population $) \times 100$.

3. Mean is the average of the differences in employment rates between the EAPS and KLIPS

$$
: \text { Mean }=\frac{1}{12} \sum_{t=2003}^{2014}\left(E m p_{t}^{E A P S}-E m p_{t}^{K L I P S}\right) .
$$

4. Corr. stands for correlation between the two series of employment rates in the EAPS and KLIPS: Corr $\left(E m p_{t}^{E A P S}, E m p_{t}^{K L I P S}\right)$. 
Table 3.4. The proportion of workers in wage and salary employment

(1) The proportion of wage and salary workers in the EAPS: $P_{t}^{E A P S}$

\begin{tabular}{|c|c|c|c|c|c|c|c|c|c|c|c|c|}
\cline { 2 - 12 } \multicolumn{1}{c|}{} & \multicolumn{10}{c|}{ Year $(t)$} & \multicolumn{10}{|c|}{} \\
\cline { 2 - 12 } \multicolumn{1}{c|}{} & 2003 & 2004 & 2005 & 2006 & 2007 & 2008 & 2009 & 2010 & 2011 & 2012 & 2013 & 2014 \\
\hline $\begin{array}{c}\text { Wage } \\
\text { \& salary } \\
\text { workers }\end{array}$ & $14,194,188$ & $14,616,991$ & $14,948,224$ & $15,420,543$ & $16,006,557$ & $16,257,717$ & $16,608,864$ & $17,189,358$ & $17,714,763$ & $17,941,062$ & $18,403,517$ & $18,991,829$ \\
\hline \begin{tabular}{c}
$P_{t}^{E A P S}$ \\
\hline $\begin{array}{c}\text { Total } \\
\text { number of } \\
\text { employed }\end{array}$
\end{tabular} & $63.9 \%$ & $64.9 \%$ & $65.6 \%$ & $66.4 \%$ & $67.9 \%$ & $68.2 \%$ & $69.8 \%$ & $71.0 \%$ & $71.5 \%$ & $71.4 \%$ & $72.1 \%$ & $72.5 \%$ \\
\hline
\end{tabular}

(2) The proportion of wage and salary workers in the KLIPS: $P_{t}^{K L I P S}$

\begin{tabular}{|c|c|c|c|c|c|c|c|c|c|c|c|c|}
\hline & \multicolumn{12}{|c|}{ Year $(t)$} \\
\hline & 2003 & 2004 & 2005 & 2006 & 2007 & 2008 & 2009 & 2010 & 2011 & 2012 & 2013 & 2014 \\
\hline $\begin{array}{c}\text { Wage } \\
\text { \& salary } \\
\text { workers }\end{array}$ & $11,294,661$ & $11,317,526$ & $10,889,309$ & $11,120,776$ & $11,210,039$ & $11,450,900$ & $15,478,366$ & $15,853,611$ & $17,238,872$ & $17,551,971$ & $17,860,389$ & $18,371,140$ \\
\hline$P_{t}^{K L I P S}$ & $68.1 \%$ & $68.1 \%$ & $66.2 \%$ & $67.7 \%$ & $68.0 \%$ & $68.5 \%$ & $69.8 \%$ & $70.7 \%$ & $72.2 \%$ & $72.6 \%$ & $72.9 \%$ & $73.6 \%$ \\
\hline $\begin{array}{c}\text { Total } \\
\text { number of } \\
\text { employed }\end{array}$ & $16,586,568$ & $16,628,888$ & $16,460,282$ & $16,417,498$ & $16,483,200$ & $16,710,402$ & $22,162,253$ & $22,428,819$ & $23,891,539$ & $24,170,996$ & $24,483,610$ & 24,954,694 \\
\hline
\end{tabular}

(3) Difference in the proportions of wage and salary workers between the EAPS and KLIPS: $P_{t}^{E A P S}-$ $P_{t}^{K L I P S}$

\begin{tabular}{|c|c|c|c|c|c|c|c|c|c|c|c|c|c|c|}
\hline & \multicolumn{12}{|c|}{ Year $(t)$} & \multirow[b]{2}{*}{ Mean } & \multirow[b]{2}{*}{ Corr } \\
\hline & 2003 & 2004 & 2005 & 2006 & 2007 & 2008 & 2009 & 2010 & 2011 & 2012 & 2013 & 2014 & & \\
\hline $\begin{array}{l}P_{t}^{E A P S}- \\
P_{t}^{K L I P S}\end{array}$ & $-4.2 \%$ & $-3.2 \%$ & $-0.5 \%$ & $-1.3 \%$ & $-0.1 \%$ & $-0.3 \%$ & $0.0 \%$ & $0.3 \%$ & $-0.7 \%$ & $-1.2 \%$ & $-0.8 \%$ & $-1.1 \%$ & $-1.1 \%$ & 0.90 \\
\hline
\end{tabular}

Note) 1. All values are derived using sample weights.

2. $P_{t}$ stands for the proportion of wage and salary workers in the total population

$: P_{t}=$ (The number of wage and salary workers / The number of the total population) $\mathrm{x} 100$.

3. Mean is the average of the differences in the proportions $\left(P_{t}\right)$ between the EAPS and KLIPS

$:$ Mean $=\frac{1}{12} \sum_{t=2003}^{2014}\left(P_{t}^{E A P S}-P_{t}^{K L I P S}\right)$.

4. Corr. stands for a correlation in the two series of the proportions in the EAPS and KLIPS: Corr $\left(P_{t}^{E A P S}, P_{t}^{K L I P S}\right)$.

Table 3.4. shows the share of wage and salary workers in the total employment $\left(P_{t}^{E A P S}\right.$ and $\left.P_{t}^{K L I P S}\right)$. Panel (1) and (2) in Table 3.4. provided the results using the EAPS and KLIPS data sets, respectively. In addition, panel (3) provides the difference in the proportions between the EAPS and KLIPS ( $\left.P_{t}^{E A P S}-P_{t}^{K L I P S}\right)$, and the 
last two columns contain the average of the differences and correlation between the two proportion series, $P_{t}^{E A P S}$ and $P_{t}^{K L I P S}$. According to the results in Table 3.4., the proportion of wage and salary workers is slightly higher in the KLIPS, but the difference in the proportions of the EAPS and KLIPS decreases over time, and the average of the differences is just -1.1 percentage points. Moreover, the correlation between the proportion series $\left(P_{t}^{E A P S}\right.$ and $\left.P_{t}^{K L I P S}\right)$ is 0.9 , implying the proportions of the EAPS and KLIPS move in the same direction during the sample period. Based on the results, we cannot find any significant factor that explains the different pattern of the share of alternative employment arrangements in the EAPS and KLIPS. As the next step, we investigate if there are differences in the demographic characteristics between the two data sets, focusing on age, gender, and educational attainment.

\subsubsection{Demographic characteristics in the total population: age, gender, and educational attainment}

In this section, we compare the two data sets, the EAPS and KLIPS, with respect to the demographic characteristics such age, gender and educational attainment. Changes in demographic characteristics are expected to impact on the composition of wage and salary workers because age, gender, and educational attainment are the main factors that determine types of employment arrangements in a labor market. For example, in Korea young and old people, women, and people with the low level of educational attainment are more likely to work in the peripheral sector and to hold temporary jobs. Thus, if either data set consists of younger or older people, more women, or people with lower educational attainment than the other, then this could explain the puzzle.

\section{(1) Age}

Table 3.5. provides the difference between the EAPS and KLIPS in the percentage distribution of age

categories $\left(P_{G, t}^{E A P S}-P_{G, t}^{K L I P S}\right)$. The differences are derived using [Table C6] and [Table C7] in the Appendix that contain the share of age categories in the total population in the EAPS and KLIPS. According to the results in Table 3.5., the average of the differences in the proportions is less than 1.0 percentage point across all age categories. The mean of the differences has relatively large values in the age categories of 30-34, 3539 , and $40-44(0.5 \%-0.9 \%)$. However, this is because they are relatively large groups among the age 
categories taking up about $11 \%$ of the total population each. In addition, every correlation in the age categories has a positive sign, although the correlation in the age category of 65-69 is almost zero. Based on the results, we cannot find any substantial difference in the share across age categories for the two data sets, which implies that the puzzle cannot be explained by the difference in the age distribution.

Table 3.5. Differences in the share of age category between the EAPS and KLIPS: $P_{G, t}^{E A P S}-P_{G, t}^{K L I P S}$

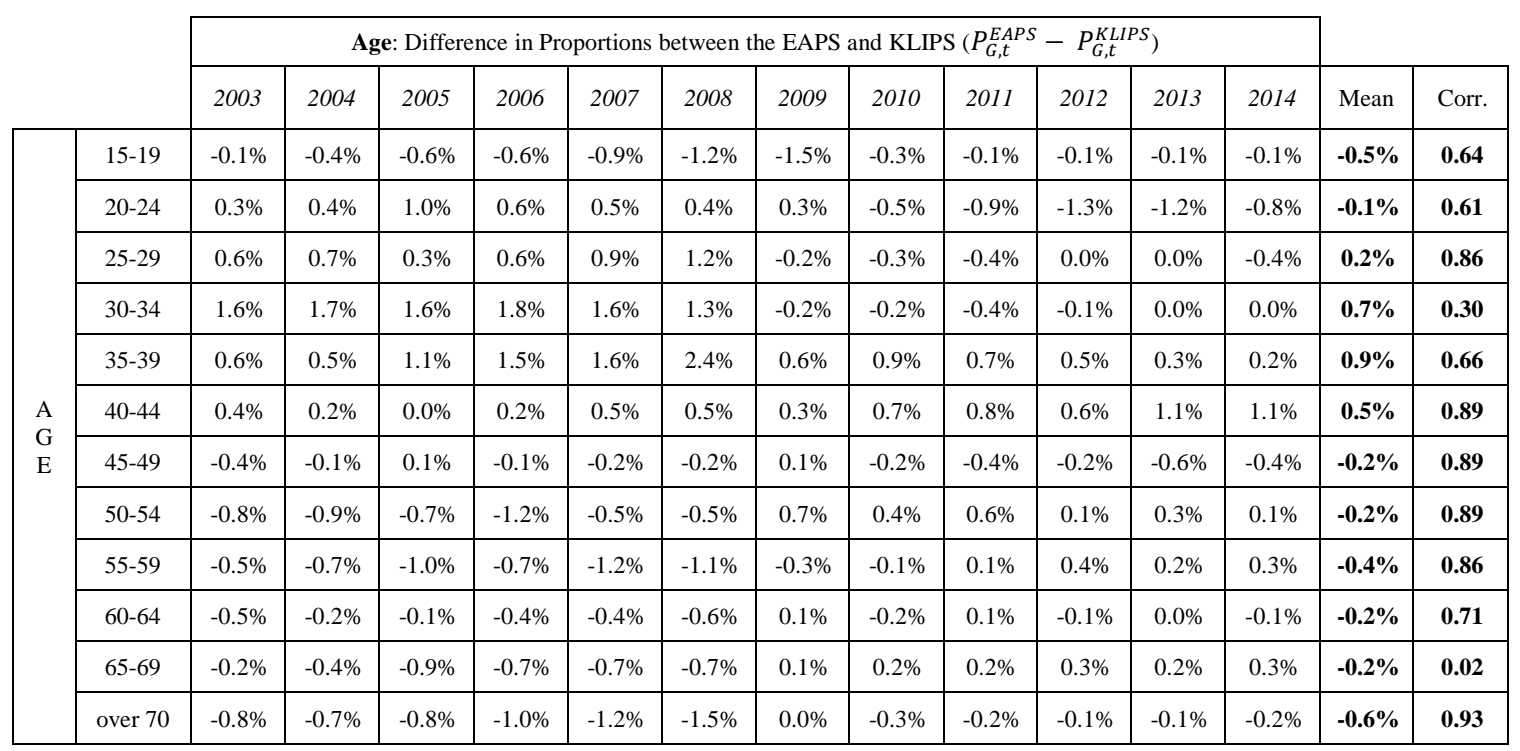

Note) 1. All values are derived using the proportion of age categories $\left(P_{G, t}^{E A P S}\right.$ and $\left.P_{G, t}^{K L I P S}\right)$ in [Table C6] and [Table C7].

2. $P_{G, t}$ stands for the proportion of the age category $G$ in the total population at $t$ where $G=1 \ldots 12$

$: P_{G, t}=$ (The number of people in the age category $G /$ The number of the total population) $\mathrm{x} 100$.

3. Mean of the age category $G$ is the average of the differences in the proportions $\left(P_{G, t}\right)$ between the EAPS and KLIPS

$$
: \text { Mean }=\frac{1}{12} \sum_{t=2003}^{2014}\left(P_{G, t}^{E A P S}-P_{G, t}^{K L I P S}\right) .
$$

4. Corr. of the age category $G$ stands for a correlation in the two series of the proportions in the EAPS and KLIPS

$$
\text { : } \operatorname{Corr}\left(P_{G, t}^{E A P S}, P_{G, t}^{K L I P S}\right) \text {. }
$$

\section{(2) Gender}

Table 3.6. shows the difference in the share of women in the total population between the EAPS and KLIPS. The differences are calculated using the proportions in [Table C8] and [Table C9] in the Appendix.

According to the results in Table 3.6., the share of women in the total population is consistently lower in the EAPS. However, the difference in the share of women varies within 1.0 percentage point except for the differences in 2008 and 2009, and hence the average of the differences during the sample period is just -0.5 
percentage points. The gaps are very small compared to the share of women, which is around 51 percent. In addition, the two proportions of the EAPS and KLIPS move in the same direction according to the correlation between the two proportion series (0.64). Thus, differences in the share of women are much too small to explain the puzzle in the share of the temporary workers.

Table 3.6. Differences in the share of women between EAPS and KLIPS: $P_{W, t}^{E A P S}-P_{W, t}^{K L I P S}$

\begin{tabular}{|c|c|c|c|c|c|c|c|c|c|c|c|c|c|c|}
\hline & \multicolumn{12}{|c|}{ Gender: Difference in Proportions between the EAPS and KLIPS $\left(P_{W, t}^{E A P S}-P_{W, t}^{K L I P S}\right)$} & \multirow[b]{2}{*}{ Mean } & \multirow[b]{2}{*}{ Corr } \\
\hline & 2003 & 2004 & 2005 & 2006 & 2007 & 2008 & 2009 & 2010 & 2011 & 2012 & 2013 & 2014 & & \\
\hline Women & $-0.1 \%$ & $-0.4 \%$ & $-0.6 \%$ & $-0.6 \%$ & $-0.9 \%$ & $-1.2 \%$ & $-1.5 \%$ & $-0.3 \%$ & $-0.1 \%$ & $-0.1 \%$ & $-0.1 \%$ & $-0.1 \%$ & $-0.5 \%$ & 0.64 \\
\hline
\end{tabular}

Note) 1. All values are derived using the proportion of women $\left(P_{W, t}^{E A P S}\right.$ and $\left.P_{W, t}^{K L I P S}\right)$ in [Table C8] and [Table C9].

2. $P_{W, t}$ stands for the proportion of women in the total population at $t$

: $P_{W, t}=$ (The number of women / The number of the population) $\mathrm{x} 100$.

3. Mean is the average of the differences in the proportions $\left(P_{W, t}\right)$ between the EAPS and KLIPS

$:$ Mean $=\frac{1}{12} \sum_{t=2003}^{2014}\left(P_{W, t}^{E A P S}-P_{W, t}^{K L I P S}\right)$.

4. Corr. stands for a correlation in the two series of the proportions in the EAPS and KLIPS: $\operatorname{Corr}\left(P_{W, t}^{E A P S}, P_{W, t}^{K L I P S}\right)$.

\section{(3) Educational attainment}

Table 3.7. shows the difference in the share by educational attainment category between the EAPS and KLIPS. The differences are calculated using the proportions in [Table C10] and [Table C11] in the Appendix. According to the results in Table 3.7., the KLIPS has more people with lower level of educational attainment (elementary and middle school graduates), but the share of high school graduates is lower in the KLIPS compared to the share in the EAPS.

The difference in the share of high school graduates seems relatively large (2.8 percentage points) compared to the share of the other level of educational attainment, but it is not so large actually taking into account the fact that the group of high school graduates is the largest one among all the educational attainment categories; the size of high school graduates (30-35 percentage) is twice as large as other groups. Moreover, the correlations in all the level of educational attainment are positive and close to 1 , which means that the 
level of educational attainment has changed in the same direction in the two surveys. Therefore, the difference in the level of educational attainment between the EAPS and KLIPS cannot be the reason for the puzzle.

Table 3.7. Differences in the share by educational attainment category between the EAPS and KLIPS:

\begin{tabular}{|c|c|c|c|c|c|c|c|c|c|c|c|c|c|c|}
\hline & \multicolumn{12}{|c|}{ Education: Difference in Proportions between the EAPS and KLIPS $\left(P_{E, t}^{E A P S}-P_{E, t}^{K L I P S}\right)$} & \multirow[b]{2}{*}{ Mean } & \multirow[b]{2}{*}{ Corr } \\
\hline & 2003 & 2004 & 2005 & 2006 & 2007 & 2008 & 2009 & 2010 & 2011 & 2012 & 2013 & 2014 & & \\
\hline $\begin{array}{l}\text { Elementary } \\
\text { School }\end{array}$ & $-2.5 \%$ & $-2.3 \%$ & $-2.7 \%$ & $-2.6 \%$ & $-2.5 \%$ & $-2.5 \%$ & $-0.9 \%$ & $-0.6 \%$ & $-0.4 \%$ & $-0.1 \%$ & $-0.2 \%$ & $0.9 \%$ & $-1.4 \%$ & 0.98 \\
\hline Middle School & $-0.6 \%$ & $-0.7 \%$ & $-1.0 \%$ & $-1.0 \%$ & $-1.1 \%$ & $-1.1 \%$ & $-1.3 \%$ & $-0.1 \%$ & $0.5 \%$ & $0.6 \%$ & $0.1 \%$ & $-0.8 \%$ & $-0.5 \%$ & 0.86 \\
\hline High School & $3.4 \%$ & $3.9 \%$ & $3.9 \%$ & $4.0 \%$ & $3.5 \%$ & $3.8 \%$ & $2.3 \%$ & $1.7 \%$ & $1.8 \%$ & $1.5 \%$ & $1.6 \%$ & $2.1 \%$ & $2.8 \%$ & 0.73 \\
\hline 2yr College & $-1.0 \%$ & $-1.1 \%$ & $-0.6 \%$ & $-0.7 \%$ & $-0.5 \%$ & $-0.9 \%$ & $-0.9 \%$ & $-1.6 \%$ & $-1.8 \%$ & $-1.4 \%$ & $-1.3 \%$ & $-2.3 \%$ & $-1.2 \%$ & 0.98 \\
\hline 4yr University & $0.9 \%$ & $0.4 \%$ & $0.5 \%$ & $0.6 \%$ & $1.1 \%$ & $0.8 \%$ & $0.9 \%$ & $0.9 \%$ & $0.5 \%$ & $0.0 \%$ & $0.4 \%$ & $0.6 \%$ & $0.6 \%$ & 0.99 \\
\hline M.A. or Ph.D. & $-0.1 \%$ & $-0.2 \%$ & $-0.1 \%$ & $-0.3 \%$ & $-0.5 \%$ & $-0.1 \%$ & $-0.1 \%$ & $-0.3 \%$ & $-0.5 \%$ & $-0.5 \%$ & $-0.6 \%$ & $-0.5 \%$ & $-0.3 \%$ & 0.96 \\
\hline
\end{tabular}

Note) 1. All values are derived using the proportion of education categories $\left(P_{E, t}^{E A P S}\right.$ and $\left.P_{E, t}^{K L I P S}\right)$ in [Table C10] and [Table C11].

2. $P_{E, t}$ stands for the proportion of the education $E$ in the total population at $t$ where $E=1 \ldots 6$

: $P_{E, t}=$ (The number of people in the education category $E /$ The number of the total population) $\mathrm{x} 100$.

3. Mean of the education category $E$ is the average of the differences in the proportions $\left(P_{E, t}\right)$ between the EAPS and KLIPS

$$
: \text { Mean }=\frac{1}{12} \sum_{t=2003}^{2014}\left(P_{E, t}^{E A P S}-P_{E, t}^{K L I P S}\right) .
$$

4. Corr. of the education category $E$ stands for a correlation in the two proportions of the EAPS and KLIPS: Corr $\left(P_{E, t}^{E A P S}, P_{E, t}^{K L I P S}\right)$.

\subsubsection{Demographic characteristics in wage and salary workers: age, gender, and educational attainment}

In the previous section, we examined difference in demographic characteristics in the total population between the EAPS and KLIPS. However, we could not find any substantial factor that suggests the reason for the puzzle. In this section, we examine the same demographic characteristics, but we focus on wage and salary workers instead of the total population because the puzzle - the different patterns of the shares of temporary worker groups in the sample period - is most closely related to the composition of wage and salary workers. 


\section{(1) Age}

Table 3.8. shows the difference in the share of age categories between the EAPS and KLIPS. The differences are derived using proportions in [Table C12] and [Table C13] in the Appendix. According to the results in Table 3.8., the average of the differences in the proportions is less than 1.0 percentage points in all age categories except for the categories of aged 20-24 (1.8 percentage points) and 45-49 (-1.4 percentage points). In addition, the correlations are positive and close to 1 in most age categories although negative correlations are found in age categories 30-34 and 40-44 (-0.05 and -0.59). However, the mean values of the two age categories with negative correlation are relatively small ( 0.1 and -0.4 percentage points) compared to actual values of the share (13-15 percentage). Therefore, it is hard to say that the differences in the share of age categories in wage and salary workers could be of importance.

Table 3.8. Differences in the share of age category between the EAPS and KLIPS

\begin{tabular}{|c|c|c|c|c|c|c|c|c|c|c|c|c|c|c|c|}
\hline & \multicolumn{12}{|c|}{ Age: Difference in Proportions between the EAPS and KLIPS $\left(P_{G, t}^{E A P S}-P_{G, t}^{K L I P S}\right)$} & \multirow[b]{2}{*}{ Mean } & \multirow[b]{2}{*}{ Corr. } \\
\hline & & 2003 & 2004 & 2005 & 2006 & 2007 & 2008 & 2009 & 2010 & 2011 & 2012 & 2013 & 2014 & & \\
\hline \multirow{12}{*}{$\begin{array}{l}\mathrm{A} \\
\mathrm{G} \\
\mathrm{E}\end{array}$} & $15-19$ & $0.8 \%$ & $0.6 \%$ & $1.0 \%$ & $0.7 \%$ & $0.7 \%$ & $0.6 \%$ & $0.8 \%$ & $0.7 \%$ & $0.6 \%$ & $0.9 \%$ & $0.9 \%$ & $0.9 \%$ & $0.8 \%$ & 0.72 \\
\hline & $20-24$ & $2.1 \%$ & $2.4 \%$ & $2.9 \%$ & $2.1 \%$ & $1.7 \%$ & $1.4 \%$ & $2.1 \%$ & $1.7 \%$ & $0.8 \%$ & $0.6 \%$ & $1.6 \%$ & $1.7 \%$ & $1.8 \%$ & 0.95 \\
\hline & $25-29$ & $0.5 \%$ & $0.5 \%$ & $0.0 \%$ & $0.5 \%$ & $1.2 \%$ & $1.1 \%$ & $-1.3 \%$ & $-1.1 \%$ & $-0.5 \%$ & $0.2 \%$ & $-0.8 \%$ & $-0.6 \%$ & $0.0 \%$ & 0.90 \\
\hline & $30-34$ & $2.0 \%$ & $1.5 \%$ & $0.8 \%$ & $1.4 \%$ & $0.9 \%$ & $0.7 \%$ & $-1.6 \%$ & $-1.4 \%$ & $-0.9 \%$ & $-0.5 \%$ & $-0.7 \%$ & $-0.6 \%$ & $0.1 \%$ & -0.05 \\
\hline & $35-39$ & $-0.8 \%$ & $0.1 \%$ & $0.9 \%$ & $1.4 \%$ & $1.0 \%$ & $3.1 \%$ & $0.3 \%$ & $0.8 \%$ & $0.1 \%$ & $0.1 \%$ & $-0.4 \%$ & $-0.6 \%$ & $0.5 \%$ & 0.43 \\
\hline & $40-44$ & $-1.3 \%$ & $-1.0 \%$ & $-1.4 \%$ & $-1.0 \%$ & $-0.6 \%$ & $-1.1 \%$ & $-0.5 \%$ & $0.0 \%$ & $0.3 \%$ & $-0.2 \%$ & $1.0 \%$ & $0.9 \%$ & $-0.4 \%$ & -0.59 \\
\hline & $45-49$ & $-1.3 \%$ & $-1.3 \%$ & $-1.2 \%$ & $-1.8 \%$ & $-1.9 \%$ & $-1.9 \%$ & $-0.5 \%$ & $-1.2 \%$ & $-1.6 \%$ & $-1.2 \%$ & $-2.1 \%$ & $-1.3 \%$ & $-1.4 \%$ & 0.89 \\
\hline & $50-54$ & $-1.0 \%$ & $-1.5 \%$ & $-1.4 \%$ & $-1.9 \%$ & $-1.7 \%$ & $-1.6 \%$ & $0.3 \%$ & $-0.3 \%$ & $-0.2 \%$ & $-0.5 \%$ & $-0.2 \%$ & $-0.9 \%$ & $-0.9 \%$ & 0.92 \\
\hline & $55-59$ & $-0.7 \%$ & $-0.9 \%$ & $-1.2 \%$ & $-1.5 \%$ & $-1.5 \%$ & $-1.5 \%$ & $-0.5 \%$ & $-0.2 \%$ & $0.0 \%$ & $-0.2 \%$ & $0.0 \%$ & $0.1 \%$ & $-0.7 \%$ & 0.90 \\
\hline & $60-64$ & $-0.4 \%$ & $0.0 \%$ & $0.0 \%$ & $-0.2 \%$ & $0.0 \%$ & $-0.8 \%$ & $0.3 \%$ & $0.4 \%$ & $0.3 \%$ & $-0.2 \%$ & $-0.2 \%$ & $-0.4 \%$ & $-0.1 \%$ & 0.77 \\
\hline & $65-69$ & $-0.1 \%$ & $-0.3 \%$ & $-0.4 \%$ & $0.1 \%$ & $-0.1 \%$ & $-0.1 \%$ & $0.4 \%$ & $0.5 \%$ & $0.4 \%$ & $0.2 \%$ & $0.1 \%$ & $0.2 \%$ & $0.1 \%$ & 0.50 \\
\hline & over 70 & $0.1 \%$ & $0.1 \%$ & $0.0 \%$ & $0.2 \%$ & $0.3 \%$ & $0.2 \%$ & $0.2 \%$ & $0.1 \%$ & $0.4 \%$ & $0.7 \%$ & $0.6 \%$ & $0.6 \%$ & $0.3 \%$ & 0.97 \\
\hline
\end{tabular}

Note) 1. All values are derived using the proportion of age categories $\left(P_{G, t}^{E A P S}\right.$ and $\left.P_{G, t}^{K L I P S}\right)$ in [Table C12] and [Table C13].

2. $P_{G, t}$ stands for the proportion of the age category $G$ among wage and salary workers at $t$ where $G=1 \ldots 12$

$: P_{G, t}=$ (The number of people in the age category $G /$ The number of the total workers) $\mathrm{x} 100$.

3. Mean of the age category $G$ is the average of the differences in the proportions $\left(P_{G, t}\right)$ between the EAPS and KLIPS

$$
: \text { Mean }=\frac{1}{12} \sum_{t=2003}^{2014}\left(P_{G, t}^{E A P S}-P_{G, t}^{K L I P S}\right) \text {. }
$$

4. Corr. of the age category $G$ stands for a correlation in the two series of the proportions in the EAPS and KLIPS

$$
\text { : Corr }\left(P_{G, t}^{E A P S}, P_{G, t}^{K L I P S}\right) \text {. }
$$




\section{(2) Gender}

Table 3.9. shows the difference in the percentages of women between the EAPS and KLIPS. The share of women in the total workers is consistently higher in the EAPS, while the share of women in the total population is lower in the EAPS (see Table 3.6.).

The average of the differences is 2.0 percentage points, but this value is small compared with the share of women, which is around 40-43 percentage. Correlation between the two proportions is positive although it is close to zero. We found difference in the share of women in the total workers between the EAPS and KLIPS, but it is much too small explain the difference in the share of alternative employment arrangements.

Table 3.9. Differences in the share of women between EAPS and KLIPS

\begin{tabular}{|c|c|c|c|c|c|c|c|c|c|c|c|c|c|c|}
\hline & \multicolumn{12}{|c|}{ Gender: Difference in Proportions between the EAPS and KLIPS $\left(P_{W, t}^{E A P S}-P_{W, t}^{K L I P S}\right)$} & \multirow[b]{2}{*}{ Mean } & \multirow[b]{2}{*}{ Corr } \\
\hline & 2003 & 2004 & 2005 & 2006 & 2007 & 2008 & 2009 & 2010 & 2011 & 2012 & 2013 & 2014 & & \\
\hline Women & $0.9 \%$ & $1.3 \%$ & $2.2 \%$ & $2.1 \%$ & $1.6 \%$ & $1.3 \%$ & $3.1 \%$ & $2.4 \%$ & $2.5 \%$ & $2.1 \%$ & $2.2 \%$ & $2.5 \%$ & $2.0 \%$ & 0.18 \\
\hline
\end{tabular}

Note) 1. All values are derived using the proportion of women $\left(P_{W, t}^{E A P S}\right.$ and $\left.P_{W, t}^{K L I P S}\right)$ in [Table C14] and [Table C15].

2. $P_{W, t}$ is the proportion of women in wage and salary workers at $t$

$: P_{W, t}=$ (The number of women / The number of the total workers) $\mathrm{x} 100$.

3. Mean is the average of the differences in the proportions $\left(P_{W, t}\right)$ between the EAPS and KLIPS

$$
: \text { Mean }=\frac{1}{12} \sum_{t=2003}^{2014}\left(P_{W, t}^{E A P S}-P_{W, t}^{K L I P S}\right) .
$$

4. Corr. stands for a correlation in the two series of the proportions in the EAPS and KLIPS: Corr $\left(P_{W, t}^{E A P S}, P_{W, t}^{K L I P S}\right)$. 


\section{(3) Educational attainment}

Table 3.10. shows the difference in the share by educational attainment category between the EAPS and KLIPS. The results are very similar to the results using total population in Table 3.7.. Based on the fact that the difference in the share is small and all correlations are very close to $1(0.88-0.97)$, the puzzle cannot be explained by the difference in the distribution of educational attainment.

Table 3.10. Differences in the share by educational attainment category between the EAPS and KLIPS

\begin{tabular}{|c|c|c|c|c|c|c|c|c|c|c|c|c|c|c|}
\hline & \multicolumn{12}{|c|}{ Education: Difference in Proportions between the EAPS and KLIPS $\left(P_{E, t}^{E A P S}-P_{E, t}^{K L I P S}\right)$} & \multirow[b]{2}{*}{ Mean } & \multirow[b]{2}{*}{ Corr. } \\
\hline & 2003 & 2004 & 2005 & 2006 & 2007 & 2008 & 2009 & 2010 & 2011 & 2012 & 2013 & 2014 & & \\
\hline $\begin{array}{l}\text { Elementary } \\
\text { School }\end{array}$ & $-2.5 \%$ & $-1.7 \%$ & $-1.8 \%$ & $-1.6 \%$ & $-1.7 \%$ & $-1.6 \%$ & $-0.1 \%$ & $0.1 \%$ & $0.1 \%$ & $0.6 \%$ & $0.3 \%$ & $0.4 \%$ & $-0.8 \%$ & 0.95 \\
\hline Middle School & $-1.0 \%$ & $-0.9 \%$ & $-1.5 \%$ & $-1.1 \%$ & $-1.3 \%$ & $-1.4 \%$ & $-0.4 \%$ & $-0.8 \%$ & $-0.3 \%$ & $-0.4 \%$ & $-0.3 \%$ & $-0.1 \%$ & $-0.8 \%$ & 0.97 \\
\hline High School & $4.2 \%$ & $3.9 \%$ & $4.9 \%$ & $4.5 \%$ & $3.5 \%$ & $4.0 \%$ & $2.1 \%$ & $2.4 \%$ & $1.2 \%$ & $0.7 \%$ & $1.2 \%$ & $2.5 \%$ & $2.9 \%$ & 0.88 \\
\hline 2yr College & $-0.6 \%$ & $-0.1 \%$ & $-0.2 \%$ & $-0.6 \%$ & $-0.1 \%$ & $-1.4 \%$ & $-0.5 \%$ & $-1.0 \%$ & $-0.8 \%$ & $-0.5 \%$ & $-0.3 \%$ & $-1.1 \%$ & $-0.6 \%$ & 0.97 \\
\hline 4yr University & $0.2 \%$ & $-0.5 \%$ & $-1.0 \%$ & $-0.3 \%$ & $0.5 \%$ & $0.6 \%$ & $-0.7 \%$ & $0.0 \%$ & $0.7 \%$ & $0.5 \%$ & $0.4 \%$ & $-0.3 \%$ & $0.0 \%$ & 0.97 \\
\hline M.A. or Ph.D. & $-0.3 \%$ & $-0.6 \%$ & $-0.4 \%$ & $-0.8 \%$ & $-1.0 \%$ & $-0.2 \%$ & $-0.4 \%$ & $-0.7 \%$ & $-1.0 \%$ & $-0.9 \%$ & $-1.3 \%$ & $-1.4 \%$ & $-0.7 \%$ & 0.91 \\
\hline
\end{tabular}

Note) 1. All values are derived using the proportion of education categories $\left(P_{E, t}^{E A P S}\right.$ and $\left.P_{E, t}^{K L I P S}\right)$ in [Table C16] and [Table C17].

2. $P_{E, t}$ stands for the proportion of the education $E$ among wage and salary workers at $t$ where $E=1 \ldots 6$

$: P_{E, t}=$ (The number of people in the education category $E /$ The number of the total workers) $\mathrm{x} 100$.

3. Mean of the education category $E$ is the average of the differences in the proportions $\left(P_{E, t}\right)$ between the EAPS and KLIPS

$$
: \text { Mean }=\frac{1}{12} \sum_{t=2003}^{2014}\left(P_{E, t}^{E A P S}-P_{E, t}^{K L I P S}\right)
$$

4. Corr. of the education category $E$ stands for a correlation in the two proportions of the EAPS and KLIPS: Corr $\left(P_{E, t}^{E A P S}, P_{E, t}^{K L I P S}\right)$. 


\subsection{Conclusion}

This study investigates to see if the upsurge of the alternative employment arrangements after the reform is found in the EAPS as well as in the KLIPS. For this, we compare the two labor market surveys, the EAPS and KLIPS, from the perspective of reported employment arrangements. The same survey questions in both the EAPS and KLIPS were used to classify the employment types of wage and salary workers. However, we are confronted with a puzzle because the results using two data sets show different patterns of the shares of temporary worker groups over time. In the EAPS, the proportion of the total temporary workers and the proportion of fixed-term contract workers moved together, decreasing over time, which is contrary to the results using the KLIPS data. In addition, the continued growth in the proportion of alternative employment arrangements after 2007 that we observed in the KLIPS does not appear in the EAPS.

To consider what factors cause the differences in the results, we investigate if there are differences in the populations in the EAPS and KLIPS data. First, we compare the employment rates and the proportions of wage and salary workers in the EAPS and KLIPS. Second, we investigate differences in demographic characteristics of the total population in the two data sets focusing on age, gender, and educational attainment. Third, we compare the demographic characteristics between the EAPS and KLIPS again but focusing on wage and salary workers. However, based on all the results, we cannot find any factor could explain the different pattern of the share of alternative employment arrangements in the EAPS and KLIPS. We find small difference in the share of women in wage and salary worker between the EAPS and KLIPS, but it is too much small to explain the different results in the EAPS and KLIPS. In conclusion, the different results in the two data sets may not be attributed to the differences in demographic characteristics between the EAPS and KLIPS. Further studies are needed to identify a main factor to cause the puzzle. 


\section{Appendix A: Appendix to Chapter 1}

Table A.1. Kaplan-Meier nonparametric estimates for the hazard function $h(r)$

\begin{tabular}{|c|c|c|c|c|c|c|}
\hline \multicolumn{7}{|c|}{ Control Group } \\
(Before the reform : Jan, 2001 June, 2007$)$ \\
\hline $\boldsymbol{r}$ & $\boldsymbol{n}(\boldsymbol{r})$ & $\boldsymbol{f}(\boldsymbol{r})$ & $\boldsymbol{c}(\boldsymbol{r})$ & $\boldsymbol{h}(\boldsymbol{r})$ & $\boldsymbol{I}-\boldsymbol{h}(\boldsymbol{r})$ & $\boldsymbol{S}(\boldsymbol{r})$ \\
\hline 1 & 2314 & 48 & 31 & 0.021 & 0.979 & 0.979 \\
\hline 2 & 2235 & 140 & 31 & 0.063 & 0.937 & 0.918 \\
\hline 3 & 2064 & 172 & 27 & 0.083 & 0.917 & 0.841 \\
\hline 4 & 1865 & 133 & 60 & 0.071 & 0.929 & 0.781 \\
\hline 5 & 1672 & 104 & 22 & 0.062 & 0.938 & 0.733 \\
\hline 6 & 1546 & 87 & 20 & 0.056 & 0.944 & 0.692 \\
\hline 7 & 1439 & 85 & 10 & 0.059 & 0.941 & 0.651 \\
\hline 8 & 1344 & 86 & 7 & 0.064 & 0.936 & 0.609 \\
\hline 9 & 1251 & 73 & 21 & 0.058 & 0.942 & 0.574 \\
\hline 10 & 1157 & 70 & 18 & 0.061 & 0.939 & 0.539 \\
\hline 11 & 1069 & 63 & 4 & 0.059 & 0.941 & 0.507 \\
\hline 12 & 1002 & 59 & 14 & 0.059 & 0.941 & 0.477 \\
\hline 13 & 929 & 55 & 7 & 0.059 & 0.941 & 0.449 \\
\hline 14 & 867 & 40 & 17 & 0.046 & 0.954 & 0.428 \\
\hline 15 & 810 & 38 & 17 & 0.047 & 0.953 & 0.408 \\
\hline 16 & 755 & 28 & 31 & 0.037 & 0.963 & 0.393 \\
\hline 17 & 696 & 19 & 9 & 0.027 & 0.973 & 0.382 \\
\hline 18 & 668 & 27 & 11 & 0.040 & 0.960 & 0.367 \\
\hline 19 & 630 & 26 & 4 & 0.041 & 0.959 & 0.352 \\
\hline 20 & 600 & 17 & 5 & 0.028 & 0.972 & 0.342 \\
\hline 21 & 578 & 15 & 12 & 0.026 & 0.974 & 0.333 \\
\hline 22 & 551 & 19 & 12 & 0.034 & 0.966 & 0.321 \\
\hline 23 & 520 & 11 & 8 & 0.021 & 0.979 & 0.315 \\
\hline 24 & 501 & 18 & 16 & 0.036 & 0.964 & 0.303 \\
\hline 25 & 467 & 27 & 6 & 0.058 & 0.942 & 0.286 \\
\hline 26 & 434 & 16 & 9 & 0.037 & 0.963 & 0.275 \\
\hline 27 & 409 & 9 & 6 & 0.022 & 0.978 & 0.269 \\
\hline 28 & 394 & 8 & 30 & 0.020 & 0.980 & 0.264 \\
\hline 29 & 356 & 11 & 14 & 0.031 & 0.969 & 0.256 \\
\hline 30 & 331 & 9 & 10 & 0.027 & 0.973 & 0.249 \\
\hline
\end{tabular}

\begin{tabular}{|c|c|c|c|c|c|c|}
\hline \multicolumn{7}{|c|}{ Treatment Group } \\
\hline \multicolumn{7}{|c|}{ (After the reform : July, 2007 Aug, 2016$)$} \\
\hline $\boldsymbol{r}$ & $\boldsymbol{n}(\boldsymbol{r})$ & $\boldsymbol{f}(\boldsymbol{r})$ & $\boldsymbol{c}(\boldsymbol{r})$ & $\boldsymbol{h}(\boldsymbol{r})$ & $\boldsymbol{1}-\boldsymbol{h}(\boldsymbol{r})$ & $\boldsymbol{S}(\boldsymbol{r})$ \\
\hline 1 & 3438 & 39 & 19 & 0.011 & 0.989 & 0.989 \\
\hline 2 & 3380 & 74 & 46 & 0.022 & 0.978 & 0.967 \\
\hline 3 & 3260 & 128 & 55 & 0.039 & 0.961 & 0.929 \\
\hline 4 & 3077 & 111 & 44 & 0.036 & 0.964 & 0.896 \\
\hline 5 & 2922 & 105 & 51 & 0.036 & 0.964 & 0.863 \\
\hline 6 & 2766 & 116 & 36 & 0.042 & 0.958 & 0.827 \\
\hline 7 & 2614 & 119 & 29 & 0.046 & 0.954 & 0.789 \\
\hline 8 & 2466 & 112 & 33 & 0.045 & 0.955 & 0.754 \\
\hline 9 & 2321 & 110 & 17 & 0.047 & 0.953 & 0.718 \\
\hline 10 & 2194 & 102 & 25 & 0.046 & 0.954 & 0.685 \\
\hline 11 & 2067 & 83 & 25 & 0.040 & 0.960 & 0.657 \\
\hline 12 & 1959 & 106 & 28 & 0.054 & 0.946 & 0.621 \\
\hline 13 & 1825 & 107 & 21 & 0.059 & 0.941 & 0.585 \\
\hline 14 & 1697 & 72 & 30 & 0.042 & 0.958 & 0.560 \\
\hline 15 & 1595 & 58 & 33 & 0.036 & 0.964 & 0.540 \\
\hline 16 & 1504 & 45 & 23 & 0.030 & 0.970 & 0.524 \\
\hline 17 & 1436 & 48 & 14 & 0.033 & 0.967 & 0.506 \\
\hline 18 & 1374 & 43 & 22 & 0.031 & 0.969 & 0.490 \\
\hline 19 & 1309 & 52 & 17 & 0.040 & 0.960 & 0.471 \\
\hline 20 & 1240 & 35 & 27 & 0.028 & 0.972 & 0.458 \\
\hline 21 & 1178 & 31 & 10 & 0.026 & 0.974 & 0.446 \\
\hline 22 & 1137 & 44 & 13 & 0.039 & 0.961 & 0.428 \\
\hline 23 & 1080 & 26 & 13 & 0.024 & 0.976 & 0.418 \\
\hline 24 & 1041 & 38 & 13 & 0.037 & 0.963 & 0.403 \\
\hline 25 & 990 & 37 & 16 & 0.037 & 0.963 & 0.388 \\
\hline 26 & 937 & 28 & 12 & 0.030 & 0.970 & 0.376 \\
\hline 27 & 897 & 23 & 24 & 0.026 & 0.974 & 0.366 \\
\hline 28 & 850 & 26 & 15 & 0.031 & 0.969 & 0.355 \\
\hline 29 & 809 & 19 & 14 & 0.023 & 0.977 & 0.347 \\
\hline 30 & 776 & 22 & 14 & 0.028 & 0.972 & 0.337 \\
\hline & & & & & & \\
\hline 19 &
\end{tabular}

\begin{tabular}{|l|l|}
\hline \multicolumn{2}{|c|}{$\begin{array}{c}\text { Difference } \\
\text { in } h(r)\end{array}$} \\
\hline$r$ & $\Delta h(r)$ \\
\hline 1 & -0.009 \\
\hline 2 & -0.041 \\
\hline 3 & -0.044 \\
\hline 4 & -0.035 \\
\hline 5 & -0.026 \\
\hline 6 & -0.014 \\
\hline 7 & -0.014 \\
\hline 8 & -0.019 \\
\hline 9 & -0.011 \\
\hline 10 & -0.014 \\
\hline 11 & -0.019 \\
\hline 12 & -0.005 \\
\hline 13 & -0.001 \\
\hline 14 & -0.004 \\
\hline 15 & -0.011 \\
\hline 16 & -0.007 \\
\hline 17 & 0.006 \\
\hline 18 & -0.009 \\
\hline 19 & -0.002 \\
\hline 20 & 0.000 \\
\hline 21 & 0.000 \\
\hline 22 & 0.004 \\
\hline 23 & 0.003 \\
\hline 24 & 0.001 \\
\hline 25 & -0.020 \\
\hline 26 & -0.007 \\
\hline 27 & 0.004 \\
\hline 28 & 0.010 \\
\hline 29 & -0.007 \\
\hline 30 & 0.001 \\
\hline
\end{tabular}

Note) 1. $\boldsymbol{r}$ stands for the duration of a job in months.

2. $n(r)$ is the number of jobs at risk at $r ; f(r)$ is the number of jobs terminated at $r ; c(r)$ is the number of jobs censored at $r$.

3. $h(r)$ and $S(r)$ is Kaplan-Meier estimates of the hazard and survivor functions respectively. $\Delta h(r)$ denotes the difference in the hazard estimates between the control and treatment groups. 
Table A.2. The effect of the reform on the hazards of job separation: Probit analysis

\begin{tabular}{|c|c|c|c|c|}
\hline \multirow[b]{2}{*}{ VARIABLES } & \multirow[b]{2}{*}{ Full sample } & \multicolumn{3}{|c|}{$\begin{array}{c}\text { Sub samples } \\
\text { (excluding exceptions in the regulation) }\end{array}$} \\
\hline & & Firm size $\geq 5$ & $\begin{array}{c}\text { Firm size } \geq 5 \\
\text { Age }<55\end{array}$ & $\begin{array}{c}\text { Firm size } \geq 5 \\
\text { Age }<55 \\
\text { Working } \\
\text { hours } \geq 15\end{array}$ \\
\hline$d t$ dummies & Yes & Yes & Yes & Yes \\
\hline$d t *$ Post-job dummies $(\mathrm{t}=1 \ldots 30)$ & Yes & Yes & Yes & Yes \\
\hline Female & -0.025 & -0.035 & -0.018 & -0.025 \\
\hline Marriage status (1 = Married) & $-0.088 * * *$ & $-0.109 * * *$ & $-0.161 * * *$ & $-0.137 * * *$ \\
\hline Female * Married & $0.074 * *$ & $0.078^{*}$ & $0.097 * *$ & 0.076 \\
\hline \multicolumn{5}{|l|}{ Education Level (base: High school) } \\
\hline edu level 1: Less than elementary school & -0.005 & 0.020 & 0.004 & 0.006 \\
\hline edu level 2: Middle school & -0.016 & -0.002 & 0.042 & 0.045 \\
\hline edu level 4: College (2 years) & $0.096 * * *$ & $0.084 * * *$ & $0.093 * * *$ & $0.095 * * *$ \\
\hline edu level 5: University (4 years) & $0.080 * *$ & $0.085 * *$ & $0.101 * * *$ & $0.112 * * *$ \\
\hline edu level 6: Master degree & 0.054 & 0.049 & 0.062 & 0.107 \\
\hline edu level 7: Ph.D & 0.065 & 0.019 & -0.020 & $0.349 *$ \\
\hline \multicolumn{5}{|l|}{ Age Cohort (base: age 25-29) } \\
\hline age cohort1: 15-19 & $0.416^{* * *}$ & $0.448 * * *$ & $0.432 * * *$ & $0.442 * * *$ \\
\hline age cohort $2: 20-24$ & $0.196 * * *$ & $0.188 * * *$ & $0.184 * * *$ & $0.180 * * *$ \\
\hline age cohort $4: 30-34$ & -0.028 & -0.051 & -0.044 & -0.046 \\
\hline age cohort $5: 35-39$ & $-0.064 *$ & -0.054 & -0.043 & -0.046 \\
\hline age cohort6: $40-44$ & $-0.122 * * *$ & $-0.163 * * *$ & $-0.155^{* * *} *$ & $-0.135 * * *$ \\
\hline age cohort $7: 45-49$ & $-0.125 * * *$ & $-0.160 * * *$ & $-0.156^{* * *}$ & $-0.125 * *$ \\
\hline age cohort8: $50-54$ & $-0.105^{* *}$ & $-0.097 *$ & $-0.097 *$ & $-0.091^{*}$ \\
\hline age cohort9: 55-59 & $-0.123 * *$ & $-0.118 * *$ & - & - \\
\hline age cohort10: $60-64$ & $-0.104 * *$ & $-0.141 * *$ & - & - \\
\hline age cohort11: $65-85$ & $-0.116^{* *}$ & $-0.127 * *$ & - & - \\
\hline The number of previous jobs & $0.021 * * *$ & $0.023 * * *$ & $0.024 * * *$ & $0.024 * * *$ \\
\hline $\begin{array}{l}\text { The average unemployment rate } \\
\text { over the last three months }\end{array}$ & $-0.192 * * *$ & $-0.189 * * *$ & $-0.153 * * *$ & $-0.143 * * *$ \\
\hline Private Sector & 0.013 & -0.003 & 0.016 & 0.012 \\
\hline Part-time job & -0.001 & -0.002 & 0.009 & 0.040 \\
\hline \multicolumn{5}{|l|}{ Firm size (base: $1-9$ people) } \\
\hline 10-29 people & -0.0139 & -0.006 & 0.005 & 0.001 \\
\hline 30-99 people & 0.016 & 0.021 & 0.050 & 0.047 \\
\hline 100-299 people & $-0.080 *$ & -0.076 & -0.078 & -0.086 \\
\hline 300-999 people & -0.030 & -0.028 & -0.037 & -0.008 \\
\hline 1,000 or more than 1,000 people & -0.009 & -0.008 & 0.001 & -0.002 \\
\hline Unknown & $0.063 * *$ & $0.062 *$ & $0.106^{* * *}$ & $0.124 * * *$ \\
\hline
\end{tabular}


Table A2. The effect of the reform on the hazards of job separation: Probit analysis (Continued)

\begin{tabular}{|c|c|c|c|c|}
\hline \multirow[b]{2}{*}{ VARIABLES } & \multirow[b]{2}{*}{ Full sample } & \multicolumn{3}{|c|}{$\begin{array}{c}\text { Sub samples } \\
\text { (excluding exceptions in the regulation) }\end{array}$} \\
\hline & & Firm size $\geq 5$ & $\begin{array}{l}\text { Firm size } \geq 5 \\
\text { Age }<55\end{array}$ & $\begin{array}{c}\text { Firm size } \geq 5 \\
\text { Age }<55 \\
\text { Working } \\
\text { hours } \geq 15\end{array}$ \\
\hline \multicolumn{5}{|c|}{ (Continued) } \\
\hline Union in the workplace & $-0.099 * *$ & $-0.100 * *$ & $-0.119 * *$ & $-0.121 * *$ \\
\hline Union membership & -0.120 & -0.133 & $-0.187^{*}$ & $-0.187 *$ \\
\hline \multicolumn{5}{|l|}{ Occupation (base: Office clerk) } \\
\hline Legislative officers, executives, and high managers & -0.036 & 0.026 & 0.045 & 0.054 \\
\hline Professional & $-0.103 * *$ & $-0.098 * *$ & $-0.102 * *$ & $-0.095^{*}$ \\
\hline Engineers and semi-professional & $-0.080^{* *}$ & $-0.097 * *$ & $-0.090^{*}$ & -0.073 \\
\hline Service workers & 0.010 & -0.004 & 0.020 & 0.021 \\
\hline Sales force & 0.030 & 0.073 & 0.074 & 0.076 \\
\hline Agriculture and fishery workers & -0.060 & -0.132 & $-0.381 * *$ & $-0.400^{* *}$ \\
\hline Technicians & 0.029 & 0.035 & 0.021 & 0.024 \\
\hline Equipment, machine, and assembly workers & 0.002 & 0.008 & 0.043 & 0.049 \\
\hline Unskilled workers & $0.081^{* *}$ & $0.084 * *$ & $0.092 * *$ & $0.096^{* *}$ \\
\hline unknown & 0.251 & 0.278 & 0.293 & 0.292 \\
\hline \multicolumn{5}{|l|}{ Industry (base: Manufacturing) } \\
\hline Agriculture, hunting, forestry, and fishery & -0.055 & 0.014 & 0.181 & 0.184 \\
\hline Mining & -0.071 & -0.330 & - & - \\
\hline Electricity, gas, and water & 0.180 & 0.187 & $0.278^{*}$ & $0.296 * *$ \\
\hline Construction & $-0.106 * *$ & -0.073 & -0.067 & -0.070 \\
\hline Wholesale and retail & $-0.079^{*}$ & $-0.093 * *$ & $-0.097 *$ & $-0.097^{*}$ \\
\hline Lodge and food & -0.009 & -0.012 & -0.0254 & -0.025 \\
\hline Transportation and communication service & $-0.117^{* *}$ & $-0.118^{* *}$ & -0.081 & -0.080 \\
\hline Banking and insurance & $-0.130^{* *}$ & $-0.115^{*}$ & -0.101 & -0.103 \\
\hline Real estate and leasing service & $-0.142 * *$ & $-0.207 * * *$ & 0.048 & 0.041 \\
\hline Business service & $-0.181 * * *$ & $-0.173 * * *$ & $-0.104 *$ & $-0.100^{*}$ \\
\hline Public, social security, and defense administration & $0.125^{* *}$ & $0.103 *$ & 0.063 & 0.066 \\
\hline Education service & $-0.144 * * *$ & $-0.143 * * *$ & $-0.140^{* *}$ & $-0.119 * *$ \\
\hline Health and social welfare service & $-0.080^{*}$ & $-0.098^{*}$ & $-0.103^{*}$ & $-0.105 *$ \\
\hline Entertainment, broadcasting, and performance & -0.025 & -0.033 & -0.076 & -0.067 \\
\hline Other individual service & -0.056 & -0.052 & -0.001 & -0.004 \\
\hline Other association, organization, and international agency & $-0.188^{* *}$ & -0.106 & -0.129 & -0.114 \\
\hline Unknown & $-0.326^{* *}$ & $-0.378 * *$ & $-0.357 * *$ & $-0.358^{* *}$ \\
\hline Constant & $-1.507 * * *$ & $-1.466 * * *$ & $-1.625 * * *$ & $-1.691 * * *$ \\
\hline Observations & 85,530 & 64,486 & 50,413 & 46,402 \\
\hline
\end{tabular}

Note) 1. Standard errors are clustered at a worker level.

2. $* * * p<0.01, * * p<0.05, * p<0.1$ 
Table A.3. Sensitivity test: Probit analysis with various sample periods

\begin{tabular}{|c|c|c|c|c|c|c|c|}
\hline \multirow{2}{*}{\multicolumn{2}{|c|}{ Sample period }} & \multirow{2}{*}{$\begin{array}{c}2001-2016 \\
\text { (Full sample) }\end{array}$} & \multirow[t]{2}{*}{$2001-2013$} & \multirow[t]{2}{*}{$2004-2010$} & $2001-2016$ & $2001-2013$ & $2004-2010$ \\
\hline & & & & & \multicolumn{3}{|c|}{ Excluding Jan. - Dec. 2007} \\
\hline & Before & Jan. $2001-J u n .2007$ & Jan. 2001 - Jun. 2007 & Jan. 2004 - Jun. 2007 & Jan. 2001 - Dec. 2006 & Jan. 2001 - Dec. 2006 & Jan. $2004-$ Dec. 2006 \\
\hline & After & July. 2007 -Dec. 2016 & July. $2007-$ Dec. 2013 & July. 2007-Dec. 2010 & Jan. 2008 - Dec. 2016 & Jan. 2008 - Dec. 2013 & Jan. 2008 - Dec. 2010 \\
\hline & $D_{1} *$ Post-job & $-0.247 * * *$ & $-0.211 * *$ & $-0.232 *$ & $-0.273 * * *$ & $-0.242 * *$ & $-0.292 * *$ \\
\hline & $D_{2} *$ Post-job & $-0.474 * * *$ & $-0.449 * * *$ & $-0.374 * * *$ & $-0.512 * * *$ & $-0.496 * * *$ & $-0.444 * * *$ \\
\hline & $D_{3} *$ Post-job & $-0.363 * * *$ & $-0.311 * * *$ & $-0.285^{* * *}$ & $-0.422 * * *$ & $-0.373^{* * *} *$ & $-0.388 * * *$ \\
\hline & $D_{4} *$ Post-job & $-0.319 * * *$ & $-0.296 * * *$ & $-0.222 * *$ & $-0.357 * * *$ & $-0.338 * * *$ & $-0.280 * * *$ \\
\hline & $D_{5} *$ Post-job & $-0.240 * * *$ & $-0.222 * * *$ & $-0.215 * *$ & $-0.298 * * *$ & $-0.284 * * *$ & $-0.319 * * *$ \\
\hline & $D_{6} *$ Post-job & -0.104 & -0.059 & -0.087 & $-0.166^{* *}$ & -0.122 & $-0.188 *$ \\
\hline & $D_{7} *$ Post-job & -0.103 & -0.049 & 0.021 & $-0.167 * *$ & -0.110 & -0.073 \\
\hline & $D_{8} *$ Post-job & $-0.122 *$ & -0.081 & 0.066 & $-0.197 * * *$ & $-0.155^{* *}$ & -0.044 \\
\hline & $D_{9} *$ Post-job & -0.0619 & -0.087 & 0.102 & $-0.132 *$ & $-0.156^{* *}$ & 0.007 \\
\hline & $D_{10} *$ Post-job & -0.078 & -0.135 & -0.106 & $-0.148^{*}$ & $-0.206^{* *}$ & $-0.210 *$ \\
\hline & $D_{11} *$ Post-job & -0.119 & -0.117 & -0.081 & $-0.194 * *$ & $-0.192 * *$ & -0.192 \\
\hline & $D_{12} *$ Post-job & 0.039 & 0.013 & 0.143 & -0.039 & -0.069 & 0.024 \\
\hline & $D_{13} *$ Post-job & 0.079 & 0.075 & $0.241 * *$ & -0.014 & -0.025 & 0.095 \\
\hline & $D_{14} *$ Post-job & 0.006 & 0.028 & 0.215 & -0.069 & -0.049 & 0.105 \\
\hline The coefficient & $D_{15} *$ Post-job & -0.008 & 0.026 & 0.175 & -0.104 & -0.074 & 0.027 \\
\hline of & $D_{16} *$ Post-job & -0.012 & 0.005 & 0.134 & -0.075 & -0.058 & 0.056 \\
\hline$\left[D_{\text {rit }} \cdot\right.$ Post-job $\left.{ }_{i}\right]$ & $D_{17} *$ Post-job & $0.200^{*}$ & $0.241 * *$ & $0.464 * * *$ & 0.139 & 0.181 & $0.396 * *$ \\
\hline & $D_{18} *$ Post-job & 0.012 & 0.008 & 0.100 & -0.068 & -0.075 & -0.012 \\
\hline & $D_{19} *$ Post-job & 0.086 & 0.084 & 0.182 & -0.001 & -0.005 & 0.058 \\
\hline & $D_{20} *$ Post-job & 0.195 & $0.243^{*}$ & $0.539 * * *$ & 0.136 & 0.187 & $0.482 * *$ \\
\hline & $D_{21} *$ Post-job & 0.196 & 0.193 & $0.327 *$ & 0.129 & 0.127 & 0.252 \\
\hline & $D_{22} *$ Post-job & 0.152 & 0.129 & 0.184 & 0.086 & 0.062 & 0.103 \\
\hline & $D_{23} *$ Post-job & 0.115 & 0.146 & 0.253 & 0.068 & 0.101 & 0.210 \\
\hline & $D_{24} *$ Post-job & 0.132 & 0.158 & $0.359 *$ & 0.070 & 0.095 & 0.290 \\
\hline & $D_{25} *$ Post-job & -0.080 & -0.045 & $0.387 * *$ & -0.138 & -0.103 & $0.333^{*}$ \\
\hline & $D_{26} *$ Post-job & 0.053 & 0.040 & $0.593 * *$ & -0.006 & -0.023 & $0.527 * *$ \\
\hline & $D_{27} *$ Post-job & 0.199 & 0.190 & 0.091 & 0.103 & 0.086 & -0.111 \\
\hline & $D_{28} *$ Post-job & $0.307^{*}$ & $0.309^{*}$ & $0.510 * *$ & 0.204 & 0.202 & 0.350 \\
\hline & $D_{29} *$ Post-job & 0.114 & 0.127 & 0.273 & 0.052 & 0.064 & 0.169 \\
\hline & $D_{30} *$ Post-job & 0.194 & 0.204 & $0.809 * *$ & 0.131 & 0.140 & $0.724^{*}$ \\
\hline \multicolumn{2}{|c|}{ Sample size } & 85,530 & 74,874 & 40,933 & 80,050 & 69,394 & 35,453 \\
\hline
\end{tabular}

Note) 1. Standard errors are clustered at a worker level.

$$
\text { 2. } * * * p<0.01, * * p<0.05, * p<0.1
$$


Table A.4. Placebo test: Probit analysis with false reforms

\begin{tabular}{|c|c|c|c|c|c|}
\hline & & \multicolumn{2}{|c|}{$\begin{array}{c}\text { Placebo test I: } \\
\text { False reforms } \\
\text { on temporary-contract workers }\end{array}$} & \multirow{2}{*}{\multicolumn{2}{|c|}{$\begin{array}{c}\text { Placebo test II: } \\
\text { A false reform } \\
\text { on selected regular worker groups } \\
\text { Regular workers covered by } \\
\end{array}$}} \\
\hline & & \multirow{3}{*}{$\begin{array}{l}\text { A false reform } \\
\text { in Jan. } 2004 \\
2001-2006\end{array}$} & \multirow{2}{*}{$\begin{array}{l}\text { A false reform } \\
\text { in Jan. } 2013\end{array}$} & & \\
\hline & & & & social insurance $e^{l}$ & $\begin{array}{l}\text { excluding exceptions } \\
\text { of the regulation }{ }^{2}\end{array}$ \\
\hline \multicolumn{2}{|c|}{ Sample period } & & $2010-2015$ & \multicolumn{2}{|c|}{$2001-2013$} \\
\hline & Before & Jan. $2001-$ Dec. 2003 & Jan. 2010 - Dec. 2012 & \multicolumn{2}{|c|}{ Jan. 2001 - Jun. 2007} \\
\hline & Reform & A reform in Jan. 2004 & A reform in Jan. 2013 & \multicolumn{2}{|c|}{ A reform in Jul. 2007} \\
\hline & After & Jan. 2004 - Dec. 2006 & Jan. 2013 - Dec. 2015 & \multicolumn{2}{|c|}{ Jul. 2007 - Dec. 2013} \\
\hline \multirow{30}{*}{$\begin{array}{c}\delta_{r}: \\
\text { The coefficient } \\
\text { of } \\
{\left[D_{\text {rit }} \cdot \text { Post-job } b_{i}\right]}\end{array}$} & $D_{1} *$ Post-job & 0.095 & -0.028 & -0.105 & -0.010 \\
\hline & $D_{2} *$ Post-job & 0.092 & 0.120 & 0.032 & -0.021 \\
\hline & $D_{3} *$ Post-job & 0.143 & -0.139 & $-0.255^{*}$ & -0.205 \\
\hline & $D_{4} *$ Post-job & -0.027 & -0.035 & 0.013 & 0.042 \\
\hline & $D_{5} *$ Post-job & 0.039 & $-0.231 * *$ & -0.181 & -0.219 \\
\hline & $D_{6} *$ Post-job & 0.162 & $-0.192 *$ & -0.039 & -0.054 \\
\hline & $D_{7} *$ Post-job & -0.019 & -0.069 & -0.147 & -0.137 \\
\hline & $D_{8} *$ Post-job & -0.163 & $-0.208 *$ & -0.061 & -0.126 \\
\hline & $D_{9} *$ Post-job & $-0.245^{* *}$ & $0.201 *$ & 0.056 & 0.039 \\
\hline & $D_{10} *$ Post-job & 0.093 & $0.243 * *$ & -0.056 & -0.058 \\
\hline & $D_{11} *$ Post-job & -0.041 & 0.166 & 0.006 & -0.043 \\
\hline & $D_{12} *$ Post-job & -0.080 & 0.124 & 0.001 & 0.016 \\
\hline & $D_{13} *$ Post-job & -0.039 & 0.065 & 0.141 & $0.172 *$ \\
\hline & $D_{14} *$ Post-job & $-0.345^{* *}$ & -0.039 & 0.139 & 0.139 \\
\hline & $D_{15} *$ Post-job & -0.095 & -0.068 & 0.114 & 0.084 \\
\hline & $D_{16} *$ Post-job & -0.119 & 0.124 & 0.066 & 0.068 \\
\hline & $D_{17} *$ Post-job & -0.261 & -0.292 & 0.128 & 0.104 \\
\hline & $D_{18} *$ Post-job & 0.088 & 0.136 & 0.134 & 0.090 \\
\hline & $D_{19} *$ Post-job & -0.049 & 0.209 & 0.141 & 0.127 \\
\hline & $D_{20} *$ Post-job & -0.165 & -0.153 & $0.270 * * *$ & $0.294 * * *$ \\
\hline & $D_{21} *$ Post-job & -0.073 & -0.051 & $0.266^{* * *}$ & $0.244 * *$ \\
\hline & $D_{22} *$ Post-job & 0.048 & -0.011 & $0.169 *$ & $0.211 * *$ \\
\hline & $D_{23} *$ Post-job & -0.165 & 0.142 & 0.162 & 0.092 \\
\hline & $D_{24} *$ Post-job & -0.250 & -0.195 & $0.226 * *$ & $0.200 *$ \\
\hline & $D_{25} *$ Post-job & $-0.592 * * *$ & 0.229 & $0.211 * *$ & $0.209 *$ \\
\hline & $D_{26} *$ Post-job & $-0.745 * * *$ & 0.161 & $0.243 * *$ & $0.236 * *$ \\
\hline & $D_{27} *$ Post-job & 0.358 & 0.284 & $0.212 * *$ & 0.166 \\
\hline & $D_{28} *$ Post-job & -0.115 & 0.288 & $0.254 * *$ & $0.215^{*}$ \\
\hline & $D_{29} *$ Post-job & -0.409 & $0.460 *$ & 0.044 & 0.034 \\
\hline & $D_{30} *$ Post-job & $-0.994 * * *$ & $0.570 * *$ & 0.133 & 0.182 \\
\hline \multicolumn{2}{|c|}{ Sample size } & 27,813 & 37,701 & 145,713 & 131,429 \\
\hline
\end{tabular}

Note) 1. Social insurance programs in Korea include Unemployment insurance, National pension, National health insurance, and Industrial accident compensation insurance.

2. The exceptions of the regulation that can be identifiable in the data set are as follows: (i) Firms in the private sector with fewer than five employees, (ii) Workers aged 55 or older at the time of signing an employment contract, (iii) Workers who work less than 15 hours per week regularly. 
Table A.5. The descriptive statistics for the workers providing overtime hours

\begin{tabular}{|c|c|c|c|c|c|c|c|c|c|c|c|c|c|c|c|c|c|}
\hline & \multicolumn{17}{|c|}{$O T i=1$, if a worker provides overtime work and HRi $=$ Weekly overtime hours } \\
\hline & Year & 2001 & 2002 & 2003 & 2004 & 2005 & 2006 & 2007 & 2008 & 2009 & 2010 & 2011 & 2012 & 2013 & 2014 & 2015 & 2016 \\
\hline \multirow{3}{*}{$\begin{array}{l}\text { Regular } \\
\text { workers }\end{array}$} & $\begin{array}{l}\text { The number } \\
\text { of workers }\end{array}$ & 1089 & 1147 & 1417 & 1552 & 1559 & 1726 & 1865 & 1840 & 2101 & 2100 & 2129 & 2250 & 2286 & 2274 & 2426 & 2537 \\
\hline & $\begin{array}{c}\text { The number } \\
\text { of OTi }=1 \\
\text { (\%) }\end{array}$ & $\begin{array}{r}503 \\
(46.2)\end{array}$ & $\begin{array}{r}530 \\
(46.2)\end{array}$ & $\begin{array}{r}500 \\
(35.3)\end{array}$ & $\begin{array}{l}574 \\
(37.0)\end{array}$ & $\begin{array}{r}576 \\
(36.9)\end{array}$ & $\begin{array}{r}643 \\
(37.3)\end{array}$ & $\begin{array}{l}676 \\
(36.2)\end{array}$ & $\begin{array}{r}731 \\
(39.7)\end{array}$ & $\begin{array}{l}786 \\
(37.4)\end{array}$ & $\begin{array}{l}791 \\
(37.7)\end{array}$ & $\begin{array}{r}820 \\
(38.5)\end{array}$ & $\begin{array}{c}831 \\
(36.9)\end{array}$ & $\begin{array}{r}864 \\
(37.8)\end{array}$ & $\begin{array}{r}911 \\
(40.1)\end{array}$ & $\begin{array}{r}912 \\
(37.6)\end{array}$ & $\begin{array}{r}915 \\
(36.1)\end{array}$ \\
\hline & $E[\mathrm{HR} i \mid H R i>0]$ & 9.0 & 8.9 & 8.8 & 8.8 & 8.6 & 8.5 & 8.9 & 9.4 & 8.9 & 9.7 & 9.7 & 9.4 & 9.4 & 9.6 & 9.2 & 9.1 \\
\hline \multirow{3}{*}{$\begin{array}{l}\text { Temporary- } \\
\text { contract } \\
\text { workers }\end{array}$} & $\begin{array}{l}\text { The number } \\
\text { of workers }\end{array}$ & 257 & 271 & 264 & 276 & 284 & 303 & 317 & 351 & 564 & 600 & 643 & 650 & 699 & 704 & 687 & 755 \\
\hline & $\begin{array}{c}\text { The number } \\
\text { of OTi }=1 \\
(\%)\end{array}$ & $\begin{array}{c}37 \\
(14.4)\end{array}$ & $\begin{array}{r}39 \\
(14.4)\end{array}$ & $\begin{array}{l}19 \\
(7.2)\end{array}$ & $\begin{array}{l}19 \\
(6.9)\end{array}$ & $\begin{array}{l}26 \\
(9.2)\end{array}$ & $\begin{array}{c}37 \\
(12.2)\end{array}$ & $\begin{array}{r}38 \\
(12.0)\end{array}$ & $\begin{array}{r}38 \\
(10.8)\end{array}$ & $\begin{array}{l}53 \\
(9.4)\end{array}$ & $\begin{array}{l}55 \\
(9.2)\end{array}$ & $\begin{array}{l}62 \\
(9.6)\end{array}$ & $\begin{array}{l}56 \\
(8.6)\end{array}$ & $\begin{array}{l}50 \\
(7.2)\end{array}$ & $\begin{array}{l}56 \\
(8.0)\end{array}$ & $\begin{array}{l}37 \\
(5.4)\end{array}$ & $\begin{array}{l}60 \\
(7.9)\end{array}$ \\
\hline & $E[\mathrm{HR} i \mid H R i>0]$ & 6.6 & 6.9 & 6.8 & 6.2 & 5.9 & 6.1 & 9.4 & 9.7 & 7.0 & 6.3 & 7.4 & 7.3 & 8.7 & $\begin{array}{c}12 . \\
7\end{array}$ & 8.7 & 7.9 \\
\hline
\end{tabular}

Table A.6. The descriptive statistics for the workers providing unpaid overtime hours

\begin{tabular}{|c|c|c|c|c|c|c|c|c|c|c|c|c|c|c|c|c|c|}
\hline & \multicolumn{17}{|c|}{$U O T i=1$, if a worker provides unpaid overtime work and $U H R i=$ Weekly unpaid overtime hours } \\
\hline & Year & 2001 & 2002 & 2003 & 2004 & 2005 & 2006 & 2007 & 2008 & 2009 & 2010 & 2011 & 2012 & 2013 & 2014 & 2015 & 2016 \\
\hline \multirow{3}{*}{$\begin{array}{l}\text { Regular } \\
\text { workers }\end{array}$} & $\begin{array}{l}\text { The number } \\
\text { of workers }\end{array}$ & 1089 & 1147 & 1417 & 1552 & 1559 & 1726 & 1865 & 1840 & 2101 & 2100 & 2129 & 2250 & 2286 & 2274 & 2426 & 2537 \\
\hline & $\begin{array}{c}\text { The number } \\
\text { of UOTi }=1 \\
(\%)\end{array}$ & $\begin{array}{r}194 \\
(17.8)\end{array}$ & $\begin{array}{r}194 \\
(16.9)\end{array}$ & $\begin{array}{r}213 \\
(15.0)\end{array}$ & $\begin{array}{r}250 \\
(16.1)\end{array}$ & $\begin{array}{r}248 \\
(15.9)\end{array}$ & $\begin{array}{r}270 \\
(15.6)\end{array}$ & $\begin{array}{l}273 \\
(14.6)\end{array}$ & $\begin{array}{r}322 \\
(17.5)\end{array}$ & $\begin{array}{r}363 \\
(17.3)\end{array}$ & $\begin{array}{r}344 \\
(16.4)\end{array}$ & $\begin{array}{r}359 \\
(16.9)\end{array}$ & $\begin{array}{l}360 \\
(16.0)\end{array}$ & $\begin{array}{r}397 \\
(17.4)\end{array}$ & $\begin{array}{c}421 \\
(18.5)\end{array}$ & $\begin{array}{l}453 \\
(18.7)\end{array}$ & $\begin{array}{r}444 \\
(17.5)\end{array}$ \\
\hline & $E[$ UHR $i \mid U H R i>0]$ & 9.0 & 8.4 & 7.9 & 8.1 & 8.4 & 7.7 & 7.9 & 8.0 & 8.6 & 8.6 & 9.3 & 8.8 & 8.5 & 8.3 & 8.3 & 8.4 \\
\hline \multirow{3}{*}{$\begin{array}{c}\text { Temporary } \\
\text {-contract } \\
\text { workers }\end{array}$} & $\begin{array}{l}\text { The number } \\
\text { of workers }\end{array}$ & 257 & 271 & 264 & 276 & 284 & 303 & 317 & 351 & 564 & 600 & 643 & 650 & 699 & 704 & 687 & 755 \\
\hline & $\begin{array}{c}\text { The number } \\
\text { of UOTi }=1 \\
(\%)\end{array}$ & $\begin{array}{l}23 \\
(8.9)\end{array}$ & $\begin{array}{c}19 \\
(7.0)\end{array}$ & $\begin{array}{c}8 \\
(3.0)\end{array}$ & $\begin{array}{l}15 \\
(5.4)\end{array}$ & $\begin{array}{c}5 \\
(1.8)\end{array}$ & $\begin{array}{l}14 \\
(4.6)\end{array}$ & $\begin{array}{l}12 \\
(3.8)\end{array}$ & $\begin{array}{l}11 \\
(3.1)\end{array}$ & $\begin{array}{l}28 \\
(5.0)\end{array}$ & $\begin{array}{l}28 \\
(4.7)\end{array}$ & $\begin{array}{l}31 \\
(4.8)\end{array}$ & $\begin{array}{l}28 \\
(4.3)\end{array}$ & $\begin{array}{l}20 \\
(2.9)\end{array}$ & $\begin{array}{l}26 \\
(3.7)\end{array}$ & $\begin{array}{l}17 \\
(2.5)\end{array}$ & (2.6) \\
\hline & $E[\mathrm{UHR} i \mid U H R i>0]$ & 7.0 & 6.0 & 6.5 & 6.1 & 3.6 & 5.4 & 10.2 & 7.0 & 6.0 & 5.4 & 5.8 & 6.8 & 8.9 & 15.1 & 9.9 & 6.6 \\
\hline
\end{tabular}


Table A.7. The effect of the reform on workers' overtime

\begin{tabular}{|c|c|c|c|c|c|}
\hline & & $\begin{array}{c}\text { I. } \\
\text { OTit }=1, \\
\text { if providing } \\
\text { overtime work } \\
\text { (paid \& unpaid) }\end{array}$ & $\begin{array}{c}\text { II. } \\
\text { UOTit }=1, \\
\text { if providing } \\
\text { unpaid overtime } \\
\text { work }\end{array}$ & $\begin{array}{c}\text { III. } \\
\text { HRit = average } \\
\text { Weekly } \\
\text { overtime hours } \\
\text { (paid \& unpaid) }\end{array}$ & $\begin{array}{c}\text { IV. } \\
\text { UHRit }=\text { average } \\
\text { weekly } \\
\text { hours of unpaid } \\
\text { overtime }\end{array}$ \\
\hline Variables & Variable explanation & Probit & Probit & Tobit & Tobit \\
\hline Temp & Temporary-contract & $-0.396^{* * *}$ & $-0.215^{* * *}$ & $-4.768 * * *$ & $-3.152 * * *$ \\
\hline After & Post-reform period ( $1=$ after July, 2007) & $0.106^{* * *}$ & 0.044 & $1.484 * * *$ & 0.755 \\
\hline Post-job & Post-job $=1$, if a job began after the reform & 0.058 & 0.031 & 0.451 & 0.544 \\
\hline Temp * After & Temporary-contract $*$ After & 0.031 & -0.017 & 0.201 & -0.186 \\
\hline \multirow[t]{2}{*}{ Temp * Post-job } & Temporary-contract $*$ Post-job & -0.128 & -0.142 & -1.097 & -1.570 \\
\hline & Age Cohort (base: age 35-39) & & & & \\
\hline age_c1519 & age cohort1: 15-19 & -0.026 & $-0.629 * * *$ & -0.650 & $-8.456 * * *$ \\
\hline age_c2024 & age cohort2: $20-24$ & -0.029 & -0.0672 & -0.516 & -0.912 \\
\hline age_c2529 & age cohort3: $25-29$ & 0.012 & -0.007 & 0.011 & -0.098 \\
\hline age_c3034 & age cohort4: $30-34$ & $0.057^{* *}$ & 0.028 & 0.451 & 0.210 \\
\hline age_c4044 & age cohort6: $40-44$ & $-0.063^{* *}$ & -0.049 & -0.449 & -0.651 \\
\hline age_c4549 & age cohort7: $45-49$ & $-0.147 * * *$ & $-0.100^{* *}$ & $-1.508^{* * *}$ & $-1.560^{* * *}$ \\
\hline age_c5054 & age cohort8: $50-54$ & $-0.304 * * *$ & $-0.276^{* * *}$ & $-3.376^{* * *}$ & $-4.245^{* * *}$ \\
\hline age_c5559 & age cohort9: $55-59$ & $-0.425 * * *$ & $-0.285^{* * *}$ & $-4.508^{* * *}$ & $-3.974 * * *$ \\
\hline age_c6064 & age cohort10: 60-64 & $-0.713^{* * *}$ & $-0.437 * * *$ & $-8.215 * * *$ & $-6.414 * * *$ \\
\hline age_c65up & age cohort11: 65 or older & $-1.009 * * *$ & $-0.627 * * *$ & $-12.890 * * *$ & $-9.581 * * *$ \\
\hline Female & Female & $-0.176^{* * *}$ & $-0.271 * * *$ & $-2.234 * * *$ & $-4.106^{* * *}$ \\
\hline Married & Marriage status: $1=$ married & $0.151^{* * *}$ & $0.0926^{* * *}$ & $1.677 * * *$ & $1.709 * * *$ \\
\hline \multirow[t]{2}{*}{ Female * Married } & Female $*$ Married & $-0.135 * * *$ & $-0.200 * * *$ & $-1.554 * * *$ & $-3.033 * * *$ \\
\hline & Education Level (base: High school) & & & & \\
\hline edu_1 & Elementary school or less & $0.121^{*}$ & $0.148^{*}$ & $1.712 * *$ & $2.442 *$ \\
\hline edu_2 & Middle school & 0.028 & 0.015 & 0.616 & 0.527 \\
\hline edu_4 & College ( 2 years) & -0.001 & $0.063^{*}$ & -0.178 & $0.937^{*}$ \\
\hline edu_5 & University (4years) & $0.080^{* *}$ & $0.244 * * *$ & $0.855^{* *}$ & $3.677^{* * *}$ \\
\hline edu_6 & Master & $0.174^{* * *}$ & $0.325^{* * *}$ & $1.602 * *$ & $4.682 * * *$ \\
\hline \multirow[t]{2}{*}{ edu_7 } & Ph.D. & 0.080 & $0.324 * *$ & 0.649 & $4.453^{* *}$ \\
\hline & Tenure in month (base: 13-24 months) & & & & \\
\hline tenure_1 & $1 \sim 3$ months & $-0.309^{* * *}$ & $-0.147 * * *$ & $-3.023 * * *$ & $-1.748 * *$ \\
\hline tenure_2 & $4 \sim 6$ months & $-0.129 * * *$ & $-0.093 * *$ & $-1.349^{* * *}$ & $-1.304 * *$ \\
\hline tenure_3 & $7 \sim 12$ months & $-0.080^{* * *}$ & -0.034 & $-0.828^{* *}$ & -0.637 \\
\hline tenure_5 & $25 \sim 36$ months & 0.027 & 0.038 & 0.249 & 0.534 \\
\hline tenure_6 & $37 \sim 60$ months & 0.004 & 0.022 & -0.025 & 0.360 \\
\hline tenure_7 & $61 \sim 120$ months & 0.003 & -0.006 & -0.188 & -0.081 \\
\hline tenure_8 & 121 months or more & $0.070^{*}$ & $0.082 *$ & 0.264 & 0.908 \\
\hline Private_sector & Private sector & $0.106^{* * *}$ & $0.205^{* * *}$ & $1.598^{* * *}$ & $2.935^{* * *}$ \\
\hline Union & Union in the workplace & $0.076^{* *}$ & $0.081^{* *}$ & $0.646^{*}$ & $1.122 * *$ \\
\hline Union * In-union & Union membership & $0.145^{* * *}$ & $-0.205^{* * *}$ & $1.179^{* * *}$ & $-2.866^{* * *}$ \\
\hline Parttime & Part-time job & $-0.202 * * *$ & $-0.268^{* * *}$ & $-2.372 * * *$ & $-3.401 * * *$ \\
\hline
\end{tabular}


Table A7. The effect of the reform on workers' overtime (continued)

\begin{tabular}{|c|c|c|c|c|c|}
\hline & & $\begin{array}{c}\text { I. } \\
\text { OTit }=1, \\
\text { if providing } \\
\text { overtime work } \\
\text { (paid \& } \\
\text { unpaid) }\end{array}$ & $\begin{array}{c}\text { II. } \\
\text { UOTit }=1 \text {, } \\
\text { if providing } \\
\text { unpaid } \\
\text { overtime work }\end{array}$ & $\begin{array}{c}\text { III. } \\
\text { HRit }=\text { average } \\
\text { Weekly } \\
\text { overtime } \\
\text { hours }\end{array}$ & $\begin{array}{c}\text { IV. } \\
\text { UHRit }= \\
\text { average weekly } \\
\text { hours of } \\
\text { unpaid } \\
\text { overtime }\end{array}$ \\
\hline Variables & Variable explanation & Probit & Probit & Tobit & Tobit \\
\hline \multicolumn{6}{|c|}{ ( continued) } \\
\hline & Firm size (base: $1-9$ people) & & & & \\
\hline fsize_2 & 10-29 people & $0.215^{* * *}$ & 0.0387 & $2.837 * * *$ & 0.706 \\
\hline fsize_3 & 30-99 people & $0.385 * * *$ & -0.007 & $4.916 * * *$ & 0.207 \\
\hline fsize_4 & 100-299 people & $0.439 * * *$ & -0.0247 & $5.747^{* * *}$ & -0.018 \\
\hline fsize_5 & 300-999 people & $0.498 * * *$ & -0.0519 & $6.208 * * *$ & -0.334 \\
\hline fsize_6 & 1,000 or more than 1,000 people & $0.579 * * *$ & -0.0620 & $6.896^{* * *}$ & -0.307 \\
\hline \multirow[t]{2}{*}{ fsize_7 } & unknown & $0.234 * * *$ & $-0.231 * * *$ & $3.291 * * *$ & $-2.991 * * *$ \\
\hline & Occupation (base: Office clerk) & & & & \\
\hline occupation_1 & Legislative officers, executives, and high managers & -0.110 & -0.026 & -0.469 & 0.106 \\
\hline occupation_2 & Professional & $0.117^{* * *}$ & 0.029 & $1.410^{* * *}$ & 0.561 \\
\hline occupation_3 & Engineers and semi-professional & $0.075^{*}$ & 0.022 & $0.939^{* *}$ & 0.501 \\
\hline occupation_5 & Service workers & $-0.154 * *$ & $-0.486^{* * *}$ & -1.224 & $-6.034 * * *$ \\
\hline occupation_6 & Sales force & $-0.186^{* * *}$ & $-0.266^{* * *}$ & $-1.982 * * *$ & $-3.447 * * *$ \\
\hline occupation_7 & Agriculture and fishery workers & 0.046 & -0.330 & 0.379 & -3.652 \\
\hline occupation_8 & Technicians & $0.204 * * *$ & $-0.327 * * *$ & $2.342 * * *$ & $-4.359 * * *$ \\
\hline occupation_9 & Equipment, machine, and assembly workers & $0.184 * * *$ & $-0.634 * * *$ & $2.865^{* * *}$ & $-8.437 * * *$ \\
\hline occupation_10 & Unskilled workers & -0.024 & $-0.451 * * *$ & 0.129 & $-6.120 * * *$ \\
\hline \multirow[t]{2}{*}{ occupation_11 } & unknown & 0.374 & 0.136 & $4.170^{*}$ & 2.456 \\
\hline & Industry (base: Manufacturing) & & & & \\
\hline ind_1 & Agriculture, hunting, forestry, and fishery & $-0.538^{* *}$ & -0.196 & $-6.232 * *$ & -3.336 \\
\hline ind_2 & Mining & 0.050 & -0.309 & 0.945 & -4.526 \\
\hline ind_4 & Electricity, gas, and water & $-0.501 * * *$ & -0.242 & $-6.756^{* * *}$ & $-4.105^{*}$ \\
\hline ind_5 & Construction & $-0.302 * * *$ & 0.044 & $-3.221 * * *$ & 0.616 \\
\hline ind_6 & Wholesale and retail & $-0.464 * * *$ & $-0.121 * *$ & $-5.290 * * *$ & $-1.978^{* * *}$ \\
\hline ind_7 & Lodge and food & $-0.451 * * *$ & -0.110 & $-5.022 * * *$ & -1.478 \\
\hline ind_8 & Transportation and communication service & $-0.610^{* * *}$ & $-0.171 * * *$ & $-6.936^{* * *}$ & $-2.440 * * *$ \\
\hline ind_9 & Banking and insurance & $-0.133^{* *}$ & $0.256^{* * *}$ & $-1.581 * * *$ & $3.343 * * *$ \\
\hline ind_10 & Real estate and leasing service & $-0.871 * * *$ & $-0.386^{* * *}$ & $-10.20 * * *$ & $-5.606^{* * *}$ \\
\hline ind_11 & Business service & $-0.240^{* * *}$ & $0.075^{*}$ & $-2.654 * * *$ & 0.817 \\
\hline ind_12 & Public, social security, and defense administration & $-0.303 * * *$ & -0.103 & $-3.810^{* * *}$ & -2.290 \\
\hline ind_13 & Education service & $-0.621 * * *$ & $-0.215^{* * *}$ & $-6.916^{* * *}$ & $-3.313^{* * *}$ \\
\hline ind_14 & Health and social welfare service & $-0.534 * * *$ & $-0.236^{* * *}$ & $-6.059 * * *$ & $-3.309^{* * *}$ \\
\hline ind_15 & Entertainment, broadcasting, and performance & $-0.626^{* * *}$ & $-0.280 * * *$ & $-6.877^{* * *}$ & $-3.622 * *$ \\
\hline ind_16 & Other individual service & $-0.494 * * *$ & -0.034 & $-5.453 * * *$ & -0.928 \\
\hline ind_17 & Other association, organization, and international agency & $-0.605^{* * *}$ & -0.111 & $-6.890^{* * *}$ & -2.061 \\
\hline ind_18 & unknown & $-0.490^{*}$ & -0.154 & $-4.887^{*}$ & -2.470 \\
\hline year & Linear time trend (in year) & $-0.039 * * *$ & $-0.039 * * *$ & $-0.373 * * *$ & $-0.567^{* * *}$ \\
\hline year_sq & Square of linear time trend & $0.002 * *$ & $0.002 * * *$ & $0.016^{* *}$ & $0.030 * * *$ \\
\hline emprate & Employment rate in each year & 0.021 & -0.0302 & 0.185 & -0.534 \\
\hline unemprate & Unemployment rate in each year & -0.030 & 0.006 & -0.398 & -0.008 \\
\hline Constant & & -1.637 & 0.920 & -16.78 & 18.66 \\
\hline Sigma $(\sigma)$ & & - & - & $11.91^{* * *}$ & $14.39^{* * *}$ \\
\hline Observations & $\begin{array}{l}\text { Total number of observations } \\
\text { (left-censored observations at zero) }\end{array}$ & 37,835 & 37,835 & $\begin{array}{l}37,835 \\
(25,663) \\
\end{array}$ & $\begin{array}{l}37,835 \\
(32,452) \\
\end{array}$ \\
\hline
\end{tabular}

Note) 1. Standard errors are clustered at an individual level (the number of individuals: 8,497 ).

2. *** $p<0.01, * * p<0.05, * p<0.1$ 


\section{Appendix B: Appendix to Chapter 2}

Table B.1. Survey questions on employment arrangement and perceived job security in KLIPS

Q1. Was the period of an employment contract determined when you (a worker) were hired on the job?

(1) Yes, the contract period was fixed in advance.

(2) No, it was not fixed. ( $\rightarrow$ Q2)

(3) Unknown

Q2. Unless the firm discontinues its business or lay off workers due to its financial exigency, or you do something wrong, can you continue your current job in the firm as long as you want?

(1) Yes $(\rightarrow \mathbf{Q 3})$

(2) No $(\rightarrow$ Q4)

Q3. What is the reason for answering 'Yes' to the Q2?

(1) Permanent employment contract

(2) Employment continues with repeated renewal of a contract

(3) Common employment practice in the firm (e.g. retirement age)

Q4. What is the reason for answering 'No' to the Q2?

(1) Hired on the condition that an employee quit his/her current job at the employer's request

(2) Termination of employment contract according to common practice

(3) The expiry of the employment contract

(4) Completion of the current project

(5) The return of the previous worker to the job

(6) Seasonal employment

(7) Looking for other jobs

(8) Retirement according to the firm's regulation or common practice

(9) To quit the job due to illness/education/family support

(10) Dismissal due to the firm's financial exigency 
Table B.2. The time (year) fixed effect on the probability of having insecure jobs: Logit analysis

\begin{tabular}{|c|c|c|c|}
\hline & & \multicolumn{2}{|c|}{ Logit Model } \\
\hline & VARIABLES & \multicolumn{2}{|c|}{$\begin{array}{l}\mathbf{1}=\text { Insecure Job for Involuntary Reason }(\mathbf{C} \& \mathbf{D}) \\
0=\text { the other jobs }\end{array}$} \\
\hline & & \multicolumn{2}{|c|}{ Time (year) Fixed Effect } \\
\hline & & No Control & Control \\
\hline & Year (base: 2002) & & \\
\hline 2003 & & 0.201 & 0.223 \\
\hline 2004 & & 0.264 & 0.328 \\
\hline 2005 & & $0.815 * * *$ & $0.881 * * *$ \\
\hline 2006 & & 0.306 & $0.520^{* *}$ \\
\hline 2007 & & $1.077 * * *$ & $1.278 * * *$ \\
\hline 2008 & & $1.523 * * *$ & $1.812 * * *$ \\
\hline 2009 & & $1.922 * * *$ & $2.256 * * *$ \\
\hline 2010 & & $2.448 * * *$ & $2.908 * * *$ \\
\hline 2011 & & $2.524 * * *$ & $2.955 * * *$ \\
\hline 2012 & & $2.885 * * *$ & $3.447 * * *$ \\
\hline 2013 & & $2.729 * * *$ & $3.249 * * *$ \\
\hline 2014 & & $2.665 * * *$ & $3.189 * * *$ \\
\hline 2015 & & $2.709 * * *$ & $3.256^{* * *}$ \\
\hline 2016 & & $2.705^{* * * *}$ & 3.281 *** \\
\hline Female & Female & & 0.095 \\
\hline Married & Marriage status: $1=$ married & & $-0.349 * * *$ \\
\hline \multirow[t]{2}{*}{ Female $*$ Married } & Female $*$ Married & & $0.337 * * *$ \\
\hline & Education Level (base: High school) & & \\
\hline edu_1 & Elementary school or less & & $0.211 * *$ \\
\hline edu_2 & Middle school & & $0.186 * *$ \\
\hline edu_4 & College (2 years) & & $-0.520 * * *$ \\
\hline edu_5 & University (4years) & & $-0.797 * * *$ \\
\hline edu_6 & Master & & $-0.696 * * *$ \\
\hline \multirow[t]{2}{*}{ edu_7 } & Ph.D. & & $-0.923 *$ \\
\hline & Age Cohort (base: age 35-39) & & \\
\hline age_c1519 & age cohort1: $15-19$ & & 0.175 \\
\hline age_c2024 & age cohort $2: 20-24$ & & 0.098 \\
\hline age_c2529 & age cohort $3: 25-29$ & & -0.133 \\
\hline age_c3034 & age cohort $4: 30-34$ & & $-0.187 * *$ \\
\hline age_c4044 & age cohort6: $40-44$ & & $0.221 * * *$ \\
\hline age_c4549 & age cohort $7: 45-49$ & & $0.212 * *$ \\
\hline age_c5054 & age cohort8: $50-54$ & & $0.370 * * *$ \\
\hline age_c5559 & age cohort9: $55-59$ & & $0.453 * * *$ \\
\hline age_c6064 & age cohort10: $60-64$ & & $0.489 * * *$ \\
\hline \multirow[t]{2}{*}{ age_c65up } & age cohort11: 65 or older & & $0.368 * * *$ \\
\hline & Tenure in month (base: $13-24$ months) & & \\
\hline tenure_1 & $1 \sim 3$ months & & $0.258 * * *$ \\
\hline tenure_2 & $4 \sim 6$ months & & $0.209 * * *$ \\
\hline tenure_3 & $7 \sim 12$ months & & $0.102 *$ \\
\hline tenure_5 & $25 \sim 36$ months & & $-0.136 * *$ \\
\hline tenure_6 & $37 \sim 60$ months & & $-0.329 * * *$ \\
\hline tenure_7 & $61 \sim 120$ months & & $-0.408 * * *$ \\
\hline \multirow[t]{2}{*}{ tenure_8 } & 121 months or more & & $-0.670 * * *$ \\
\hline & Firm size (base: $1-4$ people) & & \\
\hline fsize_2 & 5-9 people & & $-0.254 * * *$ \\
\hline fsize_3 & 10-29 people & & $-0.536 * * *$ \\
\hline fsize_4 & 30-49 people & & $-0.714 * * *$ \\
\hline fsize_5 & 50-69 people & & $-1.019 * * *$ \\
\hline fsize_6 & 70-99 people & & $-1.182 * * *$ \\
\hline fsize_7 & 100-299 people & & $-1.090 * * *$ \\
\hline fsize_8 & 300-499 people & & $-1.266 * * *$ \\
\hline fsize_9 & 500-999 people & & $-1.072 * * *$ \\
\hline fsize_10 & 1,000 or more than 1,000 people & & $-1.155 * * *$ \\
\hline fsize_11 & unknown & & -0.062 \\
\hline
\end{tabular}


Table B2. The time (year) fixed effect on the probability of having insecure jobs: Logit analysis

(Continued)

\begin{tabular}{|c|c|c|c|}
\hline & & \multicolumn{2}{|c|}{$\begin{array}{r}\text { Logit Model } \\
\end{array}$} \\
\hline \multicolumn{2}{|r|}{ VARIABLES } & \multicolumn{2}{|c|}{1 = Insecure Job for Involuntary Reason $(C \& D)$} \\
\hline \multicolumn{4}{|c|}{ ( Continued) } \\
\hline & & \multicolumn{2}{|c|}{ Time (year) Fixed Effect } \\
\hline & & No Control & Control \\
\hline & Occupation (base: Office clerk) & & \\
\hline occupation_1 & Legislative officers, executives, and high managers & & $-0.706^{*}$ \\
\hline occupation_2 & Professional & & -0.053 \\
\hline occupation_3 & Engineers and semi-professional & & $0.658 * * *$ \\
\hline occupation_5 & Service workers & & $0.858 * * *$ \\
\hline occupation_6 & Sales force & & $0.970 * * *$ \\
\hline occupation_7 & Agriculture and fishery workers & & $1.100 * * *$ \\
\hline occupation_8 & Technicians & & $0.989 * * *$ \\
\hline occupation_9 & Equipment, machine, and assembly workers & & $0.461 * * *$ \\
\hline occupation_10 & Unskilled workers & & $1.170 * * *$ \\
\hline \multirow[t]{2}{*}{ occupation_11 } & unknown & & - \\
\hline & Industry (base: Manufacturing) & & \\
\hline ind_1 & Agriculture, hunting, forestry, and fishery & & $1.216 * * *$ \\
\hline ind_2 & Mining & & 0.320 \\
\hline ind_4 & Electricity, gas, and water & & $-1.734 * * *$ \\
\hline ind_5 & Construction & & $1.569 * * *$ \\
\hline ind_6 & Wholesale and retail & & $0.360 * * *$ \\
\hline ind_7 & Lodge and food & & $0.557 * * *$ \\
\hline ind_8 & Transportation and communication service & & 0.009 \\
\hline ind_9 & Banking and insurance & & 0.197 \\
\hline ind_10 & Real estate and leasing service & & $-0.276^{*}$ \\
\hline ind_11 & Business service & & $0.306 * * *$ \\
\hline ind_12 & Public, social security, and defense administration & & $-0.900 * * *$ \\
\hline ind_13 & Education service & & $0.452 * * *$ \\
\hline ind_14 & Health and social welfare service & & $-0.459 * * *$ \\
\hline ind_15 & Entertainment, broadcasting, and performance & & $0.767 * * *$ \\
\hline ind_16 & Other individual service & & $0.457 * * *$ \\
\hline \multirow[t]{2}{*}{ ind_17 } & Other association, organization, and international agency & & -0.454 \\
\hline & Region (base: Seoul) & & \\
\hline region_2 & BuSan & & -0.012 \\
\hline region_3 & DaeGu & & $-0.223 * *$ \\
\hline region_4 & DaeJeon & & $-1.325 * * *$ \\
\hline region_5 & InChon & & $-0.850 * * *$ \\
\hline region_6 & GwangJu & & $-0.701 * * *$ \\
\hline region_7 & UlSan & & $-0.425 * *$ \\
\hline region_8 & GyeongGi & & $-0.147 * *$ \\
\hline region_9 & GangWon & & $-1.134 * * *$ \\
\hline region_10 & Chung-Buk & & $-0.645 * * *$ \\
\hline region_11 & Chung-Nam & & $-1.128 * * *$ \\
\hline region_12 & Jeon-Buk & & $-1.252 * * *$ \\
\hline region_13 & Jeon-Nam & & $-0.878 * * *$ \\
\hline region_14 & Gyeong-Buk & & -0.092 \\
\hline region_15 & Gyeong-Nam & & $-0.267 * * *$ \\
\hline region_16 & JeJu & & $1.585 * * *$ \\
\hline region_17 & Unknown & & -0.246 \\
\hline Constant & & $-4.564 * * *$ & $-5.122 * * *$ \\
\hline \multicolumn{2}{|r|}{ Observations (The number of individuals) } & $72,986(12,043)$ & $70,200(11,744)$ \\
\hline
\end{tabular}

Note) 1. Robust standard errors are in parenthesis, which are clustered at the individual level.

$$
\text { 2. } * * * \mathrm{p}<0.01, * * \mathrm{p}<0.05, * \mathrm{p}<0.1
$$


Table B.3. The effect of the reform on the probability of having insecure jobs: Logit analysis

\begin{tabular}{|c|c|c|c|}
\hline & & \multicolumn{2}{|c|}{ I. Logit Model } \\
\hline & \multirow[t]{2}{*}{ VARIABLES } & \multicolumn{2}{|c|}{$\begin{array}{l}\mathbf{1}=\text { Insecure Job }(\mathbf{C} \& \mathbf{D}) \\
0=\text { Other Jobs }\end{array}$} \\
\hline & & No Control & Control \\
\hline After & Post-reform period (1=after July, 2007) & $1.645 * * *$ & $1.880 * * *$ \\
\hline Post-job & Post-job $=1$, if a job began after the reform & $0.747 * * *$ & $0.674 * * *$ \\
\hline Female & Female & & 0.095 \\
\hline Married & Marriage status: $1=$ married & & $-0.376^{* * *}$ \\
\hline \multirow[t]{2}{*}{ Female * Married } & Female * Married & & $0.349 * * *$ \\
\hline & Education Level (base: High school) & & \\
\hline edu_1 & Elementary school or less & & 0.101 \\
\hline edu_2 & Middle school & & $0.128 *$ \\
\hline edu_4 & College (2 years) & & $-0.475 * * *$ \\
\hline edu_5 & University (4years) & & $-0.744 * * *$ \\
\hline edu_6 & Master & & $-0.655 * * *$ \\
\hline \multirow[t]{2}{*}{ edu_7 } & Ph.D. & & $-0.858 *$ \\
\hline & Age Cohort (base: age 35-39) & & \\
\hline age_c1519 & age cohort1: $15-19$ & & 0.158 \\
\hline age_c2024 & age cohort2: $20-24$ & & 0.065 \\
\hline age_c2529 & age cohort3: $25-29$ & & $-0.206^{* *}$ \\
\hline age_c3034 & age cohort4: $30-34$ & & $-0.197 * *$ \\
\hline age_c4044 & age cohort6: 40-44 & & $0.230 * * *$ \\
\hline age_c4549 & age cohort7: $45-49$ & & $0.217^{* *}$ \\
\hline age_c5054 & age cohort8: $50-54$ & & $0.429 * * *$ \\
\hline age_c5559 & age cohort9: $55-59$ & & $0.544^{* * *}$ \\
\hline age_c6064 & age cohort10: $60-64$ & & $0.583^{* * * *}$ \\
\hline \multirow[t]{2}{*}{ age_c65up } & age cohort11: 65 or older & & $0.511 * * *$ \\
\hline & Tenure in month (base: $13-24$ months) & & \\
\hline tenure_1 & $1 \sim 3$ months & & $0.196^{* * *}$ \\
\hline tenure _2 & $4 \sim 6$ months & & $0.155^{* *}$ \\
\hline tenure_3 & $7 \sim 12$ months & & 0.054 \\
\hline tenure_5 & $25 \sim 36$ months & & -0.079 \\
\hline tenure_6 & $37 \sim 60$ months & & $-0.188 * * *$ \\
\hline tenure_7 & $61 \sim 120$ months & & -0.010 \\
\hline \multirow[t]{2}{*}{ tenure_8 } & 121 months or more & & 0.009 \\
\hline & Firm size (base: $1-4$ people) & & \\
\hline fsize_2 & 5-9 people & & $-0.243 * * *$ \\
\hline fsize_3 & 10-29 people & & $-0.525 * * *$ \\
\hline fsize_4 & 30-49 people & & $-0.705 * * *$ \\
\hline fsize_5 & 50-69 people & & $-1.011 * * *$ \\
\hline fsize_6 & 70-99 people & & $-1.162^{* * *}$ \\
\hline fsize_7 & 100-299 people & & $-1.095 * * *$ \\
\hline fsize_8 & 300-499 people & & $-1.264 * * *$ \\
\hline fsize_9 & 500-999 people & & $-1.090 * * *$ \\
\hline fsize_10 & 1,000 or more than 1,000 people & & $-1.180^{* * *}$ \\
\hline fsize_11 & unknown & & -0.084 \\
\hline emprate & Regional employment rate in each year & & $0.0535^{* *}$ \\
\hline unemprate & Reginal unemployment rate in each year & & $-0.108 * *$ \\
\hline
\end{tabular}


Table B3. The effect of the reform on the probability of having insecure jobs: Logit analysis (Continued)

\begin{tabular}{|c|c|c|c|}
\hline \multirow{2}{*}{\multicolumn{2}{|c|}{ VARIABLES }} & \multicolumn{2}{|c|}{ I. Logit Model } \\
\hline & & No Control & Control \\
\hline \multicolumn{4}{|c|}{ (Continued) } \\
\hline & Occupation (base: Office clerk) & & \\
\hline occupation_1 & Legislative officers, executives, and high managers & & $-0.735^{*}$ \\
\hline occupation_2 & Professional & & -0.084 \\
\hline occupation_3 & Engineers and semi-professional & & $0.631 * * *$ \\
\hline occupation_5 & Service workers & & $0.842^{* * * *}$ \\
\hline occupation_6 & Sales force & & $0.951 * * *$ \\
\hline occupation_7 & Agriculture and fishery workers & & $1.045^{* * * *}$ \\
\hline occupation_8 & Technicians & & $0.986^{* * * *}$ \\
\hline occupation_9 & Equipment, machine, and assembly workers & & $0.434 * * *$ \\
\hline occupation_10 & Unskilled workers & & $1.145^{* * * *}$ \\
\hline \multirow[t]{2}{*}{ occupation_11 } & unknown & & - \\
\hline & Industry (base: Manufacturing) & & \\
\hline ind_1 & Agriculture, hunting, forestry, and fishery & & $1.207 * * *$ \\
\hline ind_2 & Mining & & 0.258 \\
\hline ind_4 & Electricity, gas, and water & & $-1.731 * * *$ \\
\hline ind_5 & Construction & & $1.524 * * *$ \\
\hline ind_6 & Wholesale and retail & & $0.362 * * *$ \\
\hline ind_7 & Lodge and food & & $0.545^{* * * *}$ \\
\hline ind_8 & Transportation and communication service & & 0.024 \\
\hline ind_9 & Banking and insurance & & 0.202 \\
\hline ind_10 & Real estate and leasing service & & $-0.292 *$ \\
\hline ind_11 & Business service & & $0.308 * * *$ \\
\hline ind_12 & Public, social security, and defense administration & & $-0.900^{* * *}$ \\
\hline ind_13 & Education service & & $0.425^{* * * *}$ \\
\hline ind_14 & Health and social welfare service & & $-0.426^{* * *}$ \\
\hline ind_15 & Entertainment, broadcasting, and performance & & $0.738^{* * * *}$ \\
\hline ind_16 & Other individual service & & $0.426^{* * *}$ \\
\hline \multirow[t]{2}{*}{ ind_17 } & Other association, organization, and international agency & & $-0.539^{*}$ \\
\hline & Region (base: Seoul) & & \\
\hline region_2 & BuSan & & 0.155 \\
\hline region_3 & $\mathrm{DaeGu}$ & & -0.204 \\
\hline region_4 & DaeJeon & & $-1.300^{* * *}$ \\
\hline region_5 & InChon & & $-0.863 * * *$ \\
\hline region_6 & GwangJu & & $-0.662 * * *$ \\
\hline region_7 & UlSan & & $-0.489 * * *$ \\
\hline region_8 & GyeongGi & & $-0.240^{* * *}$ \\
\hline region_9 & GangWon & & $-1.167 * * *$ \\
\hline region_10 & Chung-Buk & & $-0.865 * * *$ \\
\hline region_11 & Chung-Nam & & $-1.328 * * *$ \\
\hline region_12 & Jeon-Buk & & $-1.366^{* * *}$ \\
\hline region_13 & Jeon-Nam & & $-1.255^{* * * *}$ \\
\hline region_14 & Gyeong-Buk & & $-0.398^{* * *}$ \\
\hline region_15 & Gyeong-Nam & & $-0.467 * * *$ \\
\hline region_16 & JeJu & & $0.986^{* * * *}$ \\
\hline region_17 & Unknown & & -0.185 \\
\hline Constant & & $-4.156^{* * *}$ & $-7.345^{* * *}$ \\
\hline & $\begin{array}{c}\text { Observations } \\
\text { (The number of individuals) }\end{array}$ & $\begin{array}{c}72,986 \\
(12,043) \\
\end{array}$ & $\begin{array}{c}70,200 \\
(11,744) \\
\end{array}$ \\
\hline
\end{tabular}

Note) 1. Robust standard errors are in parenthesis, which are clustered at the individual level.

2. $* * * \mathrm{p}<0.01, * * \mathrm{p}<0.05, * \mathrm{p}<0.1$ 


\section{Appendix C: Appendix to Chapter 3}

Table C.1. Survey questions on employment arrangement and perceived job security

Q1. Was the period of an employment contract determined when you (a worker) were hired on the job?

(4) Yes, the contract period was fixed in advance.

(5) No, it was not fixed. ( $\rightarrow$ Q2)

(6) Unknown

Q2. Unless the firm discontinues its business or lay off workers due to its financial exigency, or you do something wrong, can you continue your current job in the firm as long as you want?
(3) Yes $(\rightarrow$ Q3)
(4) No $(\rightarrow$ Q4)

Q3. What is the reason for answering 'Yes' to the Q2?

(4) Permanent employment contract

(5) Employment continues with repeated renewal of a contract

(6) Common employment practice in the firm (e.g. retirement age)

Q4. What is the reason for answering 'No' to the Q2?

(11) Hired on the condition that an employee quit his/her current job at the employer's request

(12) Termination of employment contract according to common practice

(13) The expiry of the employment contract

(14) Completion of the current project

(15) The return of the previous worker to the job

(16) Seasonal employment

(17) Looking for other jobs

(18) Retirement according to the firm's regulation or common practice

(19) To quit the job due to illness/education/family support

(20) Dismissal due to the firm's financial exigency 
Table C.2. EAPS - Unweighted: The number of workers who chose each answer to the four questions

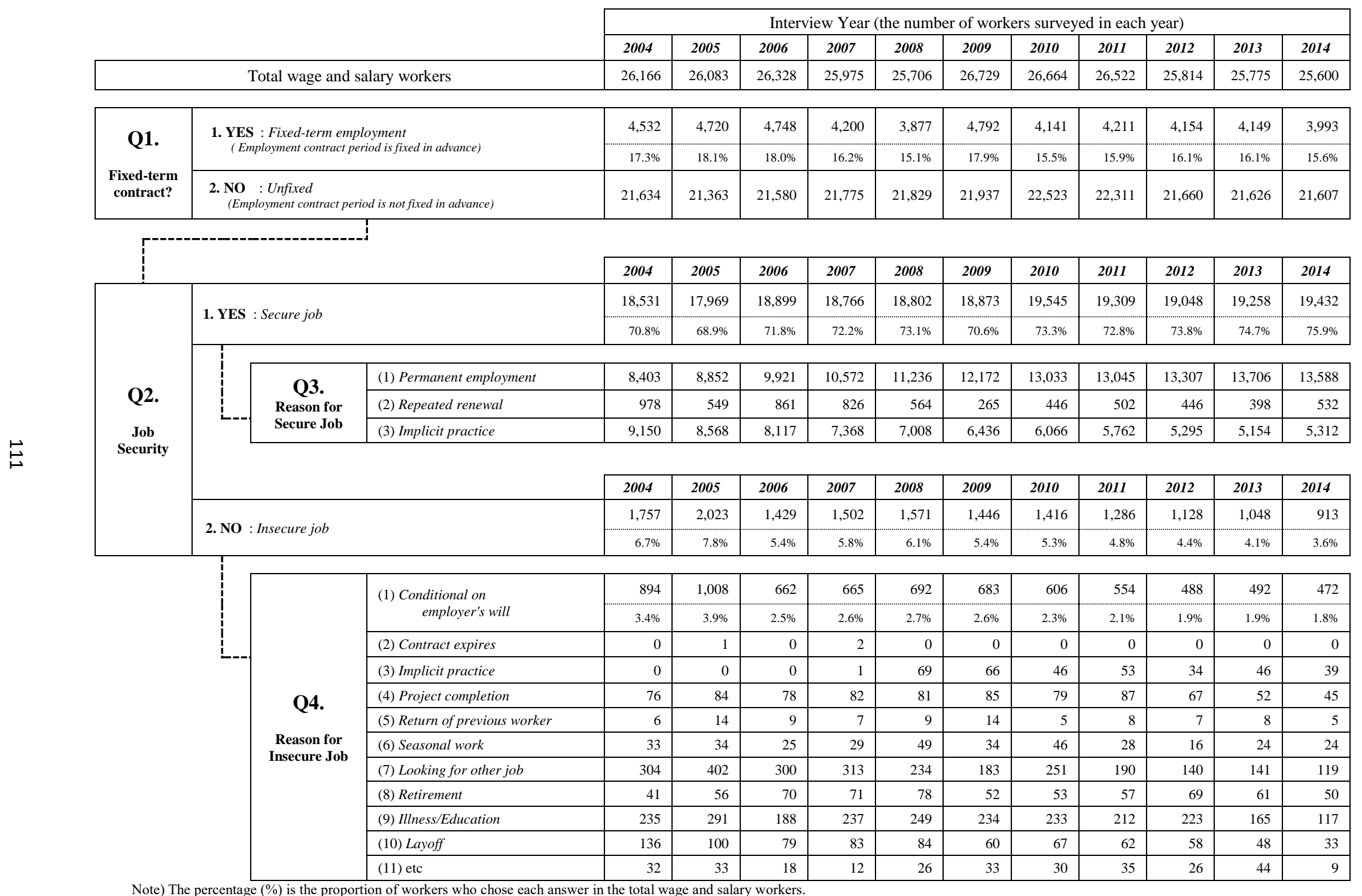

Note) The percentage (\%) is the proportion of workers who chose each answer in the total wage and salary workers. 
Table C.3. EAPS - Weighted: The number of workers who chose each answer to the four questions

\begin{tabular}{|c|c|c|c|c|c|c|c|c|c|c|c|c|c|}
\hline & & & \multicolumn{11}{|c|}{ Interview Year (the number of workers surveyed in each year) } \\
\hline & & & 2004 & 2005 & 2006 & 2007 & 2008 & 2009 & 2010 & 2011 & 2012 & 2013 & 2014 \\
\hline \multicolumn{3}{|c|}{ Total wage and salary workers } & $14,616,991$ & $14,948,224$ & $15,420,543$ & $16,006,557$ & $16,257,717$ & $16,608,864$ & $17,189,358$ & $17,714,763$ & $17,941,062$ & $18,403,517$ & $18,991,829$ \\
\hline \multirow{3}{*}{$\begin{array}{c}\text { Q1. } \\
\text { Fixed-term } \\
\text { contract? }\end{array}$} & \multirow{2}{*}{\multicolumn{2}{|c|}{$\begin{array}{l}\text { 1. YES : Fixed-term employment } \\
\text { ( Employment contract period is fixed in advance) }\end{array}$}} & $2,502,473$ & $2,725,130$ & $2,740,452$ & 2,556,214 & $2,388,235$ & $2,828,109$ & $2,500,046$ & 2,686,529 & $2,729,303$ & $2,770,169$ & $2,762,491$ \\
\hline & & & $17.1 \%$ & $18.2 \%$ & $17.8 \%$ & $16.0 \%$ & $14.7 \%$ & $17.0 \%$ & $14.5 \%$ & $15.2 \%$ & $15.2 \%$ & $15.1 \%$ & $14.5 \%$ \\
\hline & \multicolumn{2}{|c|}{$\begin{array}{l}\text { 2. NO : Unfixed } \\
\text { (Employment contract period is not fixed in advance) }\end{array}$} & $12,114,518$ & $12,223,094$ & $12,680,091$ & $13,450,343$ & $13,869,482$ & $13,780,755$ & $14,689,312$ & $15,028,234$ & $15,211,759$ & $15,633,348$ & $16,229,338$ \\
\hline \multicolumn{3}{|c|}{ ['----------------------.' } & 2004 & 2005 & 2006 & 2007 & 2008 & 2009 & 2010 & 2011 & 2012 & 2013 & 2014 \\
\hline \multirow{9}{*}{$\begin{array}{c}\text { Q2. } \\
\text { Job } \\
\text { Security }\end{array}$} & \multirow{2}{*}{\multicolumn{2}{|c|}{ 1. YES : Secure job }} & $10,520,109$ & $10,436,425$ & $11,171,992$ & $11,685,269$ & $12,045,347$ & $11,996,338$ & $12,900,133$ & $13,221,116$ & $13,544,938$ & $14,067,435$ & $14,750,791$ \\
\hline & & & $72.0 \%$ & $69.8 \%$ & $72.4 \%$ & $73.0 \%$ & $74.1 \%$ & $72.2 \%$ & $75.0 \%$ & $74.6 \%$ & $75.5 \%$ & $76.4 \%$ & $77.7 \%$ \\
\hline & \multirow{3}{*}{$\begin{array}{c}\text { Q3. } \\
\text { Reason for } \\
\text { Secure Job }\end{array}$} & (1) Permanent employment & $4,875,043$ & $5,351,175$ & $6,053,149$ & 6,828,466 & $7,335,442$ & $7,837,031$ & $8,689,919$ & $9,003,080$ & $9,566,811$ & $10,222,631$ & $10,591,173$ \\
\hline & & (2) Repeated renewal & 585,768 & 301,626 & 469,288 & 561,630 & 378,112 & 172,989 & 311,136 & 344,033 & 294,576 & 261,530 & 358,003 \\
\hline & & (3) Implicit practice & $5,059,298$ & $4,783,624$ & $4,649,555$ & $4,295,173$ & $4,331,793$ & $3,986,318$ & $3,899,078$ & $3,874,003$ & $3,683,551$ & $3,583,274$ & $3,801,615$ \\
\hline & & & & & & & & & & & & & \\
\hline & & & 2004 & 2005 & 2006 & 2007 & 2008 & 2009 & 2010 & 2011 & 2012 & 2013 & 2014 \\
\hline & \multirow{2}{*}{\multicolumn{2}{|c|}{ 2. NO : Insecure job }} & 925,078 & $1,073,439$ & 846,243 & 921,300 & $1,002,125$ & 899,004 & 914,989 & 832,714 & 788,249 & 737,321 & 663,079 \\
\hline & & & $6.3 \%$ & $7.2 \%$ & $5.5 \%$ & $5.8 \%$ & $6.2 \%$ & $5.4 \%$ & $5.3 \%$ & $4.7 \%$ & $4.4 \%$ & $4.0 \%$ & $3.5 \%$ \\
\hline & \multirow{12}{*}{$\begin{array}{c}\text { Q4. } \\
\text { Reason for } \\
\text { Insecure Job }\end{array}$} & \multirow{2}{*}{$\begin{array}{l}\text { (1) Conditional on } \\
\text { employer's will }\end{array}$} & 471,306 & 516,625 & 370,770 & 396,722 & 437,386 & 420,116 & 392,643 & 344,064 & 332,235 & 335,853 & 325,271 \\
\hline & & & $3.2 \%$ & $3.5 \%$ & $2.4 \%$ & $2.5 \%$ & $2.7 \%$ & $2.5 \%$ & $2.3 \%$ & $1.9 \%$ & $1.9 \%$ & $1.8 \%$ & $1.7 \%$ \\
\hline & & (2) Contract expires & - & 822 & - & 2,099 & - & - & - & - & - & - & - \\
\hline & & (3) Implicit practice & - & - & - & 1,149 & 40,539 & 35,201 & 28,084 & 33,045 & 21,126 & 31,270 & 31,541 \\
\hline & & (4) Project completion & 33,094 & 41,627 & 50,048 & 42,396 & 46,039 & 48,314 & 40,378 & 48,950 & 37,277 & 29,889 & 34,153 \\
\hline & & (5) Return of previous worker & 2,951 & 8,273 & 6,017 & 3,879 & 5,722 & 7,877 & 3,100 & 3,798 & 4,797 & 6,643 & 4,201 \\
\hline & & (6) Seasonal work & 15,475 & 17,494 & 12,351 & 15,765 & 26,235 & 15,522 & 22,308 & 13,075 & 7,429 & 10,510 & 13,310 \\
\hline & & (7) Looking for other job & 170,401 & 229,067 & 192,029 & 209,981 & 162,037 & 127,791 & 185,520 & 137,266 & 107,544 & 106,760 & 93,597 \\
\hline & & (8) Retirement & 19,802 & 31,545 & 37,960 & 38,990 & 45,460 & 33,680 & 31,631 & 37,100 & 46,669 & 41,130 & 36,100 \\
\hline & & (9) Illness/Education & 117,918 & 156,909 & 116,602 & 154,584 & 168,321 & 148,900 & 152,053 & 154,412 & 171,236 & 127,505 & 91,902 \\
\hline & & (10) Layoff & 79,844 & 55,168 & 48,178 & 48,257 & \begin{tabular}{|l|}
55,583 \\
\end{tabular} & 40,332 & 43,093 & 38,115 & 41,347 & 37,776 & 24,887 \\
\hline & & (11) etc & 14,287 & 15,909 & 12,288 & 7,478 & 14,803 & 20,198 & 16,179 & 22,889 & 18,589 & 9,985 & 8,117 \\
\hline
\end{tabular}

Note) The percentage (\%) is the proportion of workers who chose each answer in the total wage and salary workers. 
Table C.4. KLIPS - Unweighted: The number of workers who chose each answer to the four questions

\begin{tabular}{|c|c|c|c|c|c|c|c|c|c|c|c|c|c|}
\hline & & & \multicolumn{11}{|c|}{ Interview Year (the number of workers surveyed in each year) } \\
\hline & & & 2004 & 2005 & 2006 & 2007 & 2008 & 2009 & 2010 & 2011 & 2012 & 2013 & 2014 \\
\hline \multicolumn{3}{|c|}{ Total wage and salary workers } & 4,257 & 4,085 & 4,300 & 4,346 & 4,340 & 5,189 & 5,289 & 5,361 & 5,450 & 5,462 & 5,327 \\
\hline \multirow{3}{*}{$\begin{array}{c}\text { Q1. } \\
\text { Fixed-term } \\
\text { contract? }\end{array}$} & \multirow{2}{*}{\multicolumn{2}{|c|}{$\begin{array}{l}\text { 1. YES : Fixed-term employment } \\
\text { ( Employment contract period is fixed in advance) }\end{array}$}} & 227 & 281 & 327 & 398 & 304 & 486 & 508 & 521 & 562 & 574 & 655 \\
\hline & & & $5.3 \%$ & $6.9 \%$ & $7.6 \%$ & $9.2 \%$ & $7.0 \%$ & $9.4 \%$ & $9.6 \%$ & $9.7 \%$ & $10.3 \%$ & $10.5 \%$ & $12.3 \%$ \\
\hline & \multicolumn{2}{|c|}{$\begin{array}{l}\text { 2. NO : Unfixed } \\
\text { (Employment contract period is not fixed in advance) }\end{array}$} & 4,000 & 3,755 & 3,949 & 3,948 & 4,033 & 4,703 & 4,781 & 4,840 & 4,887 & 4,886 & 4,671 \\
\hline \multicolumn{3}{|c|}{ 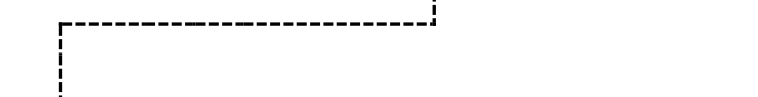 } & 2004 & 2005 & 2006 & 2007 & 2008 & 2009 & 2010 & 2011 & 2012 & 2013 & 2014 \\
\hline \multirow{9}{*}{$\begin{array}{c}\text { Q2. } \\
\text { Job } \\
\text { Security }\end{array}$} & \multirow{2}{*}{\multicolumn{2}{|c|}{ 1. YES : Secure job }} & 3,609 & 3,369 & 3,600 & 3,499 & 3,550 & 4,001 & 3,913 & 3,922 & 3,785 & 3,908 & 3,744 \\
\hline & & & $84.8 \%$ & $82.5 \%$ & $83.7 \%$ & $80.5 \%$ & $81.8 \%$ & $77.1 \%$ & $74.0 \%$ & $73.2 \%$ & $69.4 \%$ & $71.5 \%$ & $70.3 \%$ \\
\hline & \multirow{5}{*}{\multicolumn{2}{|c|}{$\begin{array}{c}\text { Q3. } \\
\text { Reason for } \\
\text { Secure Job }\end{array}$}} & - & - & - & 2,643 & 2,607 & 2,938 & 2,930 & 2,999 & 3,017 & 3,027 & 2,728 \\
\hline & & & - & - & - & 19 & 145 & 252 & 154 & 164 & 98 & 107 & 235 \\
\hline & & & - & - & - & 837 & 798 & 811 & 829 & 759 & 670 & 773 & 781 \\
\hline & & & & & & & & & & & & & \\
\hline & & & 2004 & 2005 & 2006 & 2007 & 2008 & 2009 & 2010 & 2011 & 2012 & 2013 & 2014 \\
\hline & \multirow{2}{*}{\multicolumn{2}{|c|}{ 2. NO : Insecure job }} & 111 & 175 & 98 & 106 & 139 & 267 & 440 & 487 & 721 & 564 & 493 \\
\hline & & & $2.6 \%$ & $4.3 \%$ & $2.3 \%$ & $2.4 \%$ & $3.2 \%$ & $5.1 \%$ & $8.3 \%$ & $9.1 \%$ & $13.2 \%$ & $10.3 \%$ & $9.3 \%$ \\
\hline & \multirow{12}{*}{$\begin{array}{c}\text { Q4. } \\
\text { Reason for } \\
\text { Insecure Job }\end{array}$} & \multirow{2}{*}{$\begin{array}{l}\text { (1) Conditional on } \\
\text { employer's will }\end{array}$} & 14 & 34 & 9 & 46 & 68 & 155 & 300 & 358 & 516 & 384 & 372 \\
\hline & & & $0.3 \%$ & $0.8 \%$ & $0.2 \%$ & $1.1 \%$ & $1.6 \%$ & $3.0 \%$ & $5.7 \%$ & $6.7 \%$ & $9.5 \%$ & $7.0 \%$ & $7.0 \%$ \\
\hline & & (2) Contract expires & 10 & 3 & 8 & 1 & 12 & 25 & 30 & 17 & 39 & 31 & 15 \\
\hline & & (3) Implicit practice & 2 & 2 & 3 & 3 & 19 & 24 & 38 & 34 & 57 & 59 & 32 \\
\hline & & (4) Project completion & 11 & 24 & 15 & 9 & 3 & 15 & 12 & 11 & 19 & 16 & 14 \\
\hline & & (5) Return of previous worker & 0 & 0 & 0 & 0 & 1 & 0 & 2 & 0 & 0 & 0 & 0 \\
\hline & & (6) Seasonal work & 0 & 0 & 1 & 0 & 2 & 3 & 2 & 3 & 3 & 2 & 5 \\
\hline & & (7) Looking for other job & 17 & 36 & 8 & 16 & 9 & 5 & 20 & 16 & 23 & 21 & 18 \\
\hline & & (8) Retirement & 4 & 8 & 5 & 9 & 8 & 11 & 10 & 12 & 10 & 11 & 11 \\
\hline & & (9) Illness/Education & 13 & 19 & 16 & 12 & 10 & 18 & 16 & 20 & 32 & 22 & 14 \\
\hline & & (10) Layoff & 32 & 47 & 28 & 1 & 6 & 11 & 4 & 10 & 15 & 12 & 10 \\
\hline & & (11) etc & 8 & 2 & 5 & 9 & 1 & 0 & 6 & 6 & 7 & 6 & 2 \\
\hline
\end{tabular}

Note) The percentage (\%) is the proportion of workers who chose each answer in the total wage and salary workers. 
Table C.5. KLIPS - Weighted: The number of workers who chose each answer to the four questions

\begin{tabular}{|c|c|c|c|c|c|c|c|c|c|c|c|c|c|}
\hline & & & \multicolumn{11}{|c|}{ Interview Year (the number of workers surveyed in each year) } \\
\hline & & & 2004 & 2005 & 2006 & 2007 & 2008 & 2009 & 2010 & 2011 & 2012 & 2013 & 2014 \\
\hline \multicolumn{3}{|c|}{ Total wage and salary workers } & $11,317,526$ & $10,889,309$ & $11,254,867$ & $11,351,450$ & $11,566,853$ & $15,478,366$ & $15,853,611$ & $17,238,872$ & $17,551,971$ & $17,860,389$ & $18,371,140$ \\
\hline \multirow{3}{*}{$\begin{array}{c}\text { Q1. } \\
\text { Fixed-term } \\
\text { contract? }\end{array}$} & \multirow{2}{*}{\multicolumn{2}{|c|}{$\begin{array}{l}\text { 1. YES : Fixed-term employment } \\
\text { (Employment contract period is fixed in advance) }\end{array}$}} & 590,393 & 772,332 & 870,980 & $1,072,171$ & 853,693 & $1,413,710$ & $1,519,761$ & $1,633,763$ & $1,787,047$ & $1,879,296$ & $2,319,864$ \\
\hline & & & $5.2 \%$ & $7.1 \%$ & $7.7 \%$ & $9.4 \%$ & $7.4 \%$ & $9.1 \%$ & $9.6 \%$ & $9.5 \%$ & $10.2 \%$ & $10.5 \%$ & $12.6 \%$ \\
\hline & \multicolumn{2}{|c|}{$\begin{array}{l}\text { 2. NO : Unfixed } \\
\text { (Employment contract period is not fixed in advance) }\end{array}$} & $10,646,983$ & $9,984,049$ & $10,322,764$ & $10,279,279$ & $10,704,917$ & $14,064,656$ & $14,333,850$ & $15,605,109$ & $15,762,561$ & $15,974,320$ & $16,047,599$ \\
\hline \multicolumn{3}{|c|}{ 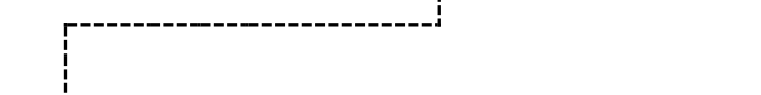 } & 2004 & 2005 & 2006 & 2007 & 2008 & 2009 & 2010 & 2011 & 2012 & 2013 & 2014 \\
\hline \multirow{9}{*}{$\begin{array}{c}\text { Q2. } \\
\text { Job } \\
\text { Security }\end{array}$} & \multirow{2}{*}{\multicolumn{2}{|c|}{ 1. YES : Secure job }} & $9,619,283$ & $8,988,361$ & $9,388,583$ & $9,091,187$ & $9,392,391$ & $12,148,840$ & $11,967,647$ & $12,874,149$ & $12,443,018$ & $13,103,454$ & $13,266,198$ \\
\hline & & & $85.0 \%$ & $82.5 \%$ & $83.4 \%$ & $80.1 \%$ & $81.2 \%$ & $78.5 \%$ & $75.5 \%$ & $74.7 \%$ & $70.9 \%$ & $73.4 \%$ & $72.2 \%$ \\
\hline & \multirow{5}{*}{\multicolumn{2}{|c|}{$\begin{array}{c}\text { Q3. } \\
\text { Reason for } \\
\text { Secure Job }\end{array}$}} & - & - & - & $6,790,709$ & $6,901,925$ & $8,935,432$ & $8,929,996$ & $9,831,115$ & $9,837,445$ & $10,123,577$ & $9,562,365$ \\
\hline & & & - & - & - & 48,112 & 344,353 & 754,415 & 436,171 & 522,485 & 339,555 & 337,369 & 764,938 \\
\hline & & & - & - & & $2,252,366$ & $2,146,113$ & $2,458,993$ & $2,601,480$ & $2,520,549$ & $2,266,018$ & $2,640,895$ & $2,938,895$ \\
\hline & & & & & & & & & & & & & \\
\hline & & & 2004 & 2005 & 2006 & 2007 & 2008 & 2009 & 2010 & 2011 & 2012 & 2013 & 2014 \\
\hline & \multirow{2}{*}{\multicolumn{2}{|c|}{ 2. NO : Insecure job }} & 315,063 & 463,827 & 269,436 & 287,065 & 383,316 & 762,874 & $1,257,495$ & $1,559,701$ & $2,263,707$ & $1,729,413$ & $1,566,242$ \\
\hline & & & $2.8 \%$ & $4.3 \%$ & $2.4 \%$ & $2.5 \%$ & $3.3 \%$ & $4.9 \%$ & $7.9 \%$ & $9.0 \%$ & $12.9 \%$ & $9.7 \%$ & $8.5 \%$ \\
\hline & \multirow{12}{*}{$\begin{array}{c}\text { Q4. } \\
\text { Reason for } \\
\text { Insecure Job }\end{array}$} & \multirow{2}{*}{$\begin{array}{l}\text { (1) Conditional on } \\
\text { employer's will }\end{array}$} & 55,088 & 96,015 & 22,697 & 115,035 & 192,921 & 440,193 & 853,196 & $1,131,169$ & $1,606,328$ & $1,147,641$ & $1,161,085$ \\
\hline & & & $0.5 \%$ & $0.9 \%$ & $0.2 \%$ & $1.0 \%$ & $1.7 \%$ & $2.8 \%$ & $5.4 \%$ & $6.6 \%$ & $9.2 \%$ & $6.4 \%$ & $6.3 \%$ \\
\hline & & (2) Contract expires & 24,969 & 7,610 & 32,426 & 2,073 & 26,324 & 71,897 & 92,423 & 52,134 & 111,793 & 93,614 & 53,259 \\
\hline & & (3) Implicit practice & 7,263 & 4,845 & 10,006 & 7,690 & 42,921 & 59,389 & 104,518 & 114,161 & 168,103 & 202,026 & 116,141 \\
\hline & & (4) Project completion & 31,556 & 58,730 & 33,493 & 26,367 & 10,779 & 40,263 & 33,053 & 35,767 & 67,701 & 44,943 & 43,301 \\
\hline & & (5) Return of previous worker & - & - & & - & 2,841 & & 8,215 & - & - & - & \\
\hline & & (6) Seasonal work & - & & 2,546 & - & 4,976 & 7,339 & 7,900 & 11,953 & 11,455 & 7,343 & 15,075 \\
\hline & & (7) Looking for other job & 37,813 & 99,118 & 21,132 & 36,780 & 29,001 & 18,275 & 51,067 & 65,098 & 79,035 & 83,256 & 71,863 \\
\hline & & (8) Retirement & 14,791 & 23,651 & 23,156 & 34,881 & 14,765 & 40,109 & 22,014 & 35,379 & 20,840 & 27,790 & 24,094 \\
\hline & & (9) Illness/Education & 37,244 & 50,462 & 42,043 & 41,829 & 32,271 & 52,955 & 48,275 & 72,959 & 122,447 & 67,010 & 46,658 \\
\hline & & (10) Layoff & 83,157 & 120,121 & 66,542 & 1,959 & 19,534 & 32,454 & 10,101 & 30,417 & 52,424 & 31,957 & 29,004 \\
\hline & & (11) etc & 23,182 & 3,275 & 15,395 & 20,451 & 6,983 & 0 & 26,733 & 10,664 & 23,581 & 23,833 & 5,762 \\
\hline
\end{tabular}

Note) The percentage (\%) is the proportion of workers who chose each answer in the total wage and salary workers. 
Table C.6. EAPS: The share of age category in the total population aged 15 and over $\left(P_{G, t}^{E A P S}\right)$

\begin{tabular}{|c|c|c|c|c|c|c|c|c|c|c|c|c|c|}
\hline & \multicolumn{12}{|c|}{ Year $(t)$} \\
\hline & & 2003 & 2004 & 2005 & 2006 & 2007 & 2008 & 2009 & 2010 & 2011 & 2012 & 2013 & 2014 \\
\hline \multirow{24}{*}{ 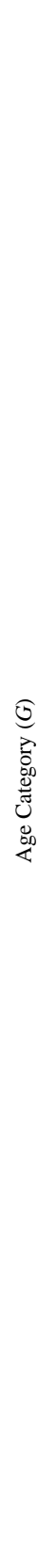 } & \multirow{2}{*}{$\begin{array}{l}15- \\
19\end{array}$} & $3,139,877$ & $3,042,598$ & $3,020,903$ & $3,044,241$ & $3,129,234$ & $32,257,900$ & $3,309,890$ & $3,369,488$ & 3364803 & 3328002 & 3266213 & 3186274 \\
\hline & & $8.4 \%$ & $8.0 \%$ & $7.9 \%$ & $7.9 \%$ & $8.0 \%$ & $8.1 \%$ & $8.2 \%$ & $8.2 \%$ & $8.1 \%$ & $7.9 \%$ & $7.7 \%$ & $7.4 \%$ \\
\hline & \multirow{2}{*}{$\begin{array}{l}20- \\
24\end{array}$} & 3,371,599 & $3,296,759$ & $3,118,159$ & $2,970,060$ & $2,782,004$ & $26,456,732$ & $2,589,460$ & $2,592,277$ & $2,696,805$ & 2,789,697 & $2,906,441$ & 2,997,124 \\
\hline & & $9.0 \%$ & $8.7 \%$ & $8.2 \%$ & $7.7 \%$ & $7.1 \%$ & $6.6 \%$ & $6.4 \%$ & $6.3 \%$ & $6.5 \%$ & $6.7 \%$ & $6.9 \%$ & $7.0 \%$ \\
\hline & \multirow{2}{*}{$\begin{array}{l}25- \\
29\end{array}$} & $3,869,941$ & $3,792,950$ & $3,795,375$ & $3,882,868$ & $3,968,773$ & $39,955,018$ & $3,927,055$ & $3,760,144$ & $3,585,979$ & 3,392,228 & $3,255,555$ & $3,208,832$ \\
\hline & & $10.3 \%$ & $10.0 \%$ & $9.9 \%$ & $10.0 \%$ & $10.1 \%$ & $10.0 \%$ & $9.7 \%$ & $9.2 \%$ & $8.6 \%$ & $8.1 \%$ & $7.7 \%$ & $7.5 \%$ \\
\hline & \multirow{2}{*}{$\begin{array}{l}30- \\
34\end{array}$} & $4,441,289$ & $4,410,404$ & $4,315,818$ & $4,178,801$ & $4,034,490$ & $39,136,493$ & $3,830,949$ & $3,861,359$ & $3,942,122$ & $4,025,281$ & $4,045,393$ & $3,988,551$ \\
\hline & & $11.9 \%$ & $11.7 \%$ & $11.3 \%$ & $10.8 \%$ & $10.3 \%$ & $9.8 \%$ & $9.5 \%$ & $9.4 \%$ & $9.5 \%$ & $9.6 \%$ & $9.6 \%$ & $9.3 \%$ \\
\hline & \multirow{2}{*}{$\begin{array}{l}35- \\
39\end{array}$} & $4,137,478$ & $4,197,251$ & $4,254,631$ & $4,351,840$ & $4,436,255$ & $44,845,606$ & $4,437,194$ & $4,349,605$ & $4,194,672$ & $4,043,101$ & $3,911,511$ & $3,832,583$ \\
\hline & & $11.0 \%$ & $11.1 \%$ & $11.2 \%$ & $11.2 \%$ & $11.3 \%$ & $11.3 \%$ & $11.0 \%$ & $10.6 \%$ & $10.1 \%$ & $9.6 \%$ & $9.2 \%$ & $8.9 \%$ \\
\hline & \multirow{2}{*}{$\begin{array}{l}40- \\
44\end{array}$} & $4,318,202$ & $4,283,561$ & $4,219,676$ & $4,161,546$ & $4,135,609$ & $41,305,660$ & $4,234,361$ & $4,301,628$ & $4,398,019$ & $4,468,746$ & $4,502,632$ & $4,449,624$ \\
\hline & & $11.5 \%$ & $11.3 \%$ & $11.1 \%$ & $10.8 \%$ & $10.5 \%$ & $10.4 \%$ & $10.5 \%$ & $10.5 \%$ & $10.6 \%$ & $10.7 \%$ & $10.6 \%$ & $10.4 \%$ \\
\hline & \multirow{2}{*}{$\begin{array}{l}45- \\
49\end{array}$} & $3,582,032$ & $3,806,569$ & $3,964,794$ & $4,138,148$ & $4,247,760$ & $43,362,589$ & $4,300,454$ & $4,247,533$ & $4,171,977$ & $4,150,242$ & $4,130,592$ & $4,286,526$ \\
\hline & & $9.6 \%$ & $10.1 \%$ & $10.4 \%$ & $10.7 \%$ & $10.8 \%$ & $10.9 \%$ & $10.7 \%$ & $10.4 \%$ & $10.1 \%$ & $9.9 \%$ & $9.8 \%$ & $10.0 \%$ \\
\hline & \multirow{2}{*}{$\begin{array}{c}50- \\
54\end{array}$} & $2,572,726$ & $2,681,760$ & $2,885,358$ & $3,119,827$ & $3,307,642$ & $35,448,108$ & $3,774,031$ & $3,954,411$ & $4,164,262$ & $4,263,504$ & $4,348,484$ & $4,317,501$ \\
\hline & & $6.9 \%$ & $7.1 \%$ & $7.6 \%$ & $8.1 \%$ & $8.4 \%$ & $8.9 \%$ & $9.3 \%$ & $9.7 \%$ & $10.0 \%$ & $10.2 \%$ & $10.3 \%$ & $10.1 \%$ \\
\hline & \multirow{2}{*}{$\begin{array}{c}55- \\
59\end{array}$} & $2,115,103$ & $2,206,129$ & $2,293,776$ & $2,371,057$ & $2,449,163$ & $25,284,913$ & $2,635,914$ & $2,846,792$ & $3,084,213$ & $3,266,013$ & $3,484,579$ & $3,719,025$ \\
\hline & & $5.6 \%$ & $5.8 \%$ & $6.0 \%$ & $6.1 \%$ & $6.2 \%$ & $6.3 \%$ & $6.5 \%$ & $7.0 \%$ & $7.4 \%$ & $7.8 \%$ & $8.2 \%$ & $8.7 \%$ \\
\hline & \multirow{2}{*}{$\begin{array}{c}60- \\
64\end{array}$} & $1,949,667$ & $1,946,139$ & $1,943,808$ & $1,936,230$ & $1,970,278$ & $20,353,687$ & $2,128,033$ & $2,222,553$ & $2,310,976$ & $2,385,033$ & $2,454,538$ & $2,566,281$ \\
\hline & & $5.2 \%$ & $5.1 \%$ & $5.1 \%$ & $5.0 \%$ & $5.0 \%$ & $5.1 \%$ & $5.3 \%$ & $5.4 \%$ & $5.6 \%$ & $5.7 \%$ & $5.8 \%$ & $6.0 \%$ \\
\hline & \multirow{2}{*}{$\begin{array}{c}65- \\
69\end{array}$} & $1,652,647$ & $1,702,542$ & $1,682,819$ & $1,733,069$ & $1,823,816$ & $18,545,558$ & $1,833,763$ & $1,828,540$ & $1,864,876$ & $1,893,823$ & $1,946,835$ & $2,074,492$ \\
\hline & & $4.4 \%$ & $4.5 \%$ & $4.4 \%$ & $4.5 \%$ & $4.6 \%$ & $4.7 \%$ & $4.5 \%$ & $4.5 \%$ & $4.5 \%$ & $4.5 \%$ & $4.6 \%$ & $4.8 \%$ \\
\hline & \multirow{2}{*}{$\begin{array}{l}\text { ove } \\
\text { r } 70\end{array}$} & $2,310,675$ & $2,451,344$ & $2,662,939$ & 2,820,819 & $2,965,673$ & $31,570,798$ & $3,365,545$ & $3,555,406$ & $3,680,054$ & $3,904,086$ & $4,106,503$ & $4,233,683$ \\
\hline & & $6.2 \%$ & $6.5 \%$ & $7.0 \%$ & $7.3 \%$ & $7.6 \%$ & $7.9 \%$ & $8.3 \%$ & $8.7 \%$ & $8.9 \%$ & $9.3 \%$ & $9.7 \%$ & $9.9 \%$ \\
\hline & $\begin{array}{c}\text { Tota } \\
1\end{array}$ & $37,461,236$ & $37,818,006$ & $38,158,056$ & $38,708,506$ & $39,250,697$ & $398,523,062$ & $40,366,649$ & $40,889,736$ & $41,458,758$ & $41,909,756$ & $42,359,276$ & $42,860,496$ \\
\hline
\end{tabular}

Note) 1. All values are derived using sample weights.

2. $P_{G, t}=$ (The number of people in the age category $G /$ The number of the total population) $\mathrm{x} 100$ 
Table C.7. KLIPS: The share of age category in the total population aged 15 and over $\left(P_{G, t}^{K L I P S}\right)$

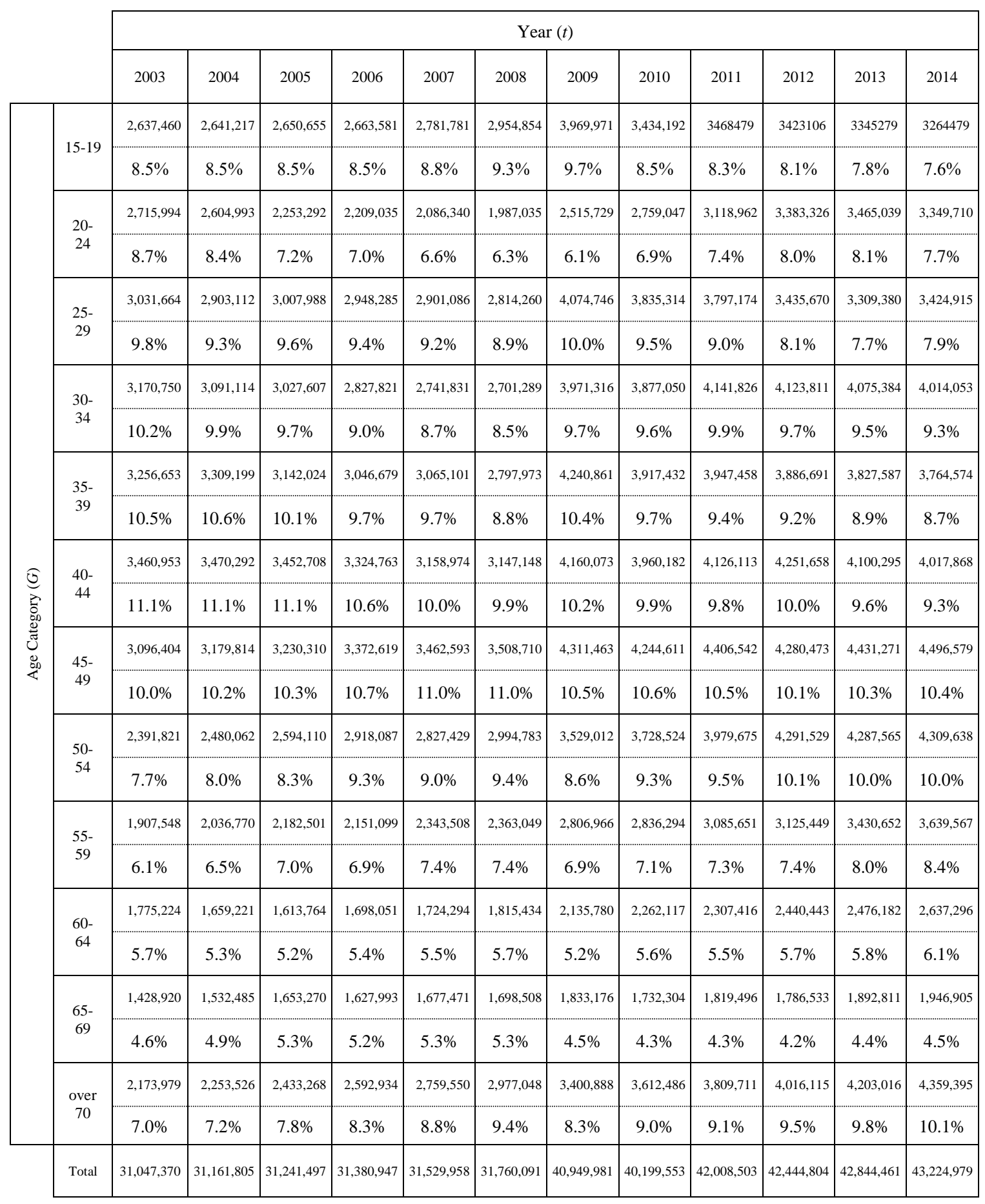

Note) 1 . All values are derived using sample weights.

2. $P_{G, t}=$ (The number of people in the age category $G /$ The number of the total population) $\mathrm{x} 100$ 
Table C.8. EAPS: The share of women in the total population aged 15 and over $\left(P_{W, t}^{E A P S}\right)$

\begin{tabular}{|c|c|c|c|c|c|c|c|c|c|c|c|c|}
\hline & \multicolumn{12}{|c|}{ Year $(t)$} \\
\hline & 2003 & 2004 & 2005 & 2006 & 2007 & 2008 & 2009 & 2010 & 2011 & 2012 & 2013 & 2014 \\
\hline \multirow{2}{*}{ Women } & $19,266,309$ & $19,431,273$ & $19,599,132$ & $19,834,649$ & 20,084,149 & $203,697,857$ & $20,624,336$ & $20,877,224$ & $21,153,228$ & $21,384,958$ & $21,603,112$ & $21,835,741$ \\
\hline & $51.4 \%$ & $51.4 \%$ & $51.4 \%$ & $51.2 \%$ & $51.2 \%$ & $51.1 \%$ & $51.1 \%$ & $51.1 \%$ & $51.0 \%$ & $51.0 \%$ & $51.0 \%$ & $50.9 \%$ \\
\hline Total & $37,461,236$ & $37,818,006$ & $38,158,056$ & $38,708,506$ & $39,250,697$ & $398,523,062$ & $40,366,649$ & $40,889,736$ & $41,458,758$ & $41,909,756$ & $42,359,276$ & $42,860,496$ \\
\hline
\end{tabular}

Note) 1. All values are derived using sample weights.

2. $P_{W, t}=$ (The number of women / The number of the total population) $\mathrm{x} 100$

Table C.9. KLIPS: The share of women in the total population aged 15 and over $\left(P_{W, t}^{K L I P S}\right)$

\begin{tabular}{|c|c|c|c|c|c|c|c|c|c|c|c|c|}
\hline & \multicolumn{12}{|c|}{ Year $(t)$} \\
\hline & 2003 & 2004 & 2005 & 2006 & 2007 & 2008 & 2009 & 2010 & 2011 & 2012 & 2013 & 2014 \\
\hline \multirow{2}{*}{ Women } & $16,016,926$ & $15,986,365$ & $16,097,495$ & $16,116,933$ & $16,065,942$ & $16,217,906$ & $20,579,922$ & $20,399,137$ & $21,103,461$ & $21,327,108$ & $21,535,861$ & $21,731,416$ \\
\hline & $51.6 \%$ & $51.3 \%$ & $51.5 \%$ & $51.4 \%$ & $51.0 \%$ & $51.1 \%$ & $50.3 \%$ & $50.7 \%$ & $50.2 \%$ & $50.2 \%$ & $50.3 \%$ & $50.3 \%$ \\
\hline Total & $31,047,370$ & $31,161,805$ & $31,241,497$ & $31,380,947$ & $31,529,958$ & $31,760,091$ & $40,949,981$ & $40,199,553$ & $42,008,503$ & $42,444,804$ & $42,844,461$ & $43,224,979$ \\
\hline
\end{tabular}

Note) 1. All values are derived using sample weights.

2. $P_{W, t}=($ The number of women $/$ The number of the total population $) \times 100$ 
Table C.10. EAPS: The share of education level in the total population aged 15 and over $\left(P_{E, t}^{E A P S}\right)$

\begin{tabular}{|c|c|c|c|c|c|c|c|c|c|c|c|c|}
\hline & \multicolumn{12}{|c|}{ Year $(t)$} \\
\hline & 2003 & 2004 & 2005 & 2006 & 2007 & 2008 & 2009 & 2010 & 2011 & 2012 & 2013 & 2014 \\
\hline \multirow{2}{*}{ Elementary } & $6,956,895$ & $6,891,449$ & $6,789,278$ & $6,731,437$ & $6,599,332$ & $65,817,534$ & $6,570,756$ & $6,547,997$ & $6,451,742$ & $6,292,234$ & $6,127,626$ & $5,896,076$ \\
\hline & $18.6 \%$ & $18.2 \%$ & $17.8 \%$ & $17.4 \%$ & $16.8 \%$ & $16.5 \%$ & $16.3 \%$ & $16.0 \%$ & $15.6 \%$ & $15.0 \%$ & $14.5 \%$ & $13.8 \%$ \\
\hline \multirow{2}{*}{$\begin{array}{l}\text { Middle } \\
\text { School }\end{array}$} & $5,983,909$ & $5,959,212$ & $5,830,807$ & $5,871,749$ & $5,848,838$ & $58,675,725$ & $5,834,756$ & $5,948,933$ & $5,937,569$ & $5,921,928$ & $5,790,656$ & $5,660,476$ \\
\hline & $16.0 \%$ & $15.8 \%$ & $15.3 \%$ & $15.2 \%$ & $14.9 \%$ & $14.7 \%$ & $14.5 \%$ & $14.5 \%$ & $14.3 \%$ & $14.1 \%$ & $13.7 \%$ & $13.2 \%$ \\
\hline \multirow{2}{*}{$\begin{array}{l}\text { High } \\
\text { School }\end{array}$} & $13,209,754$ & $13,327,511$ & $13,301,412$ & $13,306,106$ & $13,225,226$ & $131,919,923$ & $\mid$\begin{tabular}{|l|}
$13,172,077$ \\
\end{tabular} & $|13,118,967|$ & $13,277,076$ & $13,325,605$ & 13,331,583 & $13,644,542$ \\
\hline & $35.3 \%$ & $35.2 \%$ & $34.9 \%$ & $34.4 \%$ & $33.7 \%$ & $33.1 \%$ & $32.6 \%$ & $32.1 \%$ & $32.0 \%$ & $31.8 \%$ & $31.5 \%$ & $31.8 \%$ \\
\hline \multirow{2}{*}{$\begin{array}{c}2 \mathrm{yr} \\
\text { College }\end{array}$} & 4,994,939 & $5,122,391$ & $5,426,768$ & $5,625,600$ & $5,989,007$ & $61,673,792$ & $6,371,871$ & $6,644,410$ & $6,940,545$ & $7,213,739$ & $7,442,803$ & $7,365,045$ \\
\hline & $13.3 \%$ & $13.5 \%$ & $14.2 \%$ & $14.5 \%$ & $15.3 \%$ & $15.5 \%$ & $15.8 \%$ & $16.2 \%$ & $16.7 \%$ & $17.2 \%$ & $17.6 \%$ & $17.2 \%$ \\
\hline \multirow{2}{*}{$\begin{array}{c}4 \mathrm{yr} \\
\text { University }\end{array}$} & $5,640,815$ & $5,786,251$ & $6,052,169$ & $6,368,150$ & $6,745,429$ & $70,270,674$ & $7,350,220$ & $7,553,967$ & $7,734,646$ & $7,958,904$ & $8,388,119$ & $8,953,713$ \\
\hline & $15.1 \%$ & $15.3 \%$ & $15.9 \%$ & $16.5 \%$ & $17.2 \%$ & $17.6 \%$ & $18.2 \%$ & $18.5 \%$ & $18.7 \%$ & $19.0 \%$ & $19.8 \%$ & $20.9 \%$ \\
\hline \multirow{2}{*}{$\begin{array}{l}\text { M.A. or } \\
\text { Ph.D. }\end{array}$} & 674,924 & 731,192 & 757,622 & 805,464 & 842,865 & $10,165,414$ & $1,066,969$ & $1,075,462$ & $1,117,180$ & $1,197,346$ & $1,278,489$ & $1,340,644$ \\
\hline & $1.8 \%$ & $1.9 \%$ & $2.0 \%$ & $2.1 \%$ & $2.1 \%$ & $2.6 \%$ & $2.6 \%$ & $2.6 \%$ & $2.7 \%$ & $2.9 \%$ & $3.0 \%$ & $3.1 \%$ \\
\hline Total & $37,461,236$ & $37,818,006$ & $38,158,056$ & $38,708,506$ & $39,250,697$ & $398,523,062$ & $40,366,649$ & $40,889,736$ & $41,458,758$ & $41,909,756$ & $42,359,276$ & $42,860,496$ \\
\hline
\end{tabular}

Note) 1. All values are derived using sample weights.

2. $P_{E, t}=$ (The number of people in the education category $E /$ The number of the total population) $\mathrm{x} 100$

Table C. 11. KLIPS: The share of education level in the total population aged 15 and over $\left(P_{E, t}^{K L I P S}\right)$

\begin{tabular}{|c|c|c|c|c|c|c|c|c|c|c|c|c|}
\hline & \multicolumn{12}{|c|}{ Year $(t)$} \\
\hline & 2003 & 2004 & 2005 & 2006 & 2007 & 2008 & 2009 & 2010 & 2011 & 2012 & 2013 & 2014 \\
\hline \multirow{2}{*}{ Elementary } & $6,552,503$ & $6,399,252$ & 6,407,566 & $6,280,506$ & $6,089,383$ & $6,054,427$ & $7,034,868$ & $6,665,465$ & $6,718,911$ & $6,425,788$ & $6,272,008$ & $5,576,448$ \\
\hline & $21.1 \%$ & $20.5 \%$ & $20.5 \%$ & $20.0 \%$ & $19.3 \%$ & $19.1 \%$ & $17.2 \%$ & $16.6 \%$ & $16.0 \%$ & $15.1 \%$ & $14.6 \%$ & $12.9 \%$ \\
\hline \multirow{2}{*}{$\begin{array}{l}\text { Middle } \\
\text { School }\end{array}$} & $5,150,409$ & $5,114,073$ & $5,079,616$ & $5,064,862$ & $5,034,679$ & $5,033,034$ & $6,464,803$ & $5,904,200$ & $5,816,138$ & $5,749,652$ & $5,805,069$ & $6,043,875$ \\
\hline & $16.6 \%$ & $16.4 \%$ & $16.3 \%$ & $16.1 \%$ & $16.0 \%$ & $15.8 \%$ & $15.8 \%$ & $14.7 \%$ & $13.8 \%$ & $13.5 \%$ & $13.6 \%$ & $14.0 \%$ \\
\hline \multirow{2}{*}{$\begin{array}{l}\text { High } \\
\text { School }\end{array}$} & $9,888,026$ & $9,774,662$ & $9,668,182$ & $9,525,561$ & $9,519,166$ & $9,295,189$ & $12,424,849$ & $12,207,969$ & $12,695,659$ & $12,840,054$ & $12,807,409$ & $12,843,242$ \\
\hline & $31.9 \%$ & $31.4 \%$ & $30.9 \%$ & $30.4 \%$ & $30.2 \%$ & $29.3 \%$ & $30.3 \%$ & $30.4 \%$ & $30.2 \%$ & $30.3 \%$ & $29.9 \%$ & $29.7 \%$ \\
\hline \multirow{2}{*}{$\begin{array}{c}2 \mathrm{yr} \\
\text { College }\end{array}$} & $4,449,808$ & $4,561,944$ & 4,629,069 & $4,793,826$ & 4,957,363 & $5,189,409$ & $6,839,183$ & $7,185,819$ & $7,781,513$ & $7,912,498$ & $8,103,254$ & $8,417,468$ \\
\hline & $14.3 \%$ & $14.6 \%$ & $14.8 \%$ & $15.3 \%$ & $15.7 \%$ & $16.3 \%$ & $16.7 \%$ & $17.9 \%$ & $18.5 \%$ & $18.6 \%$ & $18.9 \%$ & $19.5 \%$ \\
\hline \multirow{2}{*}{$\begin{array}{c}4 \mathrm{yr} \\
\text { University }\end{array}$} & $4,402,462$ & $4,646,185$ & $4,788,328$ & $4,973,753$ & $5,075,858$ & $5,337,667$ & $7,073,033$ & 7,066,682 & $7,634,347$ & $8,078,222$ & $8,309,951$ & $8,788,244$ \\
\hline & $14.2 \%$ & $14.9 \%$ & $15.3 \%$ & $15.9 \%$ & $16.1 \%$ & $16.8 \%$ & $17.3 \%$ & $17.6 \%$ & $18.2 \%$ & $19.0 \%$ & $19.4 \%$ & $20.3 \%$ \\
\hline \multirow{2}{*}{$\begin{array}{l}\text { M.A. or } \\
\text { Ph.D. }\end{array}$} & 596,067 & 655,437 & 665,399 & 738,186 & 843,433 & 849,389 & $1,112,428$ & $1,167,543$ & $1,360,732$ & $1,433,955$ & $1,541,708$ & $1,554,453$ \\
\hline & $1.9 \%$ & $2.1 \%$ & $2.1 \%$ & $2.4 \%$ & $2.7 \%$ & $2.7 \%$ & $2.7 \%$ & $2.9 \%$ & $3.2 \%$ & $3.4 \%$ & $3.6 \%$ & $3.6 \%$ \\
\hline Total & $31,039,275$ & $31,151,553$ & $31,238,160$ & $31,376,694$ & $31,519,882$ & $31,759,115$ & $40,949,164$ & $40,197,678$ & $42,007,300$ & $42,440,169$ & $42,839,399$ & $43,223,730$ \\
\hline
\end{tabular}

Note) 1. All values are derived using sample weights.

2. $P_{E, t}=$ (The number of people in the education category $E$ / The number of the total population) $\mathrm{x} 100$ 
Table C. 12. EAPS: The share of age category in the total wage and salary workers $\left(P_{G, t}^{E A P S}\right)$

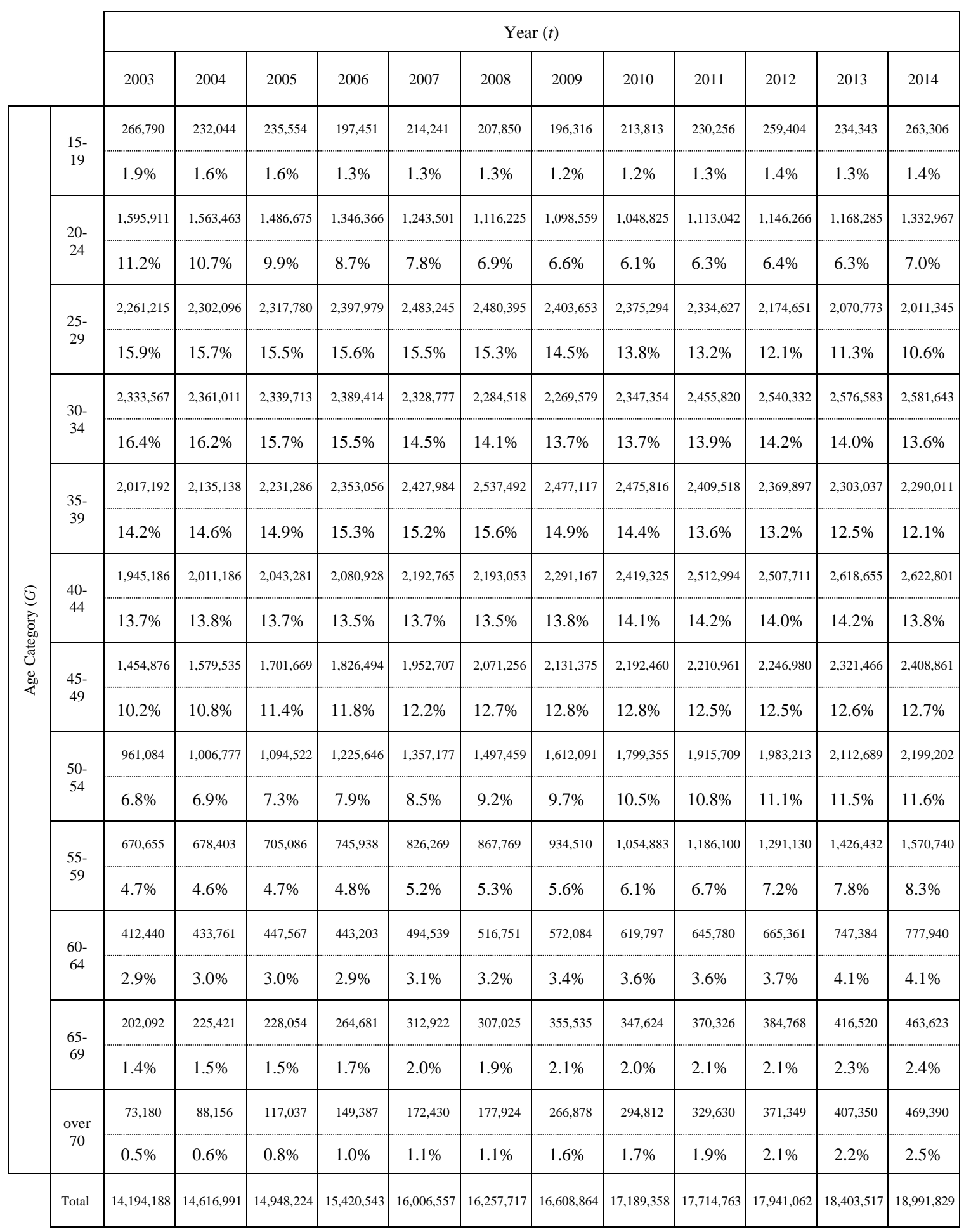

Note) 1. All values are derived using sample weights.

2. $P_{G, t}=$ (The number of people in the age category $G /$ The number of the total workers) $\mathrm{x} 100$ 
Table C.13. KLIPS: The share of age category in the total wage and salary workers $\left(P_{G, t}^{K L I P S}\right)$

\begin{tabular}{|c|c|c|c|c|c|c|c|c|c|c|c|c|c|}
\hline & & \multicolumn{12}{|c|}{ Year $(t)$} \\
\hline & & 2003 & 2004 & 2005 & 2006 & 2007 & 2008 & 2009 & 2010 & 2011 & 2012 & 2013 & 2014 \\
\hline \multirow{24}{*}{ 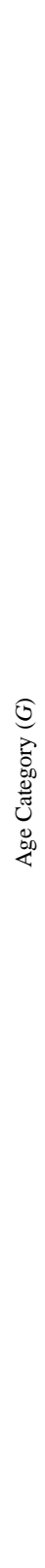 } & \multirow{2}{*}{$15-19$} & 116,356 & 110,371 & 60,569 & 68,677 & 72,623 & 79,972 & 55,825 & 82,559 & 124,462 & 88,241 & 61,604 & 85,843 \\
\hline & & $1.0 \%$ & $1.0 \%$ & $0.6 \%$ & $0.6 \%$ & $0.6 \%$ & $0.7 \%$ & $0.4 \%$ & $0.5 \%$ & $0.7 \%$ & $0.5 \%$ & $0.3 \%$ & $0.5 \%$ \\
\hline & \multirow{2}{*}{$\begin{array}{c}20- \\
24\end{array}$} & $1,032,848$ & 943,678 & 765,146 & 736,518 & 680,612 & 621,198 & 698,696 & 696,709 & 938,540 & $1,019,860$ & 847,170 & 973,161 \\
\hline & & $9.1 \%$ & $8.3 \%$ & $7.0 \%$ & $6.6 \%$ & $6.1 \%$ & $5.4 \%$ & $4.5 \%$ & $4.4 \%$ & $5.4 \%$ & $5.8 \%$ & $4.7 \%$ & $5.3 \%$ \\
\hline & \multirow{2}{*}{$\begin{array}{l}25- \\
29\end{array}$} & $1,742,948$ & $1,727,044$ & $1,692,153$ & $1,669,107$ & $1,599,864$ & $1,624,452$ & $2,440,177$ & $2,364,323$ & $2,351,852$ & $2,083,656$ & $2,146,080$ & $2,051,040$ \\
\hline & & $15.4 \%$ & $15.3 \%$ & $15.5 \%$ & $15.0 \%$ & $14.3 \%$ & $14.2 \%$ & $15.8 \%$ & $14.9 \%$ & $13.6 \%$ & $11.9 \%$ & $12.0 \%$ & $11.2 \%$ \\
\hline & \multirow{2}{*}{$\begin{array}{l}30- \\
34\end{array}$} & $1,631,750$ & $1,660,662$ & $1,621,647$ & $1,571,400$ & $1,534,536$ & $1,527,068$ & $2,369,477$ & $2,379,746$ & $2,539,788$ & $2,574,673$ & $2,620,956$ & $2,607,85$ \\
\hline & & $14.4 \%$ & $14.7 \%$ & $14.9 \%$ & $14.1 \%$ & $13.7 \%$ & $13.3 \%$ & $15.3 \%$ & $15.0 \%$ & $14.7 \%$ & $14.7 \%$ & $14.7 \%$ & $14.2 \%$ \\
\hline & \multirow{2}{*}{$\begin{array}{c}35- \\
39\end{array}$} & $1,691,505$ & $1,644,804$ & $1,523,249$ & $1,539,811$ & $1,588,185$ & $1,427,779$ & $2,263,756$ & $2,160,873$ & $2,321,927$ & $2,300,628$ & $2,308,223$ & $2,334,33$ \\
\hline & & $15.0 \%$ & $14.5 \%$ & $14.0 \%$ & $13.8 \%$ & $14.2 \%$ & $12.5 \%$ & $14.6 \%$ & $13.6 \%$ & $13.5 \%$ & $13.1 \%$ & $12.9 \%$ & $12.7 \%$ \\
\hline & \multirow{2}{*}{$\begin{array}{c}40- \\
44\end{array}$} & $1,692,328$ & $1,672,565$ & $1,642,248$ & $1,610,167$ & $1,601,958$ & $1,673,612$ & $2,216,257$ & $2,237,835$ & $2,389,071$ & $2,487,981$ & $2,357,169$ & $2,370,25$ \\
\hline & & $15.0 \%$ & $14.8 \%$ & $15.1 \%$ & $14.5 \%$ & $14.3 \%$ & $14.6 \%$ & $14.3 \%$ & $14.1 \%$ & $13.9 \%$ & $14.2 \%$ & $13.2 \%$ & $12.9 \%$ \\
\hline & \multirow{2}{*}{$\begin{array}{c}45- \\
49\end{array}$} & $1,302,325$ & $1,373,147$ & $1,369,786$ & $1,515,197$ & $1,586,149$ & $1,681,616$ & $2,067,885$ & $2,215,050$ & $2,422,475$ & $2,400,204$ & $2,625,143$ & $2,568,62$ \\
\hline & & $11.5 \%$ & $12.1 \%$ & $12.6 \%$ & $13.6 \%$ & $14.1 \%$ & $14.7 \%$ & $13.4 \%$ & $14.0 \%$ & $14.1 \%$ & $13.7 \%$ & $14.7 \%$ & $14.0 \%$ \\
\hline & \multirow{2}{*}{$\begin{array}{c}50- \\
54\end{array}$} & 878,053 & 945,968 & 944,381 & $1,096,547$ & $1,142,394$ & $1,232,858$ & $1,455,405$ & $1,705,409$ & $1,891,925$ & $2,029,683$ & $2,084,263$ & $2,294,37$ \\
\hline & & $7.8 \%$ & $8.4 \%$ & $8.7 \%$ & $9.9 \%$ & $10.2 \%$ & $10.8 \%$ & $9.4 \%$ & $10.8 \%$ & $11.0 \%$ & $11.6 \%$ & $11.7 \%$ & $12.5 \%$ \\
\hline & \multirow{2}{*}{$\begin{array}{c}55- \\
59\end{array}$} & 612,206 & 628,998 & 648,672 & 702,234 & 744,430 & 788,524 & 954,155 & $1,002,910$ & $1,147,562$ & $1,302,293$ & $1,377,074$ & $1,501,188$ \\
\hline & & $5.4 \%$ & $5.6 \%$ & $6.0 \%$ & $6.3 \%$ & $6.6 \%$ & $6.9 \%$ & $6.2 \%$ & $6.3 \%$ & $6.7 \%$ & $7.4 \%$ & $7.7 \%$ & $8.2 \%$ \\
\hline & \multirow{2}{*}{$\begin{array}{c}60- \\
64\end{array}$} & 368,908 & 339,956 & 330,840 & 340,634 & 341,314 & 456,259 & 479,846 & 513,848 & 574,217 & 679,848 & 764,054 & 816,839 \\
\hline & & $3.3 \%$ & $3.0 \%$ & $3.0 \%$ & $3.1 \%$ & $3.0 \%$ & $4.0 \%$ & $3.1 \%$ & $3.2 \%$ & $3.3 \%$ & $3.9 \%$ & $4.3 \%$ & $4.4 \%$ \\
\hline & \multirow{2}{*}{$\begin{array}{c}65- \\
69\end{array}$} & 177,623 & 210,234 & 208,513 & 183,329 & 230,654 & 232,039 & 265,975 & 245,155 & 293,813 & 345,734 & 379,843 & 415,560 \\
\hline & & $1.6 \%$ & $1.9 \%$ & $1.9 \%$ & $1.6 \%$ & $2.1 \%$ & $2.0 \%$ & $1.7 \%$ & $1.5 \%$ & $1.7 \%$ & $2.0 \%$ & $2.1 \%$ & $2.3 \%$ \\
\hline & \multirow{2}{*}{$\begin{array}{c}\text { over } \\
70\end{array}$} & 47,811 & 60,099 & 82,105 & 87,155 & 87,320 & 105,523 & 210,912 & 249,194 & 243,240 & 239,170 & 288,810 & 352,066 \\
\hline & & $0.4 \%$ & $0.5 \%$ & $0.8 \%$ & $0.8 \%$ & $0.8 \%$ & $0.9 \%$ & $1.4 \%$ & $1.6 \%$ & $1.4 \%$ & $1.4 \%$ & $1.6 \%$ & $1.9 \%$ \\
\hline & Total & $11,294,661$ & $11,317,526$ & $10,889,309$ & $11,120,776$ & $11,210,039$ & $11,450,900$ & $15,478,366$ & $15,853,611$ & $17,238,872$ & $17,551,971$ & $17,860,389$ & $18,371,140$ \\
\hline
\end{tabular}

Note) 1. All values are derived using sample weights.

2. $P_{G, t}=$ (The number of people in the age category $G /$ The number of the total workers) $\mathrm{x} 100$ 
Table C.14. EAPS: The share of women in the total wage and salary workers $\left(P_{W, t}^{E A P S}\right)$

\begin{tabular}{|c|c|c|c|c|c|c|c|c|c|c|c|c|}
\hline & \multicolumn{12}{|c|}{ Year $(t)$} \\
\hline & 2003 & 2004 & 2005 & 2006 & 2007 & 2008 & 2009 & 2010 & 2011 & 2012 & 2013 & 2014 \\
\hline \multirow{2}{*}{ Women } & $5,882,990$ & $6,102,720$ & $6,281,392$ & $6,467,134$ & $6,680,381$ & $6,793,062$ & $7,020,134$ & $7,319,469$ & $7,546,675$ & $7,662,648$ & $7,886,896$ & $8,195,958$ \\
\hline & $41.4 \%$ & $41.8 \%$ & $42.0 \%$ & $41.9 \%$ & $41.7 \%$ & $41.8 \%$ & $42.3 \%$ & $42.6 \%$ & $42.6 \%$ & $42.7 \%$ & $42.9 \%$ & $43.2 \%$ \\
\hline Total & $14,194,188$ & $14,616,991$ & $14,948,224$ & $15,420,543$ & $16,006,557$ & $16,257,717$ & $16,608,864$ & $17,189,358$ & $17,714,763$ & $17,941,062$ & $18,403,517$ & $18,991,829$ \\
\hline
\end{tabular}

Note) 1. All values are derived using sample weights.

2. $P_{W, t}=$ (The number of women / The number of the total workers) $\mathrm{x} 100$.

Table C.15. KLIPS: The share of women in the total wage and salary workers $\left(P_{W, t}^{K L I P S}\right)$

\begin{tabular}{|c|c|c|c|c|c|c|c|c|c|c|c|c|}
\hline & \multicolumn{12}{|c|}{ Year $(t)$} \\
\hline & 2003 & 2004 & 2005 & 2006 & 2007 & 2008 & 2009 & 2010 & 2011 & 2012 & 2013 & 2014 \\
\hline \multirow{2}{*}{ Women } & $4,583,995$ & $4,580,924$ & $4,338,027$ & $4,427,783$ & $4,499,446$ & $4,635,105$ & $6,065,392$ & $6,367,510$ & $6,919,637$ & $7,128,026$ & $7,257,510$ & $7,468,737$ \\
\hline & $40.6 \%$ & $40.5 \%$ & $39.8 \%$ & $39.8 \%$ & $40.1 \%$ & $40.5 \%$ & $39.2 \%$ & $40.2 \%$ & $40.1 \%$ & $40.6 \%$ & $40.6 \%$ & $40.7 \%$ \\
\hline Total & $11,294,661$ & $11,317,526$ & $10,889,309$ & $11,120,776$ & $11,210,039$ & $11,450,900$ & $15,478,366$ & $15,853,611$ & $17,238,872$ & $17,551,971$ & $17,860,389$ & $18,371,140$ \\
\hline
\end{tabular}

Note) 1. All values are derived using sample weights.

2. $P_{W, t}=$ (The number of women / The number of the total workers) $\mathrm{x} 100$. 
Table C.16. EAPS: The share of education level in the total wage and salary workers $\left(P_{E, t}^{E A P S}\right)$

\begin{tabular}{|c|c|c|c|c|c|c|c|c|c|c|c|c|}
\hline & \multicolumn{12}{|c|}{ Year $(t)$} \\
\hline & 2003 & 2004 & 2005 & 2006 & 2007 & 2008 & 2009 & 2010 & 2011 & 2012 & 2013 & 2014 \\
\hline \multirow{2}{*}{$\begin{array}{l}\text { Elementary } \\
\text { School }\end{array}$} & $1,310,558$ & $1,273,626$ & $1,254,464$ & $1,219,392$ & $1,229,963$ & $1,204,217$ & $1,298,294$ & $1,306,142$ & $1,262,192$ & $1,220,968$ & $1,182,495$ & $1,171,300$ \\
\hline & $9.2 \%$ & $8.7 \%$ & $8.4 \%$ & $7.9 \%$ & $7.7 \%$ & $7.4 \%$ & $7.8 \%$ & $7.6 \%$ & $7.1 \%$ & $6.8 \%$ & $6.4 \%$ & $6.2 \%$ \\
\hline \multirow{2}{*}{$\begin{array}{l}\text { Middle } \\
\text { School }\end{array}$} & $1,448,577$ & $1,442,029$ & $1,380,755$ & $1,423,089$ & $1,405,469$ & $1,352,384$ & $1,337,422$ & $1,368,657$ & $1,416,924$ & $1,374,005$ & $1,337,214$ & $1,306,228$ \\
\hline & $10.2 \%$ & $9.9 \%$ & $9.2 \%$ & $9.2 \%$ & $8.8 \%$ & $8.3 \%$ & $8.1 \%$ & $8.0 \%$ & $8.0 \%$ & $7.7 \%$ & $7.3 \%$ & $6.9 \%$ \\
\hline \multirow{2}{*}{$\begin{array}{l}\text { High } \\
\text { School }\end{array}$} & $5,660,458$ & $5,786,472$ & $5,861,640$ & $5,944,220$ & $6,003,128$ & $5,951,654$ & $5,878,306$ & $6,065,628$ & $6,068,438$ & $6,079,246$ & $6,182,872$ & $6,473,856$ \\
\hline & $39.9 \%$ & $39.6 \%$ & $39.2 \%$ & $38.5 \%$ & $37.5 \%$ & $36.6 \%$ & $35.4 \%$ & $35.3 \%$ & $34.3 \%$ & $33.9 \%$ & $33.6 \%$ & $34.1 \%$ \\
\hline \multirow{2}{*}{$\begin{array}{l}2 \text { year } \\
\text { College }\end{array}$} & $2,251,140$ & $2,393,556$ & $2,569,746$ & $2,679,218$ & $2,904,570$ & $2,986,913$ & $3,133,537$ & $3,274,414$ & $3,505,301$ & $3,674,093$ & $3,718,813$ & $3,770,508$ \\
\hline & $15.9 \%$ & $16.4 \%$ & $17.2 \%$ & $17.4 \%$ & $18.1 \%$ & $18.4 \%$ & $18.9 \%$ & $19.0 \%$ & $19.8 \%$ & $20.5 \%$ & $20.2 \%$ & $19.9 \%$ \\
\hline \multirow{2}{*}{$\begin{array}{c}4 \text { year } \\
\text { University }\end{array}$} & $3,036,974$ & $3,205,012$ & $3,329,430$ & $3,574,310$ & $3,846,915$ & $4,026,227$ & $4,182,915$ & $4,389,672$ & $4,645,681$ & $4,731,660$ & $5,079,881$ & $5,342,141$ \\
\hline & $21.4 \%$ & $21.9 \%$ & $22.3 \%$ & $23.2 \%$ & $24.0 \%$ & $24.8 \%$ & $25.2 \%$ & $25.5 \%$ & $26.2 \%$ & $26.4 \%$ & $27.6 \%$ & $28.1 \%$ \\
\hline \multirow{2}{*}{$\begin{array}{l}\text { M.A. } \\
\text { or Ph.D. }\end{array}$} & 486,481 & 516,296 & 552,189 & 580,314 & 616,512 & 736,322 & 778,390 & 784,845 & 816,227 & 861,090 & 902,242 & 927,796 \\
\hline & $3.4 \%$ & $3.5 \%$ & $3.7 \%$ & $3.8 \%$ & $3.9 \%$ & $4.5 \%$ & $4.7 \%$ & $4.6 \%$ & $4.6 \%$ & $4.8 \%$ & $4.9 \%$ & $4.9 \%$ \\
\hline Total & $14,194,188$ & $14,616,991$ & $14,948,224$ & $15,420,543$ & $16,006,557$ & $16,257,717$ & $16,608,864$ & $17,189,358$ & $17,714,763$ & $17,941,062$ & $18,403,517$ & $18,991,829$ \\
\hline
\end{tabular}

Note) 1. All values are derived using sample weights.

2. $P_{E, t}=$ (The number of people in the education category $E$ / The number of the total workers) $\mathrm{x} 100$

Table C.17. KLIPS: The share of education level in the total wage and salary workers $\left(P_{E, t}^{K L I P S}\right)$

\begin{tabular}{|c|c|c|c|c|c|c|c|c|c|c|c|c|}
\hline & \multicolumn{12}{|c|}{ Year $(t)$} \\
\hline & 2003 & 2004 & 2005 & 2006 & 2007 & 2008 & 2009 & 2010 & 2011 & 2012 & 2013 & 2014 \\
\hline \multirow{2}{*}{$\begin{array}{c}\text { Elementary } \\
\text { School }\end{array}$} & $1,322,891$ & $1,180,945$ & $1,106,977$ & $1,058,184$ & $1,047,057$ & $1,029,861$ & $1,227,395$ & $1,189,046$ & $1,203,610$ & $1,089,077$ & $1,098,660$ & $1,060,822$ \\
\hline & $11.7 \%$ & $10.4 \%$ & $10.2 \%$ & $9.5 \%$ & $9.3 \%$ & $9.0 \%$ & $7.9 \%$ & $7.5 \%$ & $7.0 \%$ & $6.2 \%$ & $6.2 \%$ & $5.8 \%$ \\
\hline \multirow{2}{*}{$\begin{array}{l}\text { Middle } \\
\text { School }\end{array}$} & $1,268,350$ & $1,219,384$ & $1,172,918$ & $1,151,347$ & $1,134,276$ & $1,113,967$ & $1,309,339$ & $1,381,625$ & $1,423,928$ & $1,414,946$ & $1,352,589$ & $1,282,991$ \\
\hline & $11.2 \%$ & $10.8 \%$ & $10.8 \%$ & $10.4 \%$ & $10.1 \%$ & $9.7 \%$ & $8.5 \%$ & $8.7 \%$ & $8.3 \%$ & $8.1 \%$ & $7.6 \%$ & $7.0 \%$ \\
\hline \multirow{2}{*}{$\begin{array}{l}\text { High } \\
\text { School }\end{array}$} & $4,023,239$ & $4,041,658$ & $3,732,546$ & $3,791,662$ & $3,809,271$ & $3,736,728$ & $5,156,218$ & $5,219,005$ & $5,695,330$ & $5,814,749$ & $5,782,826$ & $5,808,604$ \\
\hline & $35.6 \%$ & $35.7 \%$ & $34.3 \%$ & $34.1 \%$ & $34.0 \%$ & $32.6 \%$ & $33.3 \%$ & $32.9 \%$ & $33.0 \%$ & $33.1 \%$ & $32.4 \%$ & $31.6 \%$ \\
\hline \multirow{2}{*}{$\begin{array}{l}2 \text { year } \\
\text { College }\end{array}$} & $1,856,155$ & $1,869,334$ & $1,894,235$ & $2,002,357$ & $2,041,555$ & $2,261,945$ & $3,004,761$ & $3,177,787$ & $3,547,568$ & $3,686,044$ & $3,668,163$ & $3,841,592$ \\
\hline & $16.4 \%$ & $16.5 \%$ & $17.4 \%$ & $18.0 \%$ & $18.2 \%$ & $19.8 \%$ & $19.4 \%$ & $20.0 \%$ & $20.6 \%$ & $21.0 \%$ & $20.5 \%$ & $20.9 \%$ \\
\hline \multirow{2}{*}{$\begin{array}{c}4 \text { year } \\
\text { University }\end{array}$} & $2,398,079$ & $2,542,920$ & 2,539,403 & $2,611,633$ & $2,634,160$ & $2,765,025$ & $3,999,074$ & $4,049,276$ & $4,400,428$ & $4,544,093$ & $4,848,816$ & $5,219,489$ \\
\hline & $21.2 \%$ & $22.5 \%$ & $23.3 \%$ & $23.5 \%$ & $23.5 \%$ & $24.1 \%$ & $25.8 \%$ & $25.5 \%$ & $25.5 \%$ & $25.9 \%$ & $27.2 \%$ & $28.4 \%$ \\
\hline \multirow{2}{*}{$\begin{array}{l}\text { M.A. or } \\
\text { Ph.D. }\end{array}$} & 422,306 & 463,285 & 443,230 & 505,593 & 543,720 & 542,398 & 780,762 & 836,872 & 968,008 & 999,723 & $1,105,594$ & $1,157,642$ \\
\hline & $3.7 \%$ & $4.1 \%$ & $4.1 \%$ & $4.5 \%$ & $4.9 \%$ & $4.7 \%$ & $5.0 \%$ & $5.3 \%$ & $5.6 \%$ & $5.7 \%$ & $6.2 \%$ & $6.3 \%$ \\
\hline Total & $11,291,020$ & $11,317,526$ & $10,889,309$ & $11,120,776$ & $11,210,039$ & $11,449,924$ & $15,477,549$ & $15,853,611$ & $17,238,872$ & $17,548,632$ & $17,856,648$ & $18,371,140$ \\
\hline
\end{tabular}

Note) 1 . All values are derived using sample weights.

2. $P_{E, t}=$ (The number of people in the education category $E$ / The number of the total workers) $\mathrm{x} 100$ 


\section{BIBLIOGRAPHY}

Amuedo-Dorantes, C. (2000). Work transitions into and out of involuntary temporary employment in a segmented market: evidence from Spain. ILR Review, 53(2), 309-325.

Amuedo-Dorantes, C. (2001). From "temp-to-perm" Promoting permanent employment in Spain. International Journal of Manpower, 22(7), 625-647.

Alba-Ramirez, A. (1998). How temporary is temporary employment in Spain?. Journal of Labor Research, 19(4), 695-710.

Bentolila, S., \& Dolado, J. J. (1994). Labour flexibility and wages: lessons from Spain. Economic policy, 9(18), 53-99.

Blanchard, O., \& Landier, A. (2002). The perverse effects of partial labour market reform: fixed-term contracts in France. The Economic Journal, 112(480), F214-F244.

Blundell, R., \& Costa Dias, M. (2000). Evaluation methods for non-experimental data. Fiscal studies, 21(4), $427-468$.

Boockmann, B., \& Hagen, T. (2008). Fixed-term contracts as sorting mechanisms: Evidence from job durations in West Germany. Labour Economics, 15(5), 984-1005.

Booth, A. L., Francesconi, M., \& Frank, J. (2002). Temporary jobs: stepping stones or dead ends?. The Economic Journal, 112(480), F189-F213.

Booth, A. L., Francesconi, M., \& Frank, J. (2003). A sticky floors model of promotion, pay, and gender. European Economic Review, 47(2), 295-322.

D'Addio, A. C., \& Rosholm, M. (2005). Exits from temporary jobs in Europe: A competing risks analysis. Labour Economics, 12(4), 449-468.

Engellandt, A., \& Riphahn, R. T. (2005). Temporary contracts and employee effort. Labour Economics, 12(3), 281-299. 
Farber, H. S. (1994). The analysis of interfirm worker mobility. Journal of Labor Economics, 12(4), 554-593.

Grubb, D., Lee, J. K., \& Tergeist, P. (2007). Addressing labour market duality in Korea. OECD Social Employment and Migration Working Papers, No. 61.

Güell, M., \& Petrongolo, B. (2007). How binding are legal limits? Transitions from temporary to permanent work in Spain. Labour Economics, 14(2), 153-183.

Holmlund, B., \& Storrie, D. (2002). Temporary work in turbulent times: the Swedish experience. The economic journal, 112(480), F245-F269.

Jang, S. (2012). A study on the definition of non-regular workers and its scale in Korea. Korean Journal of Industrial Relations, 22(1), 55-77

Jones, R. S., \& Urasawa, S. (2012). Promoting social cohesion in Korea. OECD Economics Department Working Papers, No. 963.

Jones, R. S., \& Urasawa, S. (2013). Labour market policies to promote growth and social cohesion in Korea. OECD Economics Department Working Papers, No. 1068.

Jones, R. S., \& Urasawa, S. (2014). Reducing income inequality and poverty and promoting social mobility in Korea. OECD Economics Department Working Papers, No. 1153.

Jovanovic, B. (1979a). Job matching and the theory of turnover. Journal of Political Economy, 87(5, Part 1), 972-990.

Jovanovic, B. (1979b). Firm-specific capital and turnover. Journal of Political Economy, 87(6), 1246-1260.

Kahn, L. M. (2007). The impact of employment protection mandates on demographic temporary employment patterns: International microeconomic evidence. The Economic Journal, 117(521), F333-F356.

Kahn, L. M. (2012). Labor market policy: A comparative view on the costs and benefits of labor market flexibility. Journal of Policy Analysis and Management, 31(1), 94-110.

Kang, B. G., \& Yun, M. S. (2008). Changes in Korean wage inequality, 1980-2005, IZA Discussion Paper, No. 3780 
Landers, R. M., Rebitzer, J. B., \& Taylor, L. J. (1996). Rat race redux: Adverse selection in the determination of work hours in law firms. The American Economic Review, 329-348.

Lazear, E. P. (1990). Job security provisions and employment. Quarterly Journal of Economics, 105, 699726.

Lee, B. (2009). The employment effect of the time limit regulation on non-regular contracts. Korean Journal of Labor Studies, 15(2), 1-26.

Lee, B. (2011). Employment effect of the acts on the protection of non-regular workers. Journal of Korean Economic Development, 17(2), 235-258

Lee, D. R. (1996). Why is flexible employment increasing? Journal of Labor Research, 17(4), 543-553.

Marinescu, I. (2009). Job security legislation and job duration: Evidence from the United Kingdom. Journal of Labor Economics, 27(3), 465-486.

Nam, J. \& Park, K. (2010). The effects of the acts protecting non-standard workers on employment in Korea. Quarterly Journal of Labor Policy, 10(4), 65-99

SaKong, I. (1993). Korea in the World Economy, Washington, DC: Institution for International Economics.

Yoo, G., \& Kang, C. (2012). The effect of protection of temporary workers on employment levels: evidence from the 2007 reform of South Korea. Industrial \& Labor Relations Review, 65(3), 578-606.

Korea Development Institute (KDI) (2009), Study on Non-regular workers, Seoul (in Korean)

Korea Labor Institution (KLI) (2012), Overview of discrimination correction system for non-regular workers and the improvement proposal (in Korean)

OECD (2013). Strengthening social cohesion in Korea, OECD publishing, Paris.

http://dx.doi.org/10.1787/9789264188945-en

OECD (2016), OECD Economic Surveys: Korea 2016, OECD Publishing, Paris.

http://dx.doi.org/10.1787/eco_surveys-kor-2016-en 


\section{VITA}

Tai Lee was born and raised in Seoul, South Korea. He earned his Bachelor degree in Economics from Sungkyunkwan University, South Korea. He began his Ph.D. program in Economics at the University of Missouri-Columbia in the fall of 2013. While at the University of Missouri, he was advised by Dr. Peter Mueser and his primary area of specialization is labor economics, focusing on evaluation of labor market policy using micro-level data. He was a graduate teaching assistant from the fall of 2013 to the spring of 2019. He also taught an undergraduate course, Money, Banking and Financial Markets, as a lab instructor from 2017 to 2018 . 